\title{
Economics of Disaster Risk and Resilience in Small Island Developing States
}

\section{Tauisi Taupo}

\author{
A thesis \\ submitted to the Victoria University of Wellington \\ in fulfilment of the requirements for the degree of \\ Doctor of Philosophy in Economics.
}

Victoria University of Wellington 



\section{Abstract}

The four essays investigate the impacts and implications of climate change and disasters in Small Island Developing States (SIDS) in the Pacific by examining disaster risk, resilience, response, and recovery in Tuvalu.

The first chapter starts with a survey on the conceptual framework of disaster risk which relies on its associated components of hazard, vulnerability and exposure. It is an introductory literature review that sets the scene for the other chapters. It is not intended to make an original contribution nor a critical review of the literature justified to be publishable. How we measure these risks depends on how we define disaster risk and its components. Though there are diverse views on these definitions in different disciplines, we can capitalise on their commonalities to frame disaster risk models.

The second chapter investigates the vulnerability of households to climatic disasters in Tuvalu. Small Island Developing States, particularly the atoll islands, are considered to be the most vulnerable to climatic change, and in particular to sea-level rise and its associated risks. From the Tuvalu Statistics Department household survey, we construct poverty and hardship profiles for households on the different islands of Tuvalu, and combine these with geographic and topographic information to assess the exposure differentials among different groups using spatial econometric models. Besides the observation that households in hardship are more vulnerable to negative shocks because they lack the resources to respond, we also find that they are also more likely to reside in highly exposed areas to disasters (closer to the coasts and at lower elevation) and have less ability to migrate (between and within the islands). 
The third chapter examines cyclones. The intensity of cyclones in the Pacific is predicted to increase and sea levels are predicted to rise, so an atoll nation like Tuvalu can serve as the 'canary in the coal mine' pointing to the new risks that are emerging because of climatic change. Based on a household survey we conducted in Tuvalu, we quantify the impacts of Tropical Cyclone Pam (March 2015) on households, and the determinants of these impacts in terms of hazard, exposure, vulnerability and responsiveness. Households experienced significant damage due to the storm surge caused by the cyclone, even though the cyclone itself passed very far away (about a 1,000 km). This risk of distant cyclones has been overlooked in the literature, and ignoring it leads to significant under-estimation of the disaster risk facing low-lying atoll islands. Lastly, we constructed hypothetical policy scenarios, and calculated the estimated loss and damage they would have been associated with - a first step in building careful assessments of the feasibility of various disaster risk reduction policies.

The fourth chapter examines the financing of disaster risk management. Future climate and disaster risks are likely to impose increasing financial pressure on the governments of low-lying atoll nations. The aftermath of a disaster such as a cyclone requires financial means for quick response and recovery. Hence, we quantify appropriate levels of financial support for expected disasters in Tuvalu and Kiribati by building on the Pacific Catastrophe Risk Assessment and Financing Initiative (PCRAFI) calculated likely costs for disasters. To these, we add estimates of the potential effects of distant cyclones, droughts, sea level rise and climate change as they are predicted to affect low-lying atoll islands. There are several potential financial instruments available for disaster risk management in the Pacific Islands. We focus on the potential contribution of the sovereign wealth funds (SWF) of Tuvalu and Kiribati in reducing reliance on foreign aid for both ex-ante and ex-post disaster risk management. We forecast the future size of the SWF using Monte Carlo simulations and an Auto-Regressive Integrated Moving Average model. We examine the long-term sustainability of the SWF, and the feasibility of extending their mandate to cover and pay for at least some climate change adaptation and disaster risk reduction. 
This is dedicated to my beloved parents 


\section{Acknowledgements}

It is virtually impossible to succeed in any level of study without the input, cooperation, support, and assistance of people who generously avail precious time out of their busy schedules. I am deeply honoured to have connected to them, thus accessing their rich insights.

I would like to place on record my heartfelt gratitude to my primary supervisor, Professor Ilan Noy, for his guidance, wisdom, professionalism, humour and invaluable insights throughout this journey. His thoughts, suggestions and input have extremely enhanced the quality of this thesis. I am deeply indebted to him and my secondary supervisor, Dr. Harold Cuffe, whose input, guidance and advice were enormously fruitful.

I remain grateful to my past academic mentors at the University of Hawai'i at Manoa - Professor James Roumasset and Professor Hyop Lee; and Professor Biman Prasad, Professor Wadan Narsey, the late Professor Bill Rao and Dr. Rup Singh from the University of the South Pacific. Sincere gratitude to: Dr. Mohammed Khaled for his suggestions in restructuring of the Pam survey to make it more appealing to the Ethics Committee and comments on the time series model specifications; Dr. William Cochrane and Prof. John Gibson for sharing their ideas and suggestions on spatial econometric models; Dr. Christopher Edmonds and Dr. Stephen Howes for providing economic insights on the Pacific region that are relevant to my study; Mr. Michael Wulsohn and Dr. Xibing Zhang for their suggestions on Monte Carlo modelling; Prof. Dave Frame and A/Prof. Ralph Chapman for guidance on climate science and climate change issues relating to my thesis; Ms. Valeria Zingaretti for the introduction and guidance in using ArcGIS; A/Prof. Hai Lin, Dr. Paul Calcott, Dr. Robert Kirkby, Ms Ingrid Watts (you always go the extra mile), Ms 
Francine McGee, and School of Economics \& Finance (SEF) staff for lending their expertise, friendship, and for fostering a conducive environment for my doctoral research; SEF PhD colleagues (Miles, Azreen, Polly, Rio, Melissa, Diana, Aditya, Farnaz, Cuong, Jacob, Olivia, Hannah and Belinda) for their friendship and all the discussions on various issues; Mr. Barry Lewis and Ms. Tara Fisher from the Faculty of Graduate Research (FGR) for their guidance on policies related to the doctoral programme; Mr. Philip Worthington (subject librarian) from the Commerce Library for his guidance on any library related matters; Information Technology Services (ITS) for their technical support; Ms. Robyn Kenealy for proofreading my thesis; journal editors and anonymous referees for their priceless reviews and suggestions; and to participants of the Disastrous Doctorates workshops (2015 and 2016), the New Zealand Association of Economists annual conferences (2016 and 2017), the Pacific Climate Change Conference (2016), the $6^{\text {th }}$ International Conference on Building Resilience (2016), the Pacific Update conferences (2015, 2016, and 2017), the $4^{\text {th }}$ International Conference on Urban Disaster Reduction (2016), and the $13^{\text {th }}$ Australasian Development Economics Workshop (2017) for their valuable suggestions and comments on my papers and presentations.

As a recipient of the New Zealand Commonwealth Scholarship, I am deeply thankful to the New Zealand Agency for International Development (NZAID) for making this study possible and for the NZD1,000 support grant for my survey. In this connection, my special thanks to all interviewers: Ms. Talesi, Mr. Kaulua, Ms. Niulasi, Ms. Ielemia, Mr. Pulusi, Ms. Lagitupu, Ms. Paka, and Ms. Folitau; and interviewees who helped make the Pam survey a success. I am also thankful to our School of Economics \& Finance and the Asian Development Bank (ADB) for availing funds for me to attend and present in conferences and workshops both domestic and overseas. Not forgetting our NZAID office and my scholarship coordinators, I thank Dr. Helena Cook, Mr. Lawther, and Mr. Stuart for their help and guidance on matters related to the scholarship. Prior to this, I am deeply thankful to the U.S Department of State (Bureau of Educational and Cultural Affairs) for funding my studies (United States South Pacific scholarship at the University of Hawai'i at Manoa) and internship to the International Monetary Fund (IMF) in Washington D.C. Also, I am grateful to the East-West Center for administering the United States South Pacific scholarship programme, facilitating educational programmes, 
and for promoting a cooperative environment for study, research, and dialogue.

I extend my great thanks to Dr. Jan Feld of the School of Economics \& Finance (Victoria University of Wellington), Professor Bob Reed of the Department of Economics \& Finance (University of Canterbury), and Dr. Matthew Dornan of the Crawford School of Public Policy (Australian National University) for thoroughly reviewing my thesis, and for their valuable feedback, comments and encouragement to submit my chapters in recognized journals. Special thanks to Associate Professor Nancy Bertler for chairing my thesis oral examination in a professional and gracious manner.

I am grateful to Ms. Sualo and Ms. Kitiona from the Tuvalu Trust Fund Secretariat, Mr. Malona and Ms. Alapati from the Central Statistics Division, Mr. Tauati and Ms. Mika from the Ministry of Finance \& Economic Development of Kiribati for providing required data for my research.

Immeasurable thanks and love to: my amazing, loving and wonderful parents (Minute Alapati Taupo and Seleta Kapua Vanele); my beautiful and lovely wife (Tenanoia Veronica Simona); my joyful, sweet, and adorable children (Simoia Lisi-Marie Taupo and Jnr. Minute Jeffrick Taupo); my reliable and irreplaceable siblings (Susana Taupo and Alapati Taupo); my generous and caring families here in New Zealand (Wellington, Auckland and Hamilton); the Tuvalu community in Wellington; and my extended family and friends around the globe who have been very supportive, encouraging, understanding, helpful, and motivating throughout my educational strives.

Finally, I wish to thank the Almighty GOD with all my heart for his continuous and never-ending provision, protection, guidance, and blessings.

Fakafetai Lahi Te Atua. 


\section{Declaration}

I hereby declare that this thesis is my original work and has not been submitted before to any institution for assessment purposes. To the best of my knowledge, this thesis contains no materials that has been written or published before by any other person. However, I have acknowledged all sources and have cited these in the reference section. Any queries should be directed to Tauisi.Taupo@vuw.ac.nz.

This thesis contains three publishable papers, whereby I was the sole researcher and primary author. At this moment, Chapter 3 has been published in the Economics of Disasters and Climate Change journal, Chapter 2 has been accepted for publication in the journal of Environmental Economics and Policy Studies, and Chapter 4 is currently under review by the Pacific Economic Review journal. 


\section{Contents}

$\begin{array}{ll}\text { Introduction } & 1\end{array}$

Chapter 1 - A Survey of Disaster Risk and Resilience in Small Island States 5

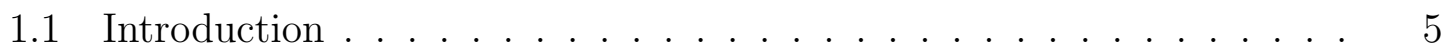

1.2 Disaster Risk . . . . . . . . . . . . . . . . . . . . . . 7

1.3 Hazard . . . . . . . . . . . . . . . . . . . . . . . . . . . . . 8

1.4 Exposure . . . . . . . . . . . . . . . . . . . . 8

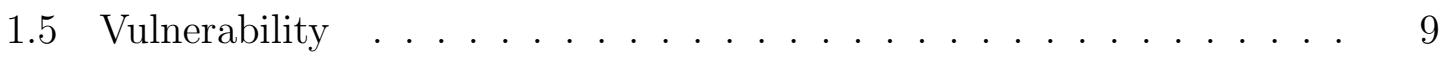

1.6 Resilience . . . . . . . . . . . . . . . . . . . . . . . 11

1.7 Measurements of Disaster Risk . . . . . . . . . . . . . . . . 13

1.8 Policy Implications . . . . . . . . . . . . . . . . . . . . . 15

1.9 Applicability to Tuvalu . . . . . . . . . . . . . . . . 16

1.10 Conclusion . . . . . . . . . . . . . . . . . . . . . . . 19

$\begin{array}{ll}\text { Appendices } & 21\end{array}$

1.A Rainfall . . . . . . . . . . . . . . . . . . . . . 21

Chapter 2 - Household Vulnerability on the Frontline of Climate Change: The Pacific Atoll Nation of Tuvalu 23

2.1 Introduction . . . . . . . . . . . . . . . . . . 23

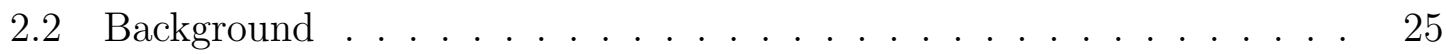

2.3 Economic Stability and Resilience . . . . . . . . . . . . 26

2.4 Exposure to Natural Disasters . . . . . . . . . . . . . . . 30

2.5 Estimation Methods . . . . . . . . . . . . . . . . . . . 32

2.6 Data . . . . . . . . . . . . . . . . . 36 
2.7 Estimation Results and Discussions . . . . . . . . . . . . . 37

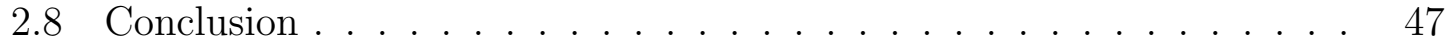

$\begin{array}{ll}\text { Appendices } & 49\end{array}$

2.A Map of Tuvalu . . . . . . . . . . . . . . . . . . . . . 50

2.B Sea Levels on Funafuti . . . . . . . . . . . . . . . . . . . . . 51

2.C Hardship Maps . . . . . . . . . . . . . . . . . . . . . . 52

2.D Elevation Maps . . . . . . . . . . . . . . . . . . . 54

2.E Definitions of Indicators $\ldots \ldots \ldots \ldots \ldots$

2.F Description of Variables . . . . . . . . . . . . . . . 57

2.G Panel Data Models . . . . . . . . . . . . . . . . . . . . 58

Chapter 3 - At the Very Edge of a Storm: The Impact of a Distant Cyclone on Atoll Islands $\quad 59$

3.1 Introduction . . . . . . . . . . . . . . . . . . . . . . . . . 59

3.2 The Literature on Disaster Risk . . . . . . . . . . . . . . . . . 62

3.3 Estimation Method and Survey Data . . . . . . . . . . . . . . . 64

3.4 Analysis of Survey Responses _. . . . . . . . . . . . . . . 67

3.4.1 Household Characteristics . . . . . . . . . . . . . 67

3.4 .2 Loss and Damage . . . . . . . . . . . . . . . . . 70

3.4 .3 Hazard . . . . . . . . . . . . . . . . . . . . . 72

3.4 .4 Exposure . . . . . . . . . . . . . . . . . . 74

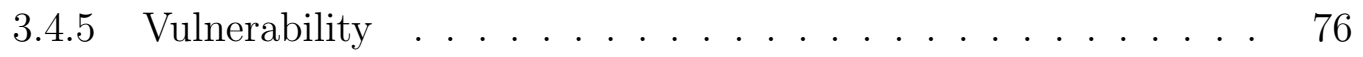

3.4.6 Responsiveness and Poverty . . . . . . . . . . . . 76

3.5 Estimation Results . . . . . . . . . . . . . . . . . . . . . . . 79

3.6 Hypothetical Scenarios of DRR Policies . . . . . . . . . . . . . . 81

3.7 Conclusions and Policy . . . . . . . . . . . . . . . . . 86

$\begin{array}{ll}\text { Appendices } & 91\end{array}$

3.A Hypothetical Scenarios . . . . . . . . . . . . . . . . . . . 92

3.B Loss and Damage Maps . . . . . . . . . . . . . . . . . . 93

3.C Model Estimation . . . . . . . . . . . . . . . . . . . . 94

3.D Pam Survey . . . . . . . . . . . . . . . . . . . . . . . . 95 
Chapter 4 - Financing Climate and Disaster Resilience in Atoll Islands: Evidence from Tuvalu and Kiribati 107

4.1 Introduction . . . . . . . . . . . . . . . . . 107

4.2 Climate Change and Disaster Financing Instruments . . . . . . . 110

4.3 Sovereign Wealth Funds . . . . . . . . . . . . . . . . . . 114

4.3.1 Tuvalu Trust Fund and the Revenue Equalizer Reserve Fund . 117

4.4 Data and Methods . . . . . . . . . . . . . . . . . 121

4.4.1 Monte Carlo Simulation Method . . . . . . . . . . . . . . 122

4.4 .2 ARIMA Models . . . . . . . . . . . . . . . . . 123

4.5 Results and Discussions . . . . . . . . . . . . . . . . 124

4.5.1 Assessing Risk and Determining Contribution to Disaster Funds 125

4.5.2 Investment Return Simulation . . . . . . . . . . . . 129

4.5.3 ARIMA Models . . . . . . . . . . . . . . . 131

4.6 Conclusion . . . . . . . . . . . . . . . . . . . . 135

$\begin{array}{ll}\text { Appendices } & 139\end{array}$

4.A Diagnostic Tests. . . . . . . . . . . . . . . . . . . . 139

4.B ARIMA Models for SWF . . . . . . . . . . . . . . . 140

4.C Scenarios of Inundation by Sea Level Rise . . . . . . . . . . 142

4.D Contributions to the TTF . . . . . . . . . . . . 143

4.E SWF vs GDP under MC Simulation . . . . . . . . . . . . 144

4.F SWF vs GDP under ARIMA . . . . . . . . . . . . . 146

4. G Stylized Illustrations . . . . . . . . . . . . . . . . . 148

$4 . \mathrm{H}$ Summary . . . . . . . . . . . . . . . . 150

$\begin{array}{ll}\text { Conclusions } & 151\end{array}$

$\begin{array}{ll}\text { References } & 153\end{array}$ 


\section{List of Figures}

1.A.1Annual rainfalls on Funafuti (Tuvalu) from 1933 to 2013 . . . . . . . 21

2.1 Incidence of economic stability and resilience indicators . . . . . . . . 29

2.2 Household vulnerability and exposure indicators to disasters by island 31

2.3 Household exposure . . . . . . . . . . . . . . . . . . . . . . 32

2.A.1Map of the Islands of Tuvalu . . . . . . . . . . . . . . . . . 50

2.B.1Maximum and mean sea levels on Funafuti from 1993 to 2014 . . . . 51

2.C.1Hardship incidence in the Northern Islands . . . . . . . . . . . . . 52

2.C.2Hardship incidence in the Southern Islands . . . . . . . . . . . . 53

2.D.1Elevation in the Northern Islands . . . . . . . . . . . . . . . . . 54

2.D.2Elevation in the Southern Islands . . . . . . . . . . . . . . . 55

3.1 Tuvalu Islands and the trajectory of the TC Pam . . . . . . . . . . 61

3.2 Asset ownership . . . . . . . . . . . . . . . . . . . . . . 68

3.3 Cyclone impacts . . . . . . . . . . . . . . . . . . . 68

3.4 Multiple stressors affecting households . . . . . . . . . . . . . . . 69

3.5 Losses incurred by households . . . . . . . . . . . . . . . . . . . . . . 72

3.6 Damages incurred by households . . . . . . . . . . . . . . . 73

3.7 Income, expenditure, loss and damage by income classification . . . . 74

3.8 Household exposure . . . . . . . . . . . . . . . . . . . . 75

3.9 Responding to the cyclone . . . . . . . . . . . . . . . . . . . 77

3.10 Relocation decision . . . . . . . . . . . . . . . . . . . 89

3.A.1Hypothetical scenarios for Nui Island . . . . . . . . . . . . . . . . . . 92

3.B.1Loss and damage for Nanumea, Nanumaga, Niutao and Nukulaelae . 93

4.1 Humanitarian aid flows for disasters in selected PICs . . . . . . . . . 112

4.2 Humanitarian aid flows for disasters in low-lying atoll Islands . . . . . 112 
4.3 ODA and GDP for Tuvalu . . . . . . . . . . . . . . . . 113

4.4 ODA and GDP for Kiribati . . . . . . . . . . . . . . . 114

4.5 Tuvalu Trust Fund resource flow . . . . . . . . . . . . . . . . 119

4.6 Alternative Tuvalu Trust Fund resource flow . . . . . . . . . . 120

4.7 Annual Average Loss (AAL) adjustments for Tuvalu and Kiribati . . 128

4.8 TTF forecast performance from 2017 to 2050 with MC simulations . . 130

4.9 RERF forecast performance from 2017 to 2050 with MC simulations . 131

4.10 TTF forecast performance from 2017 to 2026 using an ARIMA model 133

4.11 RERF forecast performance from 2017 to 2026 using an ARIMA model 134

4.C.1Flood areas by sea-level on Funafuti Island . . . . . . . . . . . . 142

4.D.1Contributions to the TTF . . . . . . . . . . . . . 143

4.E.1TTF vs GDP under MC simulation . . . . . . . . . . . . . 144

4.E.2RERF vs GDP under MC simulation . . . . . . . . . . . 145

4.F.1TTF vs GDP under ARIMA . . . . . . . . . . . . . . . 146

4.F.2RERF vs GDP under ARIMA . . . . . . . . . . . . . . 147

4.G.1Alternative Tuvalu Trust Fund Resource Flow Illustration for Year 1148

4.G.2Alternative Tuvalu Trust Fund Resource Flow Illustration for Year 2149 


\section{List of Tables}

2.1 Comparing means of selected indicators . . . . . . . . . . 38

2.2 Estimation results - LHS income per person (2010) . . . . . . . . 40

2.3 Estimation results - LHS expenditure per person (2010) . . . . . . . 42

2.4 Estimation results - LHS poverty binary indicator (2010) . . . . . . 44

2.5 Internal migration of households . . . . . . . . . . 46

2.E.1Definitions of Economic Stability and Resilience Indicators . . . . . 56

2.F.1Description of variables . . . . . . . . . . . . 57

2.G.1Comparing estimators for panel data models . . . . . . . . . . 58

3.1 Description of variables and their sources . . . . . . . . 66

3.2 Risk, vulnerability and resilience indicators . . . . . . . 78

3.3 Model estimation results explaining the $\log$ of losses and damages . . 82

3.4 Hypothetical scenarios . . . . . . . . . . . . . . . . . . . 83

3.5 Hypothetical scenarios . . . . . . . . . . . . . . . . . . . . . 84

3.C.1Model estimation results explaining the $\log$ of damages $\ldots \ldots \ldots .94$

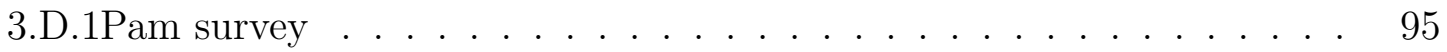

4.1 List of Global Climate Fund projects for the PICs . . . . . . . . 115

4.2 Compliance with the Santiago Principles by fund for selected PICs . . 117

4.A.1Dickey-Fuller tests ． . . . . . . . . . . . . . . . . . . . . . . 139

4.B.1Selected ARIMA models for TTF . . . . . . . . . . . . . 140

4.B.2Selected ARIMA models for RERF . . . . . . . . . . . . . . . . 141

4.H.1Summary of adjusted Annual Average Loss . . . . . . . . . . . . 150 
xviii 


\section{Introduction}

Natural disasters such as cyclones, earthquakes, floods, tsunamis, storm surges, and heatwaves have distressed the lives of the people around the world. The Asia-Pacific region is the area most prone to disasters with the highest number of affected people in the world (see UNESCAP and UNISDR, 2012). In the Pacific region, disaster risk has been increasing in the past decades, most likely because of increased exposure of people and economic assets. Disasters on Small Island Developing States (SIDS) have been especially destructive, particularly in per capita terms. Within the Pacific SIDS, the Smaller Island States ${ }^{1}$ like Tuvalu and Kiribati are extremely vulnerable to climatic disasters, climate change and sea level rise. These vulnerabilities threaten lives and livelihoods, leaving these countries with an insecure future and limited options for mitigation, relocation and migration. Their extreme vulnerability and exposure stem from their geographical characteristics: their land area, their low elevation, and proximity to coasts. By United Nations (UN) standards, Smaller Island States are mostly categorised as Least Developed Countries (LDCs). Their vulnerability, exposure and economic status slow their graduation from being LDCs (see UNCTAD, 2016).

Notably, and worryingly, vulnerable populations are especially highly exposed as they are more likely to reside in disaster prone areas (e.g., near the coasts and low elevation areas). These marginalised populations face hardship and live in fragile houses that are not structurally fit to withstand disasters. Adaptation to climate change, resilience to disasters, and sustainable development were strengthened

\footnotetext{
${ }^{1}$ Smaller Island States classified under the Pacific Islands Forum comprise of Cook Islands, Federated States of Micronesia, Kiribati, Marshall Islands, Nauru, Niue, Palau and Tuvalu. We focus on Tuvalu and Kiribati since they are low-lying atolls and sovereign states.
} 
through the formation of three international frameworks in 2015: the Paris Agreement on Climate Change, the United Nations Sustainable Development Goals (SDGs) agreement, and the Sendai Framework for Disaster Risk Reduction. These were designed with the intention to steer the global community towards a secure and sustainable future. Their agendas complement and support each other, and hence the need for an integrated framework to address them. Encouraging climate change adaptation, reducing disaster risk and promoting sustainable development have the potential to pull people out of hardship, reduce inequality, protect the environment, and ensure economic and social growth.

This thesis consists of four chapters on the economics of disaster risk and resilience in Tuvalu. Disaster risk is a major concern for low-lying, Pacific, small island states, such as Tuvalu. There has been an explosion of economic research on the impacts and consequences of disasters. As a starting point, Chapter 1 provides a survey of the literature on disaster risk and its associated components. At this juncture, we review the literature that examines disaster risk and the development of its association with hazards, exposure, vulnerability, and resilience. We discuss the widely used framework of Disaster Risk $=$ Hazard $\times$ Exposure $\times$ Vulnerability where 'disaster risk' is explained by: 'hazard' which refers to the occurrence of climate extremes; 'exposure' or the presence of people and assets in locations that could be adversely affected by the hazard; and 'vulnerability' is the susceptibility to be adversely affected by the hazard. So, for example, the hazard is the cyclone's storm surge, the exposure is the location of a house close enough to the shore so it is exposed to these waves, and vulnerability is the extent of damage that the house should incur if it is indeed hit by the storm surge. Our ability to use the disaster risk model depends, of course, on the available data and therefore the variables that can be used in the empirical version of this model. In our framework, the empirical model's dependent variable is an indicator of the disaster impact (i.e., realised risk) that is regressed on explanatory independent variables representing hazard, exposure and vulnerability.

To truly understand how people in SIDS are facing, coping and adapting to climatic disasters, we first analyse micro household-level data and examine the vulnerability and exposure of households to these negative shocks. Chapter 2 examines the exposure and vulnerability of households to climatic disasters in the low-lying islands of Tuvalu using spatial regression models that investigate the 
determinants of income. The terms 'vulnerability' and 'exposure' are not defined consistently throughout the thesis because of the different definitions of these terms used in the literature that is covered in each chapter. In Chapter 2, we focus on 'vulnerability' and 'resilience' from an economic/development perspective and follow that literature's definition, as oppose to the disaster risk perspective of 'exposure' and 'vulnerability' used in the other chapters. 'Vulnerability' is defined in Chapter 2 as the sum of 'hardship' and 'vulnerability to hardship'; both are based on measured income, which is the indicator available to us from the Household Income \& Expenditure Survey (HIES) data. The definition of these terms, and the reliance on income as their indicator follows the practice in development economics, as these concepts were developed at the World Bank. 'Exposure' here, as in the other chapters, refers to the disaster risk definition; in this case to measurements that can be utilized from the geo-coded locations of households such as the household's ground elevation and distance to the coast. These are indicators for exposure to weather events like cyclones that are often associated with storm surges and flooding in Tuvalu. By using geo-coded locations to link household level data to geographical and topographical characteristics of the household we were able to: investigate the determinants of income; produce profiles, maps, and thresholds for economic stability and resilience; and produce exposure maps (for households, villages and islands) to examine the heterogeneity in the magnitude of disaster risk experienced by households. Chapter 2 has no hazard variables as these are not available in the HIES data. We use empirical evidence of household vulnerability using household and census data from Tuvalu's Central Statistics Office. We estimate a probit model to examine household characteristics that make households more or less likely to be in poverty. Lastly, we conduct a panel analysis to examine the relationship between the level of income and movements of households. This chapter contributes to our understanding of why and how are households vulnerable and exposed to climatic disasters in SIDS.

The Pacific Islands have been hampered by apparent increasing intensity of cyclones, changes in cyclone trajectories, sea level rise, and other climatic changes. To better understand how the conceptual framework of disaster risk and its components - hazard, exposure, and vulnerability - interact to increase overall losses, we collected our own survey in Chapter 3 and use OLS regressions to look at a specific case study. This chapter focuses directly on understanding disaster risk, hence it employs the 
disaster risk model by quantifying the relative importance of hazard, vulnerability, exposure and responsiveness in influencing experienced loss and damages from Tropical Cyclone Pam (TC Pam). In this case, we study the impacts of TC Pam that hit Tuvalu in March 2015. Through this, we extend the components of disaster risk to include responsiveness as an additional explanatory variable in explaining losses. For evaluation of disaster risk reduction policy, we create hypothetical scenarios of expected variations in estimated loss and damage given changes in the components of risk. This chapter's aim is to contribute to our understanding of exposure, vulnerability, and responsiveness of households in low-lying atoll islands to distant cyclones, and describe the disaster risk reduction policy implications.

According to the United Nations (2015b), the increase in future economic losses from disasters like earthquakes, tsunamis, cyclones and flooding is estimated to be US $\$ 314$ billion (annually). This motivates Chapter 4 to delve into financial mechanisms to finance climate change and disaster resilience in the Small Island Developing States (SIDS) of Tuvalu and Kiribati. We focus on a specific option, examining the potential of sovereign wealth funds (SWFs) - the Tuvalu Trust Fund (TTF) and the Kiribati's Revenue Equalizer Reserve Fund (RERF) - to serve as buffers for financing disaster recovery. Since the Pacific Catastrophe Risk Assessment and Financing Initiative (PCRAFI) has calculated the expected economic costs (e.g., annual average loss) for disasters in Pacific Island Countries (PICs), we build on these calculations by adding the unaccounted factors that are relevant specifically for low-lying atolls in terms of distant cyclones, droughts, climate change, and sea level rise. With these quantified additions, we assess risk and determine appropriate contributions to a disaster fund from the countries' SWFs. We then examine the feasibility and sustainability of SWFs in handling disaster contributions by forecasting their expected performances using the Monte Carlo simulation and ARIMA methods with given scenarios of 'with' and 'without' contributions to disaster funds. 


\section{Chapter 1}

\section{A Survey of Disaster Risk and Resilience in Small Island States}

\section{$1.1 \quad$ Introduction}

The Asia-Pacific region is the most highly exposed to disasters in the world, with the highest overall disaster-related deaths, representing $75 \%$ of global mortality for the years between 1970 and 2011 (UNESCAP and UNISDR, 2012). Changes in the climate, sea level rise and the intensity of climatic disasters like tropical cyclones ${ }^{1}$, droughts, and floods have an extremely negative impact on economies, communities, households, people, and physical assets (see World Bank and United Nations, 2010; World Bank, 2013c). Developing countries are especially vulnerable to these impacts due to their underlying limited natural endowments, economic constraints, and limited adaptive capacity (Ahsan, 2014). Small Island Developing States (SIDS) are especially vulnerable to large-scale economic and environmental disasters, whereby their geography and size makes them highly exposed and vulnerable, with less capacity to respond (Barnett and Waters, 2016).

Among the Pacific Island Countries (PICs), the Pacific island nation of Tuvalu

\footnotetext{
${ }^{1}$ According to Raddatz (2009) small countries are more vulnerable to windstorms than other countries which can lead to a decline of 3 percent in GDP per capita.
} 
consisting of low-lying ${ }^{2}$ stretches of atoll islands is one of the most vulnerable countries to natural disasters in per capita terms, particularly to destructive cyclones with associated storm surges that can easily flood large parts of the islands. In Tuvalu, natural disasters such as cyclones with associated storm surges often flood some islands, inflicting significant damage on the livelihoods and physical assets of the population, whilst imposing adverse effects on the economy and ecosystems.

The cyclone of 1972 is the worst event ever experienced by Tuvalu. ${ }^{3}$ However, there have been other noticeable strong storms in the recent past. A more recent event, in 2015, was a distant cyclone (about 1,000 km away) called Tropical Cyclone Pam (TC Pam), affecting the islands of Tuvalu with estimated damage and losses of $10 \%$ of GDP (ADB, 2015). The changes in weather patterns and the threat of rising sea levels due to climate change further aggravate these threats.

This inquiry reviews the growing body of recent literature on disaster risk and associated components influencing it. We aim to understand the concepts of disaster risk in order to recognise its challenges, opportunities, and implications for SIDS, particularly low-lying islands like Tuvalu. Through this, we can acquire ideas of what is needed to improve Disaster Risk Management (DRM) and ways to advocate for and strengthen Disaster Risk Reduction (DRR) efforts. Reviewing the literature on disaster risk will also situate this research in its broader context, in order to provide direction for future research in this growing field, with the focus on small island states.

\footnotetext{
${ }^{2}$ McLeod (1999) stated that the whole land in Tuvalu lies below 5 meters.

${ }^{3}$ Yamamoto and Esteban (2014, p.57) stated that "In October 1972, cyclone "Bebe" hit Tuvalu, killing several people destroying millions of dollars worth of property. The capital atoll of Funafuti was engulfed by waves from both the ocean and lagoon side, with a huge $19 \mathrm{~km}$ long, 30-40 m wide and $4 \mathrm{~m}$ high embankment (called a "storm ridge") being formed as a consequence of the waves moving huge quantities of sediments. The storm damaged houses, infrastructure, boats, coconut trees, the reef flats and caused extensive scouring of the islets in the atoll." See http: //www.janeresture.com/hurribebe/hurricanebebe2.htm for full details of the impact of cyclone Bebe on Funafuti Island, including documented stories from seven people who experienced the devastation of the event.
} 


\section{CHAPTER 1. A SURVEY OF DISASTER RISK AND RESILIENCE IN SMALL ISLAND STATES}

\subsection{Disaster Risk}

Natural disasters affect people world-wide, causing losses and damages. Climate change and its influence on the frequency and intensity of natural disasters has been part of the emergence of the new branch of economics research on the economics of disasters.

UNISDR (2009, p.9) defined disaster as "a serious disruption of the functioning of a community or a society involving widespread human, material, economic or environmental losses and impacts, which exceeds the ability of the affected community or society to cope using its own resources". Here, disasters are being described in relation to exposure, vulnerability, and coping mechanisms. The definition of disaster risk reflects on the meaning of disasters; disaster risk is not only the likelihood of a disastrous event, but also often associated with mechanisms that inflate the impacts of such events. Particularly, disaster risk is a function of three interlinked components: hazard, exposure, and vulnerability (GFDRR, 2016). By definition, UNISDR (2009, p.9) refers to disaster risk as "the potential disaster losses, in lives, health, status, livelihoods, assets and services, which could occur to a particular community or a society over some specified future time period".

Wisner et al. (2003) and Wisner et al. (2012) elaborate on the framework of the dual faced character of nature that presents a set of possible opportunities and possible hazards, emphasising that disasters are not solely driven by the natural environment, but also influenced by human activities, that is, they are the product of political, social and economic environments. They also introduced a conceptual framework that defines and explains the relationship between risks, hazards, and vulnerability. This Pressure and Release (PAR) framework illustrates that the intersection of hazard, vulnerability, and coping and recovering capacities correspond to disaster risk. Moreover, Wisner et al. (2012) advanced the framework of "progression and vulnerability" comprised of root causes, dynamic pressures, and fragile livelihoods and unsafe locations. ${ }^{4}$ This framework reflects the fact that

\footnotetext{
${ }^{4}$ 'Root causes' in this context centers around existing social, economic (e.g., distribution of resources, wealth and power) and political structures. 'Dynamic pressures' concerns with societal deficiencies (relating to economic opportunities), and lack of macro forces. Unsafe conditions are specifically associated with the situation facing vulnerable people in a given time and place.
} 
limited access to resources that allow for risk reduction impede coping and recovery mechanisms for hazards. Nevertheless, disaster risk and its underlying components (hazard, exposure, and vulnerability) are changing in relation to the changes in the environment, and political, economic, and social aspects of society (GFDRR, 2016).

\subsection{Hazard}

Hazard is widely recognised as an extreme natural event or process (Wisner et al., 2012), or a potential harmful event or process (World Bank, 2013c), or a hazardous phenomenon (United Nations, 2015a). In the past, natural hazards and their characteristics were the main focus of discourses relating to disasters.

In addition to naturally occurring hazards, the evolution of the way we look at disasters has unfolded new components of disaster risk and extended its scope. UNISDR (2009, p.17) refers to hazard as "a dangerous phenomenon, substance, human activity or condition that may cause loss of life, injury or other health impacts, property damage, loss of livelihoods and services, social and economic disruption, or environmental damage." Recently, GFDRR (2016) defined hazard as the likelihood and intensity of a potentially destructive natural phenomenon, such as ground shaking induced by an earthquake or extreme winds associated with a cyclone.

Generally, hazard is interpreted as an influence that can adversely affect a system's valued attributes. Ainuddin and Routray (2012) noted that there has been a paradigm shift in the development literature on hazards and disasters, from assessing hazard to analysing vulnerability and building community resilience.

\subsection{Exposure}

GFDRR (2016) defined exposure as the location, attributes, and value of people and assets (such as buildings, agricultural land, and infrastructure) exposed to the hazard. The World Bank (2013c) broadly refers to exposure as the external environment that determines the shocks to which a system is subject. Gallopin (2006, p.296) postulated 


\section{CHAPTER 1. A SURVEY OF DISASTER RISK AND RESILIENCE IN SMALL ISLAND STATES}

that exposure is the "degree, duration, and/or extent in which the system is in contact with, or subject to, the perturbation". Christenson et al. (2014, p.2172) described exposure more discretely by referring to it as "the likelihood that an individual in a given location is exposed to a given type of climate-related hazard event over a certain period of time". They also estimated population exposure to climate-related hazards (e.g., cyclones, droughts, and floods) using gridded datasets, with which they calculated the population exposure by the relative hazard frequency in a certain area weighted by the population density frequency. As a result, they ranked countries by population exposure to these extreme events.

The United Nations (2015a), refers to exposure as the location of people, production, infrastructure, housing, and other tangible human assets in hazard-prone areas. UNISDR (2009, p.15) defined exposure as "people, property, systems, or other elements present hazard zones that are thereby subject to potential losses". The poor are exposed to disasters (Bene et al., 2012), and further, poor people are often, but not always more exposed to hazards (Hallegatte et al., 2015). Gunasekera et al. (2015) developed an exposure model for hazard risk assessment from a Country Disaster Risk Profile (CDRP) which complements vulnerability and hazard models.

\subsection{Vulnerability}

Fussel (2007) posited that the scientific use of 'vulnerability' has its roots in geography and natural hazards research but has become a central concept in many other research contexts. Vulnerability is defined as the potential extent to which physical, social, economic, and environmental assets may become damaged or disrupted when exposed to a hazard event (GFDRR, 2016). Vulnerability is a complex term with no consensus on its meaning, though it tends to include various factors that have the potential to be damaged or harmed by a hazard event. For instance, on a physical scale, it refers to physical vulnerability when looking at the level of damage sustained by built structures due to a hazard event. On the social level, it refers to 'social vulnerability' (also known as 'socioeconomic vulnerability' or 'socioeconomic resilience') where damage relates to livelihood and other social factors that influence a community's ability to respond to, cope with, and recover from a disaster (GFDRR, 2016). Social 
vulnerability can affect the number of casualties, the loss or disruption sustained, and a community's subsequent recovery time. Similarly, UNISDR (2009, p.30) defined vulnerability as "the characteristics and circumstances of a community, system or asset that make it susceptible to the damaging effects of a hazard".

Vulnerability is often seen as a potential for weakening the capacity of an individual or group to face, cope, resist, respond to, and recover from the impacts of natural and anthropogenic hazards. Turner et al. (2003) comprehensively outlined the analysed vulnerability framework and its components - exposure, sensitivity, and resilience - which are linked to dynamic factors beyond the system. The degree of vulnerability, and capacity to respond to and recover from disasters, are often determined by physical, economic, social, and political factors. Through this, vulnerability is often connected to poverty. To better respond to these disasters, there is a need for reducing hazard impact (through preparedness, mitigation, prediction, and et cetera), building and strengthening capacities to resist and cope with hazards, and attempting to reduce sources of vulnerability (e.g., through poverty reduction, good governance, equality, accessibility to resources and livelihoods).

De Haen and Hemrich (2007) argued that the extent of disaster risk depends on natural hazards and vulnerability. They also support the argument that there is a higher level of vulnerability in the urban areas due to higher population density. As poorer households tend to reside in riskier urban areas (Adger, 2006), they are more likely to face rising costs and relatively higher losses and damages during disasters. Normally, the poor are more affected due to economic and social attributes (Wisner et al., 2003). At the macro-level, De Haen and Hemrich (2007) further illustrate the notion of the 'inverted U' relationship between economic development and disaster vulnerability, indicating that middle-income countries are specifically vulnerable to natural disasters. Nadiruzzaman and Wrathall (2015) strengthened the link between poverty and disaster for Bangladesh arguing that the poor are not only more vulnerable to natural events, but have less ability to access resources due to factors such as social and political identity, kinship, social networks, financial capacity, political connections, and rivalry. They argued that the dynamics of livelihoods, local power, resilience, and cyclones are interconnected.

Smith and Rhiney (2015) examined climate justice for SIDS like the Caribbean 


\section{CHAPTER 1. A SURVEY OF DISASTER RISK AND RESILIENCE IN SMALL}

ISLAND STATES

Islands and argued that factors driving vulnerability pointed to centuries of economic neglect and political marginalisation that are strongly related to communities' socio-economic characteristics, geographic locations, heavy reliance on land-based resources, and the capacity to adapt to climate change. Lopez-Marrero and Wisner (2012) and Smith and Rhiney (2015) stressed that vulnerability to negative impacts of climate change is partly a function of different coping and adapting capabilities of various groups of people in developing countries. Smith and Rhiney (2015) further argued that vulnerability to climatic impacts is inherently developmental as differentiated levels of exposure and sensitivity to natural hazards are partly created by social and economic inequalities, as well as accessibility of land-based resources, assets, and government support. Lopez-Marrero and Wisner (2012) strengthened the notion that vulnerability and capacities to cope with natural hazards differ due to differential accessibility to resources (e.g., natural, physical, human, social, and political).

On the other hand, economic vulnerability is well documented in the literature from both conceptual and empirical viewpoints. Most studies in this stream point to the small island states as highly vulnerable to exogenous shocks due to their high degrees of economic openness and export concentration (Briguglio et al., 2009). SIDS are most vulnerable to disaster risks due to increasing intensity of cyclones and sea level rise. Briguglio (1995) recognised the vulnerability of SIDS to disasters and the lack of economic resilience arising from the relative inability of these countries to face forces of scales out of their capacity to deal with independently. Asadzadeh et al. (2015) emphasised that measuring risks and vulnerability is imperative in promoting disaster resilience in hazard prone areas.

\subsection{Resilience}

Folke (2006), Gallopin (2006), Mayunga (2007) and Cutter et al. (2008) all believed that the literature on resilience emerged from the ecology discipline, as an off-spring of an influential paper by Holling (1973) called "Resilience and stability of ecological systems". Ainuddin and Routray (2012) outlined the various definitions of community resilience. Smit et al. (1999) argued that definitions reflect on the nature of a 
system (e.g., ecological, economic, social, or political). For instance, the literature and different organisations have their own definitions for disaster resilience. Cutter et al. (2008) proposed a framework called the Disaster Resilience of Place (DROP) model and emphasised that there is more to articulate about the relationship between vulnerability, resilience and adaptive capacity. They distinguish 'vulnerability' as the characteristics that create the potential for harm, and 'resilience' as the ability to respond to and recover from disasters. Similarly, although Briguglio et al. (2009) argued that risk is determined by the two elements namely exposure and coping ability, they associate exposure to vulnerability and coping ability to resilience.

Many terms were used to describe the various efforts to reduce risk, namely preparedness, public awareness, prevention, adaptation, resistance, mitigation, response, and so on. UNISDR (2009, p.24) refers to resilience as "the ability of a system, community or society exposed to hazards to resist, absorb, accommodate to and recover from the effects of a hazard in timely and efficient manner, including through the preservation and restoration of its essential basic structures and functions". With the increasing global threat of climate change and associated disasters, measuring resilience has increased in popularity with efforts attempting to build resilience to climate change and disasters. Consequently, many papers have emerged with definitions, concepts, and indicators for measuring resilience. These concepts are often complexly interrelated. Other studies by Mitchell et al. (2013) identified economic indicators of resilience based on impact, outcome, output and input. Parsons et al. (2016) emphasise a disaster resilience framework using coping and adaptive capacities.

Furthermore, Briguglio (2003) and Briguglio (2004) compared 'economic vulnerability' and 'economic resilience' to explain the phenomenon known as the 'Singapore Paradox'. ${ }^{5}$ This is a phenomenon based on the fact that even though the small island state of Singapore is highly exposed to exogenous shocks, still they achieved and attained high levels of economic growth and GDP per capita. ${ }^{6}$ The

\footnotetext{
${ }^{5}$ See Noy and Yonson (2016) for more discussion on 'economic vulnerability' and 'economic resilience'.

${ }^{6}$ This case can be explained by its ability to face external shocks through building resilience. Unlike other isolated small island states like Tuvalu and Kiribati, Singapore has geographical advantages (port, location is heavily populated in the region) as a trade center, with the presence of multinational companies on its shores. Therefore, Singapore has the potential to build economic
} 


\section{CHAPTER 1. A SURVEY OF DISASTER RISK AND RESILIENCE IN SMALL ISLAND STATES}

importance of economic resilience to disasters was highlighted by Mitchell et al. (2013) as an enabler of many broader development goals.

Building resilience requires a clear concept of 'resilience' itself. Reflecting on the complications of civil society and the thinking behind disasters in relation to society, it is not surprising that various disciplines have diverse definitions of 'resilience'. However, there are commonalities apparent in these definitions, and this is fundamental in establishing a resilience paradigm. With more clarity and consensus on the definitions, disaster resilience can be more achievable with less confusion. ${ }^{7}$ Consequently, an evolution in defining 'resilience' has steadily enhanced the way we conceptualise disaster resilience.

On a more practical level, Kusumastuti et al. (2014) employed a resilience index measured as a ratio of preparedness (capacity to overcome a disaster) to vulnerability (exposure towards a disaster). Bene et al. (2012) revealed the 3D resilience framework whereby resilience arises as a result of the three capacities namely absorptive, adaptive, and transformative. On the other hand, Hosseini and Barker (2016) modelled infrastructure resilience by quantifying resilience as a function of absorptive, adaptive, and restorative capacities. They refer to 'absorptive' as the capacity of a system to absorb or withstand the impact of disruptive events and minimise the consequences, 'adaptive' as the capacity of a system to adapt and overcome a disruption, and 'restorative' as the capacity of a system to repair and restore from a disruption.

\subsection{Measurements of Disaster Risk}

In the economics community, there are available econometric methods to measure disaster risk (or disaster impact). Most use time series, cross-section and panel data to identify the relationship of explanatory variables on disaster risk (or disaster impact). Cavallo and Noy (2011) showed how the impacts of disasters can be measured by referring to a model of the form: $Y_{i t}=\alpha+\beta X_{i t}+\gamma D I S_{i t}+\varepsilon_{i t}$ where $Y_{i t}$ denotes resilience.

${ }^{7}$ However, there is a need for more understanding on why greater clarity around the definitions would necessarily make disaster resilience more achievable. 
disaster impact of interest, $D I S_{i t}$ is a measure of the immediate impact of disaster on country $i$ at time $t, X_{i t}$ is the typical vector of control variables affecting $Y_{i t}$, and $Y_{i, t-1}$, and $\varepsilon_{i t}$ is the error term. They also show other extended models using other estimation methodologies.

Other studies like Yodmani (2001) and Shaw et al. (2013) suggested that disaster risk is a function of hazard, vulnerability and capacity. However, discourse surrounding the definition of 'resilience' compared to 'capacity' has resulted in diverse perspectives and formulations of disaster risk. Following definitions from UNISDR (2009), Shaw et al. (2013) modified the formula proposed by Yodmani (2001) arguing that disaster risk should be a function of natural hazards, vulnerability, exposure, and resilience. They argued that this modification better reflects on the underlying purpose of Disaster Risk Reduction (DRR) in reducing vulnerability and exposure to hazard while building resilience for potential impacts. Measuring of disaster risk in this manner has become popular with the increasing intensity of disasters and associated costs (loss and damage) over time, which has in turn generated the emerging focus of research in this area followed by extensions in definitions and concepts. ECLAC (2003) breaks down the effects of disasters simply, into direct damages (affected assets) and indirect losses (affected flow of goods and services). ${ }^{8}$ These developments, extensions, and interactions (capturing resilience, adaptability, responses, and other factors) are useful in identifying areas in need of building resilience for disasters. This has made measuring and building of resilience an essential tool for reducing disaster risk.

The conceptual framework for risk under the PAR framework (Wisner et al., 2003) discussed earlier, outlines an equation of the form where Risk $=$ Hazard $\times$ Vulnerability. Nevertheless, an extension was formulated based on the IPCC (2012) expressing the crucial role of natural hazards, exposure, and vulnerability in measuring disaster risk. This widely used formulation within the disaster risk community is simply expressed as: Risk $=$ Hazard $\times$ Exposure $\times$ Vulnerability. They translate disaster risk as $Y_{i}=\alpha+\beta_{1}$ Hazard $_{i}+\beta_{2}$ Exposure $_{i}+\beta_{3}$ Vulnerability $_{i}+$ $\varepsilon_{i}$ for cross-section data. On the other hand, it can be extended to $Y_{i t}=$ $\alpha+\beta_{1}$ Hazard $_{i t}+\beta_{2}$ Exposure $_{i t}+\beta_{3}$ Vulnerability $_{i t}+\varepsilon_{i t}$ for panel data, where the

\footnotetext{
${ }^{8}$ See Cavallo and Noy (2011) for more discussion on natural disasters and the economy.
} 


\section{CHAPTER 1. A SURVEY OF DISASTER RISK AND RESILIENCE IN SMALL ISLAND STATES}

dependent variable $Y_{i t}$ is typically represented by direct impact on either people (losses or lost lives) or assets (e.g., direct damage costs) as a result of a disaster on unit $i$ at time $t$, while the explanatory variables of Hazard $_{i t}$, Exposure $_{i t}$, and Vulnerability ${ }_{i t}$ are vectors of characteristics and measures that represent them. Recently, Hallegatte et al. (2017) extended the risk framework to capture both risks to assets and well-being by including a measure of socioeconomic resilience in his risk assessment.

\subsection{Policy Implications}

For Tuvalu, these components of disaster risk - hazard, exposure and vulnerability interact to determine very high risk. Increases in the levels of these components will increase total risk and lead to greater damages and losses associated with disasters. Understanding these risks in order to measure and propose risk reduction options is therefore of vital importance.

The people of Tuvalu (on Funafuti) have only taken tsunami warnings seriously after the tsunami tragedy that hit Samoa in 2009, killing more than 100 people. For small and low-lying islands like Tuvalu, preparedness for tsunamis is a complex problem as there are no high grounds worthy to be safe zones. The option of resettling or moving to safer places is almost impossible in Tuvalu, because of limited lands, economic and legal constraints. Most of the people live close to the coasts, not by choice but by the limited lands available. ${ }^{9}$ For Tuvalu, it is much safer in the outer-islands than the capital island Funafuti (urban) since the elevation is a little higher, there is more land area, and they are less populated. But, most economic opportunities are in Funafuti.

Transferring financial risk through insurance does not exist in Tuvalu, but this is recognised as a financial resilience tool to extreme climatic events like cyclones (Surminski and Oramas-Dorta, 2014). Raschky (2008) points out the importance of having better institutions in a country in lowering human and economic losses from natural disasters. He also postulates on the non-linear relationship between economic

\footnotetext{
${ }^{9}$ With overall land area of $25 \mathrm{~km}^{2}$ and a population of 10,000 people.
} 
development and economic disaster losses. ${ }^{10}$ Social networks at the local level are vital for community resilience and recovery from disasters (Hawkins and Maurer, 2010; Aldrich, 2011; Islam and Walkerden, 2017). Often, community resilience is a foremost response to disaster impacts (Airriess et al., 2008) and also act as informal insurance after disasters (Sanyal and Routray, 2016). For small islands like Tuvalu, where almost everyone knows their neighbours (relatives and friends) and people on their islands, local social networks and communities are central to disaster response and recovery efforts.

It is commonly agreed that climate change will displace millions of people worldwide. However, low-lying islands in the Asia-Pacific are at the forefront of both disasters and environmental change. Migration by some of the community form part of an adaptation strategy. Nevertheless, migration can be the last option when security and the lives of the people are at high risk. Despite this global problem, there are no provisions under international laws to protect those who will be forced to migrate due to environmental causes. Johnson and Krishnamurthy (2010) distinguish "economic migration" from "distress migration" based on household resources, capabilities and decisions. "Migration with dignity" is a concept often advocated by some Pacific leaders (Farquhar, 2015).

Migration is seen as a survival strategy for people experiencing environmental problems, but not the only available strategy (Koubi et al., 2016). Reuveny (2007) outlines three options: stay and do nothing, and accept the costs; stay and mitigate the changes; or leave the affected areas. In relation to ecological conditions, migration decisions are complex and linked to multiple vulnerabilities, therefore relocation can be the only sustainable option as an adaptation strategy (Marino, 2012).

\subsection{Applicability to Tuvalu}

The two types of extreme events that often devastate the livelihoods of the people in Tuvalu are tropical cyclones and droughts. Throughout the last decade, Tuvalu

\footnotetext{
${ }^{10}$ Raschky (2008) refer this non-linear relationship between development and economic disaster losses where he concluded from his regression results that a 10\% increase in GDP per capita results in about 8.74 lower death toll.
} 


\section{CHAPTER 1. A SURVEY OF DISASTER RISK AND RESILIENCE IN SMALL ISLAND STATES}

has experienced some of the most severe disasters in its history, including TC Pam in 2015 and the Drought of 2011. To our knowledge, these were some of the few declared disasters by the government of Tuvalu since TC Bebe in 1972. ${ }^{11}$ Further, the intensity of disaster events has been increasing, as observed in the recent TC Pam, which caused devastation even though it was a distant cyclone. Likewise, Tuvalu experienced one of the longest drought in 2011. ${ }^{12}$ These extreme events were evaluated to be national disasters that forced the government to declare states of emergency for both events.

For Tuvalu, exposure at the household level can relate to the distance of the household from the coast and its elevation, as these are likely to be some of the determining factors of disaster risk given the size of the islands and low ground elevation. While Tuvalu is considered very exposed to hazards because of its geographical setting, some islands may be more vulnerable and exposed because of combinations of other factors. For instance, apart from distance to the coast and elevation, some islands have lagoons and islets that can serve as shields during strong winds, while others have none. The width of the island is another factor: for instance, the capital island Funafuti is no more than 900 meters in width, with an average of 347 meters on average in land width for residential areas. The impact of a cyclone depends mostly on its distance from the islands and its trajectory, but the above are some of the extra characteristics and challenges facing small and low-lying islands that need to be included in defining exposure to disasters.

A vulnerability index for the natural environment called the Environmental Vulnerability Index (EVI) was developed by the South Pacific Applied Geoscience Commission (SOPAC) and the United Nations Environmental Programme (see SOPAC, 2004), whereby Tuvalu was classified as an extremely vulnerable country (see SOPAC, 2004). ${ }^{13}$ As a Least Developed Country (LDC), Tuvalu has always been vulnerable to climatic disasters, mainly due to its geographical settings and economic

\footnotetext{
${ }^{11} \mathrm{TC}$ Bebe track passed over Tuvalu, specifically between the islands of Funafuti and Nukulaelae, based on the tropical cyclone map by the Australian Severe Weather at http://www. australiasevereweather.com/tropical_cyclones/1972_1973/jtwc/tropical_ cyclone_bebe.htm.

${ }^{12}$ Based on Tuvalu Meteorological Service (TMS) data, the year 2011 has the lowest annual rainfall (in mm) from 1933 to 2013 (see Figure 1.A.1 in Appendix).

${ }^{13}$ Note that the EVI has been subject to criticism by Barnett et al. (2008).
} 
characteristics. Population density on the capital island of Tuvalu (Funafuti), where the population density is 2,220 people per square kilometre, is another issue. ${ }^{14}$ The increasing population density in hazardous areas (Raschky, 2008) is evident on Funafuti with the population distribution of 42.5\% (in 1991), 47\% (in 2002) and $57.2 \%$ (in 2012). ${ }^{15}$ However, socio-economic characteristics such as access to resources, communications, and transportation (particularly for those in the outer islands) make some people more vulnerable than others.

Noy (2016b) measured the burden of disasters on PICs using two global datasets (Emergency Events Database (EMDAT) and the Disaster Inventory System website (desinventar.net)) and concluded that these commonly used datasets immensely underestimate the burden of disasters on the PICs, particularly atoll nations (Noy and Edmonds, 2016). Noy (2016b) also compared the burden of disasters between PICs and the Caribbean islands to find that the burden of disasters is far more significant in the Pacific, and also identified Tuvalu as the most exposed country in per capita terms. In per capita terms, the Pacific Islands face the highest disaster risk globally (Noy and Edmonds, 2016). ${ }^{16}$

With increasing occurrences of cyclones in the Pacific region, Tuvalu has to strengthen DRM, response and coordination efforts, and reduce disaster risk (e.g., prevention, preparedness, and early warning systems). Here, we need to understand first the hazards, and the exposure and vulnerability of people and assets to those hazards. Being able to identify exposure and vulnerability, and quantify the current risks and potential impacts of hazards is crucial in making decisions for prevention.

\footnotetext{
${ }^{14}$ Author's calculations based on the Tuvalu Census 2012 in Tuvalu Government (2012). For comparison purposes, McLeod (1999, p.11) stated that Tuvalu is "relatively highly densely populated at 437 people per sq km compared with an estimated 337 for India (1997), although Bangladesh one of the most densely populated areas in the planet has an estimated density of around 883 people per sq km".

${ }^{15}$ See Tuvalu Government (2012). In absolute values, population on Funafuti in 1991, 2002, and 2012 were 3839,4492 , and 6194 , respectively.

${ }^{16}$ In per capita terms, PICs (particularly Tuvalu) are more exposed to direct burden of disasters in terms of direct impact proxied by mortality, morbidity, the number of people affected, and financial damages (to infrastructure, residential housing, etc.).
} 


\section{CHAPTER 1. A SURVEY OF DISASTER RISK AND RESILIENCE IN SMALL ISLAND STATES}

\subsection{Conclusion}

The conceptual framework of disaster risk discussed is an essential stepping stone for more research, thus contributing to more knowledge about Tuvalu's disaster risk and DRM. Firstly, there is a need to examine the vulnerability and exposure of Tuvalu to climatic disasters at the household level. As such, it is important to use available household data, geographic and topographic information in assessing exposure differentials between households. Here, we can also construct hardship profiles, hardship and exposure maps for households and islands to determine who are more likely to reside in highly exposed areas to disasters. With geo-coded locations linked to household surveys, we can employ spatial regression models.

Secondly, to truly examine the impact of disasters on Tuvalu, we need to conduct a household survey to quantify the impacts of a disaster following the conceptual framework of disaster risk and its associated components of hazard, exposure and vulnerability. We can also extend this conceptual framework to include responsiveness to disasters as an additional component of disaster risk. Through this, we can estimate loss and damage costs and construct hypothetical policy scenarios for disaster risk reduction policies. Given the geographical settings of low-lying atoll islands, it is imperative to assess the impact of distant cyclones and its associated storm surge that often lead to flooding in the islands.

Last but not the least, SIDS often face financial difficulties imposed by climate and disaster risks, especially for quick response and recovery. The fact that Tuvalu does not have an insurance mechanism and, as a result, often relies on aid for disasters. This stimulates our interest in developing a potential financial instrument for disaster risk management in Tuvalu. Although there are other potential financial instruments, one option is to use its sovereign wealth fund (SWF) to contribute into a disaster fund that can then be used as a buffer for ex-post disaster risk management. We can quantify appropriate financial levels of support for expected disasters by calculating expected average annual loss (AAL). Moreover, we can assess the long-term sustainability of the SWF by forecasting its expected performance, and therefore determine the feasibility of contributing to a disaster fund. 
1.10. CONCLUSION 


\section{Appendix}

\section{A Rainfall}

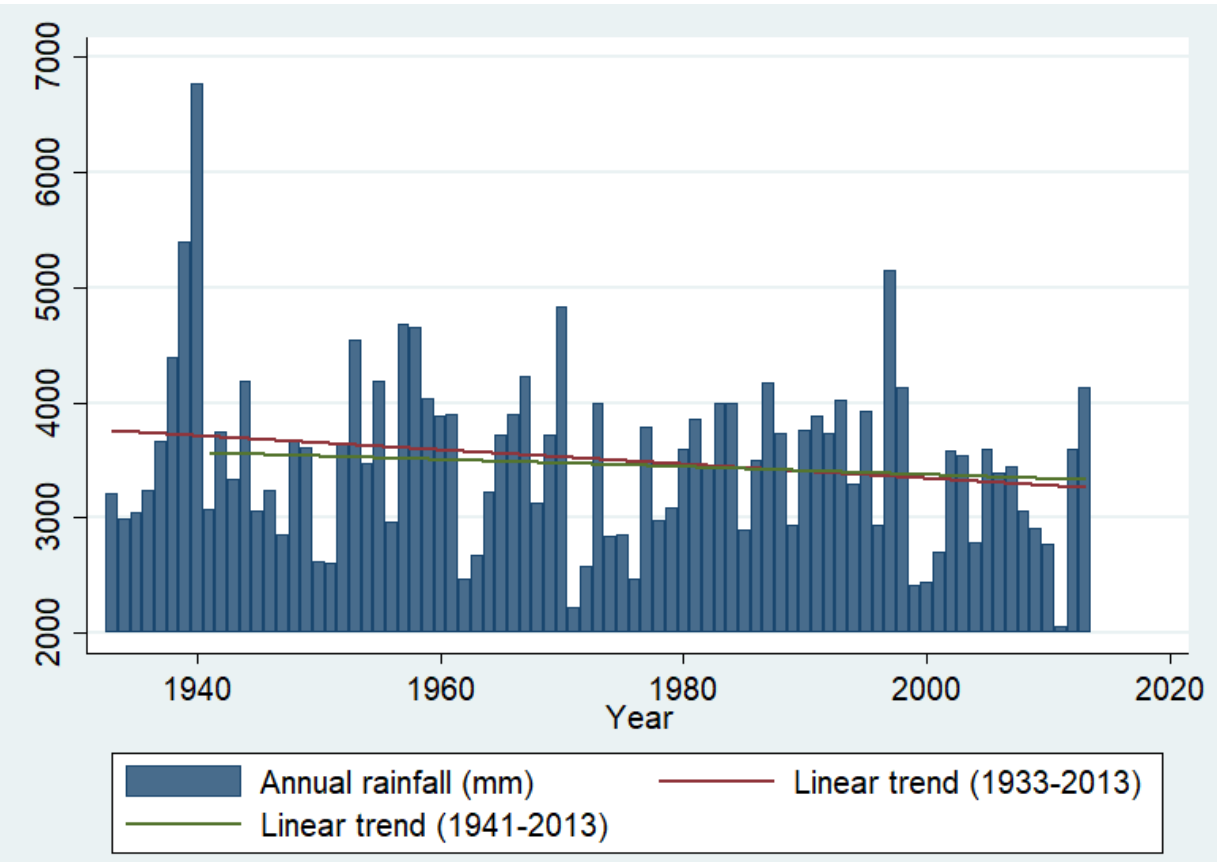

Source: Author's calculations, on rainfall data from the Tuvalu Meteorological Service (TMS). The red line is the linear trend for the whole period from 1933 to 2013, while the green line is the linear trend starting after the outlier in 1940.

Figure 1.A.1: Annual rainfalls on Funafuti (Tuvalu) from 1933 to 2013 
1.A. RAINFALL 


\section{Chapter 2}

\section{Household Vulnerability on the Frontline of Climate Change: The Pacific Atoll Nation of Tuvalu}

\section{$2.1 \quad$ Introduction}

The Pacific Island Countries (PICs), particularly low-lying islands, are confronted with a range of economic challenges because of their smallness, remoteness and limited resources. These attributes increase their populations' vulnerability to economic shocks, and have hampered the islands' capabilities to match rising global living standards. Unfortunately, for households in these small atoll islands, many of the same geographical features that raise vulnerability to economic shocks, also contribute to heightened exposure and vulnerability to climatic shocks. These countries, in particular, have seen their circumstances change with the rise in sea levels, and the increase in damage caused by climatic hazards (in particular for the Pacific island countries, cyclones). For the islands' poorest people, these dual economic and climatic threats pose an even greater challenge.

Even though poverty has been well researched globally, less attention has been given to Small Island Developing States (SIDS), and specifically to the PICs. This is 
surprising as the low-lying atoll island nations in the Pacific - Tuvalu, Kiribati and the Republic of the Marshall Islands - lie at the frontlines of climate change. The World Bank (2014, p.4) acknowledges that, "while the aggregate or macroeconomic impacts of negative shocks have been relatively well-studied, much less is known about the impacts on household well-being, due in large part to data limitations." This chapter aims to fill that gap by focusing on hardship and vulnerability facing households in the context of low-lying SIDS.

In this chapter, we consider the case of Tuvalu, and in particular, the conditions of the population which are likely to relate to rising hardship resulting from climate change. To date, there has been little previous empirical studies on hardship and vulnerability in Tuvalu, or on any other atoll country. Since disaster risk is the confluence of the hazard itself, exposure to the hazard, and the vulnerability of the exposed population, it is paramount to examine the current state of exposure and vulnerability in the affected countries. This is our intent in this chapter.

We aim to explain how and which households in Tuvalu are particularly exposed and vulnerable to climatic shocks. Specifically, we intend to: identify the degrees of economic stability and resilience; determine the relevant thresholds; classify households accordingly based on these thresholds; examine the changes in economic stability and resilience over time; examine household exposure to disasters; investigate the determinants of income; and examine household characteristics that make households more or less likely to be in hardship. Knowing these factors will assist in devising policies that reduce vulnerability and contribute to more effective Disaster Risk Management (DRM); a crucial and potentially the most important component of climate change adaptation. Using detailed income and expenditure survey data encompassing one third of the nation's population, the study is able to take a micro-perspective of the household, presenting empirical evidence of hardship and vulnerability to shocks that complements the macroeconomic analysis done elsewhere (e.g., Noy, 2015; Cabezon et al., 2015). The work sheds further light on how households are facing and coping with disasters currently. The regression estimates obtained here are not directly related to climatic disasters, but the geographical and topographical variables that we used link our estimates to environmental factors. Since we know from elsewhere, for example from the next chapter, that the locations of households are related to disaster risk, we can link this disaster vulnerability to 
CHAPTER 2. HOUSEHOLD VULNERABILITY ON THE FRONTLINE OF CLIMATE CHANGE: THE PACIFIC ATOLL NATION OF TUVALU

income (and income vulnerability and hardship). More explicitly, we find that poor households are more likely to reside closer to the coasts, areas that are more exposed and prone to climatic disasters.

The chapter proceeds as follows. The next section discusses the context of Tuvalu, section 3 provides a short survey of the relevant literature on the measurement of poverty and hardship leading to the development of our economic stability and resilience indicators, section 4 discusses Tuvalu's exposure to disasters, section 5 outlines the empirical methodology, section 6 describes the data, section 7 explains the empirical results, while conclusions are presented in section 8.

\subsection{Background}

The increasing frequency and intensity of disasters in the Pacific is well documented, and has contributed to the high (proportional) loss of human, natural, financial, social and physical capital in the region (Noy, 2016b; World Bank, 2016; Asian Development Bank, 2013). Tuvalu is a small low-lying country in the equatorial South Pacific. ${ }^{1}$ It has a population of about 11,000 people, scattered across nine low-lying atolls. It is surrounded by an exclusive economic zone of 900,000 square kilometers $\left(\mathrm{km}^{2}\right)$ with a landmass of $25.9 \mathrm{~km}^{2}$ that rarely exceed five meters above sea level. Population density is highest in the capital Funafuti, which accounts for more than half of the population of Tuvalu. Tuvalu has a dual economy consisting of a small cash economy and a subsistence economy focussed on its traditional sectors of fishing and small scale agriculture (ADB, 2007). Government revenue largely comes from issuing fishing licenses to foreign fishing vessels, '.tv' internet domain revenues, remittances, and foreign aid (directly funding the budget, and through funding distributed to the Tuvalu Trust Fund). Families in the capital Funafuti are more dependent on cash income than those living in the outer-islands. People migrate from the outer-islands to the capital Funafuti in search of job opportunities, better access to health facilities, and better education. Food and non-food items are mostly imported except for fish and a limited supply of a very narrow range of fruits and vegetables. Most of the people currently residing in the capital are originally from the outer-islands, and have

\footnotetext{
${ }^{1}$ See the map of Tuvalu in Figure 2.A.1.
} 
limited access to land and property ownership on Funafuti. Hence the reason for the high dependency on cash income in the capital. ${ }^{2}$

Most development and settlement in atoll islands occurs close to the coast, which is vulnerable to storms, floods and sea-level rise (World Bank, 2016). As a low-lying coral atoll, every high spring tide (King tide) floods properties situated in low lying-areas (including inner parts of the capital Funafuti) as the water rises through the coral ground, destroying household plantations. People typically adapt by raising gardens above the ground and cementing around and under crops to prevent intrusion of seawater. However, these precautions are not fully adequate, and the combination of high tides and storms continue to pose considerable threat to households living at low elevation and near the coastline. Adding to the problem is the fact that the sea-level rise at Funafuti is three times above the global average between 1950 and 2009 (Becker et al., 2012), and this trend will likely worsen over time (Yamano et al., 2007). Appendix Figure 2.B.1 shows the increasing trend of sea levels in Tuvalu.

\subsection{Economic Stability and Resilience}

There is a broad literature on poverty and vulnerability, but very limited focus on SIDS, especially low-lying islands like Tuvalu. Jha et al. (2009) measure the extent of vulnerability as expected poverty using cross-sectional data from a household survey in Fiji and find that vulnerability is largely a rural phenomenon. Similarly, Jha and Dang (2010) use cross-sectional data from the 1996 Household Survey for Papua New Guinea (PNG) to assess household vulnerability to poverty in PNG. These papers on Fiji and PNG do not focus on geographical and climatic factors, and the geographical settings, resource base and economic characteristics of these volcanic Pacific islands are different from low-lying atoll island countries such as Tuvalu.

We focus on poverty and exposure since they are vital indicators of how vulnerable, resilient and responsive households are to crises. According to Haughton and Khandker (2009), vulnerability is defined as the risk of falling into poverty in the

\footnotetext{
${ }^{2}$ According to the 2012 Census, only $17.7 \%$ of the people living on Funafuti are local Funafuti people, while the rest are without land ownership, and are renting houses from the locals. Based on the 2012 Census, $84.5 \%$ of rental houses in Tuvalu are on Funafuti.
} 
future, even if the person is not necessarily poor at present; it is often associated with the effects of "shocks" from disasters and economic crises. Dercon (2005) outlines, for Sub-Saharan Africa, the links between risk and vulnerability to poverty thus highlighting the vital role played by them in determining people's livelihoods and opportunities to escape poverty. ${ }^{3}$

Abject poverty in Tuvalu is rare or non-existent, partly because of cultural and community traditions. Help and support are common from families, communities, religious groups and friends. Poverty, as a term, is therefore not frequently used in many of the PICs that have similar circumstances and cultural practices. ${ }^{4} \mathrm{We}$ compare poverty levels from the three household surveys from different years to examine how poverty levels have changed over time.

We define four degrees of economic stability namely poverty, hardship, vulnerability, and non-resilience. ${ }^{5}$ These four degrees of economic stability are defined (see Table 2.E.1 in the appendix) by the thresholds calculated and used to classify households. These four degrees of economic stability are defined to reflect the economic stability and resilience of households. Thresholds were drawn to identify and classify households into groups reflecting these measures. We follow Ravallion (1998) and Haughton and Khandker (2009) in defining and measuring poverty. Hence, we define poverty incidence as the percentage of households who fall below the food consumption level. Hardship is similarly defined for households whose expenditures fall below the benchmark food and non-food consumption levels. The vulnerability to poverty incidence refers to the percentage of households who are above the hardship threshold, but are vulnerable to falling under it as a result of negative shocks (measured as $110 \%$ of the hardship level). ${ }^{6}$ In addition, we also

\footnotetext{
${ }^{3}$ Recent papers on Asian and African poverty and vulnerability are Dasgupta and Baschieri (2010); Dutta et al. (2011); Echevin (2014); a recent comprehensive survey of this literature is Hallegatte et al. (2015).

${ }^{4}$ Abbott and Pollard (2004) emphasise that 'hardship' is a more acceptable terminology. The World Bank (2014) also argues that "the label of poverty is considered culturally inappropriate because it is viewed as implying a failure of traditional, community-based safety nets". We used hardship and to mean "living with less than expected to meet both required food consumption and non-food essentials".

${ }^{5}$ In this case, we refer 'vulnerability' in relation to income (or those in hardship in addition to those vulnerable to fall into hardship) as oppose to 'vulnerability' in a disaster context. There is a potential to confuse readers due to the inconsistency in definitions for 'vulnerability' between disciplines (i.e. development and disaster).

${ }^{6}$ In practice, this includes all those below a threshold that is $10 \%$ higher than the Basic Needs
} 
include the non-resilience incidence which refers to the percentage of households who are still vulnerable to negative shocks and could potentially fall into poverty. This non-resilience threshold is determined as those households living below 10 USD (purchasing power parity) per person per day, a measure that is believed to be necessary to achieve the degree of economic stability and resilience to shocks (see World Bank, 2013c). ${ }^{7}$ Therefore, we identify four thresholds: poverty (food), hardship (food and non-food), vulnerability (10\% above hardship), and non-resilience (10 USD).

Figure 2.1 shows that the poverty incidence has increased by less than $2 \%$ from 2004/5 to 2010 at all levels of national, urban and rural. Hardship incidence has also increased by around $4 \%$ from $2004 / 5$ to 2010 for the urban population, but decreased by $1 \%$ for the rural one. The 1994 hardship incidences from Abbott and Pollard (2004) are higher at all three levels. Poverty incidence is usually higher in the urban area when compared with the rural one. ${ }^{8}$ Some possible reasons leading to a higher urban poverty incidence are the overcrowding in the urban households and high wage unemployment. ${ }^{9}$

Except for the non-resilience measure, we did not observe dramatic increases in poverty, hardship and vulnerability in the five years separating the two surveys. Worryingly, however, we observe higher incidence of all the lower threshold measures (poverty, hardship and vulnerability) in the urban areas relative to rural ones. As

Poverty Line (BNPL). The BNPL was calculated based on Ravallion (1998), and in line with Tuvalu Statistics Office's policy. The hardship threshold is the sum of the Food threshold and the Non-Food threshold. The Food component was calculated from a basket of essential basic food items that is estimated to be equivalent to the widely used nutritional requirement for good health of 2,100 calories per person per day suggested by the Food and Agricultural Organisation (FAO) of the United Nations. The Non-Food threshold is the average Non-Food Expenditure by households in the lowest 3 deciles. The Non-Food threshold is calculated differently for rural and urban (Funafuti) areas as the non-food expenditure, especially housing, is quite different between the regions. Expenditure is derived as the sum of Food Expenditure and Non-Food Expenditure.

${ }^{7}$ USD refers to United States Dollars while AUD refers to Australian Dollars. The AUD is the legal tender in Tuvalu.

${ }^{8}$ This is also reported by Abbott and Pollard (2004) but unlike the case for Fiji reported in Jha et al. (2009).

${ }^{9}$ Other possibilities can be traced to the availability of more employment in the rural sector from the island council, clinics, island development projects, and small scale businesses (after the collapse of the Tuvalu Cooperative Society). Informal work allocation in the outer-islands is also more equally distributed amongst families and may not rely on educational qualification as much as in the urban area of Funafuti. 
CHAPTER 2. HOUSEHOLD VULNERABILITY ON THE FRONTLINE OF CLIMATE CHANGE: THE PACIFIC ATOLL NATION OF TUVALU

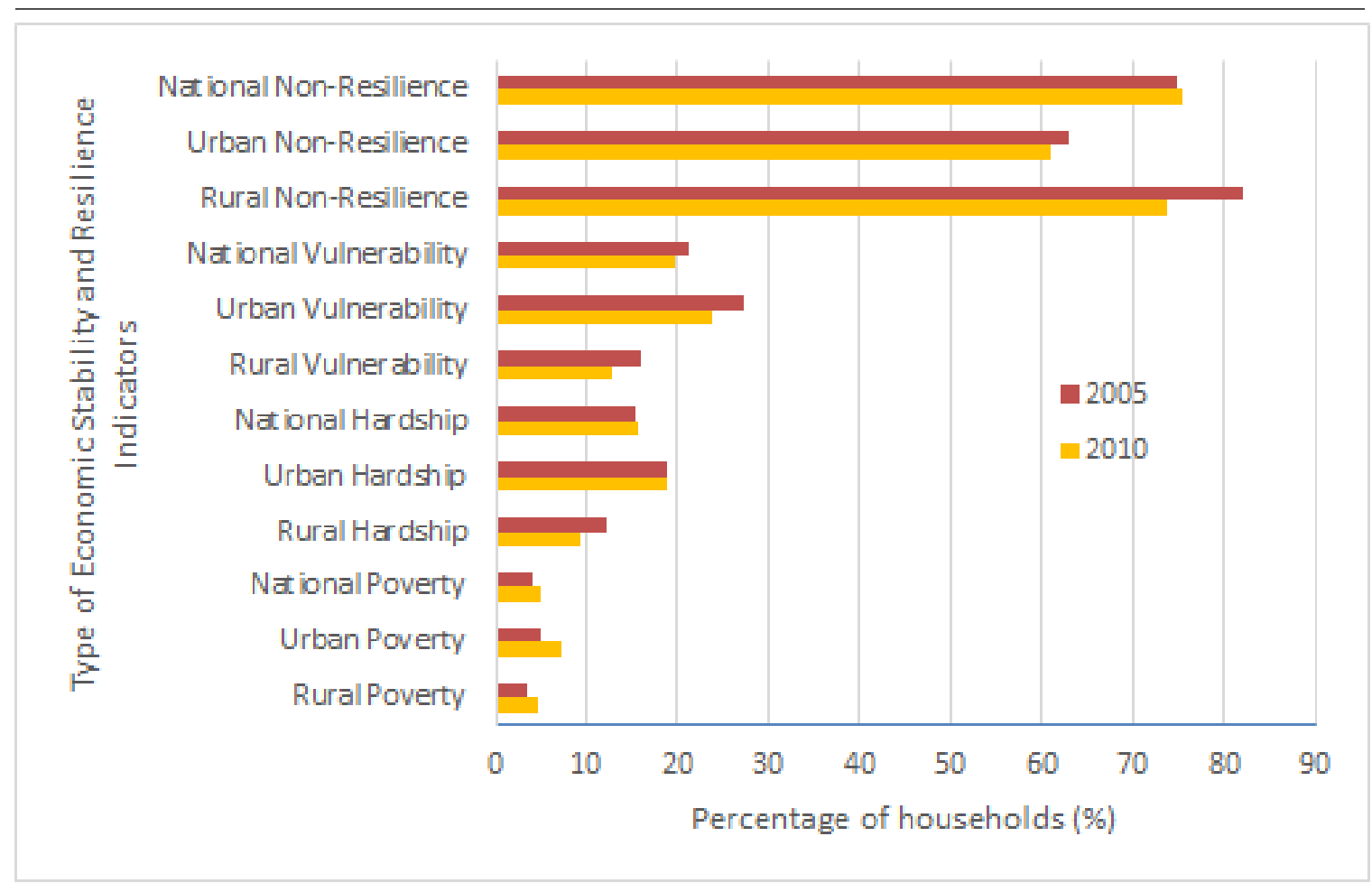

Source: Author's calculations, on data from 2004/5 \& 2010 Household Income \& Expenditure Survey (HIES).

Figure 2.1: Incidence of economic stability and resilience indicators

the urban population is increasing faster than the rural one (mostly because of rural-urban migration), this may indicate a trend decrease in well-being. However, the non-resilience incidence is higher in the rural areas, and has increased significantly, between 2005 and 2010, exclusively in the rural area by 10\%, while it decreased in the urban setting. These tabulations demonstrate that more severe poverty is found in the urban region, but that the well-being in the rural areas is also potentially fragile as households do not have sufficient resources to cushion against disaster shocks (such as cyclone Pam that hit many of the outer islands in March 2015).

Figure 2.C.1 and Figure 2.C.2 display maps of hardship incidences in the islands for different villages, we are able to construct these maps as households have been geo-located in the surveys. It is evident that households close to central areas have lower hardship incidences. We also observe that in the capital Funafuti, hardship incidence is much higher for those households living in the narrow parts of the island to the North and South and further away from the central area. Tuvalu's main atoll 
Funafuti is just $12.5 \mathrm{~km}$ long and no more than 800 meters wide. ${ }^{10}$

\subsection{Exposure to Natural Disasters}

Many households in low-lying islands are geographically exposed to climatic disasters, and in this section we quantify this exposure in Tuvalu. Figure 2.2 analyzes the vulnerability of households to disasters for all the islands. ${ }^{11}$ The islands were divided into three groups, i.e. the Northern Islands (Nanumea, Nanumaga and Niutao), the Central Islands (Nui, Nukufetau, Vaitupu and Funafuti), and the Southern Islands (Nukulaelae and Niulakita). In terms of vulnerability and exposure to climatic disasters, for each island we measured the proximity to hazard locations in reference to households living within 100 meters in land width (i.e., narrow parts of the island) ${ }^{12}$, households living within 100 meters of the east coast ${ }^{13}$, households living within 100 meters of the coastline, households living less than 5 meters of elevation, households living in non-concrete houses, and households who have less than 16,000 liters of water storage capacity. ${ }^{14}$

The Northern Islands have higher exposure indices (compared to the Central and Southern Islands). The Central Islands have the highest percentage of households residing in narrow parts of the islands which are prone to disasters. On the capital Funafuti, $13 \%$ of households reside in narrow parts of the island which are exposed to storms, while $9.3 \%$ of households live beside pits and ponds which are prone to flooding during king tides. ${ }^{15}$ While no surveyed households in the Northern and

\footnotetext{
${ }^{10}$ Author's calculations from digitized maps.

${ }^{11}$ Niulakita, the smallest island, was excluded from the household survey.

${ }^{12}$ These narrow parts of the island are illustrated in the maps in the appendix e.g. narrow parts of the island of Funafuti are the villages of Lofeagai, Teone and Tekavatoetoe.

${ }^{13}$ The distant to the east coast is important because of the easterly winds. The maps in the appendix shows that the households are mostly clustered to the western side of the islands.

${ }^{14}$ The assumed 16,000 liters water capacity storage threshold used is the median of household water storage for all households surveyed in the 2010 HIES. This is assumed to be sufficient if water is used efficiently.

${ }^{15}$ Borrow pits (we will refer to it as "pits" onward) were created by digging/borrowing of soil from parts of the island of Fongafale (Funafuti), by the American military during World War II, in order to construct the airplane runway. We used 20 meters to the pits as an indication of those living beside pits, based on the assumption that during King tides, a house within that range will most likely be flooded. This problem has been mostly solved in 2015 by the Tuvalu Borrow Pits
} 
CHAPTER 2. HOUSEHOLD VULNERABILITY ON THE FRONTLINE OF CLIMATE CHANGE: THE PACIFIC ATOLL NATION OF TUVALU

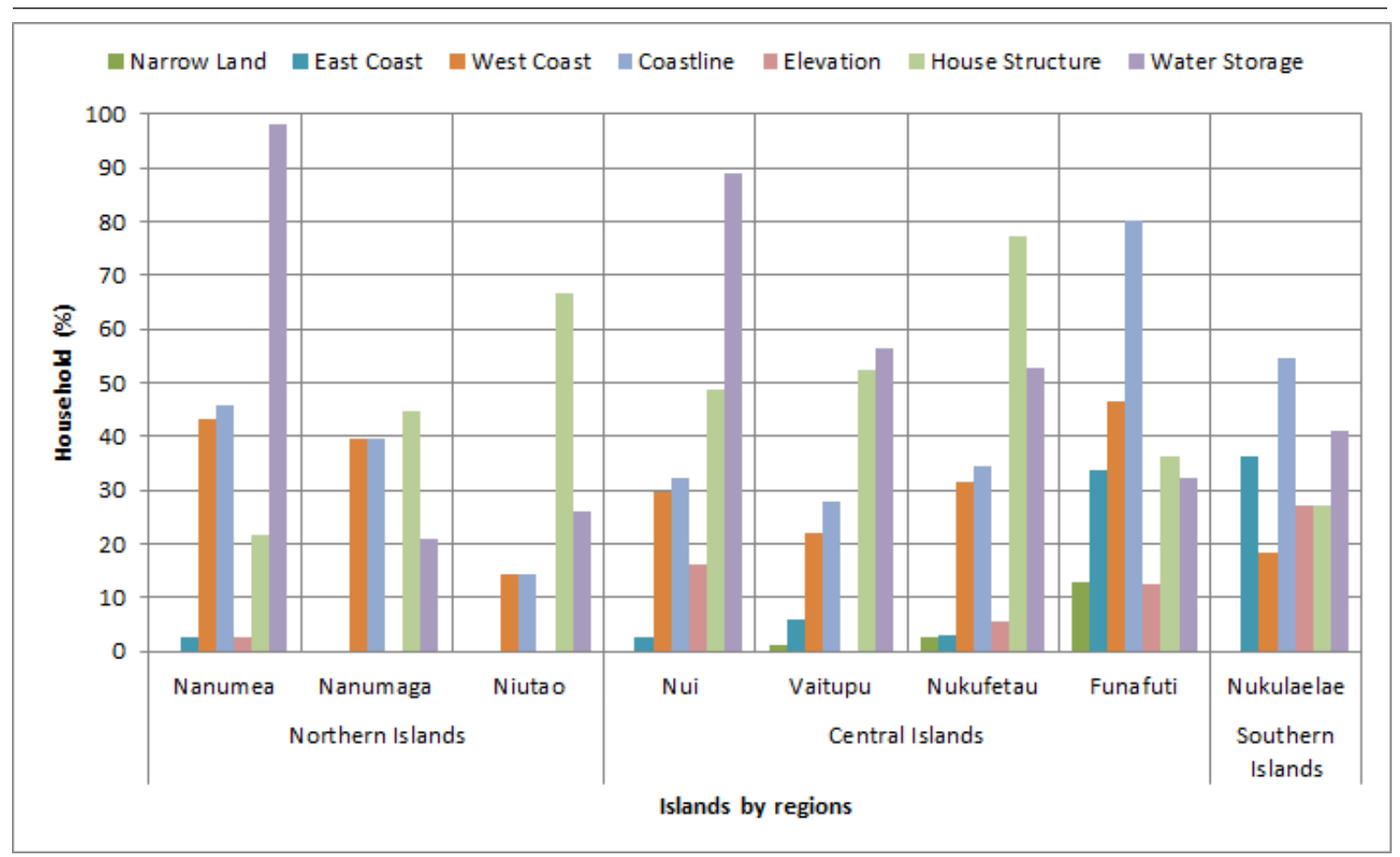

Source: Author's calculations, on data from the 2010 Household Income \& Expenditure Survey (HIES).

Figure 2.2: Household vulnerability and exposure indicators to disasters by island

Southern Islands reside fewer than 50 meters to the east coastline, it is not uncommon in the Central Islands, particularly Funafuti, with $17.2 \%$ of households living within 50 meters of the coast. Many of the households in Nukulaelae (27.3\% of households), Nui (16.2\% of households), and Funafuti (12.5\%) reside at low elevation compared to the other islands. ${ }^{16}$

Regarding house structures, $44.7 \%$ of households have concrete houses which are better able to withstand strong winds and storm surges. However, regarding

Remediation (BPR) project funded under the New Zealand Aid Programme, where ten borrow pits on Fongafale island were filled with sand except for Tafua pond to the north eastern side of the airstrip, which is a natural pond. It is yet to be seen if we will observe any future flooding in these filled up pits.

${ }^{16}$ This was obvious since Nui and Nukulaelae were flooded during the 2015 Cyclone Pam. However, the three islands that have higher elevation, Nanumaga, Niutao and Vaitupu, did not experience flooding during Cyclone Pam, but only storm surge and coastal intrusion of sea waves from the western side. All islands build their harbour and houses on the western side of the island away from easterly winds, but a cyclone that strikes from the west side will badly hit most islands without lagoons and islets on the west as shields. 
vulnerability to droughts, Nanumea and Nui have the lowest water storage capacity. ${ }^{17}$ Figure 2.3 displays exposure in terms of elevation and proximity to coastlines by income classification (hardship/non-hardship). In general, while we observe some differences across the two groups: the non-hardship group is somewhat more likely to live closer to the coast, but also in higher elevation. However, these differences are not consistent across islands and do not represent a statistically significant difference across these samples.

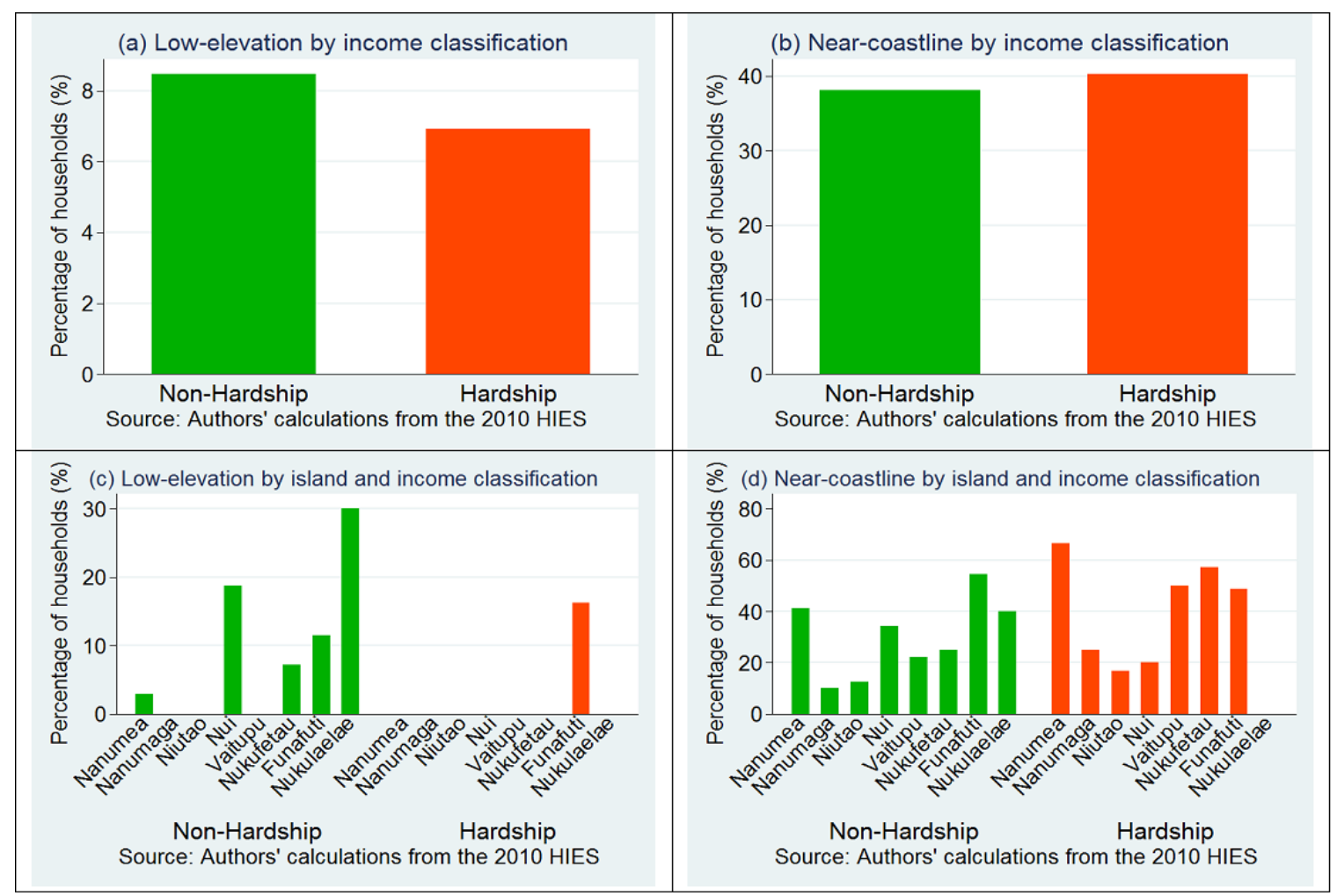

Source: Author's calculations from the 2010 Household Income \& Expenditure Survey (HIES).

Figure 2.3: Household exposure

\subsection{Estimation Methods}

We are using spatial econometric models to explain income with independent variables (i.e., household characteristics, distance and location characteristics of households,

\footnotetext{
${ }^{17}$ Nanumea has a few wells that enable access to brackish freshwater lens (Johnston et al., 2012).
} 
CHAPTER 2. HOUSEHOLD VULNERABILITY ON THE FRONTLINE OF CLIMATE CHANGE: THE PACIFIC ATOLL NATION OF TUVALU

and geographical variables). With income, we can examine and identify the economic status of a household and the degree of stability and resilience of households to shocks. The concept of resilience on the other hand is closely linked to income when we look at the ability of households to mitigate and protect themselves from negative impacts of disasters. Through this connection, we see income (the degree of economic stability and resilience to shocks) as a potential proxy for vulnerability.

Olivia et al. (2009) argued that ignoring spatial dependencies across households, when using household survey data to estimate poverty levels, may lead to misleading estimates. Gibson and McKenzie (2007) further argue for the importance of using precise geo-location systems (e.g., GPS) to determine locations and distances between households. Their work suggests that distance from households to numerous geographic features like roads, markets, schools, and health clinics might be important in understanding poverty. Olivia et al. (2011) also outlined the importance of identifying environmental factors that influence poverty. Theoretical links are discussed by the World Bank (2007) while Jalan and Ravallion (1998, 2002) provide empirical evidence linking the poor to geographical variables. Gibson and Rozelle (2003) used a probit estimation to show that poverty in Papua New Guinea (PNG) is primarily rural and is associated with communities with poor access to services, markets, and transportation.

Spatial regression methods permit us to account for spatial effects or spatial dependence between observations, where spatial data are geo-coded for location. Generally, spatial dependence refers to a situation where values observed at one household location, say household $i$, depend on the values of neighbouring households at nearby locations. Suppose we let households $i$ and $j$ represent neighbours, then the value taken by $y_{i}$ depends on that of $y_{j}$. The spatial matrix identifies neighbours or spatially close households and their effects, and the need to account for the spatial dependence in the regression model. ${ }^{18}$ Spatial models, similar to the one estimated here, have been used in other contexts in real estate economics, economic geography, and urban and regional science.

\footnotetext{
${ }^{18}$ ArcGIS was used for geo-coding of locations (households, schools, hospitals/clinics, etcetera.), creating a digitized map for all islands and islets in Tuvalu. These were then used in STATA for the empirical analysis.
} 
LeSage and Pace (2009) outline the two main motivations for estimation of spatial dependence. First, spillovers stemming from congestion effects may warrant estimation of spatial dependence models, as neighbours' outcomes directly impact one another. Second, spatial models may reduce estimation bias stemming from unobserved omitted variables which exhibit spatial dependence. ${ }^{19}$ Following this literature, ${ }^{20}$ we employed four spatial models (as described in the equations below) and also included the standard Ordinary Least Squares (OLS) model for comparison. ${ }^{21}$ The standard OLS model or the non-spatial linear regression model takes the form

$$
Y_{i}=\alpha_{i} \iota_{N}+X_{i} \beta_{i}+\varepsilon_{i}
$$

where $Y$ is the income that denotes an $N \times 1$ vector consisting of one observation on the dependent variable for the $N$ units (households) in the sample $(i=1, \ldots, N), \iota_{N}$ is an $N \times 1$ vector of ones associated with the constant term parameter to be estimated, $X$ denotes an $N \times K$ matrix of exogenous explanatory variables, $\beta$ is an associated $K \times 1$ vector with unknown parameters to be estimated, and $\varepsilon=\left(\varepsilon_{1}, \ldots, \varepsilon_{N}\right)^{T}$ is a vector of disturbance terms, where $\varepsilon_{i}$ is assumed to be independently and identically distributed for all with zero mean and variance $\sigma^{2}$.

We employ Maximum Likelihood estimation for the family of spatial regression models including Spatial Autoregressive Model (SAR), Spatial Error Model (SEM), Spatial Durbin Model (SDM) and Spatial Autocorrelation Model (SAC). The SAR, SEM, SDM and SAC models take the specifications described in (2.2), (2.3), (2.4) and (2.5), respectively, below.

\footnotetext{
${ }^{19}$ LeSage and Pace $(2009$, p.27) state that "omitted variables may easily arise in spatial modeling because unobservable factors such as location amenities, highway accessibility, or neighbourhood prestige may exert an influence on the dependent variable. It is unlikely that explanatory variables are readily available to capture these types of latent influences."

${ }^{20}$ See Anselin (1988), Elhorst (2014), Gibson and McKenzie (2007), Gibson and Rozelle (2003), Jalan and Ravallion (1998), Jalan and Ravallion (2002), LeSage and Pace (2009), and Olivia et al. (2011).

${ }^{21}$ Elhorst (2014) shows the relationship between the different spatial dependence models for cross-section data.
} 


$$
\begin{gathered}
Y_{i}=\alpha_{i} \iota_{N}+\rho W Y_{i}+X_{i} \beta_{i}+\varepsilon_{i} \\
Y_{i}=\alpha_{i} \iota_{N}+X_{i} \beta_{i}+u_{i}
\end{gathered}
$$

, where $u_{i}=\lambda W u+\varepsilon_{i}$.

$$
\begin{gathered}
Y_{i}=\alpha_{i} \iota_{N}+\rho W Y_{i}+X_{i} \beta_{i}+W X_{i} \gamma+\varepsilon_{i} \\
Y_{i}=\alpha_{i} \iota_{N}+\rho W_{1} Y_{i}+X_{i} \beta_{i}+u_{i}
\end{gathered}
$$

,where $u_{i}=\lambda_{i} W_{2} u_{i}+\varepsilon_{i}$.

$W Y$ denotes the endogenous interaction effects among the dependent variable, and $W u$ the interaction effects among the disturbance term of the different units. The parameter $\rho$ is the so-called spatial autoregressive coefficient, while $\lambda$ is the spatial autocorrelation coefficient. There is no spatial dependence in the vector of cross-sectional observations $Y$ if $\rho$ takes the value of zero, thus yielding to the OLS model. $W$ is a non-negative $N \times N$ matrix describing the spatial configuration or arrangement of the units in the sample. The spatial weight matrices will then be 'row-standardized' where the weights need to sum up to one on each row, or otherwise equal to zero if there are no neighbours. ${ }^{22}$ The spatial weight matrix is defined as $W$ with elements $w_{i j}$ indicating whether observations $i$ and $j$ are spatially close, that is, $w_{i j}=1 / d_{i j}$ for neighbours where $d_{i j}$ is the distance between households $i$ and $j$ (inverse distance weights) and otherwise $w_{i j}=0$. Beyond a certain distance, we assume that there are no spatial effects.

We also employed a binary outcome model (a probit) that is estimated with the dependent variable as the probability of a household experiencing poverty and an identical set of independent variables used in the non-spatial OLS regression.

\footnotetext{
${ }^{22}$ For our case, every household has at least one neighbour. Therefore, each row sums up to 1.
} 
Following Gibson and Rozelle (2003) and Jha et al. (2009), the dependent variable in this case is a dummy defined as:

$$
\operatorname{Pr}\left(\operatorname{Pov}_{i}=1 \mid x_{i}\right)=F(X \beta)
$$

where $X$ is the vector of explanatory variables, $\beta$ is the set of parameters reflecting the impact of changes in on the probability. The $F(X \beta)$ is the cumulative distribution function $(\mathrm{CDF})$ of the standard normal distribution. This approach estimates the households' probability of being poor, but includes no spatial component. We estimate the limited dependent variable model as a robustness check, since this is a common methodology in the literature.

\subsection{Data}

We utilize the Household Income and Expenditure Survey (HIES) data collected by the Central Statistics Division (CSD) of the Tuvalu Government for the years 2004/5 and 2010, which provides information on income and expenditures of households in Tuvalu. The 2010 HIES collected information from 541 households from all of the islands except for Niulakita ${ }^{23}$ while the 2005 HIES has a sample of 459 households. The households surveyed were randomly selected. The surveys represent around $33 \%$ of the population of Tuvalu; this large sample was necessary for accuracy as a representative sample at the national level. The sample selection was spread proportionally across all the islands with a selection process that listed each dwelling on the islands by their geographical position and systematically skipped through the list to achieve the $33 \%$ randomly selected sample.

For spatial analysis purposes, we used the 490 households with available Global Position System (GPS) locations for the 2010 HIES. ${ }^{24}$ The survey includes both individual and household variables. For our model, the dependent variable used both

\footnotetext{
${ }^{23}$ The smallest island in Tuvalu with only four households (based on the 2012 Census).

${ }^{24}$ For the sample sizes of the islands, the number of households (in brackets) per island are: Nanumea (37); Nanumaga (38); Niutao (42); Nui (37); Vaitupu (85); Nukufetau (35); Funafuti (193); and Nukulaelae (22).
} 
CHAPTER 2. HOUSEHOLD VULNERABILITY ON THE FRONTLINE OF CLIMATE CHANGE: THE PACIFIC ATOLL NATION OF TUVALU

income and expenditure as a measure of poverty and welfare. Additionally, we used a set of control variables of household characteristics and geographical measurements.

Income per capita was used as the measure of welfare for the non-spatial and spatial regressions while expenditure per capita was used to determine poverty lines where an acceptable minimum standard of that indicator was established (Ravallion, 1998; Pradhan and Ravallion, 2000; Ravallion, 1996a,b). We also used the binary indicator (poor and non-poor) as our dependent variable regressing on the same household characteristics used in the spatial and non-spatial regressions. Table 2.F.1 provides statistics about the dependent and independent variables and their sources.

\subsection{Estimation Results and Discussions}

Table 2.1 compares the means of selected variables and indicators for the years 2004/5 and 2010. Household size on average is higher in the urban areas. Education levels of heads of households increased between the two surveys with more educated household heads in the urban area; though the differences are not very large. Urban households have a higher number of dependents, depend more on cash income, live in areas of lower elevation, narrower land width, in higher density (i.e., more than three times compared to rural), and closer to coastlines. Although those in the urban area have less access to land, house ownership, fisheries and agricultural activities, they have better access to the economic opportunities present in the capital.

The diagnostic tests for spatial dependence of the spatial models were carried out using the Moran's I and Lagrange Multiplier tests (see Table 2.2). ${ }^{25}$ Moreover, the Moran's I test statistic indicates the strength of the spatial autocorrelation of the residuals while the simple Lagrange Multiplier (LM) tests for missing spatially

\footnotetext{
${ }^{25}$ The Moran's I test statistic is used to test if the data has spatial dependence. According to Olivia et al. (2009), the Moran's I for a row standardized spatial matrix where $e$ is a vector of OLS residuals and $W$ is the spatial weight matrix, asymptotically normally distributed with an expected value of $-1 /(N-1)$ and its statistical significance can be evaluated from a standardized normal table. It is expressed as $I=e^{\prime} W e / e^{\prime} e$. The Lagrange Multiplier (LM) tests for SEM and SAR whether $(\lambda=0)$ and $(\rho=0)$. The Robust LM tests were also developed by Anselin et al. (1996) to cater for the presence of both SEM and SAR (which is a weakness for the LM test as $L M_{\lambda}$ and $L M_{\rho}$ have power against the other alternative). Olivia et al. (2009) provides more detailed discussion of the tests.
} 
Table 2.1: Comparing means of selected indicators

\begin{tabular}{|c|c|c|c|c|c|c|}
\hline & & $2004 / 5$ & & & 2010 & \\
\hline & Rural & Urban & National & Rural & Urban & National \\
\hline Household size & 4.839 & 6.301 & 5.409 & 4.721 & 6.757 & 5.420 \\
\hline & $(2.4228)$ & $(3.2771)$ & $(2.8739)$ & $(2.5089)$ & $(3.6047)$ & $(3.0839)$ \\
\hline Dependents & & & & 1.993 & 2.408 & 2.136 \\
\hline & & & & $(1.4869)$ & $(2.0828)$ & $(1.724)$ \\
\hline Age & 52.157 & 46.245 & 49.851 & 51.724 & 47.461 & 50.260 \\
\hline & $(13.9806)$ & $(12.8297)$ & $(13.8336)$ & $(12.3203)$ & $(12.1625)$ & $(12.4203)$ \\
\hline Gender & 0.782 & 0.754 & 0.771 & 0.817 & 0.763 & 0.798 \\
\hline & $(0.4135)$ & $(0.4317)$ & $(0.4204)$ & $(0.3869)$ & $(0.4263)$ & $(0.4013)$ \\
\hline Marital status & 0.782 & 0.849 & 0.808 & 0.817 & 0.810 & 0.815 \\
\hline & $(0.4135)$ & $(0.3588)$ & $(0.3940)$ & $(0.3869)$ & $(0.3929)$ & $(0.3886)$ \\
\hline Ethnic & 0.950 & 0.960 & 0.954 & 0.965 & 0.934 & 0.955 \\
\hline & $(0.2183)$ & $(0.1943)$ & $(0.2091)$ & $(0.1816)$ & $(0.2474)$ & $(0.2068)$ \\
\hline Literate & & & & 0.702 & 0.928 & 0.780 \\
\hline & & & & $(0.4577)$ & $(0.2575)$ & $(0.4143)$ \\
\hline Education years & 7.689 & 9.564 & 8.420 & 7.851 & 10.526 & 8.770 \\
\hline & $(3.2736)$ & $(5.4007)$ & $(4.3246)$ & $(3.3533)$ & $(4.184)$ & $(3.8708)$ \\
\hline Work & & & & 0.275 & 0.609 & 0.390 \\
\hline & & & & $(0.4474)$ & $(0.4893)$ & $(0.4883)$ \\
\hline House owner & & & & 0.839 & 0.526 & 0.731 \\
\hline & & & & $(0.3680)$ & $(0.5007)$ & $(0.4435)$ \\
\hline Urban & 0.000 & 1.000 & 0.389 & 0.000 & 1.000 & 0.390 \\
\hline & $(0.0000)$ & $(0.0000)$ & $(0.4882)$ & $(0.0000)$ & $(0.0000)$ & $(0.4883)$ \\
\hline Distant to the central & & & & 256.016 & 1.157 & 168.437 \\
\hline & & & & $(136.8334)$ & $(1.4703)$ & $(164.1853)$ \\
\hline Distant to primary & & & & 0.399 & 0.959 & 0.592 \\
\hline & & & & $(0.4161)$ & $(1.3881)$ & $(0.9185)$ \\
\hline Distant to the hospital & & & & 0.450 & 1.261 & 0.728 \\
\hline & & & & $(0.4580)$ & $(1.3193)$ & $(0.9389)$ \\
\hline Distant to the government & & & & 256.1234 & 1.348 & 168.609 \\
\hline & & & & $(136.8127)$ & $(1.5264)$ & $(164.1447)$ \\
\hline Land width & & & & 2.1465 & 0.347 & 1.528 \\
\hline & & & & $(2.2384)$ & $(0.2125)$ & $(2.0080)$ \\
\hline Distant to the coast & & & & 0.201 & 0.096 & 0.165 \\
\hline & & & & $(0.1570)$ & $(0.0688)$ & $(0.1423)$ \\
\hline Distant to the borrow pits & & & & 68.811 & 0.382 & 45.305 \\
\hline & & & & $(58.3149)$ & $(0.4024)$ & $(57.3436)$ \\
\hline Elevation & & & & 10.659 & 6.634 & 9.277 \\
\hline & & & & $(2.7163)$ & $(1.5654)$ & $(3.0559)$ \\
\hline Rainfall & & & & 2382.575 & 2765.869 & 2514.235 \\
\hline & & & & $(525.7113)$ & $(83.8429)$ & $(465.6705)$ \\
\hline Density & & & & 858.487 & 3349.086 & 1713.998 \\
\hline & & & & $(1080.9210)$ & $(594.2642)$ & $(1512.8620)$ \\
\hline Observations & 280 & 179 & 459 & 321 & 169 & 490 \\
\hline
\end{tabular}

Source: Author's estimations from 2004/5 and 2010 HIES data. Standard deviations in parentheses. 
CHAPTER 2. HOUSEHOLD VULNERABILITY ON THE FRONTLINE OF CLIMATE CHANGE: THE PACIFIC ATOLL NATION OF TUVALU

lagged dependent variable and the Robust LM tests for error dependence in the possible presence of a missing lagged dependent variable. The diagnostic tests provide most support to the SDM specification; as they indicate the presence of spatial dependence for all levels. $\rho$ is the spatial autoregressive coefficient while $\lambda$ is the spatial autocorrelation coefficient. The values of $R^{2}$ indicate the goodness of fit of the model.

Table 2.2 shows the model estimation results explaining income with the independent (RHS) variables (i.e., household characteristics, distance and location characteristics of households, and geographic variables). ${ }^{26}$ For comparison of models and approaches, we show results from the standard linear model (column 1), the four spatial models previously described (columns 2-5) and divide the sample into the urban and rural observations (columns 6-7) with the preferred SDM estimation method (equation 4).

The age of the household head $(a g e)^{27}$, marital status of the household head (maritalstat), education level of the household head (educ), household head working in the formal sector (formalwork), living in the urban (urban), and the distant to the coast (dcoast) were all highly significant with positive correlations with income. Household size (hholdsize), house owner (houseowner) and elevation (elevation) are also highly significant, but with negative correlations with income. ${ }^{28}$ Referring to the magnitudes of the coefficients, the impact of an increase in household size by one person would decrease income per person by 11 percent; a one-year increase in education for the household head would increase income per capita by 2 percent; and a 100 meters increase in the distance of the house from the coast would increase income per capita by 4 percent. The $R^{2}$ for all models are $0.3-0.4$, at most explaining $40 \%$ of the variation in income across households.

We caution that these estimates are not causal. It is possible that the correlations we identify in our estimated regressions, described below, do not provide enough

\footnotetext{
${ }^{26}$ We classified Funafuti as the urban and outer-islands as rural since Funafuti is the capital and where the central government, commerce, main hospital, seaport and airport are located.

${ }^{27}$ Since we have a positive effect of age and a negative effect of age squared, it means that as the household head gets older the effect of age is lessened.

${ }^{28}$ The elevation projected from the Digital Elevation Model (DEM) may differ marginally with land elevation. Variations between elevation and Mean Sea Level (MSL) is explained in http: //www.esri.com/news/arcuser/0703/geoid1of3.html
} 


\subsection{ESTIMATION RESULTS AND DISCUSSIONS}

Table 2.2: Estimation results - LHS income per person (2010)

\begin{tabular}{|c|c|c|c|c|c|c|c|}
\hline & OLS & SLM & SEM & $\overline{\mathrm{SAC}}$ & $\begin{array}{c}\text { SDM } \\
\text { (National) }\end{array}$ & $\begin{array}{c}\text { SDM } \\
\text { (Urban) }\end{array}$ & $\begin{array}{c}\text { SDM } \\
\text { (Rural) }\end{array}$ \\
\hline \multirow[t]{2}{*}{ householdsize } & $-0.114^{* * *}$ & $-0.114^{* * *}$ & $-0.114^{* * *}$ & $-0.114^{* * *}$ & $-0.112^{* * *}$ & $-0.0941^{* * *}$ & $-0.126^{* * *}$ \\
\hline & $(0.00975)$ & $(0.00967)$ & $(0.00967)$ & $(0.00967)$ & $(0.00963)$ & $(0.0130)$ & $(0.0143)$ \\
\hline \multirow[t]{2}{*}{ age } & $0.0361 * *$ & $0.0356^{* *}$ & $0.0355^{* *}$ & $0.0352^{* *}$ & $0.0365^{* *}$ & $0.0574^{* *}$ & $0.0829 * * *$ \\
\hline & $(0.0149)$ & $(0.0147)$ & $(0.0147)$ & $(0.0147)$ & $(0.0144)$ & $(0.0248)$ & $(0.0214)$ \\
\hline \multirow[t]{2}{*}{ gender } & 0.00676 & 0.00590 & 0.00570 & 0.00180 & 0.0286 & -0.0968 & -0.207 \\
\hline & $(0.0828)$ & $(0.0818)$ & $(0.0818)$ & $(0.0821)$ & $(0.0868)$ & $(0.140)$ & $(0.144)$ \\
\hline \multirow[t]{2}{*}{ maritalstatus } & 0.131 & 0.130 & 0.130 & 0.134 & 0.106 & $0.293^{* *}$ & -0.00664 \\
\hline & $(0.0888)$ & $(0.0877)$ & $(0.0877)$ & $(0.0879)$ & $(0.0919)$ & $(0.133)$ & $(0.153)$ \\
\hline \multirow[t]{2}{*}{ educ } & $0.0296^{* * *}$ & $0.0300^{* * *}$ & $0.0300^{* * *}$ & $0.0298^{* * *}$ & $0.0340^{* * *}$ & $0.0700^{* * *}$ & 0.0223 \\
\hline & $(0.00833)$ & $(0.00825)$ & $(0.00825)$ & $(0.00826)$ & $(0.00888)$ & $(0.0148)$ & $(0.0136)$ \\
\hline \multirow[t]{2}{*}{ formalwork } & $0.252^{* * *}$ & $0.255^{* * *}$ & $0.255^{* * *}$ & $0.255^{* * *}$ & $0.239^{* * *}$ & 0.154 & $0.310^{* * *}$ \\
\hline & $(0.0665)$ & $(0.0659)$ & $(0.0659)$ & $(0.0658)$ & $(0.0666)$ & $(0.100)$ & $(0.0964)$ \\
\hline \multirow[t]{2}{*}{ houseowner } & $-0.127^{*}$ & $-0.132^{*}$ & $-0.133^{*}$ & $-0.128^{*}$ & -0.104 & -0.116 & $-0.580^{* * *}$ \\
\hline & $(0.0679)$ & $(0.0679)$ & $(0.0678)$ & $(0.0681)$ & $(0.0685)$ & $(0.106)$ & $(0.117)$ \\
\hline \multirow[t]{2}{*}{ urban } & $0.546^{* * *}$ & $0.562^{* * *}$ & $0.562^{* * *}$ & $0.538^{* * *}$ & $0.549^{* * *}$ & & \\
\hline & $(0.0809)$ & $(0.0854)$ & $(0.0848)$ & $(0.0933)$ & $(0.102)$ & & \\
\hline \multirow[t]{2}{*}{ elevation } & $-0.0457^{* * *}$ & $-0.0460 * * *$ & $-0.0459^{* * *}$ & $-0.0440^{* * *}$ & $-0.0280^{*}$ & 0.00418 & -0.0284 \\
\hline & $(0.0113)$ & $(0.0112)$ & $(0.0111)$ & $(0.0115)$ & $(0.0146)$ & $(0.0449)$ & $(0.0175)$ \\
\hline \multirow[t]{2}{*}{ coast_distkm } & $0.415^{*}$ & $0.430^{* *}$ & $0.431^{* *}$ & $0.444^{* *}$ & 0.310 & -1.202 & 0.374 \\
\hline & $(0.214)$ & $(0.213)$ & $(0.213)$ & $(0.214)$ & $(0.238)$ & $(0.958)$ & $(0.238)$ \\
\hline \multirow[t]{2}{*}{ agesqr } & $-0.000280^{*}$ & $-0.000274^{*}$ & $-0.000274^{*}$ & $-0.000270^{*}$ & $-0.000277^{* *}$ & $-0.000434^{*}$ & $-0.000683^{* * *}$ \\
\hline & $(0.000143)$ & $(0.000142)$ & $(0.000142)$ & $(0.000141)$ & $(0.000139)$ & $(0.000249)$ & $(0.000196)$ \\
\hline \multirow[t]{2}{*}{ w1x_householdsize } & & & & & -0.00263 & 0.0101 & $-0.584^{*}$ \\
\hline & & & & & $(0.00281)$ & $(0.00717)$ & $(0.306)$ \\
\hline \multirow[t]{2}{*}{ w1x_age } & & & & & -0.00233 & $0.0153^{*}$ & $1.323^{* *}$ \\
\hline & & & & & $(0.00222)$ & $(0.00785)$ & $(0.589)$ \\
\hline \multirow[t]{2}{*}{ w1x_gender } & & & & & 0.0365 & $-0.222^{* *}$ & -3.472 \\
\hline & & & & & $(0.0384)$ & $(0.103)$ & $(3.647)$ \\
\hline \multirow[t]{2}{*}{$\mathrm{w} 1 \mathrm{x} \_$maritalstatus } & & & & & 0.0102 & -0.0283 & -1.406 \\
\hline & & & & & $(0.0404)$ & $(0.0638)$ & $(3.576)$ \\
\hline \multirow[t]{2}{*}{ w1x_educ } & & & & & 0.00524 & $0.0233^{* * *}$ & -0.270 \\
\hline & & & & & $(0.00346)$ & $(0.00802)$ & $(0.330)$ \\
\hline \multirow[t]{2}{*}{ w1x_formalwork } & & & & & -0.0248 & $-0.133^{* * *}$ & $3.296^{*}$ \\
\hline & & & & & $(0.0216)$ & $(0.0398)$ & $(1.884)$ \\
\hline \multirow[t]{2}{*}{ w1x_houseowner } & & & & & 0.0178 & 0.00116 & $-9.712^{* * *}$ \\
\hline & & & & & $(0.0159)$ & $(0.0364)$ & $(2.677)$ \\
\hline w1x_urban & & & & & 0.0176 & & \\
\hline & & & & & $(0.0149)$ & & \\
\hline w1x_elevation & & & & & -0.0000384 & 0.00100 & $0.145^{* * *}$ \\
\hline & & & & & $(0.000964)$ & $(0.0108)$ & $(0.0561)$ \\
\hline w1x_coast_distkm & & & & & -0.0152 & $-0.831^{* *}$ & -0.111 \\
\hline & & & & & $(0.0319)$ & $(0.353)$ & $(1.868)$ \\
\hline w1x_agesqr & & & & & $0.0000349^{*}$ & $-0.000157^{*}$ & $-0.00926^{*}$ \\
\hline & & & & & $(0.0000201)$ & $(0.0000890)$ & $(0.00503)$ \\
\hline _cons & $8.453^{* * *}$ & $8.486^{* * *}$ & $8.488^{* * *}$ & $8.511^{* * *}$ & $8.268^{* * *}$ & $6.858^{* * *}$ & -6.893 \\
\hline & $(0.408)$ & $(0.408)$ & $(0.408)$ & $(0.409)$ & $(0.436)$ & $(0.796)$ & $(14.58)$ \\
\hline Rho _cons & & -0.0000480 & & 0.000786 & -0.00588 & $-0.0320^{* *}$ & $-1.446^{* * *}$ \\
\hline & & $(0.0000921)$ & & $(0.000941)$ & $(0.00568)$ & $(0.0151)$ & $(0.460)$ \\
\hline Sigma_cons & & $0.604^{* * *}$ & $0.604^{* * *}$ & $0.604^{* * *}$ & $0.590^{* * *}$ & $0.519^{* * *}$ & $0.581^{* * *}$ \\
\hline & & $(0.0193)$ & $(0.0193)$ & $(0.0193)$ & $(0.0189)$ & $(0.0292)$ & $(0.0233)$ \\
\hline Lambda_cons & & & $\begin{array}{c}-0.0000574 \\
(0.000103)\end{array}$ & $\begin{array}{l}-0.00106 \\
(0.00136)\end{array}$ & & & \\
\hline$N$ & 490 & 490 & 490 & 490 & 490 & 169 & 321 \\
\hline$R^{2}$ & 0.398 & 0.398 & 0.396 & 0.306 & 0.420 & 0.424 & 0.352 \\
\hline Moran's I & & $0.116^{* *}$ & $0.0125^{* *}$ & $0.2975^{* * *}$ & $-0.0281^{* * *}$ & $-0.0279^{* *}$ & $-0.0275^{* *}$ \\
\hline
\end{tabular}

Standard errors in parentheses. ${ }^{*} p<0.10,{ }^{* *} p<0.05,{ }^{* * *} p<0.01$. Rho $\rho$ is the spatial autoregressive coefficient while Lambda $\lambda$ is the spatial autocorrelation coefficient.

Source: Author's estimations from 2010 HIES data 
CHAPTER 2. HOUSEHOLD VULNERABILITY ON THE FRONTLINE OF CLIMATE CHANGE: THE PACIFIC ATOLL NATION OF TUVALU

information about causality. For example, it might that poorer households end up locating in specific locations because of their ability to pay for housing, and not that these locations are the cause of their poverty. In Tuvalu, however, where much of the land is customarily owned, there are few market transactions in land ownership, and rental markets are also not very dynamic, this reverse causality is likely to be less of a concern. Nevertheless, in as much as endogeneity might be biasing our results, we are still faced with the limitations of the data available to us.

Our diagnostic tests support the use of the SDM model. ${ }^{29}$ In terms of the geographic variables that will most likely be important when considering future changes in climatic conditions, we find that, ceteris paribus, poorer households are locate in higher elevation areas in the outer islands, but in lower elevation in the main island of Funafuti (where we already observed the poor are on the narrower parts of the island). For the urban area, our econometric specification does not yield statistically significant results with respect to the geographic variables when the urban sample is exclusively estimated. However, the number of observations used in the regression is reduced dramatically, so this reflects, at least in part, the expected drop in statistical power. The coefficients for the spatial variables in columns (5-7) indicate the impact of neighbouring household characteristics on the estimated household observation. As such, for example, we note that nearby households with a head of household that is older will be correlated with increased income in the estimated household. Note that in this case, we are not suggesting this is a causal relationship, but just that the distribution of income is non-random, and has a spatial component.

As household expenditure is sometime used as a measure of well-being (or lack thereof), rather than income, we estimate the determinants of per capita expenditure using similar specifications to the one described for income (see Table 2.3). In the Tuvalu case, the difference between household income and household expenditure is not very large, so that the results obtained for income are largely preserved when we examine expenditure. Even the spatial relationships appear to be similar for the two quantities.

We next examine household characteristics that make households more likely

\footnotetext{
${ }^{29}$ Moran's I test is highly significant at $1 \%$ level, indicating spatial autocorrelation.
} 


\subsection{ESTIMATION RESULTS AND DISCUSSIONS}

Table 2.3: Estimation results - LHS expenditure per person (2010)

\begin{tabular}{|c|c|c|c|c|c|c|c|}
\hline & $\overline{\text { OLS }}$ & SLM & SEM & $\overline{\mathrm{SAC}}$ & $\begin{array}{c}\text { SDM } \\
\text { (National) }\end{array}$ & $\begin{array}{c}\text { SDM } \\
\text { (Urban) }\end{array}$ & $\begin{array}{c}\text { SDM } \\
\text { (Rural) }\end{array}$ \\
\hline householdsize & $\begin{array}{c}-0.0958^{* * * *} \\
(0.00964)\end{array}$ & $\begin{array}{c}-0.0952^{* * *} \\
(0.00956)\end{array}$ & $\begin{array}{c}-0.0952^{* * *} \\
(0.00956)\end{array}$ & $\begin{array}{c}-0.0952^{* * *} \\
(0.00956)\end{array}$ & $\begin{array}{c}-0.0937^{* * *} \\
(0.00955)\end{array}$ & $\begin{array}{c}-0.0847^{* * *} * \\
(0.0130)\end{array}$ & $\begin{array}{c}-0.103^{* * *} \\
(0.0138)\end{array}$ \\
\hline age & $\begin{array}{c}0.0339^{* *} \\
(0.0147)\end{array}$ & $\begin{array}{c}0.0332^{* *} \\
(0.0145)\end{array}$ & $\begin{array}{c}0.0332^{* *} \\
(0.0145)\end{array}$ & $\begin{array}{c}0.0331^{* *} \\
(0.0145)\end{array}$ & $\begin{array}{c}0.0356^{* *} \\
(0.0143)\end{array}$ & $\begin{array}{l}0.0474^{*} \\
(0.0248)\end{array}$ & $\begin{array}{c}0.0740^{* * *} \\
(0.0209)\end{array}$ \\
\hline gender & $\begin{array}{l}-0.0519 \\
(0.0819)\end{array}$ & $\begin{array}{l}-0.0531 \\
(0.0809)\end{array}$ & $\begin{array}{l}-0.0533 \\
(0.0809)\end{array}$ & $\begin{array}{l}-0.0579 \\
(0.0812)\end{array}$ & $\begin{array}{l}-0.0277 \\
(0.0860)\end{array}$ & $\begin{array}{l}-0.125 \\
(0.140)\end{array}$ & $\begin{array}{c}-0.278^{* *} \\
(0.140)\end{array}$ \\
\hline maritalstatus & $\begin{array}{c}0.164^{*} \\
(0.0878)\end{array}$ & $\begin{array}{c}0.162^{*} \\
(0.0867)\end{array}$ & $\begin{array}{c}0.162^{*} \\
(0.0867)\end{array}$ & $\begin{array}{c}0.166^{*} \\
(0.0869)\end{array}$ & $\begin{array}{c}0.138 \\
(0.0911)\end{array}$ & $\begin{array}{c}0.310^{* *} \\
(0.133)\end{array}$ & $\begin{array}{l}0.0738 \\
(0.149)\end{array}$ \\
\hline educ & $\begin{array}{c}0.0279^{* * *} \\
(0.00823)\end{array}$ & $\begin{array}{c}0.0284^{* * *} \\
(0.00816)\end{array}$ & $\begin{array}{c}0.0284^{* * *} \\
(0.00816)\end{array}$ & $\begin{array}{c}0.0282^{* * *} \\
(0.00816)\end{array}$ & $\begin{array}{c}0.0331^{* * *} \\
(0.00880)\end{array}$ & $\begin{array}{c}0.0643^{* * * *} \\
(0.0148)\end{array}$ & $\begin{array}{c}0.0185 \\
(0.0133)\end{array}$ \\
\hline formalwork & $\begin{array}{l}0.259^{* * *} \\
(0.0657)\end{array}$ & $\begin{array}{l}0.263^{* * *} \\
(0.0651)\end{array}$ & $\begin{array}{l}0.263^{* * *} \\
(0.0651)\end{array}$ & $\begin{array}{l}0.262^{* * *} \\
(0.0651)\end{array}$ & $\begin{array}{l}0.243^{* * *} \\
(0.0660)\end{array}$ & $\begin{array}{c}0.166 \\
(0.101)\end{array}$ & $\begin{array}{l}0.322^{* * * *} \\
(0.0942)\end{array}$ \\
\hline houseowner & $\begin{array}{l}-0.124^{*} \\
(0.0671)\end{array}$ & $\begin{array}{l}-0.131^{*} \\
(0.0671)\end{array}$ & $\begin{array}{l}-0.131^{*} \\
(0.0670)\end{array}$ & $\begin{array}{l}-0.126^{*} \\
(0.0674)\end{array}$ & $\begin{array}{c}-0.110 \\
(0.0679)\end{array}$ & $\begin{array}{l}-0.117 \\
(0.106)\end{array}$ & $\begin{array}{c}-0.507^{* * *} \\
(0.114)\end{array}$ \\
\hline urban & $\begin{array}{l}0.361^{* * * *} \\
(0.0800)\end{array}$ & $\begin{array}{l}0.382^{* * * *} \\
(0.0844)\end{array}$ & $\begin{array}{l}0.382^{* * *} \\
(0.0838)\end{array}$ & $\begin{array}{c}0.355^{* * *} \\
(0.0935)\end{array}$ & $\begin{array}{c}0.375^{* * *} \\
(0.101)\end{array}$ & & \\
\hline elevation & $\begin{array}{c}-0.0472^{* * * *} \\
(0.0112)\end{array}$ & $\begin{array}{c}-0.0475^{* * *} \\
(0.0110)\end{array}$ & $\begin{array}{c}-0.0474^{* * *} \\
(0.0110)\end{array}$ & $\begin{array}{c}-0.0454^{* * * *} \\
(0.0113)\end{array}$ & $\begin{array}{l}-0.0273^{*} \\
(0.0145)\end{array}$ & $\begin{array}{c}0.000308 \\
(0.0450)\end{array}$ & $\begin{array}{l}-0.0308^{*} \\
(0.0171)\end{array}$ \\
\hline coast_distkm & $\begin{array}{c}0.441^{* *} \\
(0.211)\end{array}$ & $\begin{array}{c}0.461^{* *} \\
(0.210)\end{array}$ & $\begin{array}{c}0.462^{* *} \\
(0.210)\end{array}$ & $\begin{array}{c}0.475^{* *} \\
(0.211)\end{array}$ & $\begin{array}{c}0.355 \\
(0.236)\end{array}$ & $\begin{array}{l}-0.868 \\
(0.960)\end{array}$ & $\begin{array}{l}0.405^{*} \\
(0.233)\end{array}$ \\
\hline agesqr & $\begin{array}{c}-0.000279^{* *} \\
(0.000141)\end{array}$ & $\begin{array}{c}-0.000271^{*} \\
(0.000140)\end{array}$ & $\begin{array}{l}-0.000270^{*} \\
(0.000140)\end{array}$ & $\begin{array}{l}-0.000269^{*} \\
(0.000140)\end{array}$ & $\begin{array}{c}-0.000288^{* *} \\
(0.000138)\end{array}$ & $\begin{array}{c}-0.000336 \\
(0.000248)\end{array}$ & $\begin{array}{c}-0.000638^{* * *} \\
(0.000191)\end{array}$ \\
\hline w1x_householdsize & & & & & $\begin{array}{l}-0.00155 \\
(0.00272)\end{array}$ & $\begin{array}{c}0.0105 \\
(0.00717)\end{array}$ & $\begin{array}{l}-0.497^{*} \\
(0.283)\end{array}$ \\
\hline w1x_age & & & & & $\begin{array}{c}-0.0000177 \\
(0.00237)\end{array}$ & $\begin{array}{c}0.0143^{*} \\
(0.00738)\end{array}$ & $\begin{array}{l}1.149^{* *} \\
(0.575)\end{array}$ \\
\hline w1x_gender & & & & & $\begin{array}{c}0.0335 \\
(0.0381)\end{array}$ & $\begin{array}{c}-0.207^{* *} \\
(0.103)\end{array}$ & $\begin{array}{l}-4.542 \\
(3.565)\end{array}$ \\
\hline w1x_maritalstatus & & & & & $\begin{array}{l}0.00125 \\
(0.0401)\end{array}$ & $\begin{array}{l}-0.0416 \\
(0.0639)\end{array}$ & $\begin{array}{r}-0.0217 \\
(3.483)\end{array}$ \\
\hline w1x_educ & & & & & $\begin{array}{l}0.00567^{*} \\
(0.00344)\end{array}$ & $\begin{array}{c}0.0223^{* * *} \\
(0.00803)\end{array}$ & $\begin{array}{l}-0.357 \\
(0.322)\end{array}$ \\
\hline w1x_formalwork & & & & & $\begin{array}{l}-0.0244 \\
(0.0214)\end{array}$ & $\begin{array}{c}-0.137^{* * *} \\
(0.0398)\end{array}$ & $\begin{array}{l}3.923^{* *} \\
(1.859)\end{array}$ \\
\hline w1x_houseowner & & & & & $\begin{array}{c}0.0162 \\
(0.0158)\end{array}$ & $\begin{array}{l}0.00350 \\
(0.0363)\end{array}$ & $\begin{array}{c}-8.608^{* * *} \\
(2.610)\end{array}$ \\
\hline w1x_urban & & & & & $\begin{array}{l}0.00748 \\
(0.0135)\end{array}$ & & \\
\hline w1x_elevation & & & & & $\begin{array}{c}-0.00123 \\
(0.000948)\end{array}$ & $\begin{array}{c}0.000731 \\
(0.0108)\end{array}$ & $\begin{array}{r}-0.00152 \\
(0.0592)\end{array}$ \\
\hline w1x_coast_distkm & & & & & $\begin{array}{l}-0.0147 \\
(0.0316)\end{array}$ & $\begin{array}{c}-0.759^{* *} \\
(0.354)\end{array}$ & $\begin{array}{l}-0.861 \\
(1.829)\end{array}$ \\
\hline w1x_agesqr & & & & & $\begin{array}{c}0.00000941 \\
(0.0000213)\end{array}$ & $\begin{array}{l}-0.000148^{*} \\
(0.0000846)\end{array}$ & $\begin{array}{r}-0.00846^{*} \\
(0.00489)\end{array}$ \\
\hline _cons & $\begin{array}{c}7.519^{* * *} \\
(0.403)\end{array}$ & $\begin{array}{c}7.562^{* * *} \\
(0.403)\end{array}$ & $\begin{array}{c}7.564^{* * *} \\
(0.403)\end{array}$ & $\begin{array}{c}7.586^{* * *} \\
(0.405)\end{array}$ & $\begin{array}{c}7.280^{* * *} \\
(0.432)\end{array}$ & $\begin{array}{c}6.064^{* * *} \\
(0.796)\end{array}$ & $\begin{array}{c}1.023 \\
(14.34)\end{array}$ \\
\hline Rho_cons & & $\begin{array}{l}-0.0000719 \\
(0.000103)\end{array}$ & & $\begin{array}{l}0.000937 \\
(0.00101)\end{array}$ & $\begin{array}{c}-0.0106 \\
(0.00672)\end{array}$ & $\begin{array}{c}-0.0329^{* *} \\
(0.0152)\end{array}$ & $\begin{array}{c}-1.800^{* * *} \\
(0.545)\end{array}$ \\
\hline Sigma_cons & & $\begin{array}{l}0.597^{* * *} \\
(0.0191)\end{array}$ & $\begin{array}{l}0.597^{* * *} \\
(0.0191)\end{array}$ & $\begin{array}{l}0.597^{* * *} \\
(0.0191)\end{array}$ & $\begin{array}{l}0.585^{* * *} \\
(0.0187)\end{array}$ & $\begin{array}{l}0.520^{* * * *} \\
(0.0293)\end{array}$ & $\begin{array}{l}0.567^{* * *} * \\
(0.0231)\end{array}$ \\
\hline Lambda_cons & & & $\begin{array}{l}-0.0000835 \\
(0.000115)\end{array}$ & $\begin{array}{l}-0.00130 \\
(0.00153)\end{array}$ & & & \\
\hline$N$ & 490 & 490 & 490 & 490 & 490 & 169 & 321 \\
\hline$R^{2}$ & 0.333 & 0.334 & 0.329 & 0.227 & 0.350 & 0.389 & 0.293 \\
\hline Moran's I & & 0.0008 & 0.0023 & $0.3325^{* * *}$ & $-0.0308 * *$ & $-0.0282^{* *}$ & $-0.0290 * *$ \\
\hline
\end{tabular}

Standard errors in parentheses. ${ }^{*} p<0.10,{ }^{* *} p<0.05,{ }^{* * *} p<0.01$. Rho $\rho$ is the spatial autoregressive coefficient while Lambda $\lambda$ is the spatial autocorrelation coefficient.

Source: Author's estimations from 2010 HIES data. 
CHAPTER 2. HOUSEHOLD VULNERABILITY ON THE FRONTLINE OF CLIMATE CHANGE: THE PACIFIC ATOLL NATION OF TUVALU

or less likely to be in poverty. We used a binary probit model with a poverty indicator, for all spatial aggregations levels (national, rural and urban), by regressing a binary dependent variable (poverty indicator, i.e. 1 if poor, else 0) with the same control variables we used for the linear income models. These specifications are estimated as some of the extant literature on poverty conducts these 'determinants of poverty' investigations, and we should like our findings to be comparable. The estimation results in Table 2.4 column 1, show that households with higher household size (hholdsize), that reside on a higher elevation (elevation), and own a house (houseowner) are more likely to be poor. Nevertheless, households with higher household head's level of education $(e d u c)$ and with formal work (formalwork) are less likely to be poor.

We also replicate the same regressions, after splitting the sample into urban and rural households (columns 2-3), to compare the differences in vulnerability and exposure. It generally shows very similar results with the national level, but with a few exceptions. The minor differences are mostly in statistical significance rather than qualitatively different. To further enable comparison, not only with previous research on the determinants of poverty, but also with our previous spatial results, we estimate the probit model with spatial effects (columns 4-7), with the last column estimating the model including the spatial relationships with neighbouring households. We observe that the spatial probit model appear to estimate the coefficients somewhat differently than in the non-spatial model. In this case, some of the coefficients appear to have counter-intuitive signs (education has a positive association with the poverty indicator, for example). Urban location is associated more with poverty, and we also observe a positive coefficient for the distance variable. ${ }^{30}$

Lastly, we used a panel of 130 households that we were able to identify in both the 2004/5 and 2010 HIES to estimate income and poverty (total of 260 observations). We estimated this model using both fixed- and random-effects models and present these results in the appendix Table 2.G.1. ${ }^{31}$ The results show that higher values

\footnotetext{
${ }^{30}$ Note that the asymptotic theory of spatial models for limited dependent variables has only been developing recently, so we are uncertain about the robustness of these results (e.g., Qu and Lee (2012)).

${ }^{31}$ The Hausman panel test indicated a strong preference for the fixed-effects (FE) model over random-effects (RE); while the Breusch-Pagan indicated the panel models are preferable to the OLS estimation. The FE model for $N$ observations $(i=1, \ldots, N)$ and $T$ time periods $(t=1, \ldots, T)$
} 


\subsection{ESTIMATION RESULTS AND DISCUSSIONS}

Table 2.4: Estimation results - LHS poverty binary indicator (2010)

\begin{tabular}{|c|c|c|c|c|c|c|c|}
\hline & \multicolumn{3}{|c|}{ Probit } & \multicolumn{4}{|c|}{ Spatial Probit } \\
\hline & $\begin{array}{c}\text { National } \\
\text { (1) }\end{array}$ & $\begin{array}{c}\text { Urban } \\
(2)\end{array}$ & $\begin{array}{c}\text { Rural } \\
(3)\end{array}$ & $\begin{array}{l}\text { SLM } \\
(4)\end{array}$ & $\begin{array}{l}\text { SEM } \\
(5)\end{array}$ & $\begin{array}{c}\text { SAC } \\
(6)\end{array}$ & $\begin{array}{c}\text { SDM } \\
(7)\end{array}$ \\
\hline \multirow[t]{2}{*}{ householdsize } & $0.176^{* * *}$ & $0.197^{* * *}$ & $0.158^{* * *}$ & 0.00175 & 0.000929 & 0.00223 & 0.00483 \\
\hline & $(0.0264)$ & $(0.0379)$ & $(0.0387)$ & $(0.00147)$ & $(0.000732)$ & $(0.00154)$ & $(0.00334)$ \\
\hline \multirow[t]{2}{*}{ age } & $-0.0753^{* *}$ & $-0.0788^{*}$ & -0.0654 & $-0.0231^{* * *}$ & $-0.0115^{* * *}$ & $-0.0239 * * *$ & $-0.0264^{* * *}$ \\
\hline & $(0.0372)$ & $(0.0467)$ & $(0.0668)$ & $(0.00168)$ & $(0.000767)$ & $(0.00226)$ & $(0.00521)$ \\
\hline \multirow[t]{2}{*}{ gender } & 0.0320 & -0.0526 & 0.0927 & -0.0188 & -0.00924 & -0.0182 & -0.0471 \\
\hline & $(0.222)$ & $(0.328)$ & $(0.343)$ & $(0.0125)$ & $(0.00621)$ & $(0.0128)$ & $(0.0289)$ \\
\hline \multirow[t]{2}{*}{ maritalstatus } & -0.0922 & 0.115 & -0.375 & 0.00713 & 0.000671 & 0.0100 & 0.0194 \\
\hline & $(0.234)$ & $(0.348)$ & $(0.354)$ & $(0.0143)$ & $(0.00706)$ & $(0.0160)$ & $(0.0316)$ \\
\hline \multirow[t]{2}{*}{ educ } & $-0.0565^{* *}$ & -0.0303 & $-0.0821^{* *}$ & -0.000698 & -0.000553 & 0.000141 & $-0.0108 * * *$ \\
\hline & $(0.0225)$ & $(0.0313)$ & $(0.0342)$ & $(0.00132)$ & $(0.000641)$ & $(0.00146)$ & $(0.00331)$ \\
\hline \multirow[t]{2}{*}{ formalwork } & $-0.623^{* * *}$ & $-1.067^{* * *}$ & -0.231 & -0.0159 & -0.00682 & -0.0162 & -0.0171 \\
\hline & $(0.191)$ & $(0.307)$ & $(0.283)$ & $(0.0130)$ & $(0.00649)$ & $(0.0136)$ & $(0.0297)$ \\
\hline \multirow[t]{2}{*}{ houseowner } & $0.489^{* *}$ & 0.432 & $0.473^{*}$ & 0.00792 & 0.00110 & 0.0136 & -0.0232 \\
\hline & $(0.197)$ & $(0.307)$ & $(0.268)$ & $(0.0134)$ & $(0.00649)$ & $(0.0153)$ & $(0.0280)$ \\
\hline \multirow[t]{2}{*}{ urban } & 0.291 & & & 0.0128 & 0.00556 & 0.0202 & 0.0468 \\
\hline & $(0.218)$ & & & $(0.0147)$ & $(0.00720)$ & $(0.0158)$ & $(0.0400)$ \\
\hline \multirow[t]{2}{*}{ elevation } & $0.0578^{* *}$ & $0.0988^{* * *}$ & -0.00909 & 0.00211 & 0.000715 & 0.00285 & -0.00223 \\
\hline & $(0.0292)$ & $(0.0383)$ & $(0.0810)$ & $(0.00173)$ & $(0.000836)$ & $(0.00205)$ & $(0.00468)$ \\
\hline \multirow[t]{2}{*}{ coast_distkm } & -0.108 & -0.0508 & 0.882 & -0.0309 & -0.0132 & -0.0310 & 0.110 \\
\hline & $(0.564)$ & $(0.605)$ & $(2.131)$ & $(0.0355)$ & $(0.0177)$ & $(0.0368)$ & $(0.0878)$ \\
\hline \multirow[t]{2}{*}{ agesqr } & $0.000711^{* *}$ & $0.000778^{*}$ & 0.000588 & $0.000218^{* * *}$ & $0.000108^{* * *}$ & $0.000228 * * *$ & $0.000252^{* * *}$ \\
\hline & $(0.000351)$ & $(0.000436)$ & $(0.000643)$ & $(0.0000183)$ & $(0.00000836)$ & $(0.0000245)$ & $(0.0000505)$ \\
\hline w1x_householdsize & & & & & & & $\begin{array}{l}0.000614 \\
(0.00106)\end{array}$ \\
\hline \multirow[t]{2}{*}{ w1x_age } & & & & & & & $0.00316^{* * *}$ \\
\hline & & & & & & & $(0.000640)$ \\
\hline \multirow[t]{2}{*}{ w1x_gender } & & & & & & & $-0.0388 * * *$ \\
\hline & & & & & & & $(0.0143)$ \\
\hline \multirow[t]{2}{*}{ w1x_maritalstatus } & & & & & & & $0.0290^{* *}$ \\
\hline & & & & & & & $(0.0137)$ \\
\hline \multirow[t]{2}{*}{ w1x_educ } & & & & & & & $-0.00870^{* * *}$ \\
\hline & & & & & & & $(0.00115)$ \\
\hline w1x_formalwork & & & & & & & $0.0337^{* * *}$ \\
\hline & & & & & & & $(0.00721)$ \\
\hline w1x_houseowner & & & & & & & $-0.0252^{* * *}$ \\
\hline & & & & & & & $(0.00590)$ \\
\hline w1x_urban & & & & & & & 0.00568 \\
\hline & & & & & & & $(0.00498)$ \\
\hline w1x_elevation & & & & & & & -0.0000156 \\
\hline & & & & & & & $(0.000327)$ \\
\hline w1x_coast_distkm & & & & & & & $0.0344^{* * *}$ \\
\hline & & & & & & & $(0.0117)$ \\
\hline w1x_agesqr & & & & & & & $-0.0000294^{* * *}$ \\
\hline & & & & & & & $(0.00000736)$ \\
\hline _cons & -0.341 & -1.113 & 0.533 & 1.549 & 1.288 & 1.537 & $1.704^{* * *}$ \\
\hline & $(1.031)$ & $(1.365)$ & $(1.821)$ & . & . & . & $(0.147)$ \\
\hline Rho_cons & & & & 0.00000355 & & 0.00188 & $-0.0141^{* *}$ \\
\hline & & & & $(0.000650)$ & & $(0.00139)$ & $(0.00589)$ \\
\hline Sigma_cons & & & & $0.0398^{* * *}$ & $0.0198^{* * *}$ & $0.0408^{* * *}$ & 0.0810 \\
\hline & & & & $(0.00406)$ & $(0.00184)$ & $(0.00545)$ & . \\
\hline Lambda_cons & & & & & -0.000130 & -0.000620 & \\
\hline & & & & & $(0.000149)$ & $(0.000504)$ & \\
\hline$N$ & 490 & 321 & 169 & 490 & 490 & 490 & 490 \\
\hline Moran's I & & & & $0.0121^{* *}$ & $0.0121^{* *}$ & $0.0293^{* * *}$ & $0.0518^{* * *}$ \\
\hline
\end{tabular}


CHAPTER 2. HOUSEHOLD VULNERABILITY ON THE FRONTLINE OF CLIMATE CHANGE: THE PACIFIC ATOLL NATION OF TUVALU

of education $(e d u c)$, higher distant to the coast (dcoast), migrating between islands (b_islands), household movements within islands (w_islands) and migrating to the urban (urban_mig), are associated with higher values of income. On the other hand, household size (hhsize) is associated with lower values of income. ${ }^{32}$ Similar results were obtained from the panel data models estimating the binary poverty indicator (available upon request).

Previous research has already examined the pull of emigration in the atoll islands. Connell (2003) and Barnett (2005) find that climatic change is not the sole driver of ongoing population displacement in the Pacific. Based on interviews of a sample of the population on Funafuti in 2007, Mortreux and Barnett (2009) show that most respondents do not consider climate change as a main motive for emigration. However, emigration intentions may change following trigger events like an extreme drought or a destructive cyclone (see Noy, 2016b). Smith and McNamara (2015), while analysing the various factors that may determine emigration decisions, also suggest that migration from Tuvalu may become more common in several worst-case climate scenarios.

A total of $26 \%$ of households migrated between islands where $85 \%$ are non-poor households. ${ }^{33}$ Non-poor households dominate movements between islands except for movements of households from the capital island Funafuti to the outer-islands where the poor represent $67 \%$. Table 2.5 shows that most of the movements within islands happen with the capital Funafuti as either source or destination. It is evident that poor and low-income households move less, both between and within islands. The domination in movements by non-poor households is due to higher access to human and financial capital that is required for these moves.

There are more movements from the outer-islands to the capital Funafuti and

is $y_{i t}=\alpha_{i}+X_{i t} \beta+u_{i t}$ where $y_{i t}$ is the dependent variable observed for individual $i$ at time $t, \alpha_{i}$ is the unobserved time-invariant individual effect, $X_{i t}$ is the time-invariant $1 \times k$ regressor matrix, and $u_{i t}$ is the error term. However, we present all three specifications in the appendix Table 2.G.1 for comparison.

${ }^{32}$ Note that there are no time invariant variables on the right-hand side, e.g., variables such as "sex" and "ethnic" of the household head are not time invariant variables as they change overtime in our data depending on who is the household head at a specified time. The identity of the household head present varies over time.

${ }^{33}$ Author's calculations from data. These reflect the overall number of households that migrated between the islands and those who are non-poor. 
Table 2.5: Internal migration of households

\begin{tabular}{|c|c|c|c|c|}
\hline Movement type & $\begin{array}{l}\begin{array}{l}\text { Households that } \\
\text { moved }\end{array} \\
\text { (\% of } \\
\text { households in } \\
\text { source region) }\end{array}$ & $\begin{array}{l}\text { Non-poor } \\
\text { households that } \\
\text { moved } \\
(\% \text { of houses } \\
\text { that moved } \\
\text { from the source } \\
\text { region) }\end{array}$ & $\begin{array}{l}\text { Households } \\
\text { that moved } \\
\text { to wider land } \\
\text { width areas } \\
(\% \text { of houses } \\
\text { that moved } \\
\text { from the source } \\
\text { region) }\end{array}$ & $\begin{array}{l}\text { Households that } \\
\text { moved closer to } \\
\text { the coast } \\
(\% \text { of houses } \\
\text { that moved } \\
\text { from the source } \\
\text { region) }\end{array}$ \\
\hline $\begin{array}{l}\text { Outer-islands to } \\
\text { capital }\end{array}$ & 20 & 94 & 18 & 82 \\
\hline $\begin{array}{l}\text { Capital to } \\
\text { outer-islands }\end{array}$ & 12 & 33 & 100 & 0 \\
\hline $\begin{array}{l}\text { Between } \\
\text { outer-islands }\end{array}$ & 13 & 100 & 36 & 55 \\
\hline $\begin{array}{l}\text { Within the } \\
\text { capital }\end{array}$ & 20 & 90 & 80 & 60 \\
\hline $\begin{array}{l}\text { Within } \\
\text { outer-islands }\end{array}$ & 2 & 100 & 100 & 100 \\
\hline
\end{tabular}

Source: Author's calculations from the 2004/5 and 2010 HIES data.

within the capital itself. Unlike the capital Funafuti, the fewer movements in the outer islands are due to the limited availability of rental houses. Some of the reasons for frequent movements of households on Funafuti are civil service employees moving between government houses or rented houses, civil servants on long-term training overseas availing their or rented houses to government or others, civil servants elevating in their work positions moving to higher-level government or rental housing. Government houses on Funafuti are closer to the centre of the island - the wider part of the island in terms of land width. Household movements to the outer-islands is mainly due to retiring civil servants, those who cannot find work in the capital, and professionals (teachers, nurses, police) who have to relocate for work from one island to another. ${ }^{34}$ It is evident that not only are the poor or low-income households more vulnerable and exposed to climatic disasters, they have less capacity for movements within and between islands. For statistics on movement between the islands, obtained from the surveys we used, see Table 2.5.

\footnotetext{
${ }^{34}$ All outer-islands have primary schools, clinics and police stations. The main boarding secondary school is located in the outer-island on Vaitupu.
} 


\section{CHAPTER 2. HOUSEHOLD VULNERABILITY ON THE FRONTLINE OF CLIMATE CHANGE: THE PACIFIC ATOLL NATION OF TUVALU}

\subsection{Conclusion}

Hardship is a challenge that merits the attention of policy makers in the Pacific. Our findings indicate that poverty has increased in Tuvalu over the past decade, but other potential measures of hardship and vulnerability show a decrease over time. We do conclude that hardship levels are higher in the urban area (see Figure 2.1) compared to the rural outer islands. The proportion of households who are potentially vulnerable to falling into hardship if there is a shock is also higher in the urban area and is increasing.

Households on the urban region of Funafuti are also more exposed and vulnerable to disasters than most of the outer islands, because of their proximity and direction of exposure to the coast, and low elevation (see Figure 2.3). We also find that not only are the poor more likely to reside in areas prone to disasters in both the rural islands and the capital, they also tend to migrate internally and externally less compared to non-poor households. This observation may end up being important in the future if migration becomes the only viable adaptation option to sea level rise - as many observers foresee. ${ }^{35}$ As migration becomes more necessary, a further related concern is that those who will be most exposed and therefore the most desperate to migrate will have the least ability to do so. This may lead to 'trapped populations' that also lack the 'voice' to express their plight and mobilise assistance. ${ }^{36}$

More generally, the analysis that we provided here for Tuvalu could be applied to other Pacific atoll nations (and atoll islands elsewhere). If the patterns of poverty and hardship elsewhere are closely associated with climate vulnerability as they are in Tuvalu, this is noteworthy on its own. The atoll islands are essentially the canary-in-the-coal-mine for our understanding of the impact of climate change on vulnerable populations. The observations we presented should then further inform discussions about the future of the atoll islands in the face of accelerating climatic changes and discussions about their future through, for example, the Warsaw International Mechanism for Loss and Damage (see Mechler and Schinko (2016)).

\footnotetext{
${ }^{35}$ However, we note that migration is also widely viewed as an adaptation strategy that need not be a last resort.

${ }^{36}$ See Noy (2017); and Black and Collyer (2014), for relevant discussions about 'voice' and the risk of being 'trapped', respectively.
} 
2.8. CONCLUSION 


\section{Appendix}




\section{A Map of Tuvalu}

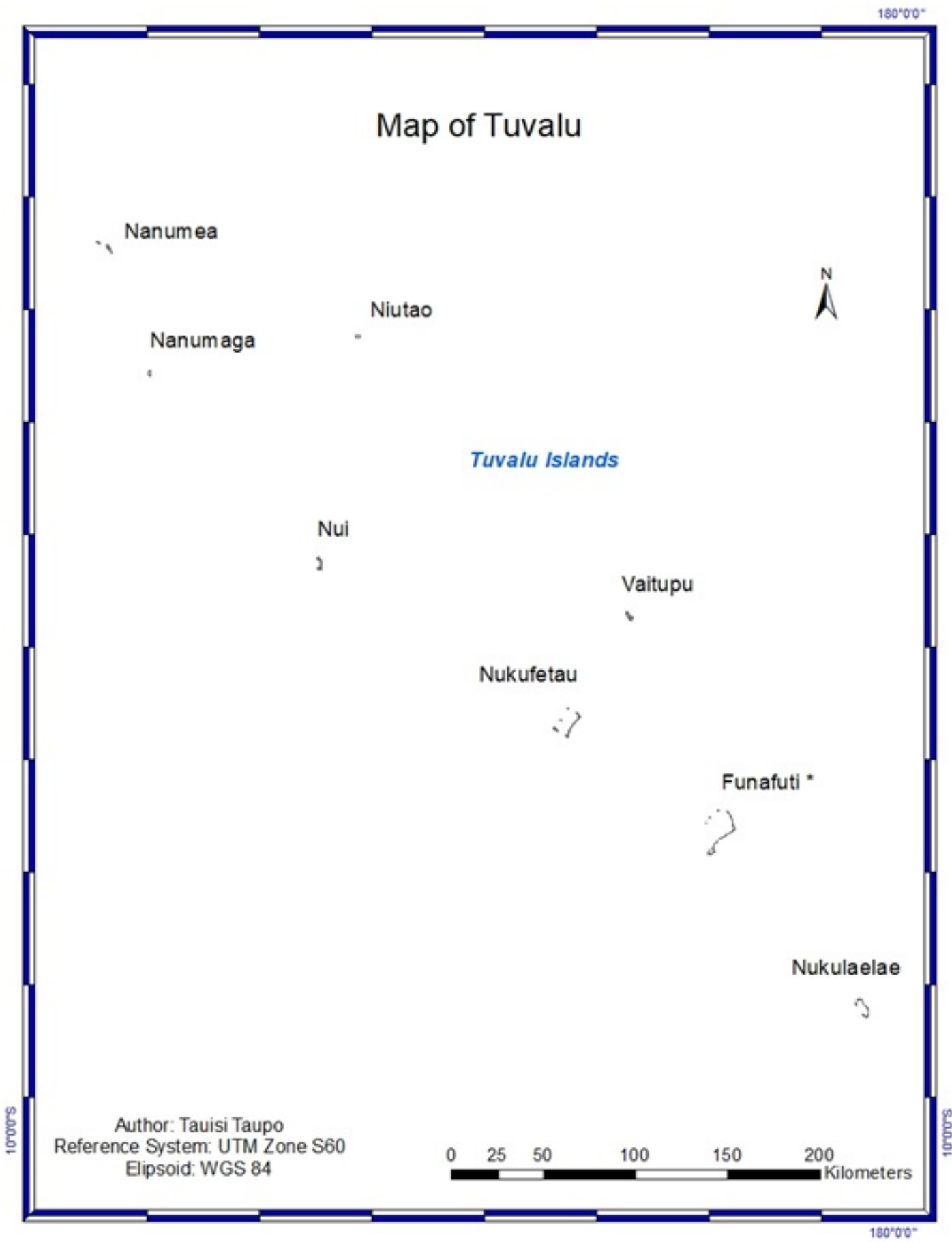

Source: Author's digitized map.

Figure 2.A.1: Map of the Islands of Tuvalu 


\section{CHAPTER 2. HOUSEHOLD VULNERABILITY ON THE FRONTLINE OF CLIMATE CHANGE: THE PACIFIC ATOLL NATION OF TUVALU}

\section{B Sea Levels on Funafuti}

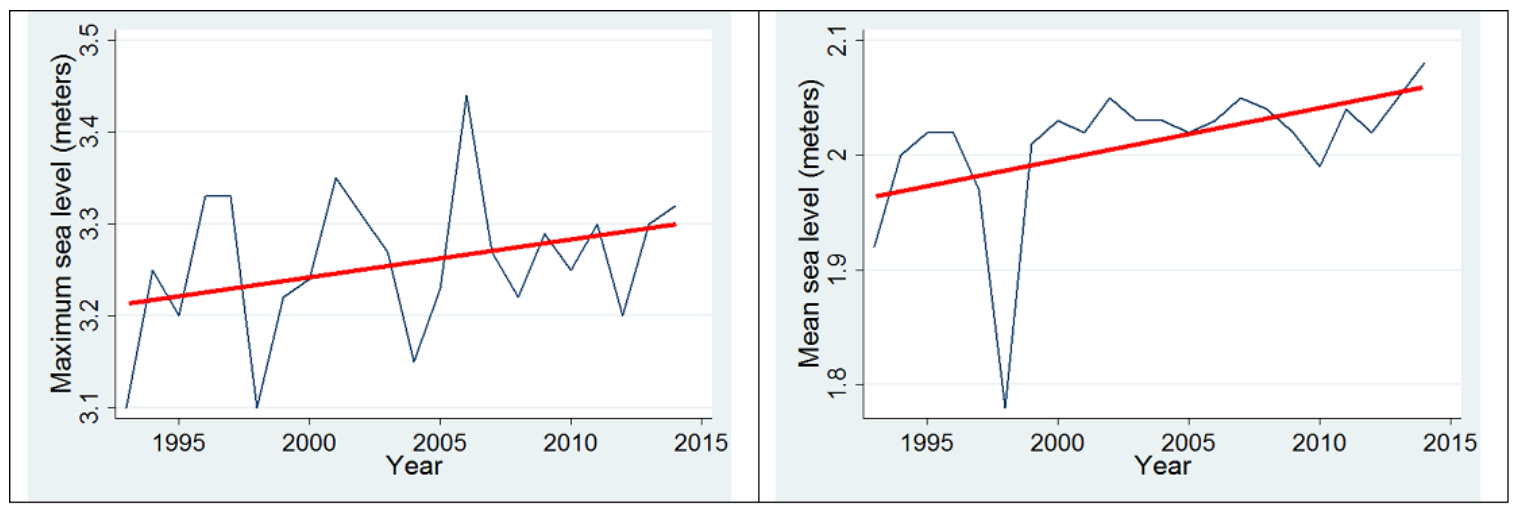

Notes: On the left shows the maximum sea levels on Funafuti (Tuvalu) from 1993 to 2014. Author's calculations, on data from the Tuvalu Meteorological Service (TMS). The floods cause sea water to come from the ground in the inner parts of Funafuti Island. From 1993 to 2002, the average number of times the sea level rose above 3 meters is 8 per year, and 10 for 2003 to 2012. Hence, using this small sample, it appears to be increasing over time. On the right shows the mean sea level on Funafuti (Tuvalu) from 1993 to 2014. Although it covers a short period of 22 years, they do show that both trends for maximum and mean sea levels are increasing over that period. This does show that sea level is rising as predicted by Science. Based on the sea level rise and elevation of no more than 3 meters above sea level, Tuvalu is generally vulnerable during high tides, but more vulnerable if strong winds and high tides are combined.

Figure 2.B.1: Maximum and mean sea levels on Funafuti from 1993 to 2014 


\section{C Hardship Maps}

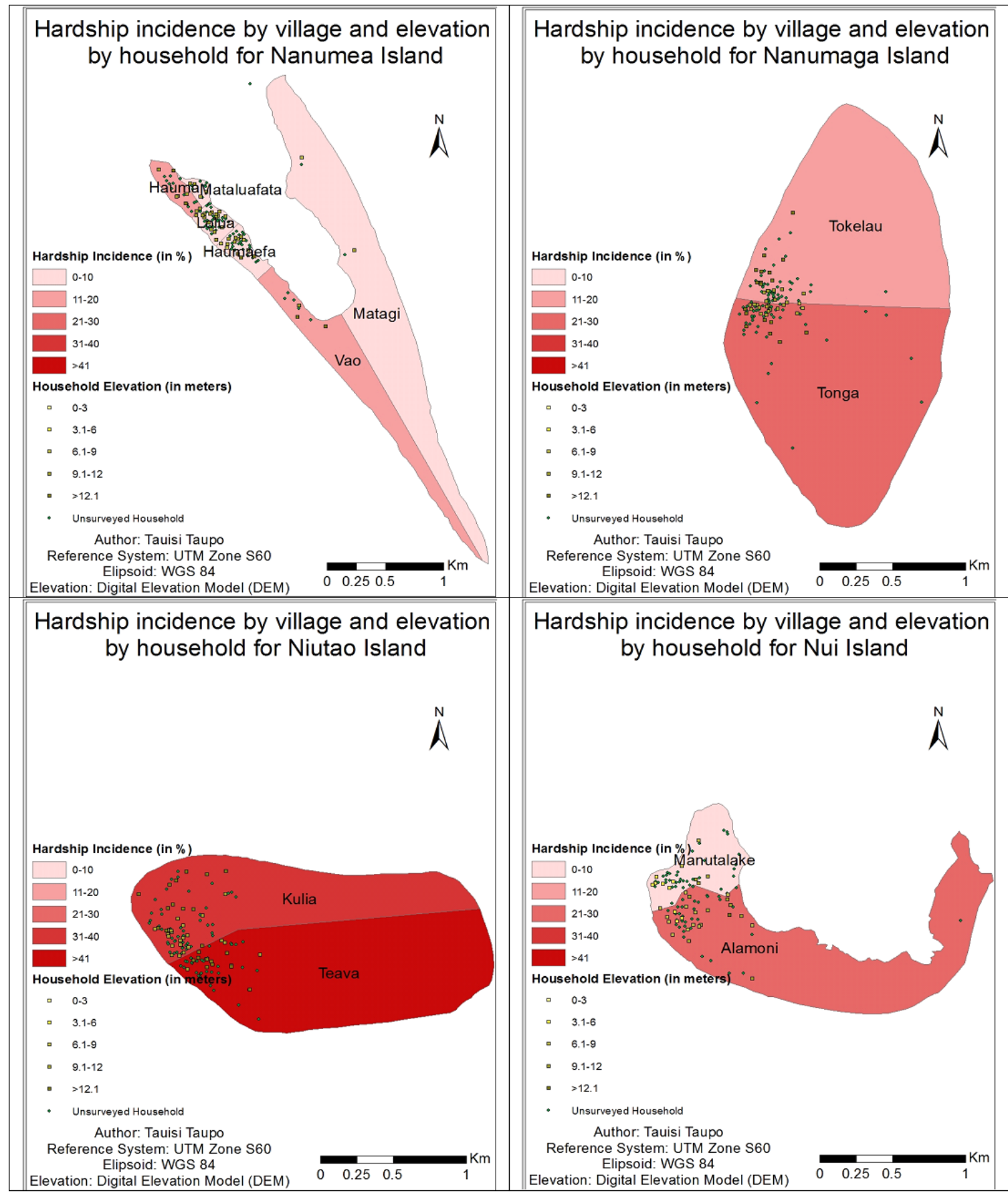

Source: Author's digitized maps.

Figure 2.C.1: Hardship incidence in the Northern Islands 
CHAPTER 2. HOUSEHOLD VULNERABILITY ON THE FRONTLINE OF CLIMATE CHANGE: THE PACIFIC ATOLL NATION OF TUVALU

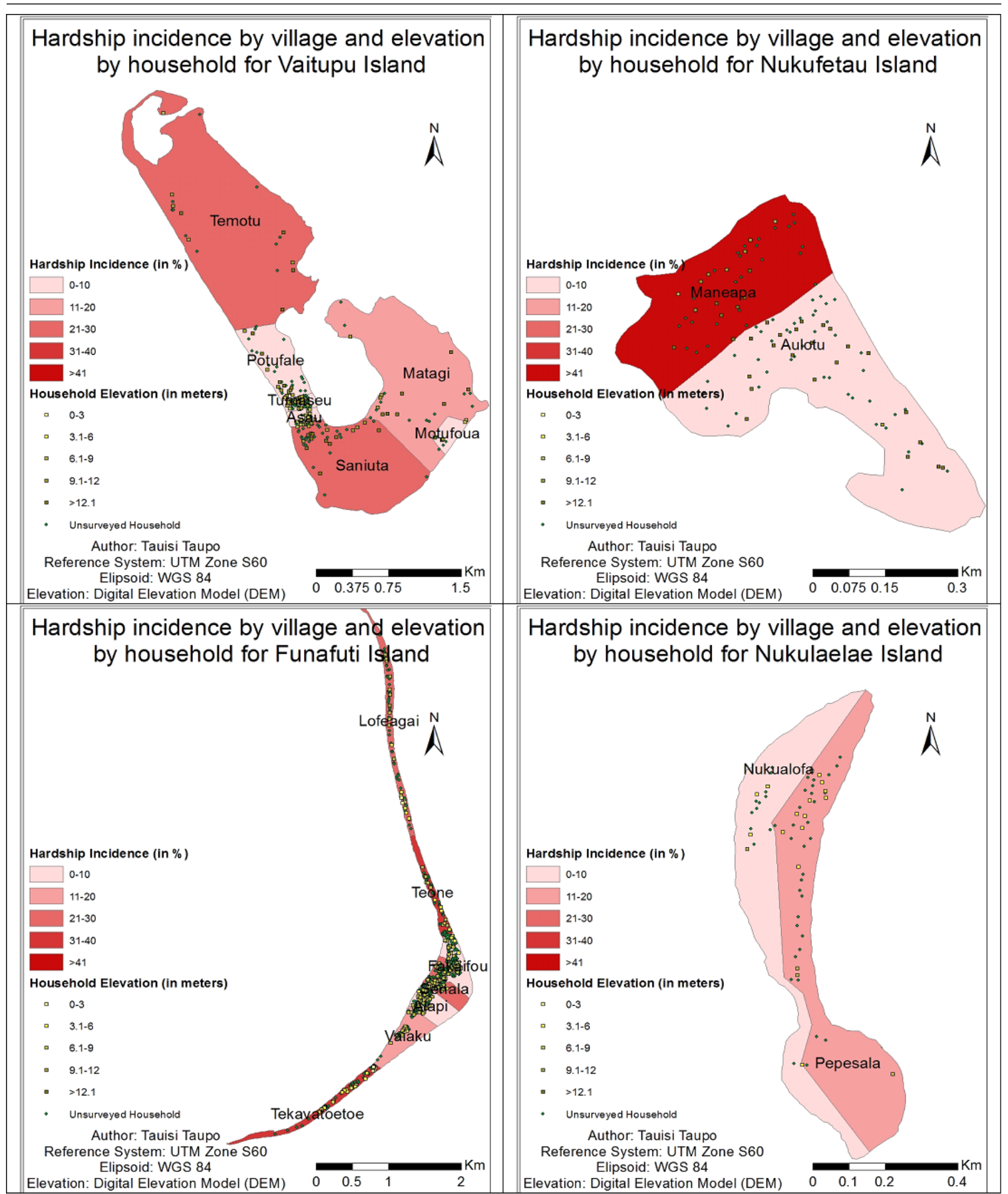

Source: Author's digitized maps.

Figure 2.C.2: Hardship incidence in the Southern Islands 


\section{D Elevation Maps}

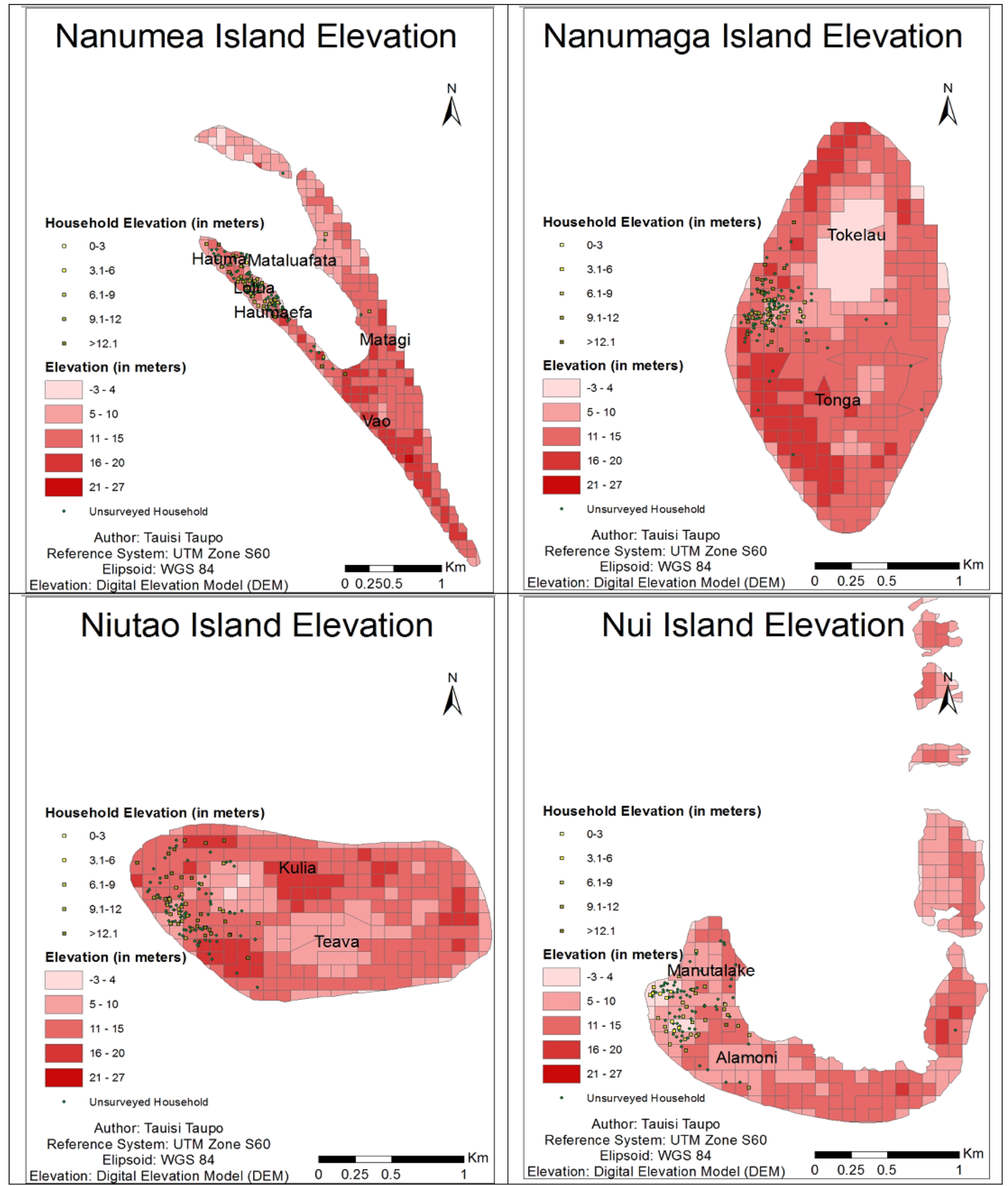

Source: Author's digitized maps.

Figure 2.D.1: Elevation in the Northern Islands 
CHAPTER 2. HOUSEHOLD VULNERABILITY ON THE FRONTLINE OF CLIMATE CHANGE: THE PACIFIC ATOLL NATION OF TUVALU

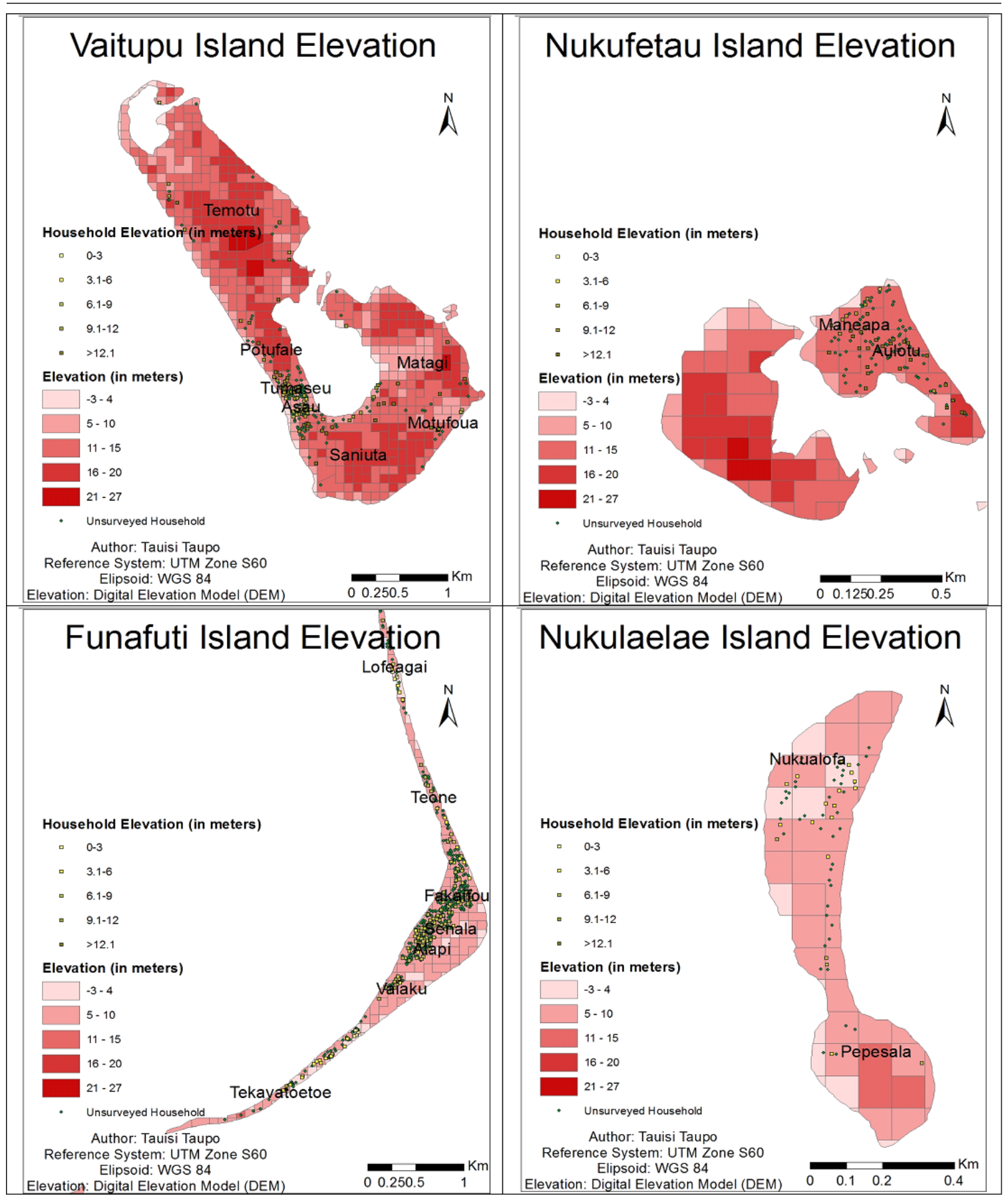

Source: Author's digitized maps.

Figure 2.D.2: Elevation in the Southern Islands 


\section{E Definitions of Indicators}

Table 2.E.1: Definitions of Economic Stability and Resilience Indicators

\begin{tabular}{|c|c|}
\hline Term & Definition \\
\hline Poverty & $\begin{array}{l}\text { Those households living below the poverty threshold. The } \\
\text { poverty threshold is calculated using a food consumption level. } \\
\text { This is often referred to as the Food Poverty Line (FPL). } \\
\text { Therefore, the poverty incidence refers to the percentage of } \\
\text { households who are below the poverty threshold. We defined } \\
\text { and measured using Ravallion (1998), Haughton and Khandker } \\
\text { (2009) and in line with the Central Statistics Office of the Tuvalu } \\
\text { Government. }\end{array}$ \\
\hline Hardship & $\begin{array}{l}\text { Those households living below the hardship threshold. The } \\
\text { hardship threshold is calculated using a food and non-food } \\
\text { consumption level. This is often referred to as the Basic Needs } \\
\text { Poverty Line (BNPL). Therefore, the hardship incidence refers } \\
\text { to the percentage of households who are below the hardship } \\
\text { threshold. We defined and measured using Ravallion (1998), } \\
\text { Haughton and Khandker (2009) and in line with the Central } \\
\text { Statistics Office of the Tuvalu Government. }\end{array}$ \\
\hline Vulnerability & $\begin{array}{l}\text { Those households living below the vulnerability threshold. The } \\
\text { vulnerability threshold is the 'hardship' threshold plus the } \\
\text { 'vulnerability to hardship' level which is the additional } 10 \% \text { of the } \\
\text { 'hardship' threshold. Therefore, the vulnerability incidence refers } \\
\text { to the percentage of households who are below the vulnerability } \\
\text { threshold. We defined and measured using Ravallion (1998), } \\
\text { Haughton and Khandker (2009) and in line with the Central } \\
\text { Statistics Office of the Tuvalu Government. }\end{array}$ \\
\hline Non-resilience & $\begin{array}{l}\text { Those households living below the non-resilience threshold. } \\
\text { The non-resilience threshold is a global standard threshold for } \\
\text { economic stability and resilience to shocks calculated and used } \\
\text { by the World Bank (2013c). Therefore, the non-resilience } \\
\text { incidence refers to the percentage of households who are below } \\
\text { the non-resilience threshold. }\end{array}$ \\
\hline
\end{tabular}




\section{F Description of Variables}

Table 2.F.1: Description of variables

\begin{tabular}{|c|c|c|c|c|c|c|c|c|}
\hline No. & Variable & Description & Obs & Mean & Std.Dev & Min & Max & Source \\
\hline 1 & linc & $\begin{array}{l}\text { Logarithm of income } \\
\text { per person. }\end{array}$ & 490 & 9.1329 & 0.7795 & 7.2605 & 11.9135 & HIES* \\
\hline 2 & hholdsize & $\begin{array}{l}\text { Number of persons } \\
\text { in the household. }\end{array}$ & 490 & 5.4265 & 3.0889 & 1 & 20 & \\
\hline 3 & age & $\begin{array}{l}\text { Years of age of the } \\
\text { household head. }\end{array}$ & 490 & 50.2551 & 12.4336 & 22 & 86 & \\
\hline 4 & gender & $\begin{array}{l}\text { Dummy, } 1 \text { if the household head } \\
\text { is a male, otherwise } 0 .\end{array}$ & 490 & 0.8 & 0.4004 & 0 & 1 & \\
\hline 5 & maritalstat & $\begin{array}{l}\text { Dummy, } 1 \text { if the household head } \\
\text { is married, otherwise } 0 .\end{array}$ & 490 & 0.8142 & 0.3892 & 0 & 1 & \\
\hline 6 & ethnic & $\begin{array}{l}\text { Dummy, } 1 \text { if the household head } \\
\text { is from Tuvalu, otherwise } 0 .\end{array}$ & 490 & 0.9551 & 0.2072 & 0 & 1 & \\
\hline 7 & lit & $\begin{array}{l}\text { Dummy, } 1 \text { if the household head } \\
\text { knows both Tuvalu \& English, otherwise } 0 .\end{array}$ & 490 & 0.7795 & 0.4149 & 0 & 1 & \\
\hline 8 & educ & $\begin{array}{l}\text { Years of education of the household } \\
\text { head. }\end{array}$ & 490 & 8.7673 & 3.8783 & 0 & 18 & \\
\hline 9 & formalwork & $\begin{array}{l}\text { Dummy, } 1 \text { if the household head } \\
\text { works in the formal sector, otherwise } 0 .\end{array}$ & 490 & 0.3877 & 0.4877 & 0 & 1 & \\
\hline 10 & houseowner & $\begin{array}{l}\text { Dummy, } 1 \text { if the household head } \\
\text { owns a house, otherwise } 0 .\end{array}$ & 490 & 0.7326 & 0.4430 & 0 & 1 & \\
\hline 11 & urban & $\begin{array}{l}\text { Dummy, } 1 \text { when the household is in } \\
\text { the urban (capital Funafuti), otherwise } 0 .\end{array}$ & 490 & 0.3918 & 0.4886 & 0 & 1 & \\
\hline 12 & d_pri & $\begin{array}{l}\text { Distant of the household to the nearest } \\
\text { Primary school in kilometers }(\mathrm{km}) \text {. }\end{array}$ & 490 & 0.5942 & 0.9198 & 0.0228 & 9.2590 & $\mathrm{DEM}^{* *}$ \\
\hline 13 & d_hosp & $\begin{array}{l}\text { Distant of the household to the nearest } \\
\text { Hospital and or Clinic in } \mathrm{km} \text {. }\end{array}$ & 490 & 0.7304 & 0.9405 & 0.0374 & 9.1691 & \\
\hline 14 & d_govt & $\begin{array}{l}\text { Distant of the household to the } \\
\text { Government/Commercial area } \\
\text { at the capital in km. }\end{array}$ & 490 & 168.0857 & 163.9198 & 0.0483 & 466.3428 & \\
\hline 15 & d_wide & $\begin{array}{l}\text { Distant of the household from } \\
\text { lagoon-coast to the sea-coast in } \mathrm{km} \text {. }\end{array}$ & 490 & 1.5295 & 2.0121 & 0.0656 & 8.2440 & \\
\hline 16 & dcoast & $\begin{array}{l}\text { Distant of the household to the } \\
\text { nearest coastline in } \mathrm{km} .\end{array}$ & 490 & 0.1653 & 0.1426 & 0.0087 & 0.9016 & \\
\hline 17 & d_pits & $\begin{array}{l}\text { Distant of the household to the } \\
\text { nearest borrow pits and ponds in } \mathrm{km} \text {. }\end{array}$ & 490 & 45.2424 & 57.3278 & 0.0023 & 128.602 & \\
\hline 18 & density & Population per km square. & 490 & 1719.915 & 1513.103 & 151.4059 & 3476.629 & \\
\hline 19 & elevation & Elevation in meters. & 490 & 9.2718 & 3.0608 & 1.8976 & 17.3287 & \\
\hline 20 & b_islands & $\begin{array}{l}\text { Dummy, } 1 \text { if household } \\
\text { moved between islands. }\end{array}$ & 260 & 0.1307 & 0.3377 & 0 & 1 & $\begin{array}{l}\text { GIS } \\
\text { and }\end{array}$ \\
\hline 21 & w_islands & $\begin{array}{l}\text { Dummy, } 1 \text { if household moved } \\
\text { within islands. }\end{array}$ & 260 & 0.0461 & 0.2102 & 0 & 1 & HIES*** \\
\hline 22 & urban_mig & $\begin{array}{l}\text { Dummy, } 1 \text { if household moved } \\
\text { from the outer-islands to the capital. }\end{array}$ & 260 & 0.0653 & 0.2476 & 0 & 1 & \\
\hline 23 & migrate_io & $\begin{array}{l}\text { Dummy, } 1 \text { if household moved } \\
\text { between outer-islands. }\end{array}$ & 260 & 0.0423 & 0.2016 & 0 & 1 & \\
\hline 24 & rural_mig & $\begin{array}{l}\text { Dummy, } 1 \text { if household moved } \\
\text { from the capital to the outer-islands. }\end{array}$ & 260 & 0.0230 & 0.1504 & 0 & 1 & \\
\hline
\end{tabular}

Source: *Author's calculations from HIES, **Author's calculations based on GPS locations of households using reference system UTM Zone S60 with elipsoid WGS 84 and the Digital Elevation Model (DEM), and ***Additional variables for panel data. Author's calculations based on GPS household locations \& household data for 2004/5 and 2010 from CSD. 


\section{G Panel Data Models}

Table 2.G.1: Comparing estimators for panel data models

\begin{tabular}{|c|c|c|c|c|c|c|}
\hline educ & $\begin{array}{c}\text { Pooled OLS } \\
0.0541^{* * *} \\
(0.0120)\end{array}$ & $\begin{array}{c}\text { Fixed Effects } \\
0.0696^{* * *} \\
(0.0263)\end{array}$ & $\begin{array}{c}\text { Random Effects } \\
0.0544^{* * *} \\
(0.0129)\end{array}$ & $\begin{array}{c}\text { Pooled OLS } \\
0.0593^{* * *} \\
(0.0119)\end{array}$ & $\begin{array}{c}\text { Fixed Effects } \\
0.0587^{* *} \\
(0.0255)\end{array}$ & $\begin{array}{c}\text { Random Effects } \\
0.0590^{* * *} \\
(0.0129)\end{array}$ \\
\hline hhsize & $\begin{array}{c}-0.0611^{* * *} \\
(0.0158)\end{array}$ & $\begin{array}{c}-0.0939^{* * *} \\
(0.0287)\end{array}$ & $\begin{array}{c}-0.0676^{* * *} \\
(0.0164)\end{array}$ & $\begin{array}{c}-0.0564^{* * *} \\
(0.0161)\end{array}$ & $\begin{array}{c}-0.0965^{* * *} \\
(0.0277)\end{array}$ & $\begin{array}{c}-0.0638^{* * *} \\
(0.0167)\end{array}$ \\
\hline sex & $\begin{array}{c}0.164 \\
(0.112)\end{array}$ & $\begin{array}{c}-0.474^{* *} \\
(0.236)\end{array}$ & $\begin{array}{l}0.0822 \\
(0.120)\end{array}$ & $\begin{array}{c}0.145 \\
(0.112)\end{array}$ & $\begin{array}{l}-0.333 \\
(0.237)\end{array}$ & $\begin{array}{l}0.0575 \\
(0.121)\end{array}$ \\
\hline age & $\begin{array}{l}0.000648 \\
(0.00311)\end{array}$ & $\begin{array}{c}-0.00131 \\
(0.00699)\end{array}$ & $\begin{array}{l}0.000191 \\
(0.00336)\end{array}$ & $\begin{array}{l}0.000428 \\
(0.00314)\end{array}$ & $\begin{array}{l}-0.00551 \\
(0.00701)\end{array}$ & $\begin{array}{l}-0.000183 \\
(0.00342)\end{array}$ \\
\hline ethnic & $\begin{array}{c}0.186 \\
(0.205)\end{array}$ & $\begin{array}{c}0.00472 \\
(0.614)\end{array}$ & $\begin{array}{c}0.147 \\
(0.226)\end{array}$ & $\begin{array}{c}0.156 \\
(0.208)\end{array}$ & $\begin{array}{c}0.219 \\
(0.593)\end{array}$ & $\begin{array}{c}0.117 \\
(0.231)\end{array}$ \\
\hline deast & $\begin{array}{l}-0.000283 \\
(0.000195)\end{array}$ & $\begin{array}{c}-0.000609^{* *} \\
(0.000305)\end{array}$ & $\begin{array}{l}-0.000350^{*} \\
(0.000200)\end{array}$ & $\begin{array}{l}-0.000243 \\
(0.000198)\end{array}$ & $\begin{array}{c}-0.000716^{* *} \\
(0.000300)\end{array}$ & $\begin{array}{l}-0.000352^{*} \\
(0.000203)\end{array}$ \\
\hline wideness & $\begin{array}{l}0.0000601 \\
(0.000183)\end{array}$ & $\begin{array}{c}0.000440 \\
(0.000273)\end{array}$ & $\begin{array}{c}0.000132 \\
(0.000186)\end{array}$ & $\begin{array}{l}0.0000331 \\
(0.000187)\end{array}$ & $\begin{array}{c}0.000797^{* * *} \\
(0.000296)\end{array}$ & $\begin{array}{c}0.000164 \\
(0.000192)\end{array}$ \\
\hline b_islands & $\begin{array}{c}0.199 \\
(0.120)\end{array}$ & $\begin{array}{c}0.419^{* * *} \\
(0.145)\end{array}$ & $\begin{array}{c}0.251^{* *} \\
(0.115)\end{array}$ & & & \\
\hline w_islands & $\begin{array}{c}0.499^{* * *} \\
(0.190)\end{array}$ & $\begin{array}{c}0.139 \\
(0.227)\end{array}$ & $\begin{array}{c}0.426^{* *} \\
(0.181)\end{array}$ & & & \\
\hline urban_migration & & & & $\begin{array}{c}0.211 \\
(0.171)\end{array}$ & $\begin{array}{c}0.982^{* * *} \\
(0.253)\end{array}$ & $\begin{array}{c}0.347^{* *} \\
(0.167)\end{array}$ \\
\hline migrate_oi & & & & $\begin{array}{l}0.363^{*} \\
(0.196)\end{array}$ & $\begin{array}{c}0.267 \\
(0.226)\end{array}$ & $\begin{array}{l}0.328^{*} \\
(0.186)\end{array}$ \\
\hline rural_migration & & & & $\begin{array}{l}-0.305 \\
(0.268)\end{array}$ & $\begin{array}{l}-0.346 \\
(0.372)\end{array}$ & $\begin{array}{l}-0.210 \\
(0.258)\end{array}$ \\
\hline _cons & $\begin{array}{c}3.675^{* * *} \\
(0.287)\end{array}$ & $\begin{array}{c}4.393^{* * *} \\
(0.639)\end{array}$ & $\begin{array}{c}3.812^{* * *} \\
(0.305)\end{array}$ & $\begin{array}{c}3.682^{* * *} \\
(0.289)\end{array}$ & $\begin{array}{c}4.115^{* * *} \\
(0.619)\end{array}$ & $\begin{array}{c}3.809^{* * *} \\
(0.308)\end{array}$ \\
\hline$N$ & 260 & 260 & 260 & 260 & 260 & 260 \\
\hline$R^{2}$ & 0.236 & 0.327 & 0.263 & 0.228 & 0.365 & 0.277 \\
\hline
\end{tabular}

Standard errors in parentheses

${ }^{*} p<0.10,{ }^{* *} p<0.05,{ }^{* * *} p<0.01$

Source: Author's estimations from 2004/5 and 2010 HIES data. 


\section{Chapter 3}

\section{At the Very Edge of a Storm: The Impact of a Distant Cyclone on Atoll Islands}

\subsection{Introduction}

A Small Island Developing State (SIDS) in the Pacific, Tuvalu consists of nine low-lying atoll islands spread over a large expanse of ocean. Tuvalu is one of the most vulnerable countries to disasters in per capita terms, and is particularly vulnerable to destructive cyclones with their associated storm surges and flooding. ${ }^{1}$ Changes in weather patterns and the threat of rising sea levels will further aggravate these threats. An under-appreciated and insufficiently modelled risk facing Tuvalu is the storm surge generated by distant storms. The risk of distant cyclones is the focus of this chapter.

Briguglio (1997), Field et al. (2014a) and the World Bank (2014) recognized the vulnerability of SIDS to disasters and the lack of economic resilience arising from the relative inability of these countries to face forces of these magnitudes. Christenson

\footnotetext{
${ }^{1}$ In terms of lowest maximum elevation, Tuvalu is the second lowest-elevation country in the world after the Maldives.
} 
et al. (2014) found out that in their estimations of population exposed to cyclones, more than half of the top 20 countries world-wide are from the SIDS.

Tuvalu is extremely vulnerable to disasters, even by SIDS standards, due to its small geographical size, insularity and exceptional remoteness, the concentration of economic activities and settlements along low-lying coastal areas, the narrow width of islands, the very limited natural resource base, a heavy reliance on subsistence agriculture and inadequate disaster mitigation capabilities. The Emergency Events Database (EM-DAT) recorded only four storms that affected Tuvalu from 1900 to 2016: the 1972 Tropical Cyclone Bebe, 1990, 1993, and the recent 2015 Tropical Cyclone (TC) Pam. Bebe in 1972 struck down 90\% of the houses and killed six people. The other publicly available database of disaster impacts - DesInventar, in contrast, lists tropical cyclones that hit Tuvalu in 1959, 1965, 1972, 1984, 1987, 1990, 1992, 1993 (twice), 1997 (twice), and 2015. Both datasets clearly underestimate disaster damages for Tuvalu for a variety of reasons (see Noy (2016b) for details). Kaly and Pratt (2000) reported that out of the 4 Pacific Island Countries they examined (Fiji, Samoa, Tuvalu and Vanuatu), Tuvalu received the highest environmental vulnerability. Of the atoll island countries, Tuvalu, Kiribati, and the Maldives were found to be extremely vulnerable while Marshall Islands and Tokelau were marginally less vulnerable. An analysis of the 2010 Household Income \& Expenditure Survey (HIES) shows that a large proportion of poor households reside near areas prone to cyclone surges (Taupo et al., 2016).

Recently, both TC Pam and TC Ula in 2015 re-focused attention on the vulnerability of Tuvalu to cyclones after a benign period of 18 years. TC Pam appeared on the world's radar screens on March $6^{\text {th }}$, but became a full blown category $\mathrm{V}$ cyclone on March $12^{\text {th }}$. In the two days previous to that date, it was not moving very fast, and generated a significant storm surge that hit the outer islands of Tuvalu. This surge peaked on March 11 ${ }^{\text {th }}$ (see map in Figure 3.1). Although TC Pam's centre passed over 1,000 kilometers (km) away from Tuvalu, Tuvaluans found themselves significantly affected by the storm surge the cyclone generated. According to our calculations based on the survey described below, Tuvaluans suffered large monetary losses amounting to almost 10\% of GDP due to damages to properties, appliances and assets, loss to plantations and livestock, and to infrastructure. ${ }^{2}$

\footnotetext{
${ }^{2}$ This figure is proportionally twice as large as the damage experienced in Japan from the 2011
} 


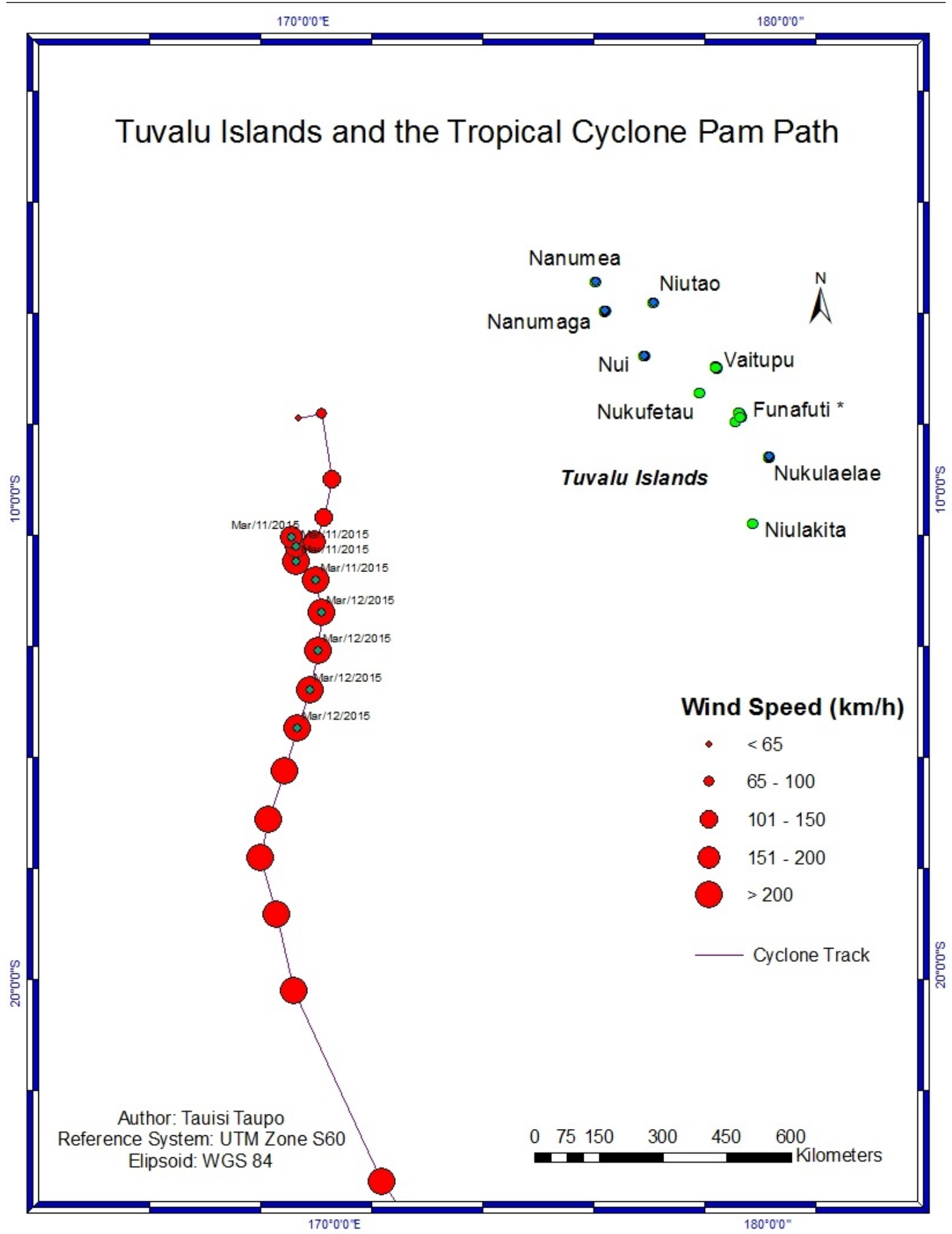

Source: Author's digitized map. The green dots on the TC Pam track denote the points when the Islands of Tuvalu were hit the hardest by the cyclone. The tracking dots are measured at 6 hour intervals. The blue dots represent the affected islands that were included in our Survey.

Figure 3.1: Tuvalu Islands and the trajectory of the TC Pam 
Here, we examine the experience of Tuvalu with TC Pam. Since many low-income households reside in high-risk areas with minimal capacity to prepare and respond to weather risk, we pay special attention to them. The main focus of this chapter is to enrich our understanding of vulnerability, exposure, and responsiveness to cyclones for the residents of SIDS, particularly to distant cyclones for atoll SIDS. ${ }^{3}$

For that purpose, we first describe the results of the post-TC-Pam household survey we conducted, and estimate the determinants of damage and loss associated with the cyclone. We then calculate the estimated damage with hypothetical scenarios accounting for reduced (or increased) vulnerability, exposure, and resilience. We end with some policy implications.

\subsection{The Literature on Disaster Risk}

There is an extensive literature, from various disciplines, covering the concepts of vulnerability and resilience with respect to natural hazards. An offspring from multiple conceptual frameworks is the now widely used framework whereby risk is a multiplicative function of hazard, exposure and vulnerability. It is this theoretical framework that grounds our empirical investigation. ${ }^{4}$

Smith and Rhiney (2015) and Lopez-Marrero and Wisner (2012) stress that vulnerability to negative impacts of weather risk is partly a function of the differential coping and adapting capabilities of various groups of people. They

triple earthquake-tsunami-nuclear accident catastrophe.

${ }^{3}$ The Atoll nations are Tuvalu, Kiribati, Nauru, Marshall Islands (in the Pacific) and the Maldives (in the Indian Ocean). There are other populated atoll islands in other countries in the Pacific and elsewhere.

${ }^{4}$ Examples include Clark et al. (1998) which stresses that the two functions of vulnerability are exposure and coping ability. This coping ability is partitioned in their analysis into resistance and resilience. According to Briguglio et al. (2009), risk is determine by exposure and coping ability that are associated with vulnerability and resilience, respectively. Cutter et al. (2008) discusses a framework called the Disaster Resilience of Place (DROP) model which explains and articulates the relationship between vulnerability, resilience and adaptive capacity. However, they defined vulnerability and resilience as the inherent characteristics that create the potential for harm, and the ability to respond and recover from disasters, respectively. There are multiple other frameworks, including many works that emphasized the root causes of vulnerability and the role of poverty in these dynamics; work that is frequently associated with Wisner and his co-authors (e.g., Wisner et al. (2003)). See Noy and Yonson (2016) for a survey of the relevant concepts and their measurement. 
further point out that vulnerability to climatic impacts is inherently developmental as the differentiated levels of exposure and sensitivity to natural hazards are partly created by basic social and economic inequalities, and access to resources, assets and government support.

Field et al. (2014b, p.5) defines Risk as the "potential for consequences where something of value is at stake and where the outcome is uncertain, recognizing the diversity of values. It is often represented as the probability of occurrence of hazardous events"; Hazard refers to the "potential occurrence of a natural or human-induced physical event or trend or physical impact that may cause loss of life, injury, or other health impacts, as well as damage and loss to property, infrastructure, livelihoods, service provision, ecosystems, and environment resources"; Exposure is the "presence of people, livelihoods, species or ecosystems, environmental functions, services, and resources, infrastructure, or economic, social, or cultural assets in places and settings that could be adversely affected"; and Vulnerability is defined as the "propensity of predisposition to be adversely affected". Vulnerability encompasses a variety of concepts and elements including sensitivity or susceptibility to harm and lack of capacity to cope and adapt (Cavallo and Noy, 2011; Noy, 2016b; Taupo et al., 2016; Yonson et al., 2016; World Bank and GFDRR, 2013; United Nations, 2015a; Wisner et al., 2012, 2003).

In our analysis, a disaster leads to (ex post) impact, which can similarly to risk be expressed as: Impact $=$ Vulnerability $\times$ Exposure $\times$ Hazard $\times$ Responsiveness. ${ }^{5}$ Our data on actual disaster damages at the household level are unique, and they enable us to estimate the role of vulnerability, exposure, hazard and responsiveness at the micro-economic level, rather than at the macro-aggregate level as has previously been done. This further enables us to estimate the likely impact various policies would have on disaster risk, were they to be implemented. Besides our methodological contribution, this chapter is one of the first, as far as we are aware, that investigates quantitatively the impact of cyclones on atoll islands. More importantly, we believe that this chapter is the first to quantify the extreme cost that very distant cyclones

\footnotetext{
${ }^{5}$ Previous empirical examinations of direct cyclone impact include, for example, Akter and Mallick (2013), which examine the impacts of a cyclone in Bangladesh, and show the negative impacts of the cyclone on income, employment, and access to clean water and sanitation.
} 
can impose on atoll islands. Since these costs are typically not assessed, nor accounted for in risk modelling, this lacunae means that disaster risk for atoll islands is typically grossly underestimated.

\subsection{Estimation Method and Survey Data}

We carried out a detailed household survey from November 2015 to January 2016 in the five islands that were affected by Tropical Cyclone Pam in March 2015. ${ }^{6}$ The survey includes administered interviews to 321 households from 14 different villages representing $58 \%$ of the total number of households in the affected islands. The interviewed households were randomly selected following a procedure followed by the Tuvalu Central Statistics Division. ${ }^{7}$ The questionnaire was translated to the Tuvaluan language. ${ }^{8}$ Detailed information was obtained on losses and damages to households; see Table 3.1. ${ }^{9}$

We estimated a statistical model to determine the association between disaster impact and vulnerability, exposure, hazard, and responsiveness where we used a conventional cross-sectional sample of $n$ independent observations of households (denoted $i$ ) from the survey we conducted after the cyclone (where $i=1, \ldots, n$ ). The observations for loss and damage are linearly conditional on a set of explanatory

\footnotetext{
${ }^{6}$ See full questionnaire in Table 3.D.1.

${ }^{7}$ We used a systematic random sampling approach. We started with the full list of households compiled by the 2012 census. From there, we calculated a skip interval before randomly selecting a starting point from this list of households (made available to us from the Central Statistical Division). We then counted down and skipped by the skip interval to identify the list of households to be questioned. The survey questionnaire was approved by the Victoria University of Wellington's Ethics Committee before the survey was conducted. We encountered some difficulties during the period of the survey around December 2015, as Tuvalu was hit by gale-force winds from TC Ula, preventing ships from going to the outer-islands for almost a week, but the administration of the survey was eventually completed in early 2016. The results presented here were weighted using weights employed by the Central Statistics Division Tuvalu to represent the population of the outer islands.

${ }^{8}$ The survey was conducted using trained interviewers, trained and supervised by myself.

${ }^{9}$ There is a risk that respondents over-report loss and damage. This risk is particularly present where households believe that the survey might inform government or donor policy, thereby influencing future resource allocations to them. Since the affected islands are small, and the interviewers actually know all households and the damage and losses encountered by households in the islands. Therefore, this minimizes the risk of over-reporting of loss and damage. In addition, we can also cross-reference unsure or doubted information against the 2010 HIES and 2012 Census.
} 
independent variables as in:

$$
L D_{i}=\alpha+\beta_{v} V u l_{i}+\beta_{e} \operatorname{Exp}_{i}+\beta_{h} H a z_{i}+\beta_{r} \operatorname{Res}_{i}+\varepsilon_{i}
$$

$L D_{i}$ is the total loss and damage experienced by household $i$, summed up from the survey responses on all the specific loss and damage items. $V u l_{i}, \operatorname{Exp}_{i}, H a z_{i}$, $R e s_{i}$ are vectors of independent variables, derived from the survey responses or the household location, and described as measuring vulnerability, exposure, hazard and response. The $\beta$ vectors are the vectors of estimated coefficients describing the partial correlation between these measures and loss and damage per household. The estimated regression also includes a constant $(\alpha)$ and an independent and identically distributed (iid) error term $\varepsilon_{i}$.

Vulnerability is a vector of household characteristics that measure household vulnerability to the cyclone; Exposure is a vector measuring the extent of household exposure to TC Pam based on their geo-location; Hazard is a vector of the distance of the cyclone path that indicates the strength of the storm hazard that households experienced; and Responsiveness is a vector that measures the ability of households to respond or react to TC Pam. All of this data is collected from responses to questions and from the households geo-location as recorded when conducting the survey.

Our data is a cross-section of household survey responses after the cyclone. Since we do not have a panel of responses (with observations from below the cyclone), we cannot do diff-and-diff estimation. This means that our results might be biased if there are omitted variables that are correlated with the hazard, exposure, or vulnerability, and the disaster's damage. However, as we have a fairly rich set of responses from households, we doubt that this missing variable bias is of significant empirical concern, though of course we cannot exclusively establish that. The model we estimate is similar to cross-country models that have been estimated by numerous papers since the pioneering work by Kahn (2005).

There is no common definition nor a widely-agreed method for calculating loss and damage. Here, similarly to ECLAC (2014), loss and damages are aggregated 
Table 3.1: Description of variables and their sources

\begin{tabular}{lcccc}
\hline \multicolumn{1}{c}{ Variable } & Mean & STD & Min & Max \\
\hline The logarithm of loss and damage (in AUD) & 6.49 & 2.11 & 3.69 & 10.30 \\
The logarithm of income per person (in AUD) & 3.63 & 1.00 & 0.69 & 7.54 \\
Loss and damage (in AUD) & 3,406 & 6,304 & 40 & 29,800 \\
Monthly income per person (in AUD) & 65.54 & 142.48 & 0 & 1,875 \\
Number of persons in the household & 4.8 & 2.6 & 1 & 15 \\
Strong house structure, 1 if cement & 0.83 & & 0 & 1 \\
Distant to the nearest coastline in meters & 166 & 107 & 27 & 563 \\
Elevation of household in meters & 9.4 & 3.5 & 1.8 & 17.7 \\
Total distant to the coasts (land width) in meters & 889.1 & 485.1 & 113.9 & $2,425.2$ \\
Distant from household to the cyclone path in km & 973.53 & 68.50 & 906.13 & $1,100.09$ \\
House preparation for cyclone, 1 if house was strengthened & 0.51 & & 0 & 1 \\
Training/capacity-building experience from cyclone response & 0.74 & & 0 & 1 \\
workshops, 1 if yes & & & & \\
Received cyclone warning at least 12 hrs in advance, 1 if Yes & 0.32 & & 0 & 1 \\
\hline \hline
\end{tabular}

Note: The only variable for which we do not have the full 321 responses is income (only 305 responses). All variables were based on author's calculations from the primary data collected in the survey. Geo-location information is based on Global Positioning System (GPS) locations of households using reference system UTM Zone S60 with ellipsoid WGS 84 and the Digital Elevation Model (DEM).

at the household level and are proxied by the estimated replacement/reconstruction costs for damages to properties and assets, and the estimated income losses due to livestock and crop losses. There was no loss of human lives from the TC Pam, nor much evidence of increased morbidity.

The hazard itself, TC Pam, passed far away from Tuvalu, but the storm surge and heavy rainfall led to flooding and wave damage. Since the storm's centre passed far away, the exact direction of each household relative to the storm's circular movement is not materially important. As a proxy for the strength of the cyclone we focused on measuring the distance of each household from the cyclone path. This measure does not vary much within each island, but enabled us to proxy the intensity of the hazard in each island.

For our measure of exposure to the cyclone, we measured the distance to the coastline and the household's elevation above sea-level. ${ }^{10}$ Following much of the literature, vulnerability is proxied by income per person, household size, and the strength of the house (whether it is made of cement or wood). The ability to react and

\footnotetext{
${ }^{10}$ In places with more nuanced topography with potentially lower elevation further inland, distance to the coast and elevation may not be enough. In such case the exact layout of the land will be necessary in order to understand exposure. For Tuvalu, this is unnecessary.
} 


\section{CHAPTER 3. AT THE VERY EDGE OF A STORM: THE IMPACT OF A DISTANT CYCLONE ON ATOLL ISLANDS}

respond positively in preparation for the cyclone is potentially effective in lessening the impact of the disaster. Our binary proxy indicators for responsiveness are whether the house was strengthened in preparation for the cyclone, whether the household head received cyclone response capacity training, and whether the household received timely cyclone warning.

\subsection{Analysis of Survey Responses}

\subsubsection{Household Characteristics}

We first asked about the household details and characteristics before elaborating on the impact of the TC Pam. About $60 \%$ of families have a gas stove, refrigerator, and a motorcycle (see Figure 3.2). More expensive durables such as air conditioners are owned by almost no one given the low monthly cash incomes for most households. Most families live in houses that are more than 20 years old. $83 \%$ of houses are made of concrete. $97 \%$ of households owned their houses. ${ }^{11}$ Around $30 \%$ of the surveyed households have a mobile phone.

We follow Haughton and Khandker (2009) in defining a poverty line to identify the poor from the non-poor. The line is determined based on the cost of basic needs where the cost of acquiring enough food for adequate nutrition is added as a measure of non-food essentials. ${ }^{12}$ Hence, we refer to the poverty incidence as the percentage of those households who fall below the basic needs consumption level. Overall, $81 \%$ of the reported income accrues to the non-poor, though almost $34 \%$ of the expenditures are consumed by poor households.

\footnotetext{
${ }^{11}$ Generally, families (homeowners) in the outer islands rarely move away from their land. Land is very scarce in Tuvalu, and owners are therefore reluctant to leave the family land (lest it be occupied by more distant relatives). It is therefore implausible that the storm triggered any population movement that will bias our sample (as the survey was conducted ex-post).

${ }^{12}$ The consumption bundle of adequate food and non-food estimates a poverty line that is seen as a reasonable minimum expenditure required to satisfy both basic food and non-food needs. We used an estimated food consumption expenditure required for daily calorie energy intake per person that is parallel with the FAO requirement of 2,100 kilocalories (Kcal). This measure is consistent with the official poverty measure used by the Government of Tuvalu. More details regarding poverty measures in Tuvalu are available from Taupo et al. (2016).
} 


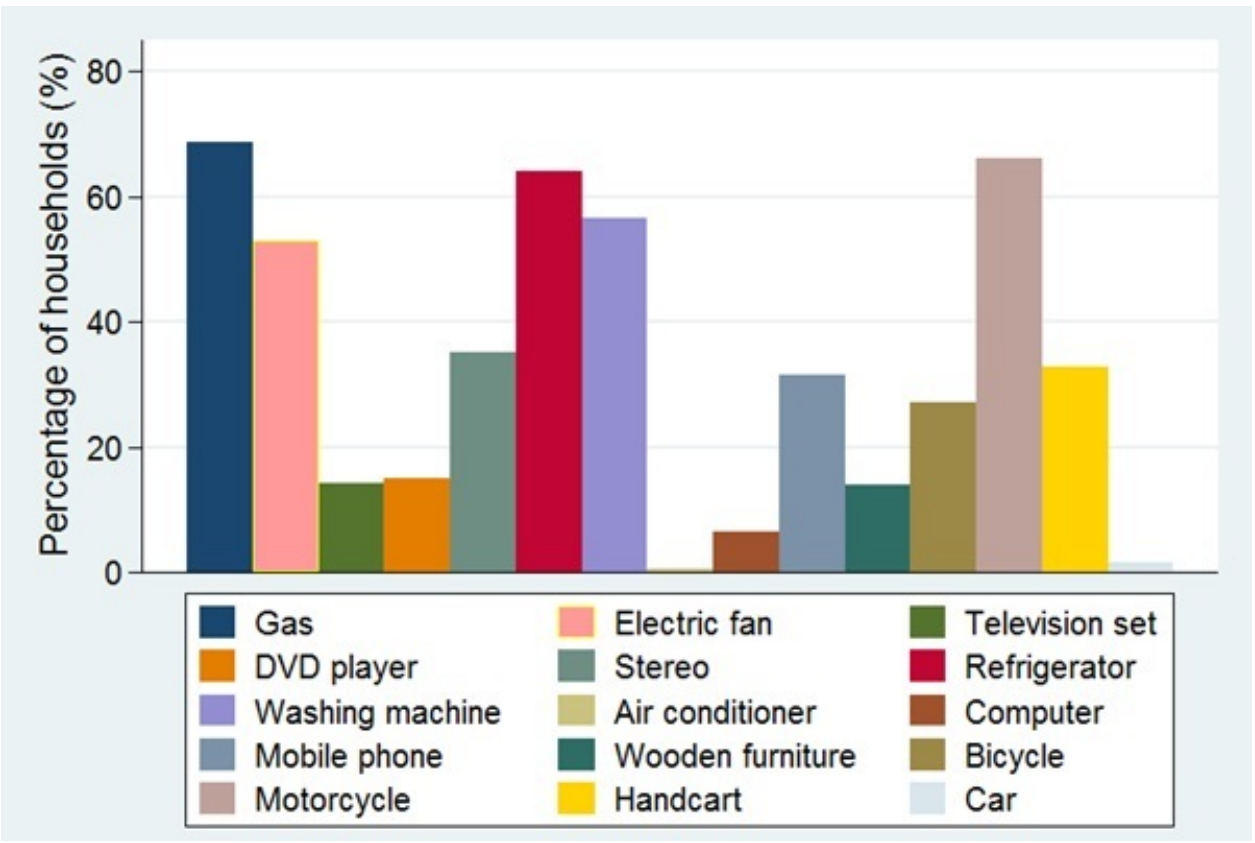

Source: Author's calculations from the Pam survey. Note that N=321.

Figure 3.2: Asset ownership

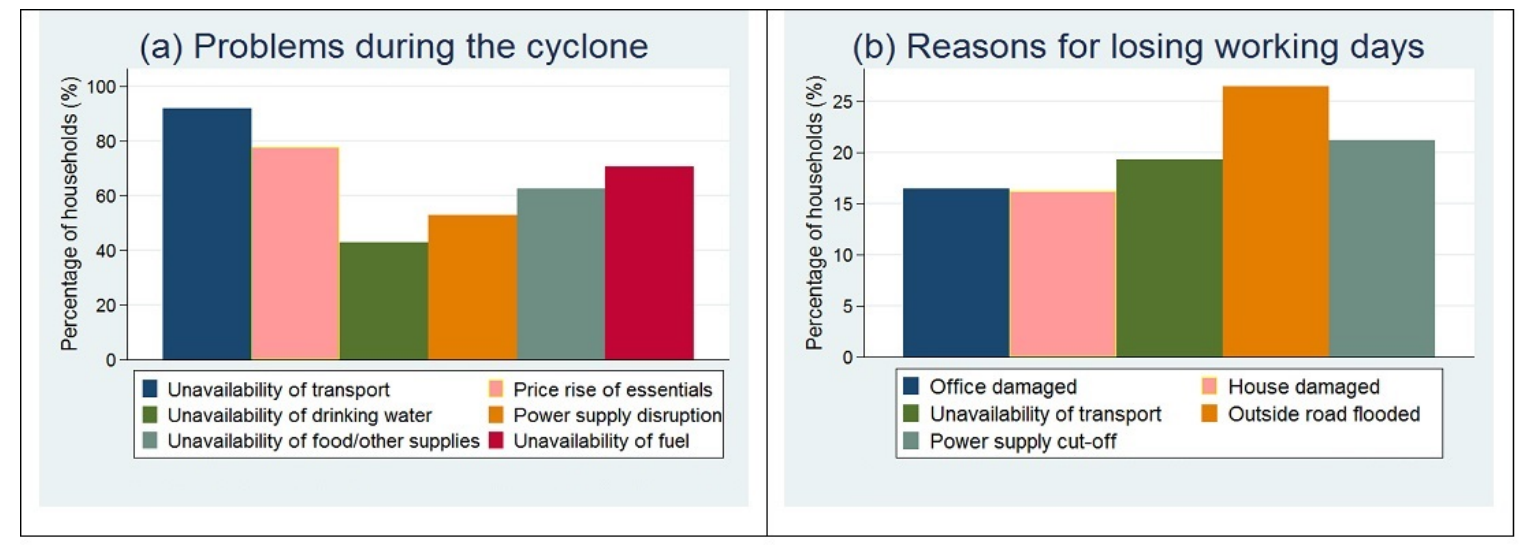

Source: Author's calculations from the Pam survey. Note that $\mathrm{N}=321$.

Figure 3.3: Cyclone impacts 

DISTANT CYCLONE ON ATOLL ISLANDS

Problems faced by households in the aftermath of the cyclone include the unavailability of transportation, price rises of essentials, unavailability of drinking water, food, fuel, and other supplies, and power supply disruptions (see Figure 3.3). Most households reported damages to kitchenware, plumbing, house structure, electrical wiring, etcetera. Kitchenware and plumbing were the most damaged items reported since households in the outer-islands typically have outdoor kitchens, and outdoor plumbing from roof gutters to water storage tanks. Flooding of the road outside and power supply cut-offs were the main reasons for losing work. On average, families went without electricity for two days. On average, households reported losing about two working days and seven school days for children.

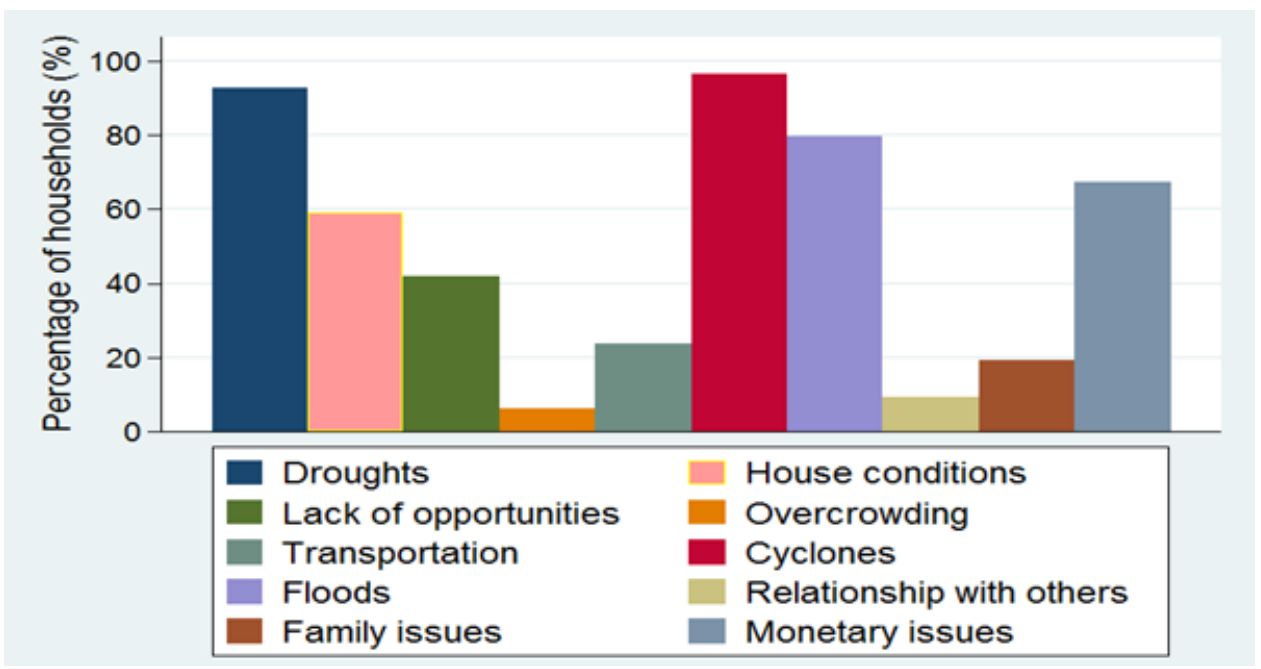

Source: Author's calculations from the Pam survey. Note that $\mathrm{N}=321$.

Figure 3.4: Multiple stressors affecting households

More households view climate-related disasters as the most significant threat to their livelihoods. Figure 3.4 shows various stressors that households identify. The highest ranked stressors are natural hazards, i.e., cyclones, droughts and floods. Most pertinent here is that almost all households view cyclones as a major threat (97\%). After climate related hazards, monetary concerns are the next stressor; while overcrowding is the least significant stressor in the outer-islands. 


\subsubsection{Loss and Damage}

As previously noted, the damage is the approximate replacement value of household assets damaged/destroyed by the cyclone. In order to properly estimate the damages to dwellings using replacement cost, we consulted with construction experts and distributors of building materials, furniture, and equipment. ${ }^{13}$ There is no formal insurance available in Tuvalu, but there is informal self-insurance from small amount of household savings and some potential for remittances from families abroad. Most costs were borne directly by the owners of assets, though they may receive external assistance (from family abroad, from the government or from external donors). Since we rely on a household survey, our estimates do not account for any damages to public buildings and public infrastructure. For the damages, we computed the estimated cost needed to rebuild or repair the damages to property and assets. ${ }^{14}$

People in the outer-islands of Tuvalu live on fish, staple crops (e.g., taro and pulaka), fruit trees (e.g., breadfruit and coconut), vegetables (e.g., cucumbers and tomatoes) and livestock (pigs). ${ }^{15}$ Livelihoods in Tuvalu's outer islands heavily depend on these essentials. Losses in terms of livestock and agricultural plantations were substantial, and are included in our estimates. On the other hand, 'damage' refers to assets e.g., houses, local kitchens, outdoor toilets, water tanks, and others that were damaged and can be repaired. Overall, $95 \%$ of households reported that they incurred loss and damage.

\footnotetext{
${ }^{13}$ We gathered price lists of building materials and furniture from hardware outlets in the capital. We used market prices for estimating equipment values.

${ }^{14}$ These estimated cost of houses, local kitchens, outdoor toilets, water tanks and others were gathered from the Public Works Department (PWD), while the 2015 prices of building materials were collected from the Central Statistics Division and quotations from the 3 main hardware stores (JY Ltd, McKenzie Ltd and Messamesui Ltd) on Funafuti. The same principles were also applied for other damages, by tagging a value on an item that is being lost or destroyed, using local market prices to determine their values. If two pigs died as a consequence of the cyclone, then we used a value of AUD 200 if they both weigh $20 \mathrm{~kg}$ at a local price of AUD 10 per $\mathrm{kg}$. We used a similar procedure for crops and plants. Local market prices for 2015 were gathered from the Central Statistics Division. Unlike crops and plants that have a shorter lifespan and are harvested and new ones are replanted again in their places, fruit trees provide fruits for a longer period. Valuing their loss is therefore more complex. The only information that was collected is the number of fruit trees and their expected lifetime left in years. For consistency across households, the acquired information together with the local market prices of the fruits were used to calculate the values of fruit trees that were lost.

${ }^{15}$ Poultry (chickens and ducks) was excluded in the calculations of losses since they are mostly left in the open. Unlike pigs, they are easily accounted as they are well kept in pigsties.
} 


\section{CHAPTER 3. AT THE VERY EDGE OF A STORM: THE IMPACT OF A DISTANT CYCLONE ON ATOLL ISLANDS}

Based on our summations from the survey responses, the estimated loss and damage to households in Tuvalu is AUD 1,796,497, which is almost $4.4 \%$ of 2015 GDP. ${ }^{16}$ However, the overall loss and damage at the national level is estimated to be around $10 \%$ of the GDP. ${ }^{17}$

Two islands, Nukufetau and the capital Funafuti, have lagoons and islets on their Western side, the side from which the storm surge came. They were thus largely shielded from the cyclone and experienced minimal direct impacts. A similar storm surge coming from the East would have been significantly more damaging as about half the population of the country, and the majority of infrastructure is located on Funafuti.

Only one island, Nukufetau, is surrounded and shielded by its islets and lagoon from all sides and is consequently much less exposed to storm surges. ${ }^{18}$ Vaitupu Island was affected, but not to the extent of the other five islands for whom the damage and loss information is provided below in Figure 3.5 and Figure 3.6.

Nui and Nukulaelae islands were the most affected in terms of losses to crops and livestock (see Figure 3.5). Nui Island suffered particularly, with damage to housing, kitchens, outdoor toilets, water tanks, livestock, crop farms, vegetable gardens, fruit trees, and boats higher than in all other islands. The combination of low elevations and the narrowness of the island contribute to the high level of impact incurred there (see maps in Appendix Figure 3.A.1).

As determined by our calculations of the poverty threshold, and on average, the median loss and damage per household is very similar for poor and non-poor households. Given the different levels of income, however, both the median and

\footnotetext{
${ }^{16}$ Based on the latest GDP figure of AUD 41.2 million in the Government of Tuvalu 2015 National Budget.

${ }^{17}$ This includes damages to households and public infrastructure. This is the summation of our calculated loss and damages to households from the Pam survey, and our estimated loss and damages to public infrastructure based on damages to community halls, community water storages, seawalls, clinics, beach ramps, roads, telecommunication wiring pits, electricity meter boxes reported by the Tuvalu Government (2015), United Nations (2015c), Tuvalu Telecom Corporation, Tuvalu Electricity, Public Works Department and the Health Department.

${ }^{18}$ Residents of Nukufetau only experienced damage to water storage facilities due to the intrusion of sea water into water storage tanks; and the crops on Nukufetau were mostly destroyed since they are located on a western islet that was directly exposed to the cyclone-generated surges.
} 


\subsection{ANALYSIS OF SURVEY RESPONSES}

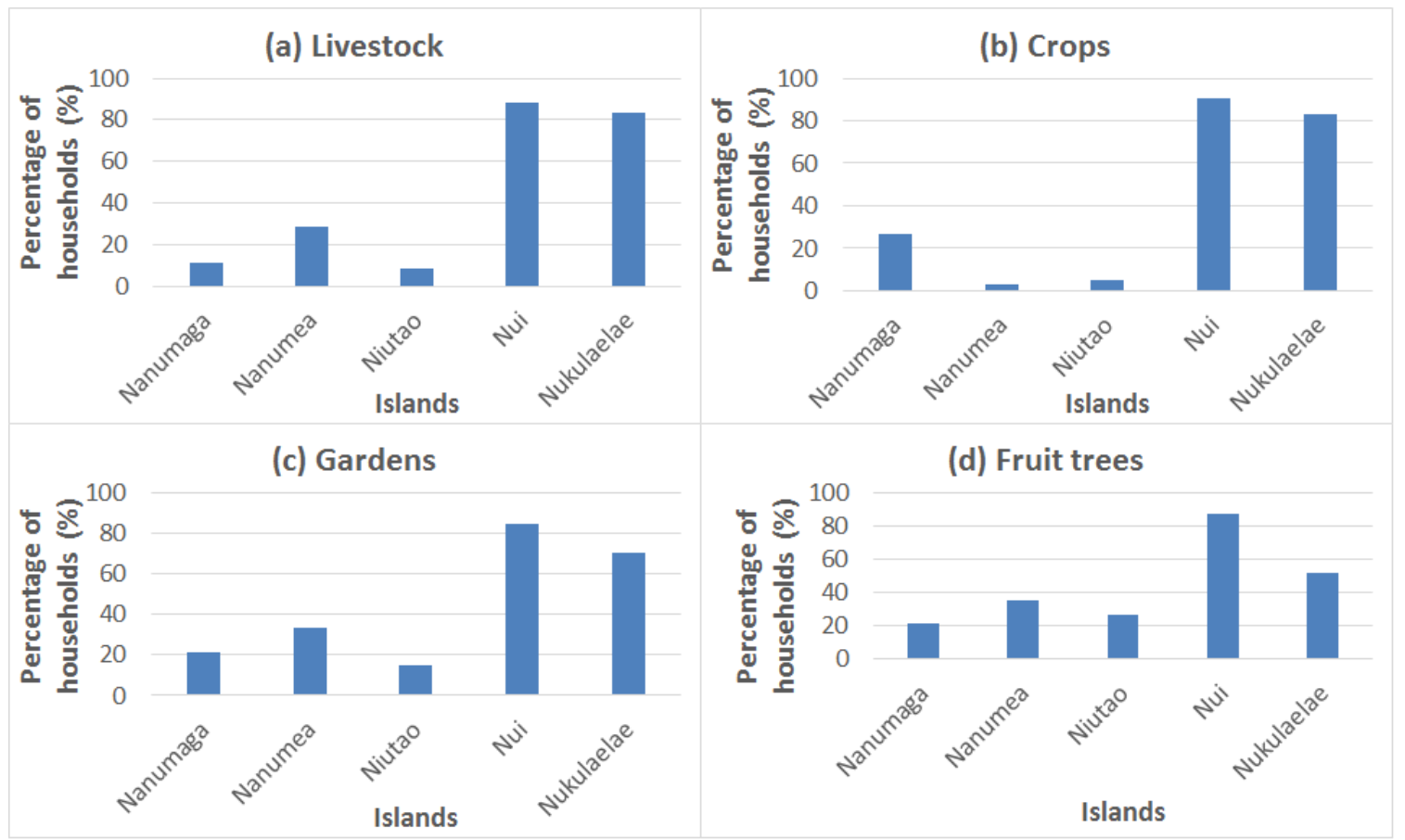

Source: Author's calculations from the Pam survey. Note that $\mathrm{N}=321$.

Figure 3.5: Losses incurred by households

spread of the relative loss and damage (to income) is much higher for poor households (Figure 3.7).

\subsubsection{Hazard}

TC Pam lasted for five days with wind velocities of more than $100 \mathrm{~km} / \mathrm{hr}$. Most research projects measure cyclone hazard using wind-speed indicators (e.g., Schumacher and Strobl (2011) and Strobl (2012)). Yonson et al. (2016), in contrast, argue that for some cyclones, most mortality, morbidity, and damage is associated with water rather than wind. In the case of TC Pam and Tuvalu, these distinctions are not important as the storm was so far away, and the topography of the islands so uniform (flat) that wind and rainfall can basically be assumed to be uniform across each island. The only distinction, and anyway the only source of damage in this case, is the storm surge that impacted households. We therefore use the nearest distance from the location of each household to the cyclone path as our hazard indicator. This 


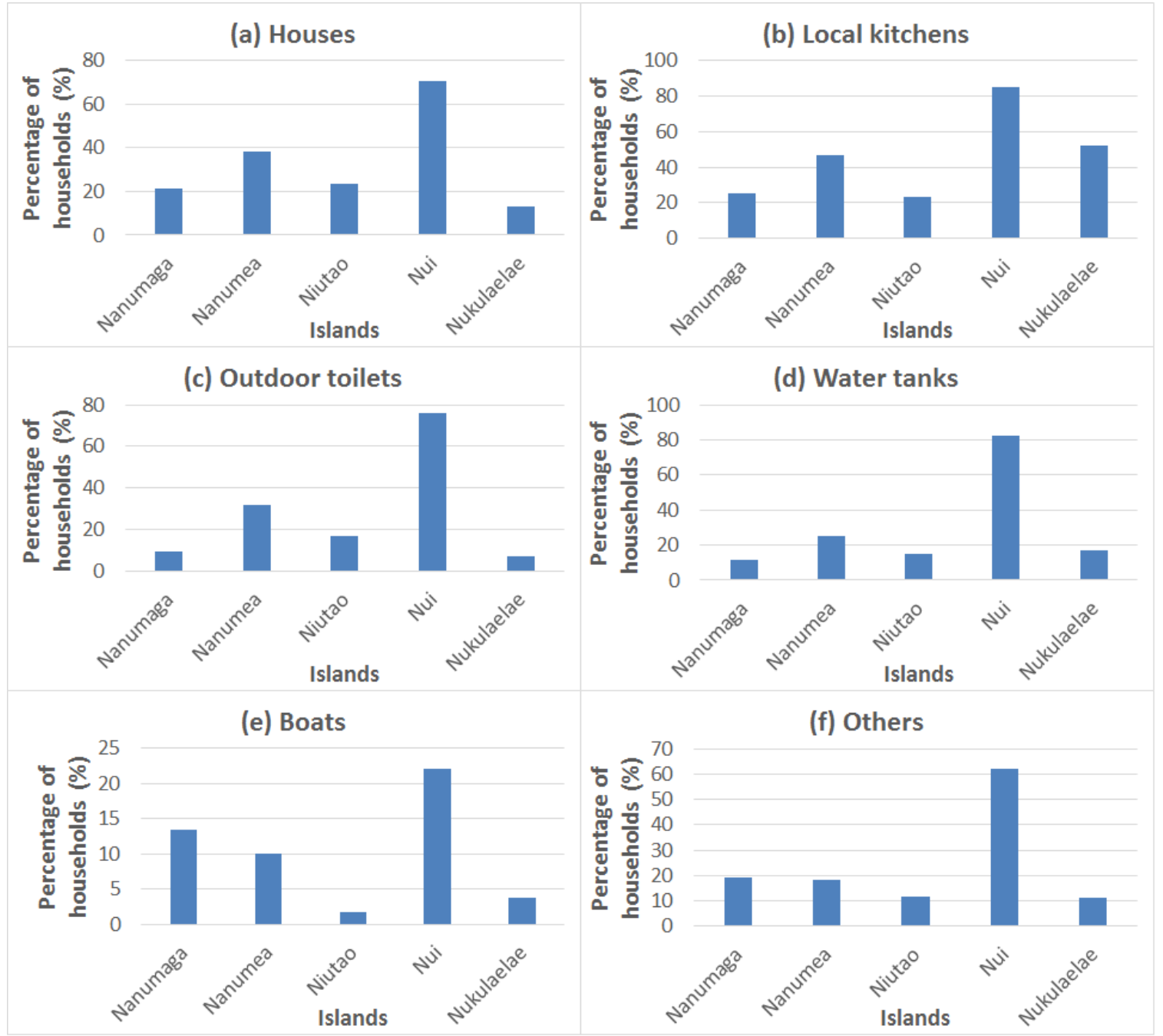

Source: Author's calculations from the Pam survey. Note that $\mathrm{N}=321$.

Figure 3.6: Damages incurred by households 


\subsection{ANALYSIS OF SURVEY RESPONSES}

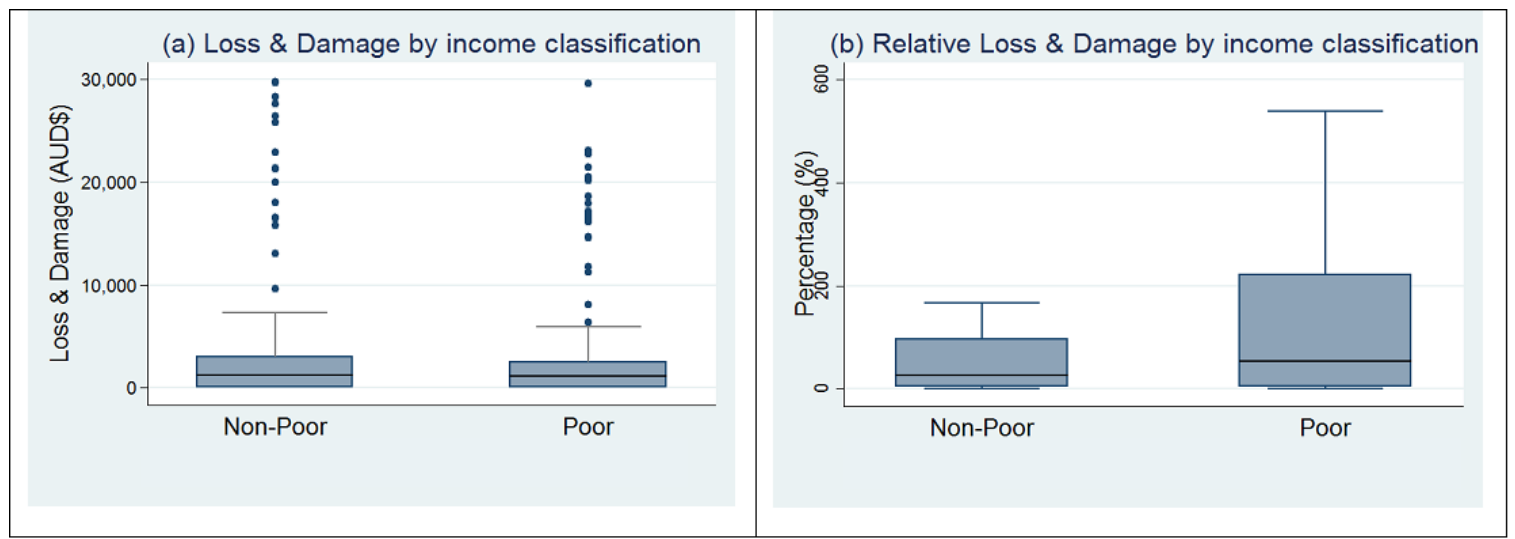

Source: Author's calculations from the Pam survey. Note that $\mathrm{N}($ Poor $)=164$ and $\mathrm{N}($ Non-Poor $)=157$. For (b), it displays box plots without outside whiskers.

Figure 3.7: Income, expenditure, loss and damage by income classification

only captures the strength and magnitude of the storm surge as it reaches the vicinity of each island. ${ }^{19}$ On average, the distance of the cyclone path from the households in our survey sample is about $1,000 \mathrm{~km} .{ }^{20}$

\subsubsection{Exposure}

Peoples exposure to storm surge and coastal flooding risk is determined by their location. Most of the affected households, indeed most households on atoll islands, reside in areas prone to storm surges. Given the small size of all the islands, the whole population of Tuvalu resides no more than one kilometer away from the sea. In almost all the islands of Tuvalu, populated areas are on the western side - the direction from which the storm surge came. ${ }^{21}$ In general, that meant that in most islands (except for, importantly, the capital Funafuti), the population was very exposed.

\footnotetext{
${ }^{19}$ Given the small size of these islands, the only significant variability in terms of distance from the storm is across islands rather than across households within an island.

${ }^{20}$ This reliance on distance as a unique indicator of hazard strength is only relevant within the unique context of a distant cyclone hitting an atoll island. A more nuanced hazard model, that also includes wind speed, rainfall, and the topography of the affected area will be required in other instances.

${ }^{21}$ The prevailing winds are easterlies. In islands without lagoons, populations tend to concentrate on the western side of the island (away from the wind), while on islands with lagoons, populations tend to reside on the lagoon side.
} 


\section{CHAPTER 3. AT THE VERY EDGE OF A STORM: THE IMPACT OF A DISTANT CYCLONE ON ATOLL ISLANDS}

The total population of Tuvalu grew steadily from 9,026 in 1991 to 10,782 in 2012. The percentage of the population living on the capital island, Funafuti, was also increasing from $32.6 \%$ in 1991 to $57 \%$ in $2012 .{ }^{22}$ We produced GIS maps linked to the household surveys and measured exposure using household distance to the coastline and household elevation (lower elevation areas are more prone to flooding associated with storm surges).

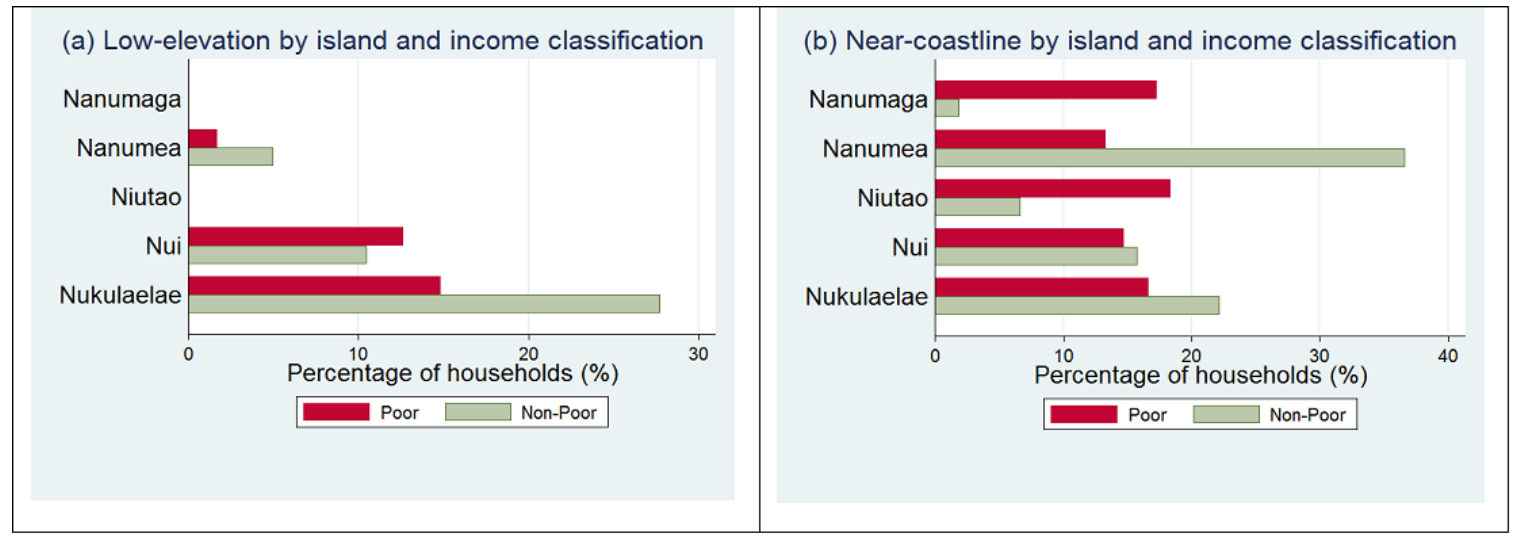

Source: Author's calculations from the Pam survey. Note that N(Poor)=164 and $\mathrm{N}($ Non-Poor $)=157$.

Figure 3.8: Household exposure

Figure 3.8 provides some statistics about the households' exposure. Households that live in houses that are less than 5 meters above the low water line are described in panel (a), while households whose residence is less than 100 meters from the coast are described in panel (b). We further distinguished between the poor and non-poor households using the definition of poverty described earlier. It is obvious to observe that the residents of Nui and Nukulaelae are the most exposed, with some additional significant exposure in Nanumea.

Many of our surveyed households reported surges from TC Pam entering their homes. On Nui, 98\% of households reported that surges from the TC Pam entered their homes. Similarly, Nanumaga, Nanumea, Niutao, and Nukulaelae reported 15\%, $60 \%, 32 \%$ and $66 \%$, respectively - again, this clearly corresponds with the exposure data described in Figure 3.8 that identified Nanumea, Nui, and Nukulaelae as the most exposed.

\footnotetext{
${ }^{22}$ Information calculated from the 1991 and 2012 Censuses.
} 


\subsubsection{Vulnerability}

Household characteristics such as income, household size and the structural strength of the house they reside in were used as indicators representing the vulnerability of households. Household income distribution in Tuvalu's outer-islands shows substantial income inequalities with $20 \%$ of the households earning less than AUD50 per month. Around $50 \%$ of the population earns below AUD150 per month, whereas the top $10 \%$ earn more than AUD475 per month. The annual per capita income is USD $414 .^{23}$ This poverty in the outer-islands also corresponds with almost $40 \%$ of the population living in non-concrete houses.

Although people in the outer-islands are less dependent on cash because they have access to natural resources to support their daily food consumption, money is increasingly being used in purchasing imported basic food items as substitutes for subsistence consumption. Practically, people in the outer-islands often receive remittances from their families working in Funafuti and overseas to pay for basic food items, electricity, and community and church contributions. The government also indirectly subsidizes electricity and shipping charges for the outer-islands by charging for these services below costs. In turn, families, communities and churches serve as safety nets in times of hardship. These support mechanisms are one reason there are few families displaying abject poverty.

\subsubsection{Responsiveness and Poverty}

The importance of early warning as a priority for disaster risk reduction is well recognized (e.g., Hallegatte (2013)). In anticipation of the cyclone, 51\% of households moved to safe shelters, and $42 \%$ shielded or covered windows. As expected, food and water were the most stocked-up items just before the cyclone. Surprisingly, strengthening the building they live in was only undertaken by a minority of the respondents (Figure 3.9). This failure to undertake significant strengthening can be explained by the timing of the early warning that was provided. Very few households

\footnotetext{
${ }^{23}$ The conversion rate of 1 USD Dollar (US Dollar) $=1.33$ AUD Dollar (Australian Dollar) was used throughout.
} 


\section{CHAPTER 3. AT THE VERY EDGE OF A STORM: THE IMPACT OF A DISTANT CYCLONE ON ATOLL ISLANDS}

received warning 48 hours ahead of the cyclone - a lag that would have enabled more preparation and strengthening. Still warning was sufficient so that $45 \%$ of households shifted their assets and valuables in anticipation of the cyclone (24\% shifted their assets to other houses and $21 \%$ elevated them within their own houses).

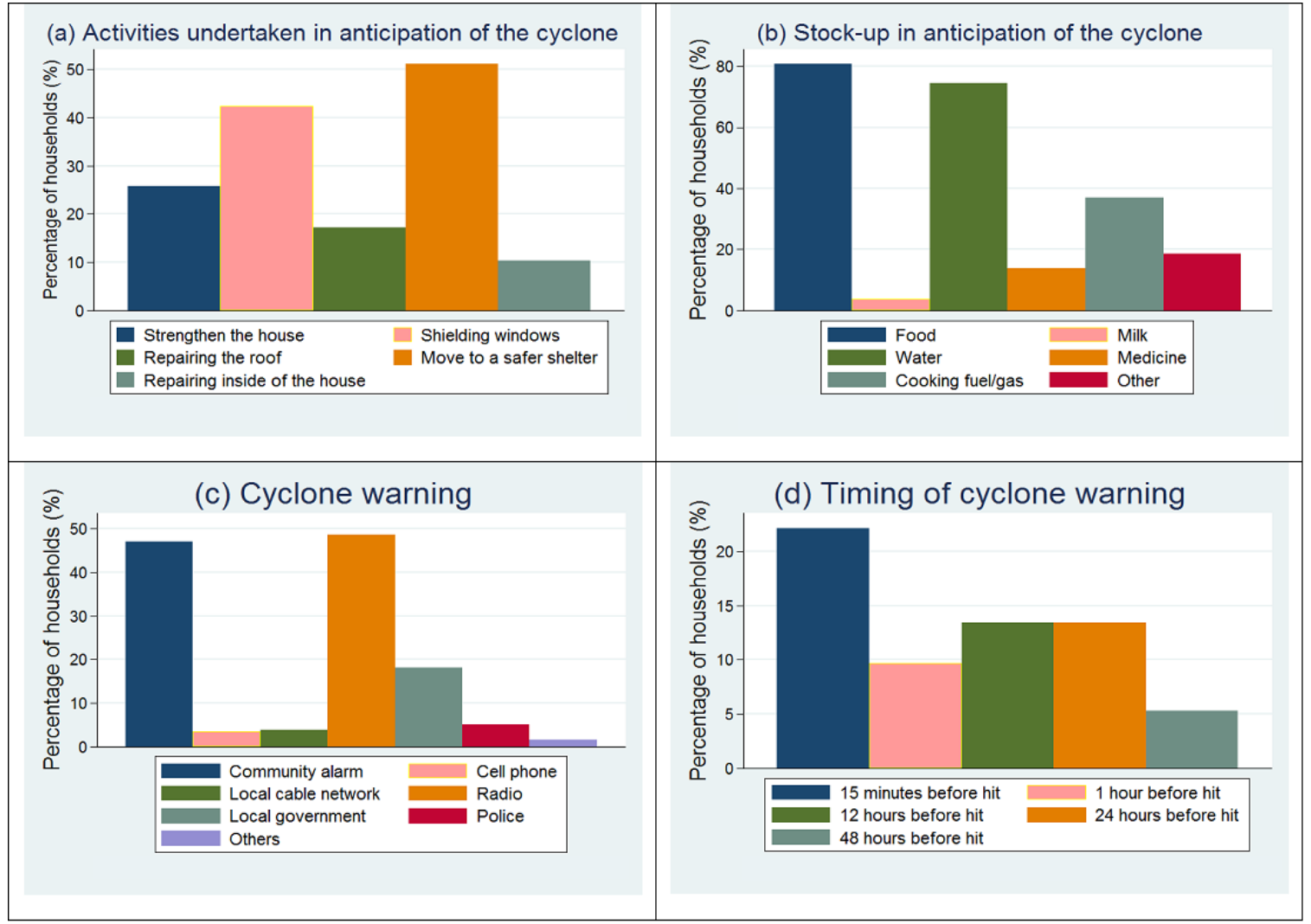

Source: Author's calculations from the Pam survey. Note that N=321.

Figure 3.9: Responding to the cyclone

The majority of people received cyclone warnings from the radio broadcast and island community alarms, but 39\% did not receive any warnings of the cyclone. Fifteen percent of households were not aware of any safe shelters that were available for them during the cyclone. The average time a household had to travel to reach a safe shelter is 13 minutes, but $57 \%$ of households never did shift to these shelters. Around $26 \%$ received some cyclone response training.

Incomes of these poor households are far less than what is needed to cover losses incurred. Only $10 \%$ of households have reported saving some money in the National 


\subsection{ANALYSIS OF SURVEY RESPONSES}

Table 3.2: Risk, vulnerability and resilience indicators

\begin{tabular}{llcc}
\hline \hline \multirow{2}{*}{ Risk } & \multicolumn{1}{c}{ Indicators } & Poor & Non-poor \\
& Loss (mean) & 680 & 942 \\
& Damage (mean) & 2,518 & 2,680 \\
& Loss and Damage (mean) & 3,186 & 3,612 \\
& Loss and Damage over income (mean) & 93 & 15 \\
\hline Vulnerability & Monthly income (mean) & 97 & 436 \\
& Households (\%) & 51.09 & 48.91 \\
& Number of persons in the household (mean) & 5 & 4 \\
& Number of dependents i.e children and elderly (mean) & 3 & 3 \\
& Household lived in concrete and wood house (\%) & 85 & 81 \\
& Distance from the cyclone shelter in minutes (mean) & 14 & 12 \\
\hline Exposure & Households within 100 meters distance from the coast (\%) & 31 & 34 \\
& Residing in low elevation (\%) & 13 & 18 \\
\hline Hazard & Distant from the cyclone path in kilometers (mean) & 973.49 & 973.57 \\
\hline Respond & Strengthen house in preparation for the cyclone (\%) & 55 & 45 \\
ability & Shift valuable assets to safe place (\%) & 47 & 43 \\
& Households attended cyclone respond workshops (\%) & 74 & 75 \\
& Households received a cyclone warning (\%) & 63 & 60 \\
& Percentage of income usually saved (\%) & 2.85 & 2.90 \\
& Household evacuated to the cyclone shelter (\%) & 44.5 & 41.1 \\
& Social safety net (\%) & 29.9 & 22.9 \\
& Access to credit (\%) & 32.9 & 33.1 \\
& Households received some form of assistance (\%) & 94.5 & 100.0 \\
\hline \hline Relocation & Prefer to relocate to a safer place (\%) & 44 & 37 \\
\hline \hline
\end{tabular}

Source: Author's calculations from the Pam survey.

Bank of Tuvalu (NBT). ${ }^{24}$ The average amount saved is about $2 \%$ of monthly income. On average, non-poor incurred more actual damages (in dollar value) than the poor by a small margin. However, poor households suffered six times more than non-poor households relative to income. If households were to use all their income to rebuild back the damages, it would take up to at least 15 months for a non-poor household to rebuild the damages and recover back to normal, while a poor household would take at least 93 months (see Table 3.2).

\footnotetext{
${ }^{24}$ In the 2012 Census, $80 \%$ of households reported having access to NBT, the only bank operating in Tuvalu.
} 


\section{CHAPTER 3. AT THE VERY EDGE OF A STORM: THE IMPACT OF A} DISTANT CYCLONE ON ATOLL ISLANDS

\subsection{Estimation Results}

Table 3.3 presents the estimation results of our econometric model explaining the log of loss and damage per household (the measures collected from the survey, as described in section 4). The benchmark regressions (Equation 3.1) are estimated for the full survey sample (305 households) and separately for poor and non-poor households as previously defined (columns 1-3). F-tests indicate overall statistical significance of the model, and the $R^{2}$ values indicate the overall goodness of fit of the model (0.28-0.33) suggesting about a third of the variability of the household damage and loss is correlated with the vulnerability, exposure, and responsiveness indicators we measured for each household.

For the vulnerability indicators, we find that income per capita is negatively associated with loss and damage in poor households (column 2) - i.e., the lower the income, the higher the losses. In richer households the association is positive (richer households have more assets of higher value that can be damaged and more crops and land because of which they can experience higher income loss). It is only for the poor households that the association is statistically significant (as the coefficient is much larger). In relation to the magnitudes of the coefficients, for example; the impact of increase in income per person by 1 percent would decrease loss and damages by 54 percent for the poor households; while rich households would experience an increase of 21 percent for loss and damages if we increase income per capita by 1 percent. For these poorer households, additional income is probably translated into improved ability to mitigate damages, resulting in this negative association. This $U$ shaped association between loss and damage (on the y-axis) and income (on the x-axis) has not been reported in the literature before, as far as we are aware. ${ }^{25}$ There is no clear association between household size and the dependent variable (loss and damage).

\footnotetext{
${ }^{25}$ Even though it is not statistically significant for non-poor households, the coefficient is considerably large, therefore it is a matter of focus and how we interpret the results. For example, when identifying loss and damages due to disasters, should we also consider a coefficient that is large but statistically insignificant as we often do to a coefficient that is statistically significant but small in size. In any case, it would be great to further examine this rare finding, as it may be valid for certain countries with unique economic and geographical characteristics, particularly SIDS (in this case, Tuvalu). However, it might be worth noting as well that aside from the explanations already given, there is also the possible explanation that the relationship does not exist - after all, it is only statistically significant for poor households.
} 
Unsurprisingly, those households that have a cement house experience lower damages; though this association is statistically not very robust.

In terms of exposure, the closer the households are to the coast, and the lower their elevation, the higher the damage and loss these households experience, holding everything else constant. The total distance measuring the width of the island at the household's location (another proxy of possible exposure) is also statistically significant and positive (for the overall sample; though the coefficients estimated in the sub-samples are of similar magnitude). From the estimated coefficients, we can calculate some counterfactuals. For example, the impact of an increase in distance to the coast by $1 \mathrm{~km}$ would decrease damage by 0.5 percent; increasing of elevation of the household by 1 meter would decrease loss and damage by 13 percent; an increase in total distance (land width) by $1 \mathrm{~km}$ would decrease loss and damage by 0.04 percent; and an increase in distance to the cyclone path by $1 \mathrm{~km}$ would decrease loss and damage by 0.5 percent. The size of this coefficient, the impact of total distance is an order of magnitude lower than the one measuring the distance to the nearest coast. These are all signed as expected, but are empirically important as projected sea-level rise will inevitably make houses in Tuvalu more exposed to these distant cyclones as the islands are reduced in size and the elevation above sea level is reduced. We investigate this further in the next section. However, we are careful in not suggesting a causal relationship.

We also observe that the closer the households were to the cyclone's path, the higher the stated losses and damages were. Interestingly, the 'decay' in the level of damage as the distance from the cyclone increases is not very large. For every additional kilometer of distance the decrease in loss and damage because of cyclone Pam is $0.5 \%$. This is an important point. It suggests that our assessment of risk for Atoll Islands should take into account also the very distant cyclones (such as Pam) that are currently not assessed as potentially destructive in most risk models - e.g., in the Pacific Catastrophe Risk Assessment and Financing Initiative (PCRAFI) model. A cyclone that passes 1,000 km away from a location, as was the case for Pam for Tuvalu, is not typically modelled as causing any damage. ${ }^{26}$

\footnotetext{
${ }^{26}$ This observation is based on conversations with AirWorldwide, the modeler for the PCRAFI program. We suspect this is the case for other natural hazard risk modelers such as Risk Management Solutions (RMS).
} 
CHAPTER 3. AT THE VERY EDGE OF A STORM: THE IMPACT OF A DISTANT CYCLONE ON ATOLL ISLANDS

In terms of the ability to respond to an oncoming cyclone, we find that households that received early warning (at least 12 hours in advance) did indeed manage to reduce their damage and loss. ${ }^{27}$ Interestingly, the efficacy of early warning was higher for poor households in reducing loss and damage; though the differences between the two subsamples are not statistically significant. Cyclone response training and ex ante house strengthening both appear to reduce loss and damage but these impacts are largely driven by their efficacy for richer households. One can speculate why that might be the case - maybe this is related to the elevated ability of non-poor households to affectively act upon the information they receive - but we have no direct evidence to demonstrate that this indeed might be the reason for these observed differences.

We investigate the efficacy of several additional control variables in Table 3.3, columns (4) to (7). The only variable for which we find a consistent, statistically significant finding, is the binary indicator measuring whether a household shifted assets to a safe place. Other variables for which data were collected were not statistically associated with the loss and damage in any materially consistent way.

\subsection{Hypothetical Scenarios of DRR Policies}

The results from Table 3.3 allow us to identify the empirically observed relationship between vulnerability, exposure, and hazard intensity and the actual loss and damage from a distant cyclone, as experienced by households living on low-lying atoll islands. These results also allow us to construct hypothetical scenarios in which vulnerability and exposure are changed (via policy choices) and estimate the likely consequence these changes may have on cyclone loss and damage. These estimates are presented in Table 3.4 and Table 3.5.

Table 3.4 presents the observed loss and damage totals, as calculated from the survey responses. The first column represents the totals obtained directly from the survey responses. The second column calculates what would have been the total loss and damage experienced by the whole population of the outer islands, as the survey

\footnotetext{
${ }^{27}$ Though we cannot rule out the possibility that the availability of early warning is somehow endogenously determined.
} 
Table 3.3: Model estimation results explaining the log of losses and damages

\begin{tabular}{|c|c|c|c|c|c|c|c|}
\hline & $\begin{array}{l}\text { All } \\
(1)\end{array}$ & $\begin{array}{c}\text { Poor } \\
(2)\end{array}$ & $\begin{array}{c}\text { Non-poor } \\
(3)\end{array}$ & $\begin{array}{l}\text { All } \\
(4) \\
\end{array}$ & $\begin{array}{l}\text { All } \\
(5)\end{array}$ & $\begin{array}{l}\text { All } \\
(6)\end{array}$ & $\begin{array}{l}\text { All } \\
(7)\end{array}$ \\
\hline lincrcap & $\begin{array}{l}-0.0467 \\
(0.113)\end{array}$ & $\begin{array}{c}-0.537^{* *} \\
(0.271)\end{array}$ & $\begin{array}{c}0.212 \\
(0.223)\end{array}$ & $\begin{array}{c}-0.0180 \\
(0.110)\end{array}$ & $\begin{array}{l}-0.0554 \\
(0.112)\end{array}$ & $\begin{array}{c}-0.0654 \\
(0.115)\end{array}$ & $\begin{array}{l}-0.0348 \\
(0.112)\end{array}$ \\
\hline hholdsize & $\begin{array}{c}0.0680 \\
(0.0445)\end{array}$ & $\begin{array}{c}0.0521 \\
(0.0644)\end{array}$ & $\begin{array}{c}0.0702 \\
(0.0628)\end{array}$ & $\begin{array}{c}0.0475 \\
(0.0433)\end{array}$ & $\begin{array}{c}0.0595 \\
(0.0441)\end{array}$ & $\begin{array}{c}0.0683 \\
(0.0445)\end{array}$ & $\begin{array}{c}0.0479 \\
(0.0434)\end{array}$ \\
\hline strhouse & $\begin{array}{c}-0.514^{*} \\
(0.290)\end{array}$ & $\begin{array}{l}-0.519 \\
(0.436)\end{array}$ & $\begin{array}{l}-0.440 \\
(0.391)\end{array}$ & $\begin{array}{l}-0.226 \\
(0.288)\end{array}$ & $\begin{array}{l}-0.470 \\
(0.287)\end{array}$ & $\begin{array}{c}-0.524^{*} \\
(0.290)\end{array}$ & $\begin{array}{l}-0.242 \\
(0.290)\end{array}$ \\
\hline coastdist & $\begin{array}{c}-0.00565^{* * *} \\
(0.00103)\end{array}$ & $\begin{array}{c}-0.00349^{* *} \\
(0.00150)\end{array}$ & $\begin{array}{c}-0.00800^{* * *} \\
(0.00147)\end{array}$ & $\begin{array}{c}-0.00479 * * * \\
(0.00102)\end{array}$ & $\begin{array}{c}-0.00549^{* * * *} \\
(0.00103)\end{array}$ & $\begin{array}{c}-0.00568 * * * \\
(0.00104)\end{array}$ & $\begin{array}{c}-0.00484^{* * *} \\
(0.00102)\end{array}$ \\
\hline elevat & $\begin{array}{c}-0.128^{* * *} \\
(0.0352)\end{array}$ & $\begin{array}{c}-0.185^{* * *} \\
(0.0485)\end{array}$ & $\begin{array}{l}-0.0746 \\
(0.0526)\end{array}$ & $\begin{array}{c}-0.146^{* * *} \\
(0.0343)\end{array}$ & $\begin{array}{c}-0.133^{* * *} \\
(0.0348)\end{array}$ & $\begin{array}{c}-0.124^{* * *} \\
(0.0354)\end{array}$ & $\begin{array}{c}-0.143^{* * *} \\
(0.0347)\end{array}$ \\
\hline totdist & $\begin{array}{c}0.000409 * * * \\
(0.000156)\end{array}$ & $\begin{array}{c}0.000348 \\
(0.000219)\end{array}$ & $\begin{array}{l}0.000417^{*} \\
(0.000228)\end{array}$ & $\begin{array}{c}0.000422^{* * * *} \\
(0.000151)\end{array}$ & $\begin{array}{c}0.000369^{* *} \\
(0.000155)\end{array}$ & $\begin{array}{c}0.000408^{* * *} \\
(0.000156)\end{array}$ & $\begin{array}{c}0.000417^{* * *} \\
(0.000153)\end{array}$ \\
\hline cycpdist & $\begin{array}{c}-0.00506^{* * *} \\
(0.00190)\end{array}$ & $\begin{array}{l}-0.00286 \\
(0.00268)\end{array}$ & $\begin{array}{c}-0.00540^{*} \\
(0.00282)\end{array}$ & $\begin{array}{c}-0.00554^{* * *} \\
(0.00184)\end{array}$ & $\begin{array}{c}-0.00553^{* * *} \\
(0.00188)\end{array}$ & $\begin{array}{c}-0.00495^{* * *} \\
(0.00190)\end{array}$ & $\begin{array}{c}-0.00548^{* * *} \\
(0.00185)\end{array}$ \\
\hline strhou & $\begin{array}{c}-0.478^{* *} \\
(0.235)\end{array}$ & $\begin{array}{l}-0.0535 \\
(0.366)\end{array}$ & $\begin{array}{c}-0.802^{* *} \\
(0.317)\end{array}$ & $\begin{array}{l}-0.415^{*} \\
(0.228)\end{array}$ & $\begin{array}{l}-0.377 \\
(0.236)\end{array}$ & $\begin{array}{c}-0.498^{* *} \\
(0.236)\end{array}$ & $\begin{array}{c}-0.423^{*} \\
(0.232)\end{array}$ \\
\hline capacity & $\begin{array}{c}-0.623^{* *} \\
(0.269)\end{array}$ & $\begin{array}{l}-0.390 \\
(0.376)\end{array}$ & $\begin{array}{l}-0.691^{*} \\
(0.404)\end{array}$ & $\begin{array}{c}-0.630 * * \\
(0.260)\end{array}$ & $\begin{array}{c}-0.652^{* *} \\
(0.266)\end{array}$ & $\begin{array}{c}-0.646^{* *} \\
(0.270)\end{array}$ & $\begin{array}{c}-0.650^{* *} \\
(0.262)\end{array}$ \\
\hline warn & $\begin{array}{c}-0.962^{* * *} \\
(0.254)\end{array}$ & $\begin{array}{c}-1.094^{* * *} \\
(0.363)\end{array}$ & $\begin{array}{c}-0.818^{* *} \\
(0.381)\end{array}$ & $\begin{array}{c}-0.913^{* * *} \\
(0.246)\end{array}$ & $\begin{array}{c}-0.916^{* * *} \\
(0.251)\end{array}$ & $\begin{array}{c}-0.941^{* * *} \\
(0.254)\end{array}$ & $\begin{array}{c}-0.894^{* * *} \\
(0.247)\end{array}$ \\
\hline ashift & & & & $\begin{array}{c}0.994^{* * * *} \\
(0.218)\end{array}$ & & & $\begin{array}{c}0.948^{* * *} \\
(0.272)\end{array}$ \\
\hline elev & & & & & $\begin{array}{c}0.723^{* * * *} \\
(0.263)\end{array}$ & & $\begin{array}{l}0.0724 \\
(0.321)\end{array}$ \\
\hline shel & & & & & & $\begin{array}{l}-0.326 \\
(0.318)\end{array}$ & $\begin{array}{l}-0.254 \\
(0.310)\end{array}$ \\
\hline _cons & $\begin{array}{c}14.23^{* * *} \\
(2.018)\end{array}$ & $\begin{array}{c}13.49^{* * *} \\
(2.760)\end{array}$ & $\begin{array}{c}13.44^{* * *} \\
(3.206)\end{array}$ & $\begin{array}{c}13.97^{* * *} \\
(1.954)\end{array}$ & $\begin{array}{c}14.61^{* * *} \\
(2.001)\end{array}$ & $\begin{array}{c}14.47^{* * * *} \\
(2.031)\end{array}$ & $\begin{array}{c}14.21^{* * *} \\
(1.985)\end{array}$ \\
\hline$N$ & 305 & 148 & 157 & 305 & 305 & 305 & 305 \\
\hline$R^{2}$ & 0.264 & 0.313 & 0.280 & 0.313 & 0.283 & 0.267 & 0.315 \\
\hline
\end{tabular}

Standard errors in parentheses

$* p<0.10,{ }^{* *} p<0.05,{ }^{* * *} p<0.01$

Source: Author's estimations from the Pam survey. 
CHAPTER 3. AT THE VERY EDGE OF A STORM: THE IMPACT OF A DISTANT CYCLONE ON ATOLL ISLANDS

Table 3.4: Hypothetical scenarios

\begin{tabular}{ccccc}
\hline & & \multicolumn{3}{c}{ Total Loss and Damage (AUD\$) } \\
\hline & & \multicolumn{3}{c}{ Outer } \\
& & Survey & Islands & National \\
& & Responses & Total & Total \\
\hline (i) & All household & $1,093,440$ & $1,796,497$ & $6,042,874$ \\
(ii) & Poor households only & 524,600 & 887,814 & $2,899,191$ \\
\hline \hline
\end{tabular}

Note: Author's calculations from survey and census data.

only reached a sample of the households living on these islands. The third column in the top panel calculates what would have been the damage and losses had the storm affected the whole population of Tuvalu, including the capital Funafuti (where about half the population of the country resides).

These calculations indicate that the total household damage and loss in Tuvalu as a consequence of cyclone Pam was about AUD 1.8 million. ${ }^{28}$ Of that amount, about a half (AUD 0.9 million) was lost to poor households (see the second row in Table 3.4). Had the cyclone hit Funafuti as well (which would have been the case if the wave surges had come from the East rather than the West), the total loss and damage would have been an estimated AUD 6 million (14\% of GDP).

The estimates we obtained in the previous section enable us to predict loss and damages that correspond with the minimum, mean and maximum scenarios for selected explanatory variables. Equation 3.1 was employed to estimate these predicted values using the estimated coefficients from Table 3.3 and the actual observed values of all variables except for the hypothetical scenario being examined. As we already observed, there are variations in cyclone impacts across households and islands and this allows us to contemplate the likely impacts had these households exposure and vulnerability been different. Although these hypothetical scenarios are not entirely credible and present extreme-case scenarios, we purposely seek to understand the differential impacts imposed by various levels of vulnerability, exposure and hazard for the islands of Tuvalu.

Table 3.5 presents the total predicted values of these hypothetical scenarios across

\footnotetext{
${ }^{28}$ The World Bank (2015a) estimated Tuvalu's GDP at AUD 41.7 million, so that total loss and damage to households was about $4.6 \%$ of GDP.
} 
Table 3.5: Hypothetical scenarios

\begin{tabular}{clc}
\hline & \multicolumn{1}{c}{ Scenario } & $\begin{array}{c}\text { Loss and Damage as \% of } \\
\text { Loss of Poor Households (ii) }\end{array}$ \\
\hline 1 & Adjusted vulnerability, minimum income pc (poor households only) & 139.7 \\
2 & Adjusted vulnerability, mean income pc (poor households only) & 69.4 \\
3 & Adjusted vulnerability maximum income pc (poor households only) & 19.9 \\
\hline & & Loss and Damage as \% of \\
& Loss of All Households (i) \\
\hline 4 & Adjusted vulnerability, all wooden houses & 143.1 \\
5 & Adjusted vulnerability, all cement houses & 91.7 \\
6 & Adjusted exposure, minimum distance to the coast & 150.1 \\
7 & Adjusted exposure, mean distance to the coast & 82.1 \\
8 & Adjusted exposure, maximum distance to the coast & 4.0 \\
9 & Adjusted exposure, minimum elevation & 192.5 \\
10 & Adjusted exposure, mean elevation & 87.3 \\
11 & Adjusted exposure, maximum elevation & 36.9 \\
12 & Adjusted exposure, minimum land width & 142.7 \\
13 & Adjusted exposure, mean land width & 106.7 \\
14 & Adjusted exposure, maximum land width & 48.1 \\
15 & Adjusted hazard, minimum distance to the cyclone path & 126.1 \\
16 & Adjusted hazard, mean distance to the cyclone path & 92.0 \\
17 & Adjusted hazard, maximum distance to the cyclone path & 27.9 \\
18 & Adjusted responsiveness, no one strengthened their houses & 140.1 \\
19 & Adjusted responsiveness, all strengthened their houses & 92.3 \\
20 & Adjusted responsiveness, no one received cyclone response training & 146.1 \\
21 & Adjusted responsiveness, all received cyclone response training & 83.7 \\
22 & Adjusted responsiveness, no one received an early warning & 119.1 \\
23 & Adjusted responsiveness, all received an early warning & 22.9 \\
\hline \hline
\end{tabular}

Note: Author's calculations from survey data and estimation results (table 3 columns 1-2).

households. In scenarios 1-3, we examine only households classified as poor, while scenarios 4-23 examine the whole affected population of the outer islands (while still maintaining the assumption that Funafuti is unaffected).

In Scenario 1, we set the income per capita to its lowest recorded value across households. Similarly, we assigned observed values of the mean income per capita and maximum income per capita for Scenario 2 and Scenario 3, respectively. As expected, the higher income per capita is associated with lower loss and damages. Note that for these scenarios we used the sample of poor households. Likewise, Scenarios 6-14 show adjusted exposure using the distance to the coast and elevation with different cases, assigning different observed values of minimum, mean and maximum across all households. Scenarios 15-17 change the parameters of the hazard, while scenarios 18-23 investigate what happens when different preparation for the cyclone is instituted. 
CHAPTER 3. AT THE VERY EDGE OF A STORM: THE IMPACT OF A DISTANT CYCLONE ON ATOLL ISLANDS

For poor households, we observe that had all of them had the income of the lowest per capita income, the damage associated with the cyclone would have been almost $40 \%$ higher (scenario 1). In contrast, had they all had the highest income in the full sample, the damages would have been $80 \%$ lower (scenario 3). For the full sample, had all houses been constructed of cement (instead of wood), the damage would have been only about $8 \%$ lower - though it is important to note that most houses are already made of cement.

The extreme exposure of Tuvaluan households is demonstrated starkly when we examine Scenarios 6-14. If all Tuvaluan households were living at minimum distance to the coast (rather than a few additional dozen meters inland), the damage wrought by a Pam-like cyclone would have been $50 \%$ higher (scenario 6). Equally, if all were living at the minimum elevation, damage would have been almost twice as high (scenario 9). As, ultimately, both of these things will happen as a result of predicted sea-level rise, it is easy to see how significant is future cyclone risk for atoll islands even if the frequency and intensity of cyclones will not change.

The distance to the cyclone path is also of specific concern. In this case, we note that a cyclone that was a little bit closer (and still $900 \mathrm{~km}$ away) would have increased the damage and loss associated with the cyclone by $26 \%$ (scenario 15 ). In terms of the possibilities of generating better preparation and response to the cyclone, the data is suggestive of some potentially beneficial interventions. In particular, strengthening all houses before the cyclone would have reduced the damage by $8 \%$, while having everyone (a representative from each household) attend a cyclone response training would have reduced damage by $17 \%$ - scenarios 19 and 21, respectively. Most striking is the apparent efficacy of supplying a better early warning system (scenario 22-23). In this case, if all were to receive an effective early warning notice (at least 12 hours before the cyclone surge), the impacts would have been lower by $77 \%$. This finding, while a specific quantitative result of benefit, is in line with other research that identifies early warning system as by far the best cost effective way of reducing disaster (and specifically cyclone) mortality.

We present some of these hypothetical scenarios for a specific island, Nui, in Figure 3.A.1. Here we map the specific changes to the different areas of the island as if some of these hypothetical changes were implemented. Potentially, one can 
present similar results for each of the 23 scenarios we evaluated at the national level. To further demonstrate the impact of the cyclone in a more dis-aggregated level, Figure 3.B.1 presents the mapping of damage and loss for each of the other four affected islands (other than Nui). In order to preserve the anonymity of respondents, we do this at the village level.

\subsection{Conclusions and Policy}

The study of cyclone risk for small low-lying islands is important as the intensity of cyclones in the Pacific is predicted to increase and sea levels are predicted to rise. In many ways, a small island developing state like Tuvalu can serve as the "canary in the coal mine' pointing to the emerging risks that are being generated as we increasingly experience the impacts of climatic change. In Tuvalu, 70 percent of households live less than 200 meters from the coastline and with an elevation of no more than 5 meters above sea-level. Households are thus acutely vulnerable to storm surges caused by cyclones even if the cyclone itself passes very far away. In order to investigate the impacts of cyclones on low-lying atoll islands, we conducted a survey in Tuvalu after the islands incurred severe damage from storm surges generated by Tropical Cyclone Pam (March, 2015).

We first observed that poor households suffered far more losses and damages relative to their income than the non-poor. This inequity has previously been reported in urban areas in developing countries as poor households are more likely to live in floodplains or on steep hillsides. Yet, it is less expected on a Pacific Island where locational decisions of households are mostly dictated by generations-old land tenure rather than through market mechanisms that force low-income households to locate in riskier areas. Having summarized the aggregate impact of the cyclone storm surge on households, we then examined the role of the hazard, exposure to it, and vulnerability to cyclones in shaping these losses.

Lastly, we constructed hypothetical scenarios in which the exposure and vulnerability of households is assumed to change, and calculated the estimated loss and damage they would have experienced. We find large variations in loss and 
CHAPTER 3. AT THE VERY EDGE OF A STORM: THE IMPACT OF A DISTANT CYCLONE ON ATOLL ISLANDS

damage that is associated with both exposure and vulnerability, and quantify these changes against the various scenarios we assessed. These hypothetical calculations can now serve as the main input into careful assessments of the feasibility and desirability of distinct disaster risk reduction (DRR) policies. Importantly, the need for careful assessment of DRR policies was central in the discussions leading up to the international Sendai Agreement on Disaster Risk Reduction that was signed by almost 200 countries at the same time that cyclone Pam was hitting Tuvalu.

Apart from the household exposure to cyclones, many other assets, activities and services were adversely affected by the cyclone, too. Offices and commercial structures, medical clinics, transportation and communication infrastructure, retail shops, educational institutions, public utilities and social amenities were all damaged by Pam. Furthermore, there were disruptions to services and amenities; households reported problems like disruption of power, water, transportation, fuel and other supplies, and working and school days that were lost. These problems are associated with indirect losses which are difficult to measure in monetary terms and were not accounted for here.

Similarly, TC Pam may have adversely affected the health of residents in the outer islands. These are also difficult to quantify. It is likely that the overall damage and loss, as experienced not only by households but also include the impact on the government, is more than twice as large as what was experienced by households (which is what we measured in this chapter).

It is important to remember that the most heavily populated island, and the one that includes much of the infrastructure including the international deep-sea port, the airport, and most government facilities, was not damaged at all. Had the storm blew from the East, rather than the West, the impact on Funafuti could have been very different. If Funafuti was as exposed to this cyclone as the outer islands, the damage and loss associated with the cyclone would have been about three times higher, even though Funafuti only contains about half of the population of the country.

Households in Tuvalu have no insurance available for them, nor any other way of transferring risk. As such, the only policy levers that are available for them is to mitigate damages through changing their levels of exposure and vulnerability. In the 
absence of insurance and formal social safety nets, the cost of repairs and replacements have to be borne by families regardless of their income, and that places an immense burden on poor households. Under these circumstances, it is not surprising that the government of Tuvalu has been contemplating providing assistance to impacted households by paying for some of the rebuilding costs associated with the impact of TC Pam. This places a significant burden on a government that has a very limited ability to collect additional tax revenue or borrow. Thus, questions about the desirability of government assistance post Pam also are connected to other questions about the government's fiscal position and the sustainability of its spending. In this context, it seems advisable for policy makers to consider alternative options to provide ex-post assistance to affected households and at the same time protect the government's fiscal stance. One possibility would be to explore ways to establish implicit or explicit saving accounts (sovereign funds), contingent credit lines or insurance contracts that can provide this buffer for disaster recovery needs and paid for through the Warsaw International Mechanism for Loss and Damage (Mechler and Schinko, 2016).

The threats of climate change, sea-level rise and climatic disasters may require relocation to safer places for households residing very close to the coast, in narrow parts of the island and low-lying areas. A limitation in the survey is that we did not include in the survey one of the factors influencing migration such as access to land or housing. This is generally seen as a potential reason for some households not to move to safer places, particularly in the capital Funafuti. For more extreme climate change scenarios with more significant sea level rise, the wholesale relocation of the country of Tuvalu may be necessary, though there is little planning for such dire scenarios at this point (Noy, 2016b). There is, however, some scope for movement within the islands, though land tenure issues may need to be resolved. Planners and policy makers should start to consider policies that enable movement options for these vulnerable and exposed households. As part of our post-Pam survey, we also asked residents of the outer islands about their views on relocation as an adaptation option. Forty one percent of households have already considered moving away from their current homes to safer places, while $86 \%$ of households will consider moving if given an option of relocation by the government (Figure 3.10).

We asked our respondents about the reasons for their choice to remain in cyclone 

DISTANT CYCLONE ON ATOLL ISLANDS

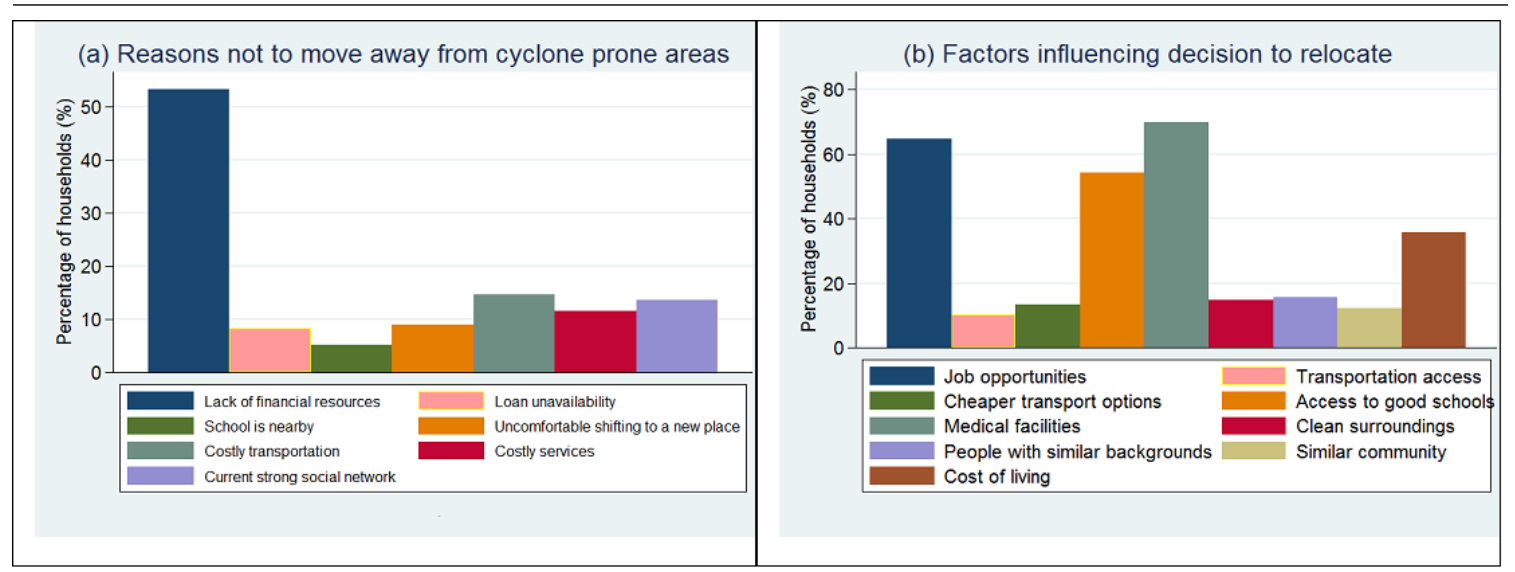

Source: Author's calculations from the Pam survey. Note that $\mathrm{N}=321$.

Figure 3.10: Relocation decision

prone areas, and about the factors that helped shape that decision to remain. Overwhelmingly, the decision not to move away is driven by financial consideration, with the absence of financial resources to permit a move the overarching concern. All other issues, including strong social networks, schooling and transportation appear of only secondary importance. Of the factors influencing the choice of relocation destination, again the availability of jobs appears of paramount importance (although puzzlingly the availability of medical facilities also appears important). As we observed about social networks, the presence of people with similar backgrounds (or a similar community) play only a very minor role in the hypothetical decision where to relocate to. 
3.7. CONCLUSIONS AND POLICY 
Appendix 


\section{A Hypothetical Scenarios}

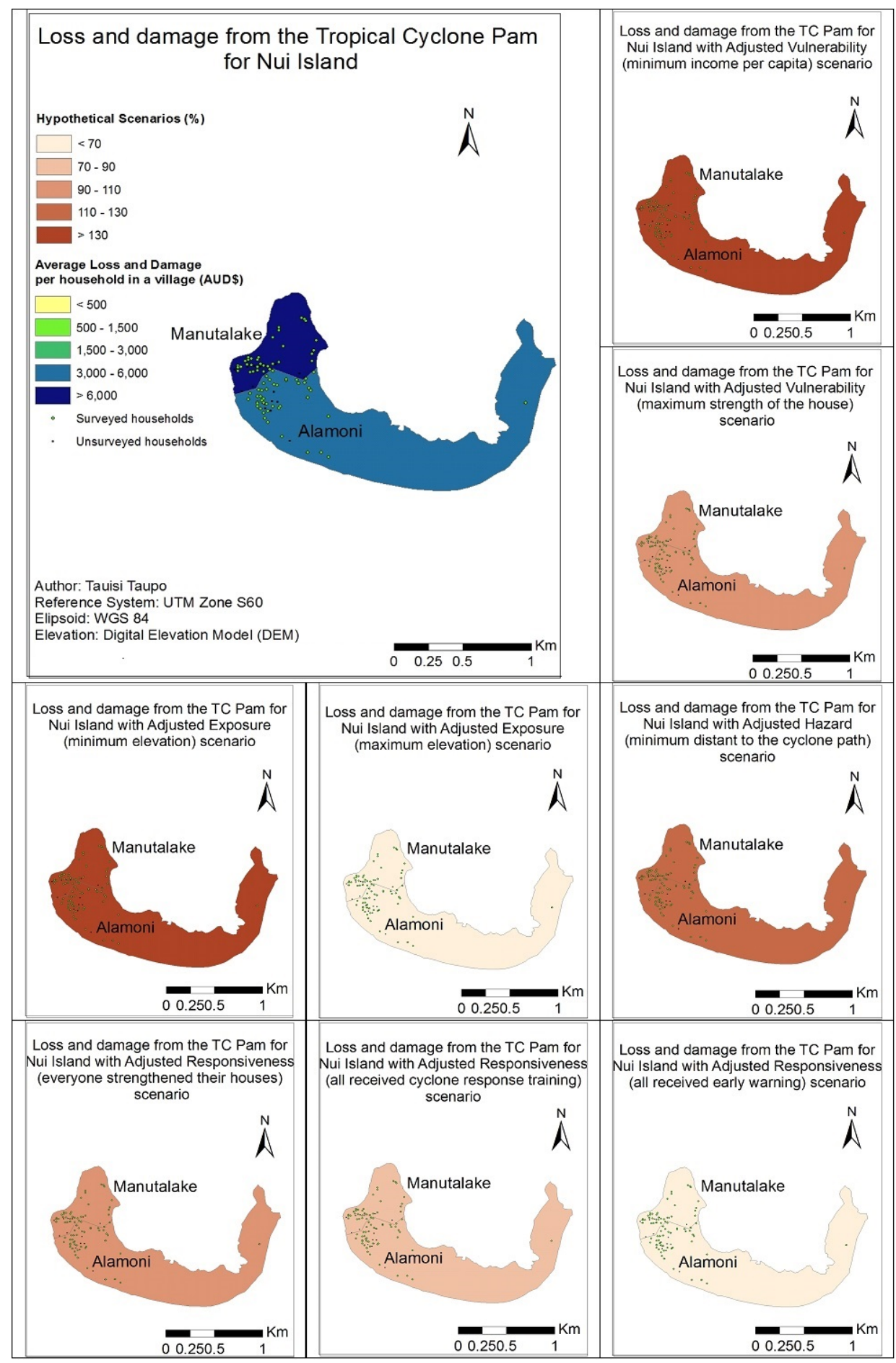

Source: Digitized maps based on the author's calculations.

Figure 3.A.1: Hypothetical scenarios for Nui Island 


\section{B Loss and Damage Maps}

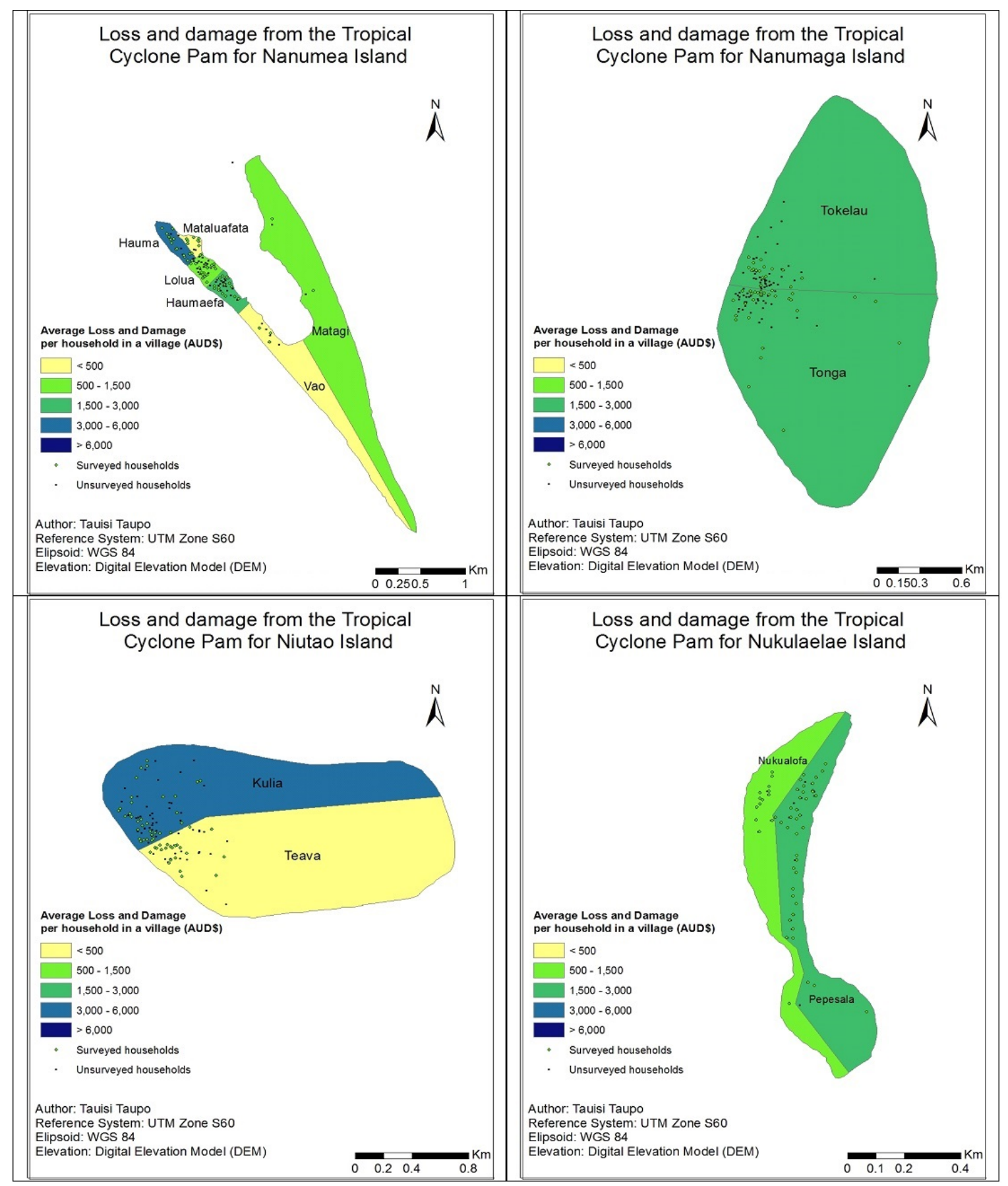

Source: Digitized maps based on the author's calculations.

Figure 3.B.1: Loss and damage for Nanumea, Nanumaga, Niutao and Nukulaelae 


\section{C Model Estimation}

Table 3.C.1: Model estimation results explaining the log of damages

\begin{tabular}{|c|c|c|c|c|c|c|}
\hline & $\overline{(1)}$ & $\overline{(2)}$ & (3) & (4) & $(5)$ & $(6)$ \\
\hline lincr_cap & $\begin{array}{c}-1.022^{* * *} \\
(0.109)\end{array}$ & $\begin{array}{c}-1.040^{* * * *} \\
(0.112)\end{array}$ & $\begin{array}{c}-1.052^{* * * *} \\
(0.122)\end{array}$ & $\begin{array}{c}-1.015^{* * *} \\
(0.109)\end{array}$ & $\begin{array}{c}-0.993^{* * *} \\
(0.107)\end{array}$ & $\begin{array}{c}-1.029^{* * *} \\
(0.111)\end{array}$ \\
\hline hsize & $\begin{array}{c}-0.166^{* * *} \\
(0.0429)\end{array}$ & $\begin{array}{c}-0.170^{* * *} \\
(0.0431)\end{array}$ & $\begin{array}{c}-0.186^{* * *} \\
(0.0523)\end{array}$ & $\begin{array}{c}-0.162^{* * *} \\
(0.0426)\end{array}$ & $\begin{array}{c}-0.185^{* * *} \\
(0.0419)\end{array}$ & $\begin{array}{c}-0.165^{* * *} \\
(0.0429)\end{array}$ \\
\hline strhouse & $\begin{array}{c}-0.567^{* *} \\
(0.279)\end{array}$ & $\begin{array}{c}-0.574^{* *} \\
(0.278)\end{array}$ & $\begin{array}{c}-0.585^{* *} \\
(0.278)\end{array}$ & $\begin{array}{l}-0.518^{*} \\
(0.278)\end{array}$ & $\begin{array}{l}-0.341 \\
(0.277)\end{array}$ & $\begin{array}{c}-0.600^{* *} \\
(0.278)\end{array}$ \\
\hline capacity & $\begin{array}{c}-0.720^{* * *} \\
(0.260)\end{array}$ & $\begin{array}{c}-0.691^{* * *} \\
(0.261)\end{array}$ & $\begin{array}{c}-0.710^{* * *} \\
(0.260)\end{array}$ & $\begin{array}{c}-0.711^{* * *} \\
(0.258)\end{array}$ & $\begin{array}{c}-0.717^{* * *} \\
(0.253)\end{array}$ & $\begin{array}{c}-0.728^{* * *} \\
(0.261)\end{array}$ \\
\hline g_warn & $\begin{array}{c}-0.901^{* * *} \\
(0.245)\end{array}$ & $\begin{array}{c}-0.912^{* * *} \\
(0.245)\end{array}$ & $\begin{array}{c}-0.896^{* * *} \\
(0.247)\end{array}$ & $\begin{array}{c}-0.916^{* * *} \\
(0.244)\end{array}$ & $\begin{array}{c}-0.866^{* * *} \\
(0.238)\end{array}$ & $\begin{array}{c}-0.899^{* * *} \\
(0.246)\end{array}$ \\
\hline coastdist & $\begin{array}{c}-0.00521 * * * \\
(0.000984)\end{array}$ & $\begin{array}{c}-0.00530 * * * \\
(0.000989)\end{array}$ & $\begin{array}{c}-0.00519^{* * * *} \\
(0.000985)\end{array}$ & $\begin{array}{c}-0.00561^{* * *} \\
(0.000995)\end{array}$ & $\begin{array}{c}-0.00442^{* * *} \\
(0.000978)\end{array}$ & $\begin{array}{r}-0.00522^{* * *} \\
(0.000985)\end{array}$ \\
\hline elevat & $\begin{array}{c}-0.128^{* * *} \\
(0.0334)\end{array}$ & $\begin{array}{c}-0.138^{* * *} \\
(0.0320)\end{array}$ & $\begin{array}{c}-0.137^{* * *} \\
(0.0321)\end{array}$ & $\begin{array}{c}-0.115^{* * *} \\
(0.0335)\end{array}$ & $\begin{array}{c}-0.155^{* * *} \\
(0.0314)\end{array}$ & $\begin{array}{c}-0.136^{* * *} \\
(0.0323)\end{array}$ \\
\hline cycpathdist & $\begin{array}{c}-0.000476^{* *} \\
(0.000203)\end{array}$ & $\begin{array}{c}-0.000472^{* *} \\
(0.000204)\end{array}$ & $\begin{array}{c}-0.000481^{* *} \\
(0.000204)\end{array}$ & $\begin{array}{c}-0.000576^{* * *} \\
(0.000206)\end{array}$ & $\begin{array}{c}-0.000522^{* * *} \\
(0.000198)\end{array}$ & $\begin{array}{c}-0.000471^{* *} \\
(0.000204)\end{array}$ \\
\hline strhou & $\begin{array}{c}-0.461^{* *} \\
(0.229)\end{array}$ & $\begin{array}{l}-0.440^{*} \\
(0.229)\end{array}$ & $\begin{array}{l}-0.446^{*} \\
(0.229)\end{array}$ & $\begin{array}{l}-0.436^{*} \\
(0.227)\end{array}$ & $\begin{array}{l}-0.369 \\
(0.225)\end{array}$ & $\begin{array}{c}-0.464^{* *} \\
(0.229)\end{array}$ \\
\hline savings & $\begin{array}{l}-0.246 \\
(0.220)\end{array}$ & & & & & \\
\hline assist & & $\begin{array}{c}0.622 \\
(0.624)\end{array}$ & & & & \\
\hline i_earners & & & $\begin{array}{c}0.113 \\
(0.160)\end{array}$ & & & \\
\hline totdist & & & & $\begin{array}{c}0.000330^{* *} \\
(0.000149)\end{array}$ & & \\
\hline a_shift & & & & & $\begin{array}{c}0.834^{* * *} \\
(0.260)\end{array}$ & \\
\hline elevate & & & & & $\begin{array}{c}0.194 \\
(0.306)\end{array}$ & \\
\hline shel & & & & & & $\begin{array}{l}-0.254 \\
(0.307)\end{array}$ \\
\hline _cons & $\begin{array}{c}14.00^{* * *} \\
(2.000)\end{array}$ & $\begin{array}{c}13.43^{* * *} \\
(2.093)\end{array}$ & $\begin{array}{c}14.14^{* * *} \\
(2.007)\end{array}$ & $\begin{array}{c}14.15^{* * * *} \\
(1.988)\end{array}$ & $\begin{array}{c}13.76^{* * *} \\
(1.954)\end{array}$ & $\begin{array}{c}14.21^{* * *} \\
(2.012) \\
\end{array}$ \\
\hline$N$ & 305 & 305 & 305 & 305 & 305 & 305 \\
\hline$R^{2}$ & 0.378 & 0.377 & 0.376 & 0.385 & 0.415 & 0.376 \\
\hline
\end{tabular}

Standard errors in parentheses

${ }^{*} p<0.10,{ }^{* *} p<0.05,{ }^{* * *} p<0.01$

Source: Author's estimations from the Pam survey. 
CHAPTER 3. AT THE VERY EDGE OF A STORM: THE IMPACT OF A DISTANT CYCLONE ON ATOLL ISLANDS

\section{D Pam Survey}

Table 3.D.1: Pam survey

\begin{tabular}{|c|c|c|}
\hline & A: IDENTIFICATION DETAILS & \\
\hline $\mathrm{A} 1$ & Household ID number: & \\
\hline $\mathrm{A} 2$ & Name of the enumerator: & \\
\hline \multirow[t]{2}{*}{ A3 } & Date of the interview (DD/MM/YY): & \\
\hline & B: HOUSEHOLD DETAILS & \\
\hline B1 & Name of respondents: & \\
\hline $\mathrm{B} 2$ & $\begin{array}{l}\text { Name of the head of household } \\
\text { (if different from respondent): }\end{array}$ & \\
\hline B3 & Date of birth (Day-Month-Year): & \\
\hline $\mathrm{B} 4$ & Island: & \\
\hline B5 & Village: & \\
\hline B6 & Home island: & \\
\hline B7 & Sex: & \\
\hline $\mathrm{B} 8$ & Marital status: & \\
\hline B9 & Number of elderly ( 65 years and above): & \\
\hline $\mathrm{B} 10$ & Contact number: & \\
\hline B11 & Email ID: & \\
\hline $\mathrm{B} 12$ & Did you reside in this house in $2012 ?:$ & (Yes or No): \\
\hline $\mathrm{B} 13$ & Number of family members : & $\begin{array}{l}\text { Adults: } \\
\text { Children: }\end{array}$ \\
\hline B14 & Number of earning members: & \\
\hline \multirow[t]{9}{*}{ B15 } & Education of Head of Household (HoH): & \\
\hline & No formal schooling & 1 \\
\hline & Primary school & 2 \\
\hline & Secondary school & 3 \\
\hline & Diploma & 4 \\
\hline & Undergraduate degree & 5 \\
\hline & Postgraduate degree & 6 \\
\hline & Doctorate degree & 7 \\
\hline & Other & 8 \\
\hline
\end{tabular}

(Tick multiple options where applicable): 


\section{D. PAM SURVEY}

Government service 2

Private service 3

Unskilled worker 4

Skilled worker $\quad 5$

Business 6

Self-employed professional $\quad 7$

\begin{tabular}{|c|c|c|}
\hline \multicolumn{3}{|c|}{ C: HOUSEHOLD INCOME, EXPENDITURE AND ASSETS } \\
\hline $\mathrm{C} 1$ & Total monthly household income: & \\
\hline \multirow[t]{7}{*}{$\mathrm{C} 2$} & Average monthly expenditure: & Total expenditure: \\
\hline & & Food: \\
\hline & & Water: \\
\hline & & Electricity: \\
\hline & & Transportation: \\
\hline & & Medical: \\
\hline & & Repairs and \\
\hline
\end{tabular}

\begin{tabular}{|c|c|c|}
\hline C3 & $\begin{array}{l}\text { Approximate percentage of savings } \\
\text { in bank account }(0-100 \%) ?: \\
\text { Approximate monthly } \\
\text { savings amount: }\end{array}$ & \\
\hline $\mathrm{C} 4$ & $\begin{array}{c}\text { Ownership of assets/durables } \\
\text { (Tick all the options } \\
\text { mentioned by the respondent) } \\
1 \text { LPG Gas } \\
2 \text { Electric fan } \\
3 \text { Television set } \\
4 \text { VCD/DVD player } \\
5 \text { Music system } \\
6 \text { Refrigerator } \\
7 \text { Washing machine } \\
8 \text { Air conditioner } \\
9 \text { Desktop/laptop } \\
10 \text { Mobile phone } \\
11 \text { Steel cupboard } \\
12 \text { Wooden furniture } \\
13 \text { Bicycle } \\
14 \text { Motorcycle/scooter } \\
15 \text { Hand cart } \\
16 \text { Car }\end{array}$ & $\begin{array}{l}\text { Cost: } \\
\text { Cost: } \\
\text { Cost: } \\
\text { Cost: } \\
\text { Cost: } \\
\text { Cost: } \\
\text { Cost: } \\
\text { Cost: } \\
\text { Cost: } \\
\text { Cost: } \\
\text { Cost: } \\
\text { Cost: } \\
\text { Cost: } \\
\text { Cost: }\end{array}$ \\
\hline
\end{tabular}


CHAPTER 3. AT THE VERY EDGE OF A STORM: THE IMPACT OF A DISTANT CYCLONE ON ATOLL ISLANDS

\section{D: HOUSEHOLD CHARACTERISTICS}

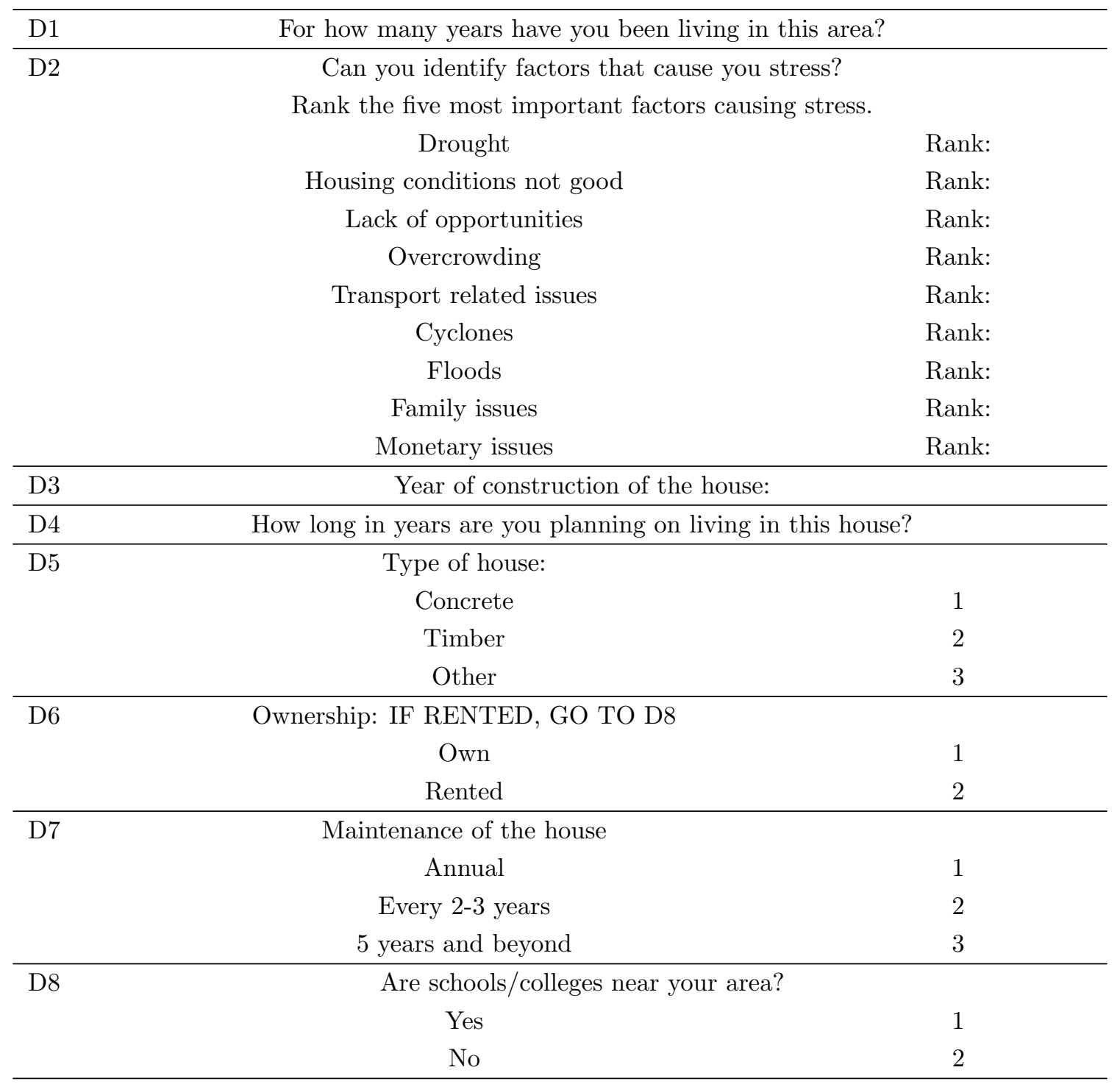

D9 What is the quality of water and sanitation services in your area?

Doesn't exist 1

Poor 2

Fair 3

Good 4

Very good 5

D10 What is the reliability of electricity in your area?

Doesn't exist 1

Poor 2

Fair 3 


\section{D. PAM SURVEY}

Good 4

Very good 5

E: EXPOSURE AND IMPACT OF CYCLONES

\begin{tabular}{ccc}
\hline E1 Does your area get strong winds and storm surge every year? & \\
& Yes & 1 \\
& No & 2 \\
\hline
\end{tabular}

E2 Did the surge/flood water from Cyclone Pam 2015 enter your house?

IF NO, GO TO E4

Yes

1

No

2

\begin{tabular}{lcl}
\hline E3 & For how many hours did the house remain flooded? & \\
\hline E4 Have the following items been damaged during Cyclone Pam 2015? & 1 \\
& Structure of the house & 2 \\
Electric wiring & 3 \\
Electric meter & 4 \\
Electronic goods & 5 \\
Furniture & 6 \\
Plumbing & 7 \\
Other kitchenware & 8 \\
\hline
\end{tabular}

E5 Did you experience these problems during Cyclone Pam 2015?

Non availability of transport $\quad 1$

Price rise of essentials 2

No drinking water 3

Disruption in power supply $\quad 4$

Non availability of food and other supplies $\quad 5$

Non availability of fuel (petrol, diesel, kerosene) 6

E6 Did you lose working days due to Cyclone Pam 2015?

$\begin{array}{ll}\text { Yes } & 1 \\ \text { No } & 2\end{array}$

If yes, how many working days were lost?

GO TO E8 IF NO DAYS ARE LOST

E7 If you did lose working days, for what reasons? List all those that apply.

Office damaged 1

House damaged 2

Transport not available $\quad 3$

Outside road flooded 4

Power supply cut off 5

E8 Did your children miss school/college on account of Cyclone Pam 2015? 
CHAPTER 3. AT THE VERY EDGE OF A STORM: THE IMPACT OF A DISTANT CYCLONE ON ATOLL ISLANDS

\begin{tabular}{cc}
\hline \multicolumn{1}{c}{ Yes } & 1 \\
No & 2 \\
If yes, how many school days were lost? & \\
\hline E9 & \\
\multicolumn{1}{c}{ Did any of your family members face any of these health } & \\
Malaria & 1 \\
Dengue & 2 \\
Typhoid & 3 \\
Jaundice & 4 \\
Diarrhea & 5 \\
Viral fever & 6 \\
Asthma attack & 7 \\
Chronic cold and cough & 8 \\
\hline \hline
\end{tabular}

\section{F: PREPARING FOR CYCLONES}

F1 Did you undertake these activities in anticipation of Cyclone Pam 2015?

Strengthen the house 1

Shielding the windows $\quad 2$

Repairing the roof 3

Move to a safe shelter 4

Repairs inside the house 5

F2 Did you stock up on the following in anticipation of Cyclone Pam 2015?

Food

Milk

2

Water

3

Medicines

4

Cooking fuel/gas $\quad 5$

Other

6

F3 During the Cyclone Pam 2015, how long, in days

did you stay without access to the following?

Water:

Sanitation:

Electricity:

Your Job:

Food:

Children's Schooling:

F4 Did you shift assets or valuables elsewhere in anticipation of a cyclone? If so where did you shift them?

Yes 
If yes, shift assets to others house. 1

If yes, keep them at higher elevation within the house. 2

\begin{tabular}{cc}
\hline F5 & Which assets did you protect first in anticipation \\
of a Cyclone Pam 2015? Rank what you would protect first, & \\
starting with 1. Ignore items that you do not own. & \\
1 High value durable items (TV, radio, fridge, computer) & Rank: \\
2 Documentation (other important documents e.g. passports, & \\
birth certificates, transcripts, etc.) & Rank: \\
3 Jewelry & Rank: \\
4 Vehicles (bicycle, motorcycle, car) & Rank: \\
5 Others & Rank:
\end{tabular}

\begin{tabular}{ll}
\hline F6 Have you undergone any training or capacity building programme \\
$\quad$ conducted for cyclone response? \\
Some training & 1 \\
No training & 2 \\
If so, which agency conducted it? & 1 \\
Government & 2 \\
NGOs & 3 \\
Other & 3
\end{tabular}

F7 Were you aware of any nearby temporary safe shelter during cyclones?

Yes 1

No 2

F8 Did you receive warnings about cyclone risks? IF NO, GO TO F11

Yes 1

No 2

F9 If yes, how did you receive the warnings?

(tick multiple responses if applicable)

Community alarm 1

Cell phone $\quad 2$

Local cable network 3

Radio/TV 4

Local government 5

Police 6

Other 7

F10 If yes, how long in advance were you warned of the Cyclone Pam 2015?

Less than fifteen minutes 1

Less than an hour before $\quad 2$

12 hours before 3

24 hours before 4

48 hours beforet 5

F11 If you needed to obtain a loan after a cyclone, what is the first 


\section{CHAPTER 3. AT THE VERY EDGE OF A STORM: THE IMPACT OF A DISTANT CYCLONE ON ATOLL ISLANDS}

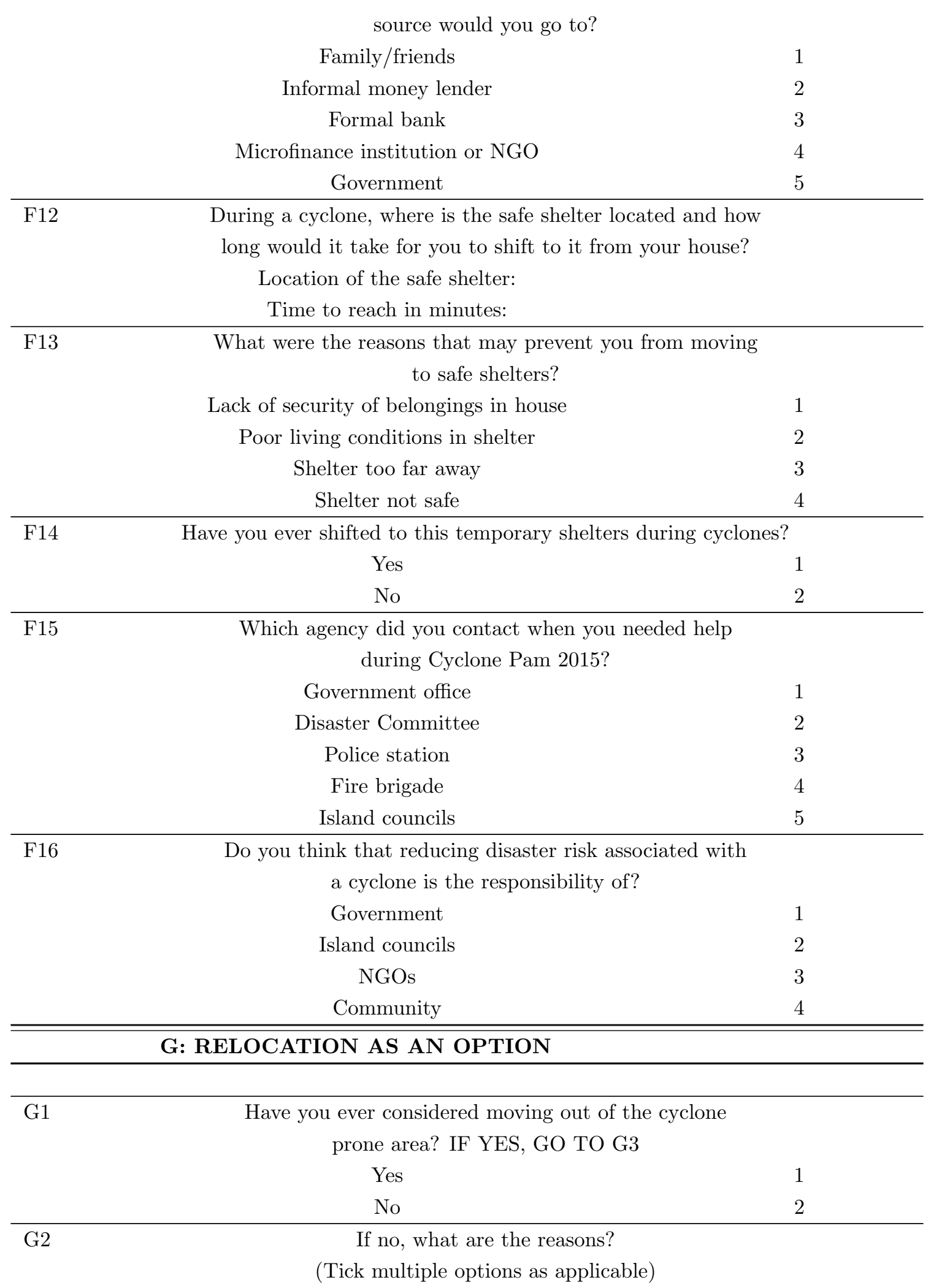




\section{D. PAM SURVEY}

Do not have enough financial resources to shift 1

Cannot avail of loan to move to another house 2

School/college is nearby

Do not feel comfortable

shifting to another location

Transportation will be very

costly if shifted to another area

Other services like water, electricity, monthly

maintenance will be costlier in another area

Have strong social network of neighbours

and friends in this area

7

\begin{tabular}{ll} 
and friends in this area & 7 \\
\hline If your family is given an option of relocation & \\
by the government, would you consider it? & 1 \\
Yes & 2 \\
No & 1 \\
\hline
\end{tabular}

G4

Consider a hypothetical situation of you being given a)

chance to move to a safer house without additional

burden on the family. What are the three most

important factors influencing your decision to move?

Job opportunities

Yes

Rank:

No

Rank:

Cost of living should not increase

2

Yes

Rank:

No

Rank:

Access to transportation

3

Yes

Rank:

No

Rank:

Cheaper transport options

4

Yes

Rank:

No

Rank:

Access to good schools/colleges

5

Yes

Rank:

No

Rank:

Medical facilities

6

Yes

Rank:

No

Rank:

Clean surroundings

7

Yes

Rank:

No

Rank:

People with similar background nearby 
CHAPTER 3. AT THE VERY EDGE OF A STORM: THE IMPACT OF A DISTANT CYCLONE ON ATOLL ISLANDS

\begin{tabular}{cc}
\hline Yes & Rank: \\
No & Rank: \\
People from the same community nearby & 9 \\
Yes & Rank: \\
No & Rank: \\
\hline \hline
\end{tabular}

\section{H: LOSS AND DAMAGE}

H1 Have you ever considered moving out of the cyclone

Yes 1

$\mathrm{No}($ Go to H3) 2

H2 What losses and damages incurred during the Tropical Cyclone Pam 2015. If YES, estimate the total value for loss and damage.

Residential house

Yes

No

Local kitchen hut

Yes

No

Outbuilding toilet

Yes

No

Water storage tank

Yes

No

Livestock

Yes

No

Root crops

Yes

No

Fruits/Vegetables

Yes

No

Fruit tree

Yes

No

Boat/Canoe

Yes

No

Others 1

2

Est. Value:

Est. Value:

2

Est. Value:

Est. Value:

3

Est. Value:

Est. Value:

4

Est. Value:

Est. Value:

5

Est. Value:

Est. Value:

6

Est. Value:

Est. Value:

7

Est. Value:

Est. Value:

8

Est. Value:

Est. Value:

9

Est. Value:

Est. Value:

9 


\section{D. PAM SURVEY}

\begin{tabular}{|c|c|c|}
\hline & $\begin{array}{l}\text { Yes } \\
\text { No }\end{array}$ & $\begin{array}{l}\text { Est. Value: } \\
\text { Est. Value: }\end{array}$ \\
\hline \multirow[t]{4}{*}{ H3 } & Did your household receive any assistance & \\
\hline & after the Tropical Cyclone 2015? & \\
\hline & Yes & 1 \\
\hline & $\mathrm{No}($ Go to $\mathrm{H} 6)$ & 2 \\
\hline \multirow[t]{19}{*}{ H4 } & Where did you receive the assistance from? & \\
\hline & Government & 1 \\
\hline & Yes & \\
\hline & No & \\
\hline & NGOs & 2 \\
\hline & Yes & \\
\hline & No & \\
\hline & Family & 3 \\
\hline & Yes & \\
\hline & No & \\
\hline & Friends & 4 \\
\hline & Yes & \\
\hline & No & \\
\hline & Development partners & 5 \\
\hline & Yes & \\
\hline & No & \\
\hline & Remittances & 6 \\
\hline & Yes & \\
\hline & No & \\
\hline
\end{tabular}

H5 What kind of assistance did you receive? If any, estimate the total value received from the assistance.

Money

Yes

No

In-kind

Yes

No

Other

Yes

No
1

Est. Value:

Est. Value:

2

Est. Value:

Est. Value:

3

Est. Value:

Est. Value:

\begin{tabular}{cc}
\hline H6 & \\
& Do you have insurance on your properties \\
damaged by Tropical Cyclone Pam 2015? & 1 \\
Yes & 2 \\
No (Go to I1) & 2 \\
\hline
\end{tabular}

What type of insurance? If any, estimate the 
CHAPTER 3. AT THE VERY EDGE OF A STORM: THE IMPACT OF A DISTANT CYCLONE ON ATOLL ISLANDS

total value you received from insurance.

\begin{tabular}{cc} 
Home & 1 \\
Yes & Est. Value: \\
No & Est. Value: \\
Vehicle & 2 \\
Yes & Est. Value: \\
No & Est. Value: \\
Boat & 3 \\
Yes & Est. Value: \\
No & Est. Value: \\
Other & 4 \\
Yes & Est. Value: \\
No & Est. Value: \\
\hline & \\
\hline
\end{tabular}


3.D. PAM SURVEY 


\section{Chapter 4}

\section{Financing Climate and Disaster Resilience in Atoll Islands: Evidence from Tuvalu and Kiribati}

\subsection{Introduction}

The Intergovernmental Panel on Climate Change (IPCC, 2012, 2014) emphasized the increasing risks associated with extreme weather events due to climatic change. Increasing frequency of high intensity storms are results of climate change and global warming in sea temperatures (Meldelsohn et al., 2012; Mei et al., 2015). The negative effects of climate-related disasters are greatly felt by developing countries, causing financial losses to increase (Briguglio, 1997; Heger et al., 2008; Klomp and Valckx, 2014).

Here, we propose to estimate the feasibility of a funding mechanism for disaster relief based on a Sovereign Wealth Fund model (SWF). For that purpose, we: (1) Quantify the need for such a funding mechanism; (2) suggest a way to structure this mechanism through the SWF of Tuvalu and Kiribati; and (3) examine the long-term sustainability of this proposed funding arrangement. We may ask why there is a need for a new disaster funding mechanism that supplements current official disaster 
assistance from development and donor partners. Autonomy, self-sufficiency, and predictability in relation to disaster response and recovery inspire this study. Because of this, we examine the two SWF of Tuvalu and Kiribati. The separation of Tuvalu from Kiribati, along with their independence from Britain, led to the establishment of the Tuvalu Trust Fund (TTF) while Kiribati's Revenue Equalizer Reserve Fund (RERF) had already been established. ${ }^{1}$

These events create significant budget volatility and fiscal risk to Pacific Island Countries (PICs) who lack the funding and capacity to ensure proper financial protection and adequate fiscal response to disasters. Most PICs face complexities in raising and accessing liquidity in the immediate aftermath of a disaster due to constraints regarding to their sizes, borrowing capacity, limited access to international financial markets, narrow revenue bases, and heavy reliance on imports and aid (World Bank, 2015b). Climate-induced sea-level rise poses an additional and existential threat to small and low-lying atoll states in the Pacific like Tuvalu and Kiribati, with moving populations or protecting the atolls at very high cost the only long-term solutions (OECD and World Bank, 2016).

Numerous studies point out the unique exposure of Pacific Islands to risks due to their economic, geographical and environmental vulnerabilities (World Bank, 2014; Taupo et al., 2016; OECD and World Bank, 2016). These intertwined vulnerabilities can reverse development efforts in these Pacific atoll islands. For instance, Cabezon et al. (2015) estimated that a damage of $1 \%$ of GDP from a disaster could be expected to decrease growth by 0.7 percentage points for Pacific Islands.

Aid plays a pivotal role in Small Island Developing States (SIDS) development, climate change adaptation and disaster risk reduction. Low-lying SIDS like Tuvalu and Kiribati are well supported by development aid, but increasing impacts of disasters are seen as emerging issues that require further funding assistance. In terms of quick response to climatic disasters (e.g., cyclones and droughts), the smallness of the islands and distances between them, and resultant communication and transportation difficulties, are major issues impeding swift response and recovery efforts. For example, both Tuvalu and Kiribati were significantly affected by the

\footnotetext{
${ }^{1}$ Tuvalu and Kiribati are categorized as Least Developed Countries (LDC) by United Nations (UN) classification.
} 
CHAPTER 4. FINANCING CLIMATE AND DISASTER RESILIENCE IN ATOLL ISLANDS: EVIDENCE FROM TUVALU AND KIRIBATI

Tropical Cyclone Pam (TC Pam) in 2015 even though the islands were of great distance away from the cyclone path (Taupo and Noy, 2016; Noy and Edmonds, 2016). The fiscal response to such catastrophes as the 2015 TC Pam has further demonstrated Tuvalu's dependency on aid donors.

Noy and Edmonds (2016) calculated a welfare risk scorecard for Tuvalu base on the model used by Hallegatte et al. (2017) to produce disaster management scorecards for countries (Hallegatte et al., 2016). Worryingly, they measured the overall risk to welfare for Tuvalu to be $0.98^{2}$, higher than most other countries measured in this way by the World Bank. Noy and Edmonds (2016, p.22) concluded that risk to welfare in Tuvalu is the highest implying that for "every dollar of damages to assets will also 'translate' into a dollar (98 cents) of lost welfare/wellbeing for Tuvalu".

Response efforts for Tuvalu after TC Pam were led by the Government through the Disaster Committee, with support from humanitarian and bilateral partners. Based on situational assessments of the impact of the disaster, the government, and regional and international organizations responded to key areas of humanitarian need. There was neither disaster fund, nor any liquid financial instrument in place at that time to assist in this endeavour, apart from the Government's redirection of other expenditure lines.

Although having a disaster fund is imperative, there are opportunity costs of paying for disasters because the funds foregone which were supposedly meant for further investments and economic development activities would be spent on response and recovery from loss and damages. The logic behind having a separate disaster fund rather than pulling money out of trust funds is because they were supposed to be used for different purposes, for instant, trust funds are basically like superannuation funds for their countries with limited legal drawing options that may not cover for natural disasters locally apart from global economic shocks that directly affects its investments. Having a separate fund can be justified due to the difference in legal requirements, purposes, mandates, procedures and management of these funds. Moreover, a well-constructed disaster fund would have mechanisms that respond more quickly to disasters than trust funds. Nevertheless, the compatibility of disaster funds

\footnotetext{
${ }^{2}$ The unit 0.98 refers to the risk (expected welfare losses) to well-being in percentage of GDP, i.e. estimated at $0.98 \%$ of GDP.
} 
in low lying SIDS may seem operational if strategize and plan properly.

As far as we are aware, no forecasts have been produced for the success of the TTF or RERF for the long run, nor any analysis of their feasibility and sustainability in providing financing mechanisms for disaster preparation and response. The possibility of extending TTF coverage to disasters apart from the provision of government support has been proposed but remains unquantified. ${ }^{3}$ This study aims to assess the feasibility and sustainability of these funds to support and contribute to disaster funds. Additionally, this chapter intends to enhance understanding of potential options available for DRR and disaster response for Tuvalu and Kiribati. Current findings can then be generalised to other Pacific or SIDS settings.

The next section discusses the background of available disaster financing instruments. Section 3 discuss the SWF, section 4 describes the data and explains the methodology, section 5 details the results, and conclusions are presented in section 6 .

\subsection{Climate Change and Disaster Financing Instruments}

There are numerous financing instruments available for climate change and climatic disasters. Linnerooth-Bayer and Mechler (2009) discuss insurance and risk-financing mechanisms for managing disasters in developing countries. ${ }^{4}$ One of these earliest instruments is the Caribbean Catastrophe Risk Insurance Facility, which is a pool of catastrophe insurance covering of small island states in the Caribbean region, with a 'parametric trigger' for immediate insurance disbursements to affected states in

\footnotetext{
${ }^{3}$ This was raised in several meetings in Tuvalu, including the TC Pam Meeting, National Summit for Tuvalu for the new National Sustainable Development Strategy for 2015-2020 and the 2015 Tuvalu TTF Board Meeting (also mentioned in their 2015 TTFAC Report).

${ }^{4}$ Some examples of risk financing instruments are the Proshika scheme which offers the Participatory Livestock Compensation Fund, the Afat Vimo disaster insurance program, the United States National Flood Insurance Program, the Turkish Catastrophe Insurance Pool, the Philippines crop insurance program, the BASIX index-based crop insurance scheme, the Mongolian index-based livestock insurance program, the Mexican catastrophe bond, the Caribbean Catastrophe Risk Insurance Facility, and the Mauritius crop insurance program.
} 


\section{CHAPTER 4. FINANCING CLIMATE AND DISASTER RESILIENCE IN ATOLL ISLANDS: EVIDENCE FROM TUVALU AND KIRIBATI}

the event of a disaster for emergency relief. ${ }^{5}$ To encourage and enforce disaster risk management and adaptation to climate change in PICs, the Pacific Catastrophe Risk Assessment and Financing Initiative (PCRAFI) was devised to model disaster risks and assess financial options, aiming at reducing financial vulnerability to disasters and climate change. Interestingly, the intended formation of the Pacific Islands Climate Change Insurance Facility (PICCIF) has become a popular topic in discourse within the Pacific region. ${ }^{6}$ In reality, insurance is not a practical instrument for disaster response and recovery for some Pacific Islands like Tuvalu given its very small size (Taupo and Noy, 2016). ${ }^{7}$ Kiribati has an operating Insurance Corporation but it does not cover the sovereign and insurance penetration is comparatively low. ${ }^{8}$

Figure 4.1 shows how some PICs are receiving post disaster assistance from foreign donors and development partners. We can focus on a group of low-lying atoll nations, members of the Coalition of Low-Lying Atoll Nations on Climate Change (CANCC) that was organised at the UN SIDS Conference in Samoa in September 2014. This group consists of the five low-lying atoll states: Kiribati, Tuvalu, the Maldives, Republic of Marshall Islands, and Tokelau, all of which are at the frontline of climate change and sea level rise, while also serving as a warning alarm for the global community. Figure 4.2 illustrates humanitarian aid flow for disasters from donors to the CANCC in the past 10 years, amounting to approximately USD $\$ 12$ million. ${ }^{9}$ The Marshall Islands dominated humanitarian aid for CANCC within this period, due to the two droughts they experienced in 2013 and 2016.

\footnotetext{
${ }^{5}$ The Caribbean Catastrophe Risk Insurance Facility was set up in 2007. A 'parametric trigger' refers to a disaster that activates an insurance policy based on parameters directly related to the risk.

${ }^{6}$ The Prime Minister of Tuvalu, in his statement at the High-Level Meeting of the Conference of Party (COP22) on the $16^{\text {th }}$ of November 2016, stressed that the Pacific region is progressing towards the development of a PICCIF to help in recovery efforts, with the help of the UNDP and the Pacific Island Forum Secretariat. He also called upon all donors and experts to help in this endeavour. See statement at http://www.tuvalu-overview.tv/eng/topics/statement-cop22. html. Another disaster insurance for some PICs is the Pacific Catastrophe Risk Insurance Company.

${ }^{7}$ Apart from the unavailability of insurance mechanisms and insufficient resources (low income), 'charity hazard' is a concern possibility deterring donors and the national government recipients (see Raschky and Weckhannemann, 2007).

${ }^{8}$ The Kiribati Insurance Corporation was established in 1981 to compensate loss and damages under two main categories Life insurance and General (Non-Life) insurance including vehicles, motor cycles, marine and aviation, fire, liability and miscellaneous. Refer to http://www.kic.org.ki/ index.php/about-us.html

${ }^{9}$ We use Australian Dollar currency (AUD) throughout this chapter, unless otherwise stated. AUD is the currency used by both Tuvalu and Kiribati.
} 


\subsection{CLIMATE CHANGE AND DISASTER FINANCING INSTRUMENTS}

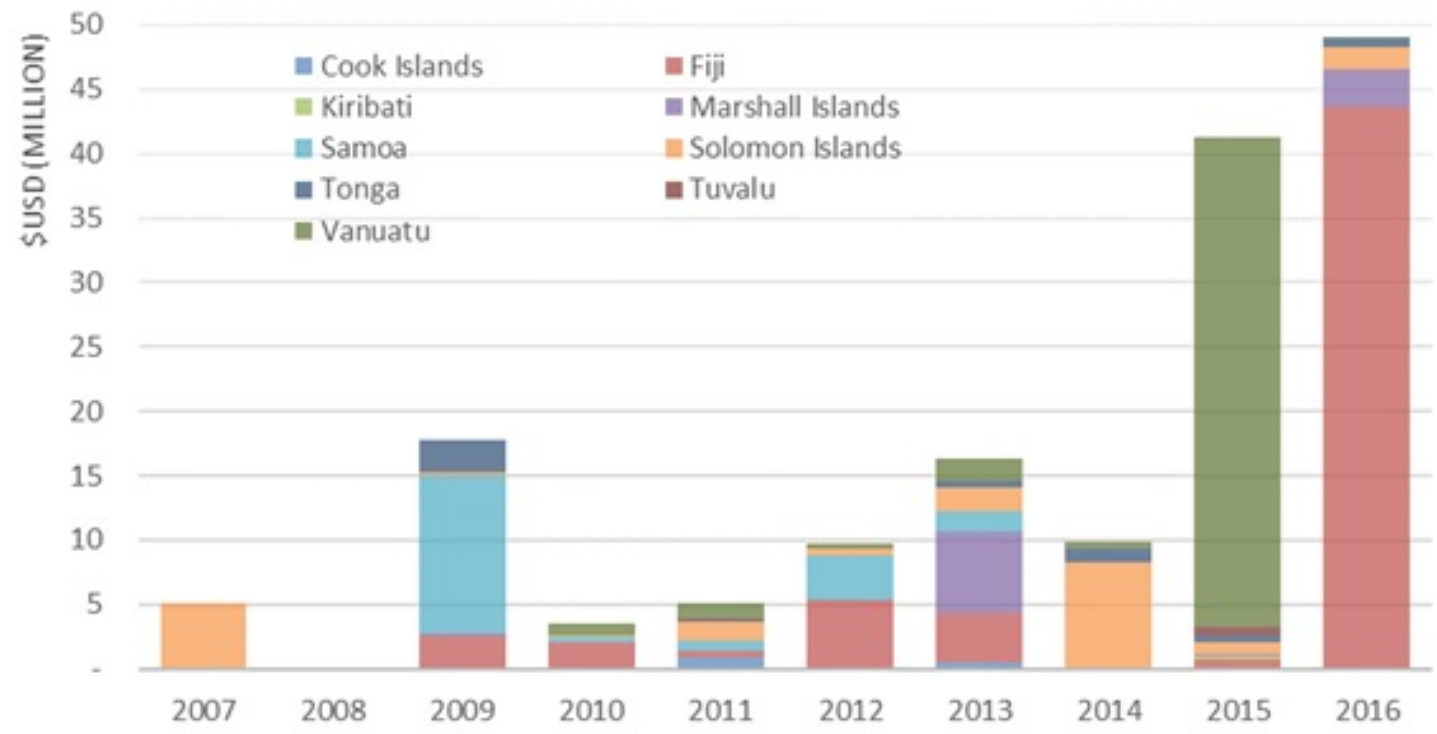

Source: United Nations Office for the Coordination of Humanitarian Affairs (UNOCHA) website [https://fts. unocha.org/countries/overview] that was accessed on the $7^{\text {th }}$ of April, 2017.

Figure 4.1: Humanitarian aid flows for disasters in selected PICs

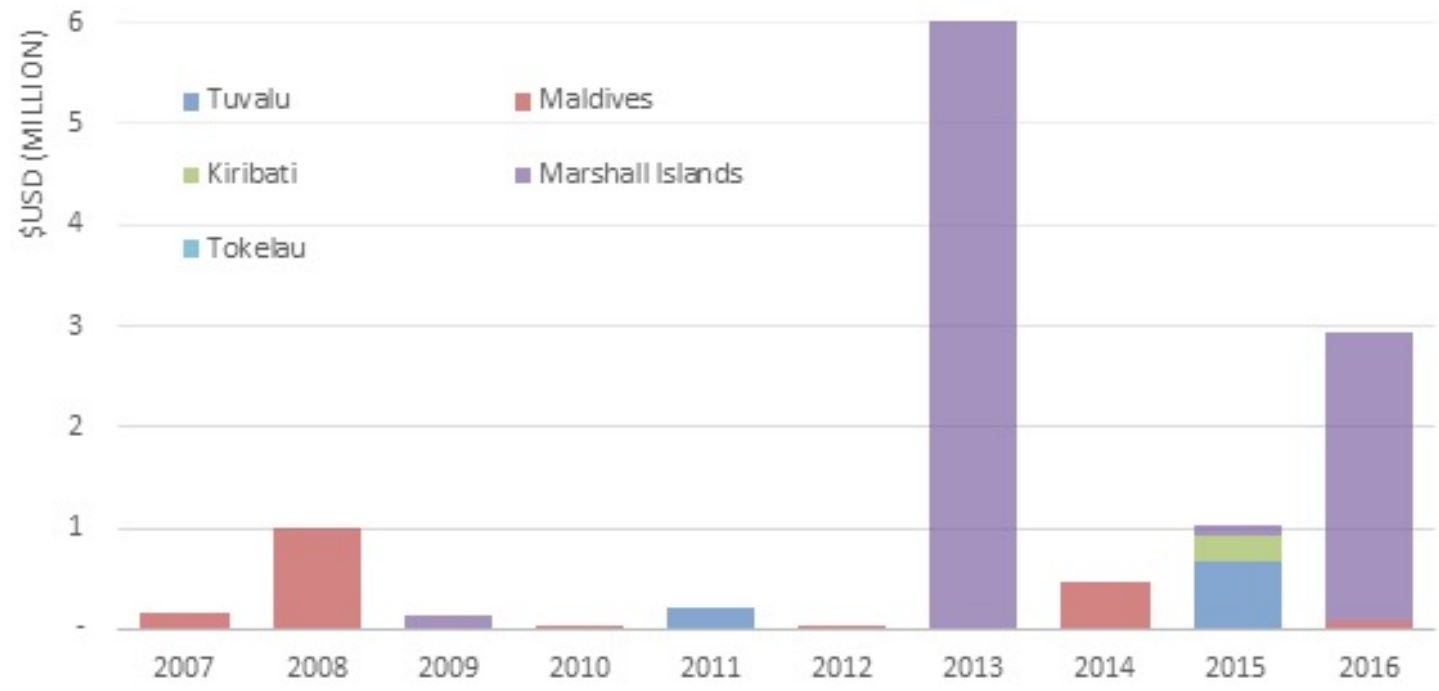

Source: United Nations Office for the Coordination of Humanitarian Affairs (UNOCHA) website [https://fts. unocha.org/countries/overview] that was accessed on the $7^{\text {th }}$ of April, 2017.

Figure 4.2: Humanitarian aid flows for disasters in low-lying atoll Islands

Tuvalu received USD $\$ 681,284$ for TC Pam in 2015. The Tuvalu Government (2015) approximated a total of AUD $\$ 3.5$ million from cash, in-kind and pledge donations for relief and recovery efforts. Figure 4.3 displays spikes of net Official 


\section{CHAPTER 4. FINANCING CLIMATE AND DISASTER RESILIENCE IN ATOLL ISLANDS: EVIDENCE FROM TUVALU AND KIRIBATI}

Development Assistance (ODA) for Tuvalu, corresponding to two state emergencies (in yellow bars): the 2011 drought and TC Pam in 2015. The year of the establishment of the Tuvalu Trust Fund is represented by the highest spike ever in 1987 (green bar). Similarly, Figure 4.4 shows ODA and GDP for Kiribati. Kiribati was also affected by the 2011 drought and TC Pam in 2015, but not to the extent like Tuvalu where a state of emergency was declared for both events.

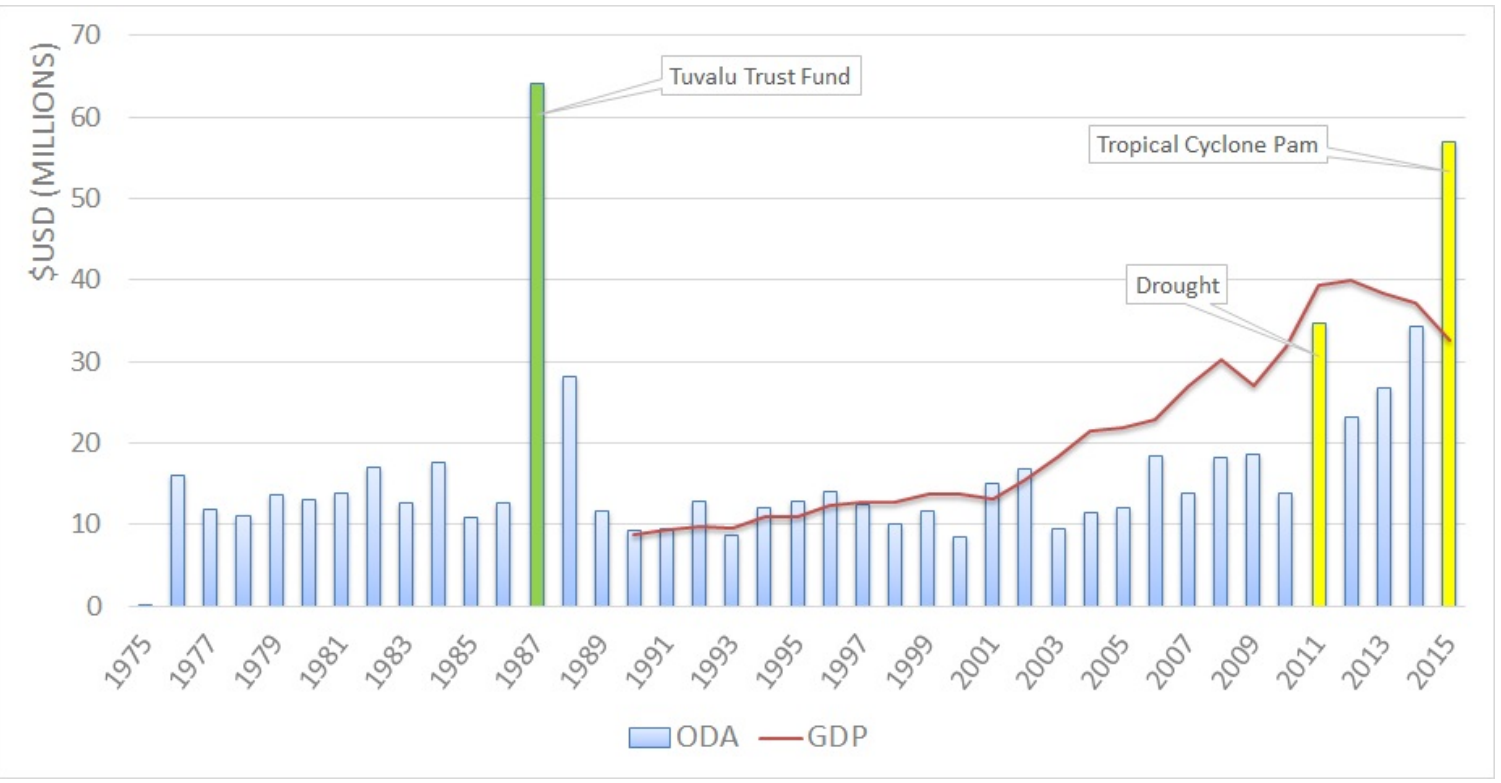

Source: Data are from the World Bank Databank website

[http://databank. worldbank.org/data/] that was accessed on the $7^{\text {th }}$ of April, 2017.

Figure 4.3: ODA and GDP for Tuvalu

PICs have received funding from other sources for climate change adaptation, mitigation, and resilience purposes. One of these sources are projects from the National Adaptation Programmes of Action (NAPA), which have provided limited funding assistance to some PICs like Tuvalu, Kiribati, Samoa, the Solomon Islands, and Vanuatu to enable effective responses and adaptation to the effects of climate change. ${ }^{10}$ Moreover, the Green Climate Fund (GCF) has approved a handful of projects for some PICs with the aim to assist vulnerable countries in building climate

\footnotetext{
${ }^{10}$ The preparation and implementation of NAPAs are financed by the Least Developed Countries Fund. This fund supports the special needs of Least Developed Countries (LDCs) who are vulnerable to the adverse impacts of climate change (see Global Environment Facility Secretariat, 2011). Information on all NAPA Priority Projects are available on the United Nations Framework Convention on Climate Change (UNFCCC) website (http://unfccc.int/adaptation/ workstreams/national_adaptation_programmes_of_action/items/4583.php).
} 


\subsection{SOVEREIGN WEALTH FUNDS}

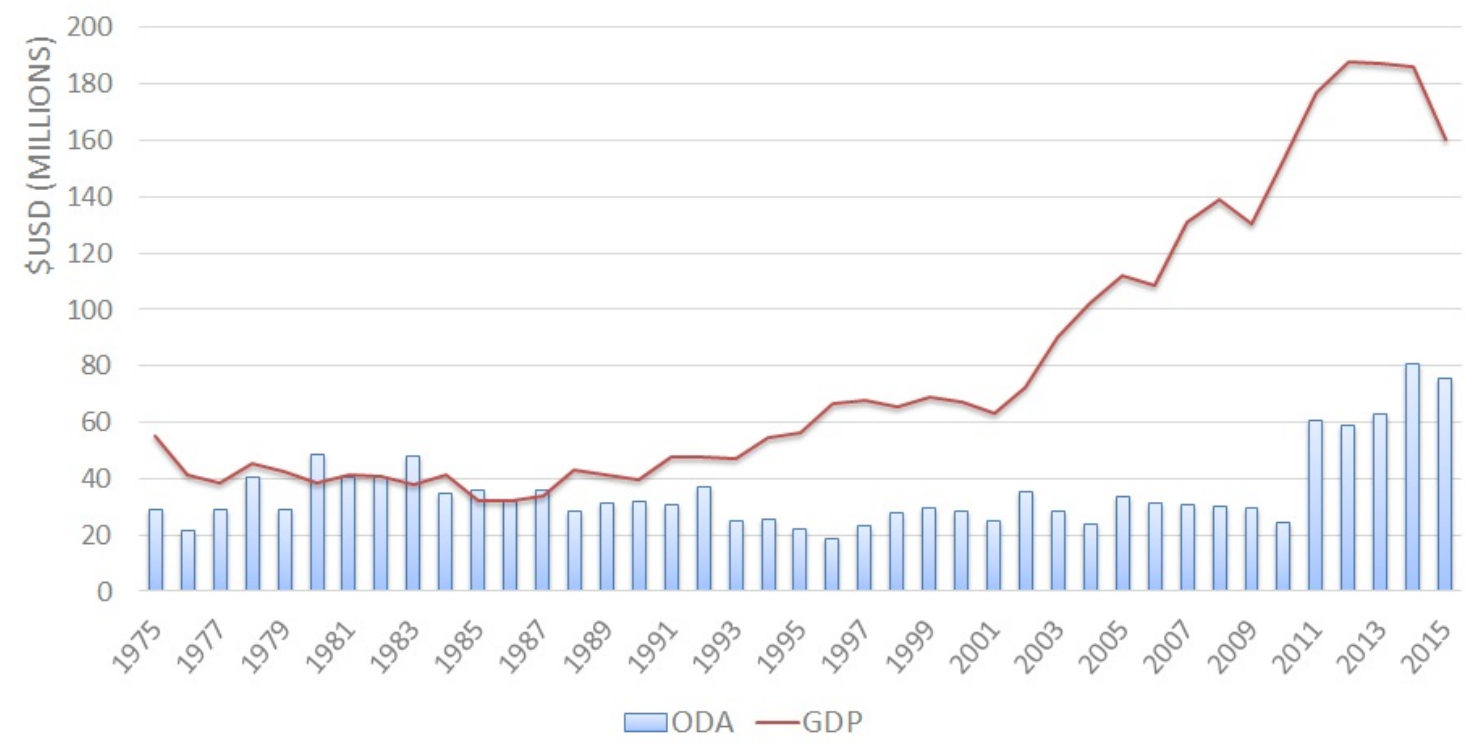

Source: Data are from the World Bank Databank website [http://databank.worldbank.org/data/] that was accessed on the $7^{\text {th }}$ of April, 2017.

Figure 4.4: ODA and GDP for Kiribati

resilience, climate adaptation, and mitigation (see Table 4.1).

Noy and Edmonds (2016) discuss risks in Pacific atoll islands and various financial instruments applicable to both ex-ante and ex-post disaster risk management: i) post-disaster budget provisions; ii) offshore funds; iii) contingent credit lines and multilateral loans and grants; iv) insurance for public assets; v) private insurance; vi) sovereign insurance, and vii) regional pooling of sovereign insurance.

\subsection{Sovereign Wealth Funds}

Alhashel (2015) discusses the recent popularity of SWFs, as they have amassed up to USD6.65 trillion in 2014. ${ }^{11}$ Balding (2012) and Clark et al. (2013) focus

\footnotetext{
${ }^{11}$ The estimate was gathered from the Sovereign Wealth Fund Institute at http://www. swfinstitute.org/fund-rankings/. Similarly, when accessing http://www.swfinstitute.org/ sovereign-wealth-fund-rankings/ on the $15^{\text {th }}$ of November 2016, the total SWFs added up to USD7.3957 trillion, which is represented by Total oil and gas related (USD4.3213 trillion) and Total others (USD3.0744 trillion). In comparison, the USD0.7457 trillion increase from 2014 to 2016 is $11.21 \%$.
} 
CHAPTER 4. FINANCING CLIMATE AND DISASTER RESILIENCE IN ATOLL ISLANDS: EVIDENCE FROM TUVALU AND KIRIBATI

Table 4.1: List of Global Climate Fund projects for the PICs

\begin{tabular}{|l|l|l|l|l|l|l|}
\hline Approved & Number & Project & Country & Theme & $\begin{array}{l}\text { Accredited } \\
\text { Entity }\end{array}$ & $\begin{array}{l}\text { Fund } \\
\text { (USD } \\
\text { million) }\end{array}$ \\
\hline $11 / 2015$ & FP008 & $\begin{array}{l}\text { Fiji Urban Water } \\
\text { Supply and Wastewater } \\
\text { Management Project }\end{array}$ & Fiji & Cross-cutting ADB & 31 \\
\hline $6 / 2016$ & FP015 & $\begin{array}{l}\text { Tuvalu Coastal } \\
\text { Adaptation Project }\end{array}$ & Tuvalu & Adaptation & UNDP & 36 \\
\hline $12 / 2016$ & FP035 & $\begin{array}{l}\text { Climate Information } \\
\text { Services for Resilient } \\
\text { Development in Vanuatu }\end{array}$ & Vanuatu & Adaptation & SPREP & 23 \\
\hline $12 / 2016$ & FP036 & $\begin{array}{l}\text { Pacific Islands Renewable } \\
\text { Energy Investment } \\
\text { Program }\end{array}$ & $\begin{array}{l}\text { Cook } \\
\text { Islands }\end{array}$ & $\begin{array}{l}\text { Mitigation } \\
\text { Adaptation }\end{array}$ & ADB & 17 \\
\hline & $\begin{array}{l}\text { Integrated } \\
\text { Management to Enhance } \\
\text { Climate Resilience of } \\
\text { the Vaisigano River } \\
\text { Catchment in Samoa }\end{array}$ & Samoa & Adaptation & UNDP & 57.7 \\
\hline
\end{tabular}

Source: GCF website [http://www.greenclimate.fund/projects/portfolio] that was accessed on the $7^{\text {th }}$ of March, 2017.

on the management, politics, and economics behind them. However, there is very limited research on SWFs in the PICs. ${ }^{12}$ Several PICs, including Kiribati, Tuvalu, Timor-Leste, Papua New Guinea, Nauru, Tonga, the Marshall Islands, Micronesia, and Palau have SWFs established from revenue sources ranging from non-renewable resources, revenue windfalls, and donor contributions. These funds have served their governments for short-term budget stabilization, long-term savings, and the improvement of self-reliance (Le Borgne and Medas, 2007).

In general, structures (legal, institutional, and governance) and investment strategies vary between these SWFs. ${ }^{13}$ These SWFs cover economic disturbances and long-term liabilities rather than natural shocks. Given the current circumstances of climate change and climatic disasters on Pacific Islands, the focus would need to be directed into the setting up of disaster funds if there are none, or contributing to existing disaster budget allocations. ${ }^{14}$

\footnotetext{
${ }^{12}$ Limited quantitative research on SWFs in Pacific Island Countries partly due to strict access to data.

${ }^{13}$ For instance, Tuvalu's TTF operation and fiscal policy requires achieving certain sustainability benchmarks such as having balanced budgets on average over the medium term; budget deficits should be below 3 percent of GDP; assets in the CIF should be above 16 percent of the TTF's assets over any four-year period; drawdown from the CIF that is compatible with the sustainability of TTF; and external debt should be below 60 percent of GDP (TTFAC Secretariat, 2003, 2006).

${ }^{14}$ Beyond this endeavour is the aim to sustain disaster funds into the long-term.
} 
A globally accepted best practice for SWFs, such as the "Santiago Principles" can weigh how SWFs are performing in terms of good governance, accountability, transparency, and prudent investment practices. ${ }^{15}$ The "Santiago Principles" consist of twenty-four Generally Accepted Principles and Practises (GAPP) that are supported by members of the International Working Group of Sovereign Wealth Funds (IWG) ${ }^{16}$ as guidelines for proper, prudent and sound management of SWF. The International Working Group of Sovereign Wealth Funds (2008) broadly arranged the twenty-four GAPP into three pillars, namely: i) legal framework, objectives, and coordination with macroeconomic policies; ii) institutional framework and governance structure, and iii) investment and risk management framework. ${ }^{17}$

The Timor-Leste Petroleum Fund (TLPF) is the only SWF from the Pacific who is a member of the IWG. Not only has it performed well against the "Santiago Principles", it has also improved over the years (see Table 4.2). In contrast, the RERF has not performed well in 2013 relative to the other forty-eight SWFs assessed, with 19 points below the SWF average score (Bagnall and Truman, 2013). On the other hand, the TTF has not been thoroughly assessed in comparison to other SWF at the international level, but only at the Pacific regional level by Edmonds (2015), where he divided the twenty-four GAPP into seven ${ }^{18}$ thematic areas and ranked the SWF for selected PICs including Timor-Leste, Tuvalu, Kiribati, Federated States of Micronesia

\footnotetext{
${ }^{15}$ The Principles were established in 2008 with inputs from the IMF, World Bank, OECD, and others.

${ }^{16}$ IWG consist of 26 IMF member countries with SWFs. The International Working Group of Sovereign Wealth Funds (2008) discusses the "Santiago Principles" in detail. The International Forum of Sovereign Wealth Funds (IFSWF) was an off spring of the 'Kuwait Declaration' in 2009, as the successor of the IWGSWF. IFSWF currently has 30 member countries.

${ }^{17}$ Furthermore, the International Forum of Sovereign Wealth Funds (2014) prescribed the "Santiago Principles" as follows: 1) sound legal framework; 2) well defined policy purpose and public disclosure of framework; 3) compliance with macroeconomic policies; 4) clearly defined policies and rules; 5) timely reporting and transparency to the owner(s);6) clearly defined division of roles; 7) clear objectives and roles for governing bodies; 8) governing bodies to act in the best interest of the SWF; 9) independence and following procedures; 10) clear accountability framework; 11) timely annual reporting; 12) independent auditors; 13) upholding internal ethical standards; 14) clear outsourcing procedures; 15) compliance with rules of foreign countries; 16) clear governance framework; 17) public transparency; 18) clear investment policies and strategies; 19) investment decisions based on economic and financial grounds; 20) privileged information restrictions; 21) shareholder ownership rights policies; 22) reliable and effective risk management; 23) clear and proper reporting of performance, and 24) regular review of compliance with the "Santiago Principles".

${ }^{18}$ The 7 categorized areas are shown in Table 4.2 .
} 
Table 4.2: Compliance with the Santiago Principles by fund for selected PICs

\begin{tabular}{|c|c|c|c|c|}
\hline & \multicolumn{4}{|c|}{ Countries (in descending order of compliance) } \\
\hline & $\begin{array}{l}\text { Timor } \\
\text { Leste } \\
(\mathrm{TLPF})\end{array}$ & $\begin{array}{l}\text { Tuvalu } \\
\text { (TTF) }\end{array}$ & \begin{tabular}{|l}
\multicolumn{2}{l}{ FSM } \\
$\& \quad$ RMI \\
(CTFs)
\end{tabular} & $\begin{array}{l}\text { Kiribati } \\
\text { (RERF) }\end{array}$ \\
\hline 2011 SWF Scoreboard* & 73 & & & \\
\hline 2013 SWF Scoreboard* & 85 & & & 35 \\
\hline 2014 Compliance Index Rating** & $\mathrm{A}$ & & & \\
\hline 2015 Rating*** & & & & \\
\hline 1. Legal Framework & Good & Good & Good & Good \\
\hline 2. Objectives and policy purpose & Good & Good & Good & Neutral \\
\hline 3. Domestic economic implications & Good & Good & Neutral & Good \\
\hline 4. Investment policy and risk management & Good & & & Poor \\
\hline 5. Governance framework & Good & Good & Good & Neutral \\
\hline $\begin{array}{l}6 \text {. Professional and ethical standards, fiduciary and public } \\
\text { responsibility }\end{array}$ & Neutral & Poor & Poor & Poor \\
\hline 7. Transparency & Good & Neutral & Neutral & Poor \\
\hline
\end{tabular}

(FSM), and the Republic of the Marshall Islands (RMI). Table 4.2 shows that Tuvalu's TTF was performing well overall in 2015, while underperforming in the categorized area 6. Likewise, Kiribati's RERF was performing poorly in categorized areas 4, 6, and 7. The identified weaknesses should be key focus areas for improvement. Tuvalu on the other hand, requires a thorough assessment of its compliance to the "Santiago Principles" in the future. However, with the inclusion of TTF contributions to the disaster fund, it will most likely deviate from the "Santiago Principles". 19

\subsubsection{Tuvalu Trust Fund and the Revenue Equalizer Reserve Fund}

The TTF is guided by its International Agreement for the Tuvalu Trust Fund with advice and monitoring from the TTFAC and Fund managers. According to the Tuvalu Government (2008, p.6) "the purpose of the Fund is to contribute to the long-term financial viability of Tuvalu by providing an additional source of revenue for recurrent expenses of the Government of Tuvalu in order to: (a) assist the Government to achieve greater financial autonomy in the management of its recurrent budget; (b) enable the Government to maintain and if possible improve existing levels of social

\footnotetext{
${ }^{19}$ Also, it does not state in the TTF Agreement.
} 
infrastructure and services; (c) enhance the capacity of the Government to receive and effectively utilize external capital development and technical assistance; (d) enable the Government to meet long-term maintenance and operating costs of social and economic infrastructure and services; and (e) assist the Government to develop the economy of Tuvalu."

The RERF is a special fund under Section 107 of the Constitution where the Minister of Finance can directly wind up the Fund under section 13(2)(b) of the Public Finance (Control and Audit) Act. ${ }^{20}$ Although we have not sighted ${ }^{21}$ the objectives, mission, and policy purposes of the RERF, both the TTF and RERF, in general support their governments fiscally, providing reliable revenue sources (fiscal buffers) to offset recurrent national budget shortfalls and occasionally smoothing out relevant market fluctuations ${ }^{22}$ when necessary.

The TTF was formed in 1987 from initial investments from both donors and the national government, while the RERF was established purely from the national government's contributions (Ministry of Finance and Economic Development, 2016; Toatu, 1993; Trease, 1993; TTFAC Secretariat, 2006, 2015; Tuvalu Trust Fund Board, 2007).

Figure 4.5 describes the current TTF structure that consists of contributions from the original donors and subsequent contributors including the Tuvalu government. Positive distributions or investment income are transferred to the Consolidated Investment Fund (CIF) for disbursement. The CIF acts as a buffer in the current

\footnotetext{
${ }^{20}$ The Constitution and the Public Finance (Control and Audit) Act were both accessed on March $21^{\text {st }}, 2017$ through http://www.paclii.org/ki/constitution/Kiribati\%20Independence\% 200rder\%201979.pdf and http://www.paclii.org/ki/legis/consol_act/pfaaa279/. See Angelo et al. (2016) for more discussion on the overview of the SWF in the Pacific and how they are distinguished from one another.

${ }^{21}$ We assume that the information for RERF is either not publicly available or does not exist at all. However, in principle, the usage of RERF is reflected in their national budgets.

${ }^{22}$ The TTFAC Secretariat (2015, p.11) identified potential "sources of fiscal risk from uncertainty include volatility in: 1) foreign exchange rates (notably USD/AUD), which affect several major USD-denominated revenue items (e.g. licence fees for fishing and .tv, and the ROC budget support payments); 2) volume of traded items (e.g. fish harvested under a licence agreement); 3) market prices of traded items (e.g. VDS fishing days); 4) timing of cash flows (e.g. sales of various fishing licences); 5) capital markets (e.g. affecting investment returns); 6) demand driven, loosely constrained expenditure policies; and the incidence of random natural disasters affecting Tuvalu (e.g. Cyclone Pam)."
} 


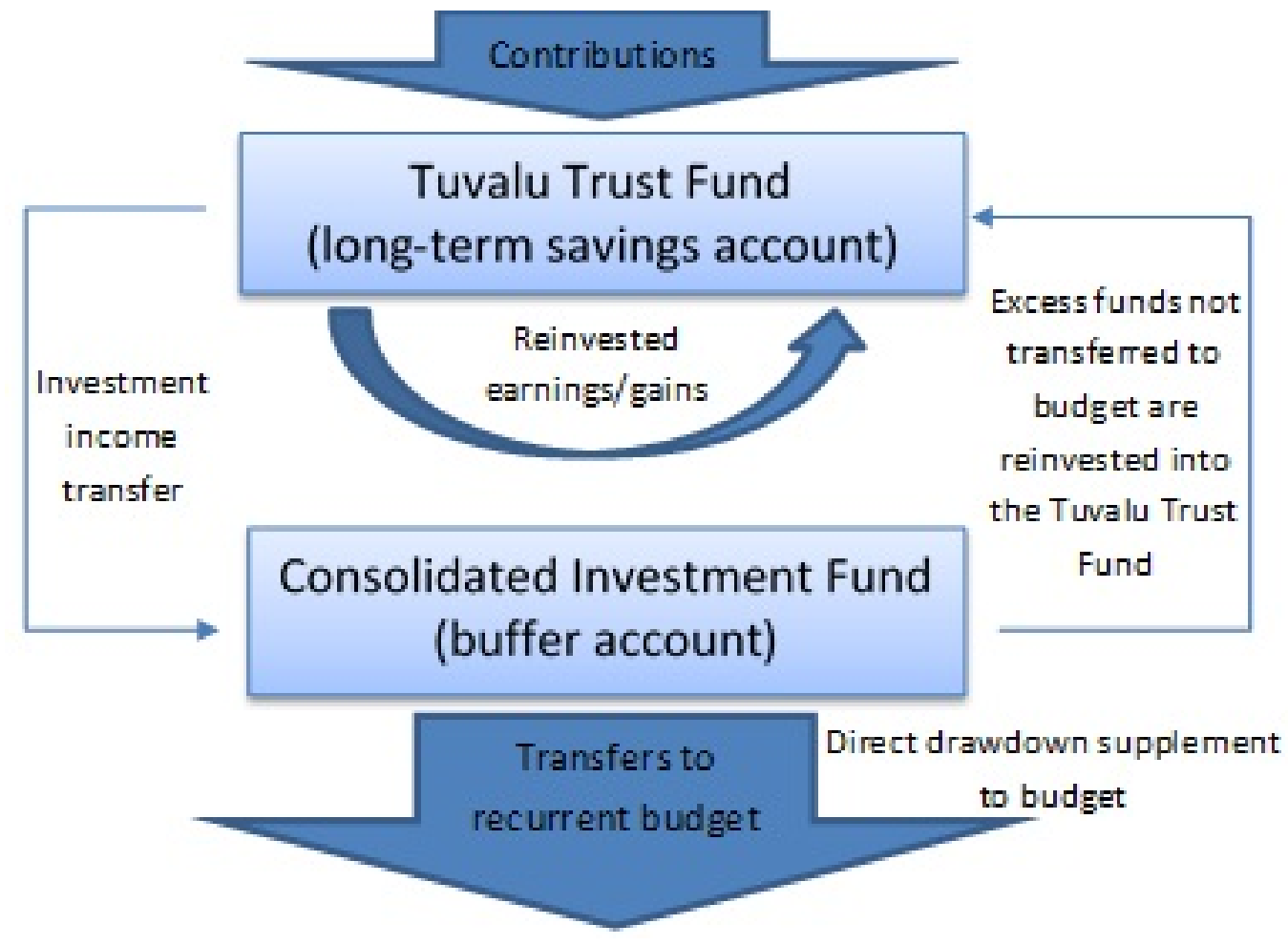

Figure 4.5: Tuvalu Trust Fund resource flow

structure. ${ }^{23}$ Any excess of funds in the CIF that are not transferred to the government budget are either stored in the CIF or reinvested back into the TTF.

Despite the TTF being widely viewed as a success, there has been dissatisfaction with its rigidity in the face of economic shocks, e.g. in the case of the global financial crisis where a fall in the value of the fund left the government unable to withdraw funds to respond to the crisis. The global financial crisis affected the TTF from 2008 to 2012. ${ }^{24}$ However, the CIF account (i.e. the buffer account) was instrumental in stabilizing the long-term financial situation of the government of Tuvalu during the crisis, hence the government was able to draw money from it to support the national budget over that five-year period.

Figure 4.6 shows a potential alternative structure for the SWF, proposing to

\footnotetext{
${ }^{23}$ Other Pacific Islands without SWFs and buffer accounts meet national budget deficits by borrowing at high interest rates.

${ }^{24}$ During the global financial crisis, there were no automatic distributions from the TTF to the CIF because the market value of the fund was less than its maintained value (or real market value).
} 
connect the TTF to a disaster fund. In this proposal, the TTF will provide support to the disaster fund in terms of contributions. This arrangement extends the current structure in Figure 4.5 to allow for both development partners and the government of Tuvalu (through own revenue sources and from the CIF) to contribute into the disaster fund. In this setup, the disaster fund can be both drawn down for natural disaster purposes and contribute to the TTF when it is successful and sustainable in the future. ${ }^{25}$

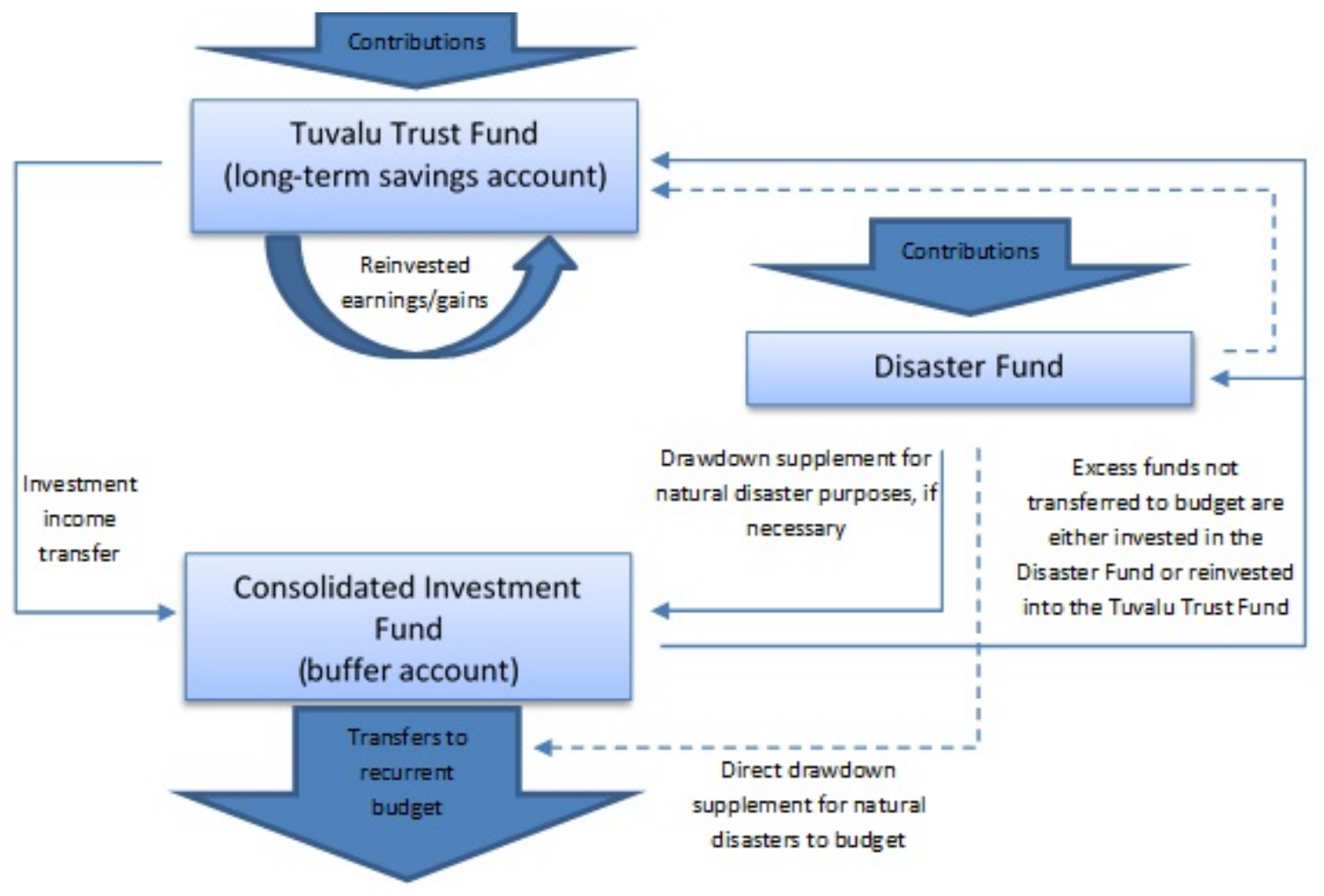

Figure 4.6: Alternative Tuvalu Trust Fund resource flow

One of the priority goals set out in the 2015 National Summit on Sustainable Development for Tuvalu is to protect the nation from the impacts of climate change through better resilience, mitigation, and adaptation. Parallel to this goal is the commitment of the government to establish in its national budget the 'Tuvalu Survival Fund', to financially support the building of resilience in communities, disaster response, and climate proofing infrastructure (Ministry of Finance and Economic Development, 2016). ${ }^{26}$ Kiribati has a disaster fund in place.

\footnotetext{
${ }^{25} \mathrm{~A}$ stylized illustration of this alternate setup is in the appendix Figure 4.G.1 and Figure 4.G.2.

${ }^{26}$ At the wake of the TC Pam, the political will to establish a disaster fund known as the 'Tuvalu
} 
CHAPTER 4. FINANCING CLIMATE AND DISASTER RESILIENCE IN ATOLL ISLANDS: EVIDENCE FROM TUVALU AND KIRIBATI

The sizes of these SWFs and the increasing income they generate display their national importance. ${ }^{27}$ Therefore, safeguarding and ensuring that these funds are put into efficient, effective, and sustainable use is paramount. ${ }^{28}$ Suggestions have further emerged on the potential of these funds to act as financial instruments to facilitate disaster risk reduction. Since small, low-lying atoll islands are vulnerable and exposed to climatic disasters, the focus on designing strong buffers with sustainable financing mechanisms to counter these unexpected shocks is imperative. Currently, the TTF is quite instrumental in providing responses to external economic shocks, but excludes natural disasters from its mandate. It could be argued that the TTF (or the CIF) should complement current preparation and response efforts to climatic disasters.

In relation to managing the performance of these funds, global market uncertainties and volatilities remains an issue. However, Tuvalu and Kiribati are mindful that strong fiscal performance can be attributed to projected fiscal surpluses, increase in revenues from grants and fishing licenses, and increasing contributions into their funds. Apart from other revenue sources, both countries earn from tuna catches, through fisheries agreements for foreign vessels to fish in their sea territories.

\subsection{Data and Methods}

We employed the Monte Carlo (MC) simulation method and an Auto-Regressive Integrated Moving Average (ARIMA) model to forecast the future values of the TTF and RERF. The MC simulation method was used to model the probability of possible outcomes while the forecasting technique of the ARIMA model enabled us to project future values and/or trends from our time series data. We used time series data on both the TTF and RERF. Data are yearly from financial years 1987 to 2016 and

Survival Fund' surfaced.

${ }^{27}$ In 2016, the market values of the TTF and RERF were $\$ 160,000,000$ and $\$ 868,100,000$, respectively.

${ }^{28}$ Over the years, these funds have gained a reputation for prudent management guided by explicit rules that are subject to parliamentary scrutiny. The Asian Development Bank (ADB) and Angelo et al. (2016) consider the Tuvalu Trust Fund (TTF) the most successful public fund in the Pacific, in terms of clear establishment structure by a treaty, clear purpose, and being a management and investment policy that deserves a model reputation for effective use of trust funds for small island state economic development (http://www.radionz.co.nz/international/pacific-news/ 155763/adb-says-tuvalu-trust-fund-considered-most-successful-in-pacific). 
1984 to 2016 for Tuvalu and Kiribati, respectively. Data on the TTF were gathered from the TTF Secretariat of the Tuvalu Government, while the RERF annual values were acquired from the Kiribati's Ministry of Finance and Economic Development. ${ }^{29}$ Annual reports on the Funds and the national budgets were also used to complement these data. ${ }^{30}$

\subsubsection{Monte Carlo Simulation Method}

The MC simulation (or stochastic sampling) method generates random numbers with a given probability distribution. ${ }^{31}$ We used it on an investment portfolio with a given starting value, an average annual return value, a standard deviation or volatility of return per annum, and assumptions on possible reinvestment and withdrawals. Similarly, Wulfsohn (2015) analysed the impact of investment return uncertainty on the long-term sustainability and stability of income from the Compact Trust Funds (CTFs) in the North Pacific, covering the Republic of the Marshall Islands (RMI) and the Federated States of Micronesia (FSM). He used a Monte Carlo investment return simulation model to simulate the effects of investment return volatility.

An example is when we generate a random rate of return for one year from today by using a function that assumes that the rate of return follows a normal distribution, where the average of that normal distribution is the average rate of return with the observed historical volatility. The historical average rates of return are $7.06 \%$ and $4.7 \%$ for TTF and RERF, respectively. Likewise, the standard deviation of return

\footnotetext{
${ }^{29}$ Data for RERF were gathered from both the Ministry of Finance \& Economic Development and their official website (http://www.mfed.gov.ki/).

${ }^{30}$ Other Pacific Islands with SWFs were also approached for their data, but declined.

${ }^{31}$ There are two main categories of MC method, namely MC simulation (or stochastic sampling) and MC integration. For our case, we used the Monte Carlo simulation method which runs an algorithm that generates random numbers with given probability distribution. A function that returns the value of $x$ such that, with the probability $p$, a normal random variable with mean $\mu$ and standard deviation $\sigma$ takes on a value less than or equal to $x$. The parameters mean $\mu$ (the average rate of return) and standard deviation $\sigma$ (standard deviation of return) with the given starting value of the fund, average annual reinvestment, and the average annual drawdown were used in our randomly generated simulation to return $x$ values. See Glasserman (2003) and Kalos and Whitlock (2008) for discussion on the development of MC methods and their application to financial engineering. Generating of random numbers and random variables are thorougly discussed in Bratley et al. (1987), Devroye (1986), Niederreiter (1992), Fishman (1996), Gentle (1998), and others.
} 
CHAPTER 4. FINANCING CLIMATE AND DISASTER RESILIENCE IN ATOLL ISLANDS: EVIDENCE FROM TUVALU AND KIRIBATI

is $5.04 \%$ and $3.5 \%$ for TTF and RERF, respectively. For the ending balance, we multiply the beginning balance by the annual randomly generated rate of return and add assumptions (e.g., additional investment) at the end of each year. A stream of possible returns is calculated for up to 34 years (i.e., from 2017 to 2050). Therefore, one possible outcome is ending with about $\$ 1$ billion in 2050 . We set up and generate 10,000 possible ending values for our portfolio, and from that we will have a reasonable idea of what our ending value could be. We examine the distribution of these possible scenarios, and calculate the $5 \%$ percentile of possible ending values and get $\$ 300$ million. So, based on these scenarios, we conclude there is a $95 \%$ chance that the TTF will have more than $\$ 300$ million (or $5 \%$ chance ending with less than $\$ 300$ million) at the end of 34 years, if returns continue as they historically have.

\subsubsection{ARIMA Models}

We used the ARIMA model proposed by Box and Jenkins (1970), which is an extension of the Auto-Regressive Moving Average (ARMA) model. ${ }^{32}$ The ARMA is the combination of Auto-Regressive (AR) and Moving Average (MA) models (thus it combines both $p$ autoregressive terms and $q$ moving average terms), both of which model lagged values of $y_{t}$ and $\varepsilon_{t}$ past errors as predictors (see e.g., Diebold, 2006). The first component in the ARMA model is the AR model, where the value in a period is related to its values in previous periods. Hence, $A R(p)$ is an autoregressive model with $p$ lags where $y_{t}=\mu+\varepsilon_{t}+\sum_{i=1}^{p} \gamma_{i} y_{t-i}$. The second component is the MA model, which accounts for the relationship between a variable in a period and the residuals in previous periods. Therefore, $M A(q)$ is a model of moving average with $q$ lags, where $y_{t}=\mu+\varepsilon_{t}+\sum_{i=1}^{q} \theta_{i} \varepsilon_{t-i}$. Hence, we arrive on the ARIMA model where $d$ is the required degree of differencing to make the series stationary, for instance, a first order differences in $y_{t}$ is the differenced variable $\Delta y_{t}=y_{t}-y_{t-1}$ (Box and Jenkins, 1970, 1976; Hyndman and Athanasopoulos, 2014). Therefore, an $A R I M A(p, d, q)$ represents a model with $p$ autoregressive lags, $q$ moving average lags, and a difference in the order of $d$ as given in Equation 4.1:

\footnotetext{
${ }^{32}$ ARIMA is sometimes referred to as the integrated ARMA model. See Diebold (2006) for detail discussions on AR, MA, and ARMA models.
} 


$$
y_{i}^{d}=\mu+\sum_{i=1}^{p} \gamma_{i} y_{t-i}^{d}+\varepsilon_{t}+\sum_{i=1}^{q} \theta_{i} \varepsilon_{t-i}
$$

Here, values of our dependent variable $y$, measured in time, $t$, that is represented by $y_{t}$ are affected by the values of $y$ in the past (or lags), $\mu$ is a constant, $\gamma_{p}$ is the coefficient for the lagged variable in time $t-p, \varepsilon_{t}$ is the error term at time $t$, and $\theta_{q}$ is the coefficient for the lagged error term in time $t-q \cdot{ }^{33}$

The stationarity condition is a requirement in modelling an $\operatorname{ARMA}(p, q)$ process, where the mean and variance does not change over time and the process does not have trends. When this condition is unmet, then non-stationary is evident in the data and we cannot use ARMA. However, we can resort to the Box-Jenkins procedures (see Box and Jenkins, 1976) by using an ARIMA model (see Equation 4.1), which is the reason we chose ARIMA instead of ARMA. ${ }^{34}$ We follow the Box-Jenkins method for ARIMA model selection in our diagnostics, where we use the Dickey-Fuller tests for stationarity ${ }^{35}$, Autocorrelation Function and Partial Autocorrelation Function for correlations, and Akaike Information Criterion (AIC) and the Bayesian Information Criterion (BIC) measures for goodness of fit of the model (see Box and Jenkins, 1976; Makridakis et al., 1997).

\subsection{Results and Discussions}

In the following, we assess risk estimates supplied by the Pacific Catastrophe Risk Assessment and Financing Initiative (PCRAFI) for Tuvalu and Kiribati to determine the required contributions into disaster funds before discussing the forecast results from the two models under discussion.

\footnotetext{
${ }^{33}$ In this ARIMA setup we have the time series data of the TTF and RERF, therefore y refers to the SWF values of TTF and RERF.

${ }^{34}$ The Box-Jenkins procedures follows the four steps: 1) preliminary transformation; 2) identification; 3) estimation of the model; and 4) diagnostic checking. Makridakis et al. (1997) further discusses the use of Box-Jenkins methods for ARIMA models, while Nasiru and Olanrewaju (2015) employed these methods.

${ }^{35}$ This procedure requires the differencing of the time series until it is stationary, this will ensure the removal of any trend or seasonal components.
} 
CHAPTER 4. FINANCING CLIMATE AND DISASTER RESILIENCE IN ATOLL ISLANDS: EVIDENCE FROM TUVALU AND KIRIBATI

\subsubsection{Assessing Risk and Determining Contribution to Disaster Funds}

Predictions of cyclone risks have been underestimated in the Pacific, particularly for low-lying atoll islands (Noy, 2016a). To compute appropriate values required for contributions from SWFs into disaster funds, we started with the current estimated Average Annual Loss (AAL) calculated by PCRAFI for the two countries. ${ }^{36}$ The computed AAL from PCRAFI estimates that annual economic losses averaged over the 10,000 simulations of next-year activity. Moreover, the adverse consequences are measured from expected losses for three assets consisting of buildings, major infrastructure, and valuable crops World Bank (2013b). However, the models used by PCRAFI in risk analysis only calculate losses from earthquakes and tropical cyclones. Therefore, in addition to the AALs produced by PCRAFI, we consider unaccounted factors for low-lying atolls, namely: (1) distant cyclones; (2) climate change; (3) droughts, and (4) sea level rise.

Firstly, the PCRAFI model did not recognize distant cyclones such as Tropical Cyclone Pam (TC Pam) and Tropical Cyclone Ula (TC Ula) as potential disasters for low-lying islands like Tuvalu. They only accounted for nearby cyclones in their models. Recently, Taupo and Noy (2016) quantified the impacts of a distant cyclone (TC Pam) which passed about 1,000 km away from Tuvalu. We accounted for distant cyclones by using the estimated cost of damages from TC Pam, for instance, and the loss and damages for Tuvalu at $10 \%$ of GDP based on both the ADB (2015) and Taupo and Noy $(2016)^{37}$. Even Kiribati, which was much further away from TC Pam's path than Tuvalu, was severely affected, with damages estimated by the International Monetary Fund (2016) at around 4\% of GDP. ${ }^{38}$ According to the World Bank (2016), a Category 5 cyclone has been a 1 in 10 year event ${ }^{39}$ for Fiji, Tonga

\footnotetext{
${ }^{36}$ Hallegatte (2013) discusses the basic measure that assesses the exposure of assets during a catastrophe, called the Exceedance Probability (EP) curve, where the area below the constructed EP curve is the AAL, which is the expected amount of loss on average per year for a certain location.

${ }^{37}$ Estimated damages of $\$ 4.12$ million for Tuvalu. The World Bank (2016) estimated more than USD $\$ 10$ million in damage, which is equivalent to $27 \%$ of the GDP. The World Bank (2015a) had a higher estimate of overall costs, standing at $\$ 14$ million or $33.6 \%$ of GDP.

${ }^{38}$ See International Monetary Fund (2016) and IFRC (2016) for details on the impacts of TC Pam, particularly on Kiribati.

${ }^{39} \mathrm{~A} 1$ in 10 -year event is the probability of occurrence in any given year which also means a recurrence interval of 10 years (or return period of 10 years) or a $10 \%$ chance of occurrence in any
} 
and Samoa, while the cyclone return period for the Solomon Islands and Vanuatu is 1 in 5 year event. ${ }^{40}$ In this connection, we used a 1 in 10 year scenario for our distant cyclone calculations. ${ }^{41}$ Building onto the PCRAFI AAL, we then adjusted the current AAL to include distant cyclones, thus increasing it to $\$ 731,738$ (or an increase of $128 \%$ ) for Tuvalu. ${ }^{42}$ Similarly, we also adjusted the AAL for Kiribati to include distant cyclones, which amounted to $\$ 1,219,704$ (or an increase by $221 \%$ ). ${ }^{43}$

Secondly, the expected changes in frequency and intensity of cyclones are of serious concern for low-lying SIDS. We therefore incorporated the effects of climate change over time into our calculations of AALs. In accounting for these characteristics of cyclones, we: 1) allowed for a 9\% increase in intensity (or strength of winds) of cyclones within the South Pacific, as was calculated in Noy $(2016 a)^{44}$; 2) adjust for the cyclone damage related to the $3.8^{t h}$ power of wind speed measure stated by Strobl (2012) in his paper on hurricanes in the Caribbean; and 3) account for the $2 \%$ decrease in cyclone frequency in the South Pacific that was argued by Noy (2016a). Since the effects of the increase cyclone intensity are far more significant than the effects of the decrease cyclone frequency, the overall impact of climate change is likely to be highly destructive. ${ }^{45}$ These expected changes are reflected in our cyclone AAL

given year.

${ }^{40}$ According to the Australian Bureau of Meteorology and CSIRO (2011, p.234), "the tropical cyclone archive for the Southern Hemisphere indicates that between the 1969/70 and 2006/07 cyclone seasons the centre of 33 tropical cyclones passed within approximately $400 \mathrm{~km}$ of Funafuti. This represents an average of eight cyclones per decade. Tropical cyclones were most frequent in El Nino years (12 cyclones per decade) and least frequent in La Nina years (four cyclones per decade)."

${ }^{41}$ Assuming that a Category 5 cyclone close to Vanuatu and the Solomon Islands are likely to be encountered as distant cyclones like TC Pam. Vanuatu was the closest to the TC Pam when it was within Category 5 strength, hence it was extremely affected with attributable loss and damages amounting to USD $\$ 449.4$ million which is equivalent to $64.1 \%$ of GDP (Government of Vanuatu, 2015).

${ }^{42}$ For consistency, since both Tuvalu and Kiribati use Australian Dollars (AUD), unless stated in other currencies we will use the AUD with a currency conversion rate of USD $\$ 1=$ AUD $\$ 1.31197$. The adjusted AAL for Tuvalu is derived from the sum of the current AAL USD $\$ 243,709=$ AUD $\$ 319,738$ and the distant cyclone part of $\$ 412,000$ (i.e., $\$ 4.12$ million or $10 \%$ of GDP, divided by the distant cyclone return period of 10).

${ }^{43}$ In 2015 prices, Kiribati's GDP was USD $\$ 160,121,929$ (or AUD $\$ 210,075,167$ ). The adjusted AAL for Kiribati is derived from the sum of the current AAL USD $\$ 289,186=$ AUD $\$ 379,403$ and the distant cyclone component of $\$ 840,301$ (i.e., $\$ 8,403,006$ or $4 \%$ of GDP, divided by the distant cyclone return period of 10).

${ }^{44}$ Noy (2016a) calculations on changes in frequency and intensity of cyclones are based from Siqueira et al. (2014).

${ }^{45}$ Since the cyclone intensity is about $30 \%$ stronger and the cyclone frequency is only $-2 \%$. 


\section{CHAPTER 4. FINANCING CLIMATE AND DISASTER RESILIENCE IN ATOLL ISLANDS: EVIDENCE FROM TUVALU AND KIRIBATI}

readjustments. To proceed, we separate the two AAL components of earthquakes and cyclones so we can readjust the cyclone part to account for distant cyclones, and for climate change in terms of potential changes in cyclone intensity and frequency. Hence, the adjusted overall AAL derived by accounting for earthquakes, cyclones, distant cyclones and climate change is $\$ 918,277 .{ }^{46}$ Similarly, Kiribati will likely incur an overall AAL of $\$ 1,567,461 .^{47}$

Thirdly, we accounted for droughts by using the estimated costs from a recent severe drought event and the expected drought return period. There are very few reports that assess the monetary costs of droughts in the South Pacific. ${ }^{48}$ According to the DesInventar Database, Tuvalu suffered monetary losses of USD $\$ 15$ million due to the drought in 1998, which was around $117 \%$ of GDP. ${ }^{49}$ It seems that the calculated losses may have been overestimated, so we resorted to calculating the impact of the drought using available information from the most recent 2011 drought report by Sinclair et al. (2012). Based on our summations from the report, the estimated loss and damage to Tuvalu was $\$ 2,072,045$, around $4 \%$ of 2011 GDP. ${ }^{50}$ The Australian Bureau of Meteorology and CSIRO (2011) projected severe drought occurrence once every 20 years for Tuvalu. Therefore, our AAL for the drought in Tuvalu corresponds

\footnotetext{
${ }^{46}$ Since our PCRAFI AAL represents the combination values of earthquakes and cyclones, we then split the cyclone component to enable us to compute the effects of cyclone intensity and frequency. First, we extracted the cyclone component, $33 \%$ of the original AAL $(\$ 106,579)$ and added the distant cyclone AAL of $\$ 412,000$, which sums up to $\$ 518,579$. Then we multiplied by $1.09^{3.8}$ to capture the cyclone intensity, thus arriving at $\$ 719,508$. Then we multiplied by frequency change of 0.98 to arrive at $\$ 705,118$, or the adjusted AAL (including cyclones, distant cyclones, cyclone intensity, cyclone frequency) without the earthquake component. So, adding the earthquake component of $\$ 213,159$ back into the AAL corresponds to the adjusted overall AAL of $\$ 918,277$.

${ }^{47}$ Likewise, for Kiribati, we multiplied straight the distant cyclone AAL of $\$ 840,301$ with $1.09^{3.8}$ to capture the cyclone intensity effects, thus arriving at $\$ 1,341,353$. Then we multiplied by the frequency change of 0.98 to come up at $\$ 1,314,526$ or the adjusted AAL (including cyclones, distant cyclones, cyclone intensity, cyclone frequency) without the earthquake component. So, adding the earthquake component $(\$ 379,403)$ back into the AALs corresponds to the adjusted overall AAL of $\$ 1,567,461$.

${ }^{48}$ Not only that, the impact of a drought depends on factors such as the drought's length, meaning it is often hard to quantify the impacts of droughts in monetary values in relation to agriculture and health associated costs.

${ }^{49}$ DesInventar database also recorded the 2011 drought, but with no monetary losses. The EM-DAT database did not record the 2011 drought for Tuvalu, but recorded the 2009 drought for Kiribati.

${ }^{50} \mathrm{GDP}$ of USD $\$ 39,312,016$ or AUD $\$ 51,576,185$, according to the World Bank. Note that the calculated costs from the 2011 drought only include impact on agriculture, while excluding health due to its complexity in translating to monetary values. For agriculture, we used ArcGIS software to compute plantation areas and used market prices in our calculations.
} 
to $\$ 103,602$. Extrapolating our computations from the case of Tuvalu for Kiribati results in expected costs of $\$ 10,153,021$, with an AAL of $\$ 507,723 .{ }^{51}$ Hereafter, the adjusted overall AALs for Tuvalu and Kiribati now correspond to $\$ 1,021,879$ and $\$ 2,075,112$, respectively.

Lastly, we used the effects of an increase in sea level for the case of Funafuti (capital of Tuvalu), where an increase by one meter in sea level would leave $15 \%$ of the land inundated on Funafuti Island (see map in Figure 4.C.1). Noy (2016a) shows that the sea level in Tuvalu is projected to rise up by $24 \mathrm{~cm}$ by 2050. Arguably, this increase would inundate $7.8 \%$ of the land. Sea level rise would exacerbate the impact of cyclones and tsunamis in this context. Therefore, we factored the expected increase in sea level into the AALs. This is reflected in an increase in overall expected AALs to $\$ 1,101,586$ and $\$ 2,236,971$ for Tuvalu and Kiribati, respectively. ${ }^{52}$ These AALs corresponds to $2.45 \%$ of GDP for Tuvalu and $1.06 \%$ for Kiribati.

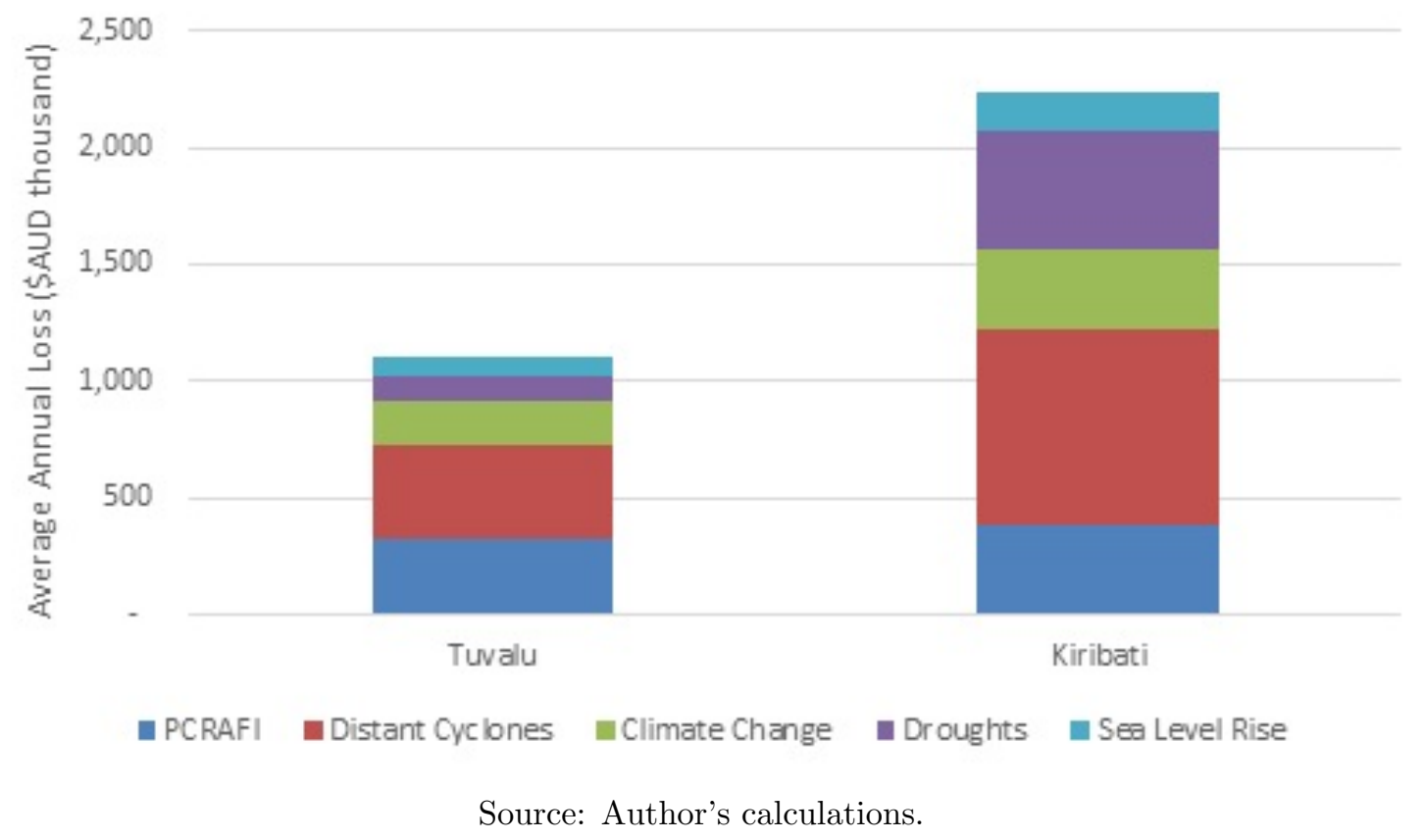

Figure 4.7: Annual Average Loss (AAL) adjustments for Tuvalu and Kiribati

\footnotetext{
${ }^{51}$ In 2015 prices, Kiribati's economy is 4.9 (i.e., USD160,121,929/USD32,673,277) times bigger than Tuvalu's economy. Multiplying the cost of the drought (AUD $\$ 2,072,045$ ) by 4.9 results to AUD $\$ 10,153,021$ (i.e., $4.83 \%$ of GDP), which is the expected cost of the disaster for Kiribati. Therefore, dividing the drought's estimated cost of AUD $\$ 10,153,021$ by the Kiribati's GDP of AUD $\$ 210,075,167$ then multiply by a 100 to convert to percentage, we get $4.83 \%$.

${ }^{52}$ Multiplied overall AAL with 1.078.
} 
CHAPTER 4. FINANCING CLIMATE AND DISASTER RESILIENCE IN ATOLL ISLANDS: EVIDENCE FROM TUVALU AND KIRIBATI

Figure 4.7 illustrates the adjusted AALs for Tuvalu and Kiribati, built on current PCRAFI AALs and adjusted to account for distant cyclones, climate change, droughts, and sea level rise. Under these conditions, the TTF and RERF would have amassed overall estimated contributions to their disaster funds at the end of the financial year 2050 in the order of $\$ 37.5$ million and $\$ 76.1$ million, respectively. ${ }^{53}$ In the following section, we will present the forecasting results for the two SWFs together with scenarios including estimated contributions to their disaster funds using the two forecasting approaches discussed below.

\subsubsection{Investment Return Simulation}

The progression of the size of these SWFs over time, including inputs of drawdowns and investments according to their account structure and rules are set out in Figure 4.8 and Figure 4.9 for the TTF and RERF, respectively. Generally, they show the distribution and spread of possible values (or ending outcomes) of the funds over time. The $95^{\text {th }}$ percentile line can be interpreted as having $95 \%$ of simulations below it (and 5\% simulations above). Likewise, $5 \%$ of simulations are below the $5^{\text {th }}$ percentile line (and 95\% simulations above). The median is represented by the $50^{\text {th }}$ percentile. A customary perception for an investment portfolio is the notion of increasing uncertainty as we stretch time further into the future, which is portrayed by the widening gap between the different percentile lines (see Figure 4.8 and Figure 4.9).

As well as the forecasted median ( $50^{\text {th }}$ percentile) of the SWF without any contributions to a disaster fund in Figure 4.8 and Figure 4.9, we added two other forecasted median scenarios, namely: 1) Disaster_aal (unbroken blue graph) representing the $50^{\text {th }}$ percentile with contributions to a disaster fund using the adjusted AAL as the annual contribution over time; and 2) Disaster_swf (unbroken orange graph) representing the $50^{\text {th }}$ percentile with contributions to a disaster fund derived from the adjusted AAL in relation to the SWF. The adjustments in (2) correspond to annual contributions as a percentage of the SWF. ${ }^{54}$ This pathway of

\footnotetext{
${ }^{53}$ These figures are direct contributions from the TTF to the disaster fund in 2016 prices, excluding other contributions from other potential sources. The values were derived from summing up of the adjusted PCRAFI AALs that accounts for distant cyclones, climate change, droughts, and sea level for the years from 2017 to 2050 (see Table 4.H.1 in the Appendix).

${ }^{54}$ We used the adjusted AAL as a percentage of SWF size in 2016 values for our annual contribution
} 


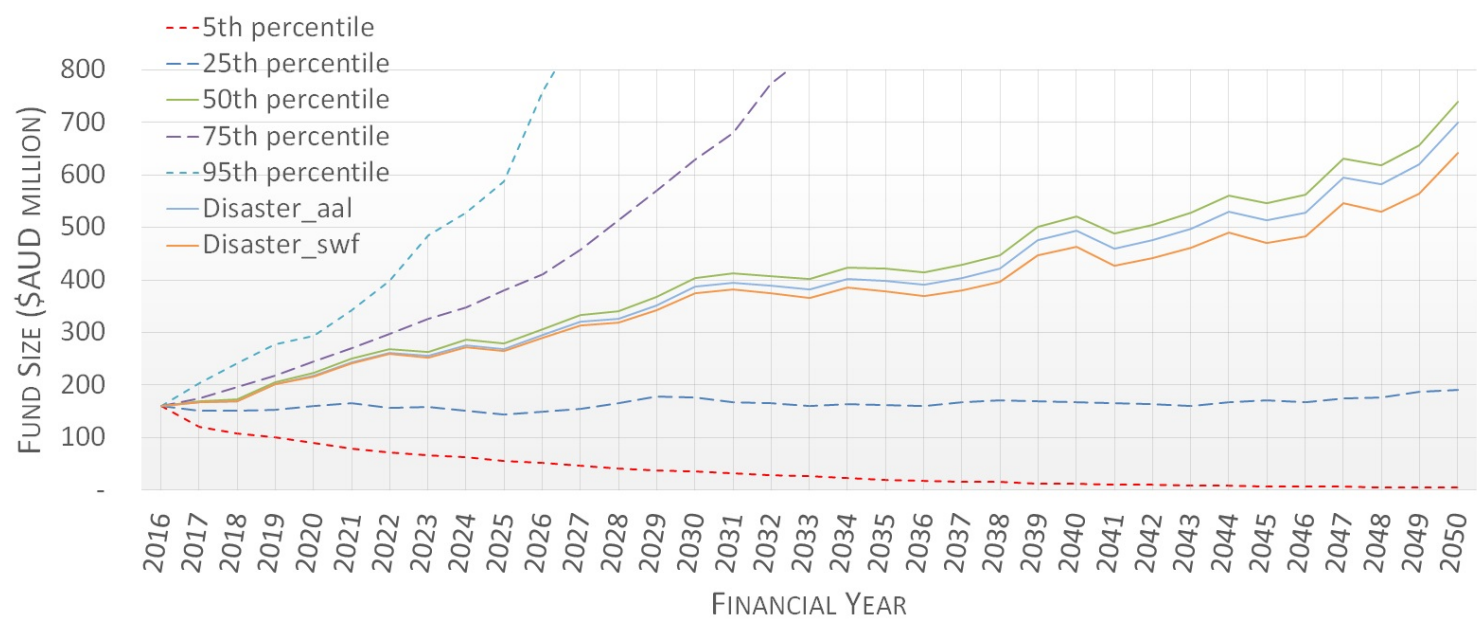

Source: Author's calculations and modelling. The disaster_aal is the $50^{\text {th }}$ percentile of TTF with incorporated contributions to the disaster fund using the adjusted AAL (fixed based on the calculated AAL in 2016 prices) as the annual contribution over time. The disaster_swf is the $50^{\text {th }}$ percentile of the TTF with adjusted calculations to include the adjusted AAL as a percentage of the TTF, so that it changes overtime based on forecasted values of the TTF.

Figure 4.8: TTF forecast performance from 2017 to 2050 with MC simulations

using the percentage of AAL on SWF would accumulate total estimated contributions by 2050 of about $\$ 97$ million for TTF and $\$ 126$ million for RERF. ${ }^{55}$ Figure 4.8 and Figure 4.9 reveal that the TTF and RERF have around $50 \%$ chance of reaching $\$ 0.73$ billion and $\$ 1.73$ billion by 2050 , respectively. ${ }^{56}$

Intuitively, the effects of contributing to a disaster fund in the forecasted performance of the SWFs are displayed by a downward shift in the median with an increasing gap as we move into the future. Both the TTF and RERF are sustainable in the long run without any contributions to their disaster funds as they have upward

(i.e., $0.685 \%$ and $0.288 \%$ for TTF and RERF, respectively), thus continuously using this percentage over time, therefore the annual contributions changes over time based on the SWF size, which is sustainable in a sense.

${ }^{55}$ This aim for the TTF maintained value to reach $\$ 200$ million by 2020 was raised in the 2015 TTF Board Meeting (I attended this closed meeting on November, 2015) and later became a goal in the 2017 National Budget of Tuvalu (see Ministry of Finance and Economic Development, 2016). This target was also raised by the Minister of Finance \& Economic Development (Hon. Maatia Toafa) in the recent parliament session on the $23^{\text {rd }}$ of March, 2017, which was accessed on a live stream of the radio Tuvalu on http://listen28radiocom.radiostream321.com/. Based on the model, Figure 4.8 shows that the TTF has about $50 \%$ chance of meeting the Government's aim to reach $\$ 200$ million by 2020 .

${ }^{56} \mathrm{TTF}$ is much larger than RERF in per capita terms. 
CHAPTER 4. FINANCING CLIMATE AND DISASTER RESILIENCE IN ATOLL ISLANDS: EVIDENCE FROM TUVALU AND KIRIBATI

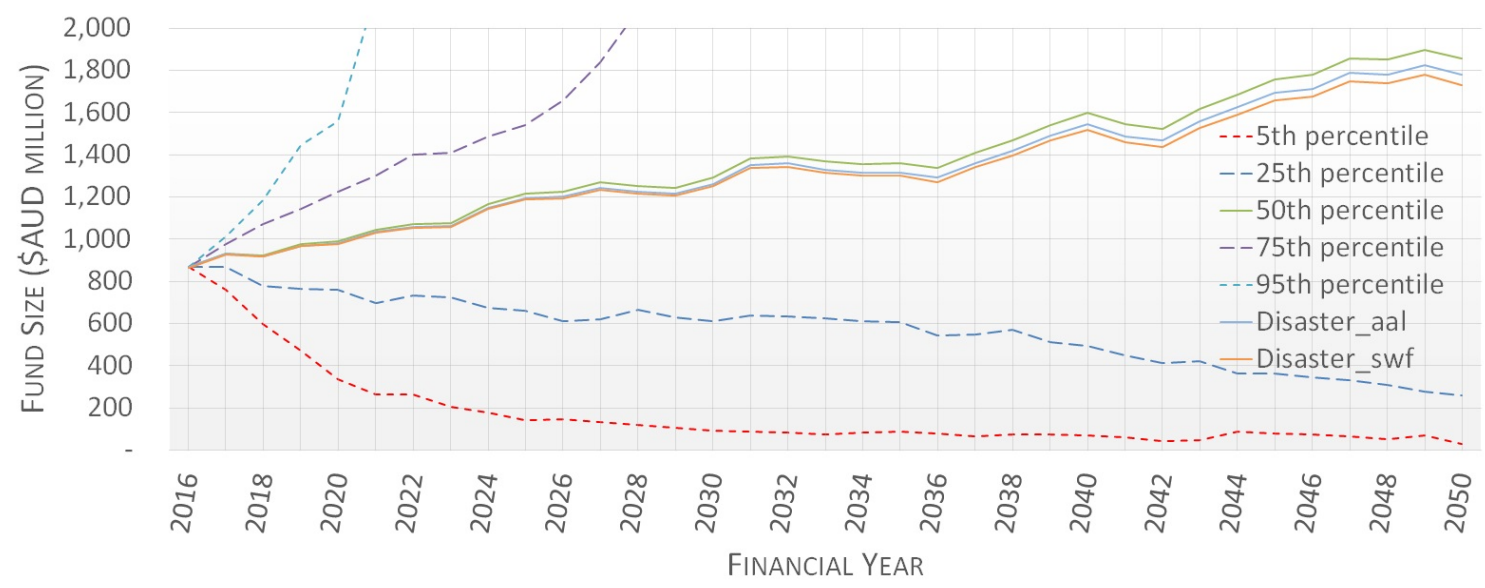

Source: Author's calculations and modelling. The disaster_aal is the $50^{\text {th }}$ percentile of RERF with incorporated contributions to the disaster fund using the adjusted AAL (fixed based on the calculated AAL in 2016 prices) as the annual contribution over time. The disaster_swf is the $50^{\text {th }}$ percentile of the RERF with adjusted calculations to include the adjusted AAL as a percentage of the RERF, so that it changes overtime based on forecasted values of the RERF.

Figure 4.9: RERF forecast performance from 2017 to 2050 with MC simulations

trends in the median over time. Similarly, these SWFs are also sustainable in the long-term if they contribute to their disaster funds but at a lower median over time. To further substantiate this argument, we plotted the ratio of the SWFs to projected GDP to examine how sustainable the size of the SWFs will be in relative to the GDP (see Figure 4.E.1 and Figure 4.E.2). However, contributing to disaster funds from a SWF poses risks to the growth and development of SWF itself.

\subsubsection{ARIMA Models}

To formally test for stationarity for both TTF and RERF data, we used the Dickey Fuller test, with which the results showed that the original variables are not stationary, but that the differences variables are stationary (see Table 4.A.1) ${ }^{57}$.

\footnotetext{
${ }^{57}$ For TTF, we have $\Delta y_{t}$ as our dependent variable and the independent variable is the first lag of $y_{t}$ which is $y_{t-1}$ where the coefficient of 0.0401 (see Table 4.A.1) is statistically insignificant, therefore it is not significantly different from 0 . Therefore, the variables are non-stationary. Similarly, RERF has original variables that are not stationary. However, both $y_{t-1}$ coefficients for TTF $(-0.97)$ and RERF (-0.764) are highly significant, thus indicating that the variables are stationary.
} 
Therefore, we resorted to the ARIMA model (as oppose to the ARMA model) where we used differences $d=1$. Based on our selection criteria (see Table 4.B.1 and Table 4.B.2), we chose our parsimonious models of ARIMA $(1,1,1)^{58}$ and ARIMA $(1,1,3)$ to forecast the TTF and RERF, respectively, since they both have significant coefficients and lowest AIC and BIC that indicate goodness of fit of the models. The regression equations for $\operatorname{ARIMA}(1,1,1)$ and $\operatorname{ARIMA}(1,1,3)$ for the TTF (Equation 4.2) and RERF (Equation 4.3), respectively, are shown below:

$$
\begin{gathered}
y_{i}^{1}=4,558,357.1+0.89 y_{t-1}^{1}+\varepsilon_{t}+\varepsilon_{t-1} \\
y_{i}^{1}=20,553,135.9+0.677 y_{t-1}^{1}+\varepsilon_{t}-0.632 \varepsilon_{t-1}+0.328 \varepsilon_{t-2}-0.696 \varepsilon_{t-3}
\end{gathered}
$$

Using the ARIMA model with 30 and 33 observations for the TTF and RERF respectively, we were able to generate forecasts for 10 periods (commencing from 2017 to 2026) out into the future with $90 \%$ confidence limits for both funds (see Figure 4.10 and Figure 4.11). ${ }^{59}$ As expected, the forecast bands widen as we move further into the forecast horizon. These forecasts show how SWFs are likely to perform with or without the inclusion of contributions to disaster funds.

Like most other SWFs, both portfolios are vulnerable to economic shocks, as was evident during the global financial crisis of 2007-2008 (see Figure 4.10 and Figure 4.11). The w/o disaster (unbroken green colour) is the expected path of the SWF without annual contributions into the disaster fund. The disaster_aal (unbroken blue colour) is the expected path where the TTF contributes the amount equivalent to the adjusted AAL annually into the disaster fund. Likewise, disaster_swf (unbroken red colour) represents the expected path of an alternative scenario with contributions to the disaster fund derived from the adjusted AAL as a percentage to SWF, which may vary over time depending on SWF size. Nevertheless, both the TTF and RERF

\footnotetext{
${ }^{58}$ For example, an $\operatorname{ARIMA}(2,1,3)$ is where 2 is the order of the autoregressive, 1 indicates the order of difference and 3 is the order of the moving average process.

${ }^{59}$ We also generated forecasts of 34 periods from 2017 to 2050, but these may not be reliable given the limitations of our observations.
} 
CHAPTER 4. FINANCING CLIMATE AND DISASTER RESILIENCE IN ATOLL ISLANDS: EVIDENCE FROM TUVALU AND KIRIBATI

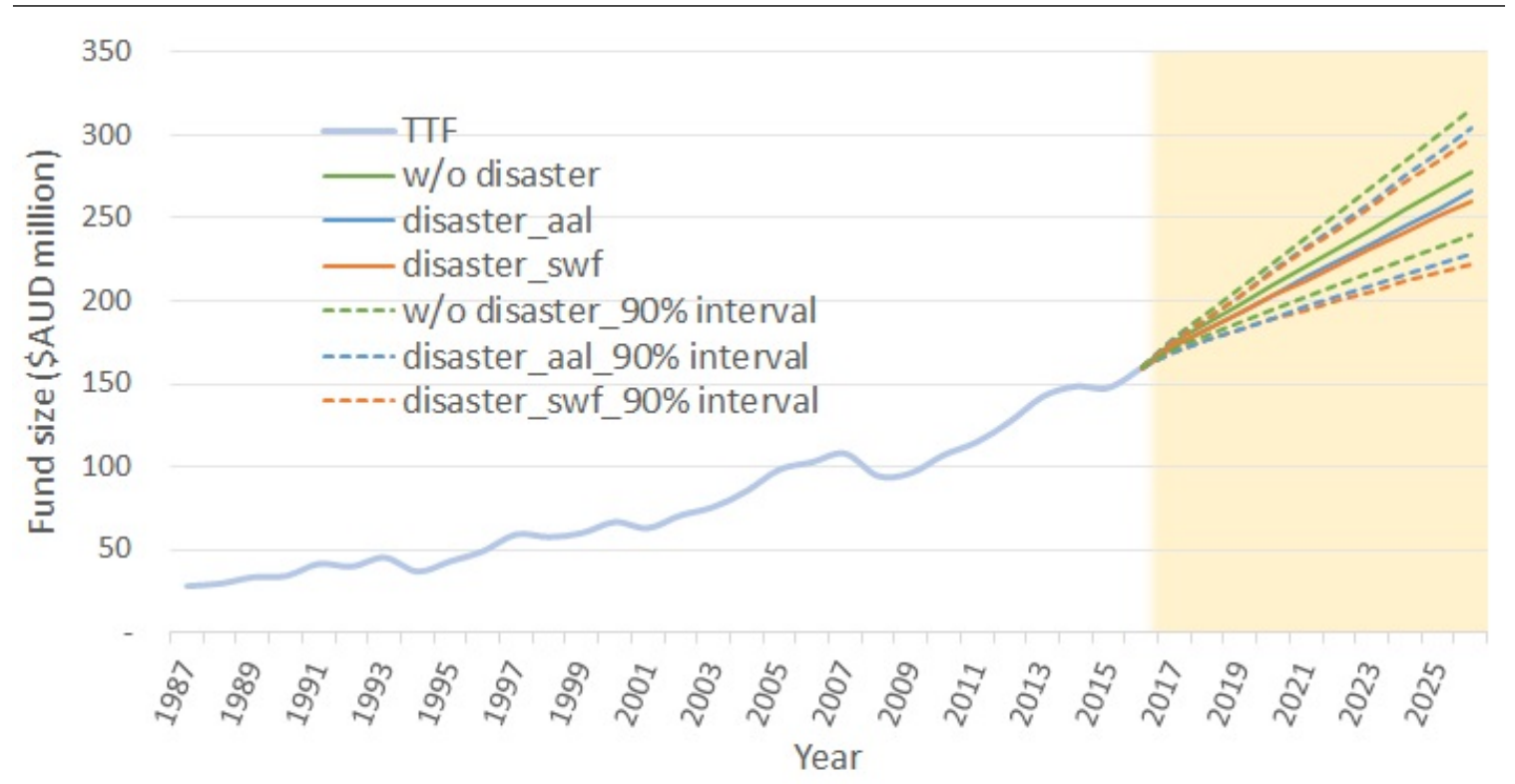

Source: Author's calculations and modelling. The disaster_aal is the TTF with incorporated contributions to the disaster fund using the adjusted AAL (fixed based on the calculated AAL in 2016 prices) as the annual contribution over time. The disaster_swf is the TTF with adjusted calculations to include the adjusted AAL as a percentage of the TTF, so that it changes overtime based on forecasted values of the TTF.

Figure 4.10: TTF forecast performance from 2017 to 2026 using an ARIMA model

have positive trends that indicate sustainability. We also plotted the ratio of the SWFs to projected GDP to further examine how sustainable the size of the SWFs will be in relative to the GDP (see Figure 4.F.1 and Figure 4.F.2).

The impact of the global financial crises of 2008/2009 was evident in the sharp fall of GDP (see Figure 4.3 for Tuvalu) in 2009 and SWF sizes (see Figure 4.10 for TTF and Figure 4.11 for RERF) in those periods. In 2010 it quickly recovered, and continued to increase afterwards in 2011 (see Figure 4.3 for the 2011 drought period) when it started to increase at a decreasing rate. Following the 2011 drought event, GDP levels decreased until they were hit by another disaster (see Figure 4.3 for TC Pam). Similarly, the TTF quickly recovered from a drop in 2008 and 2009, bouncing back in 2010, and has been increasing over time. ${ }^{60}$ It is noticeable in Figure 4.D.1 that the TTF received the highest donor contributions in 2010 (AUD\$3.6 million) and

\footnotetext{
${ }^{60}$ It took 5 years for RERF to recover back to normal and progress onwards (see Figure 4.11). Part of the problem was that from 2003 to 2013 , the government withdrew annually without contributing into the RERF.
} 


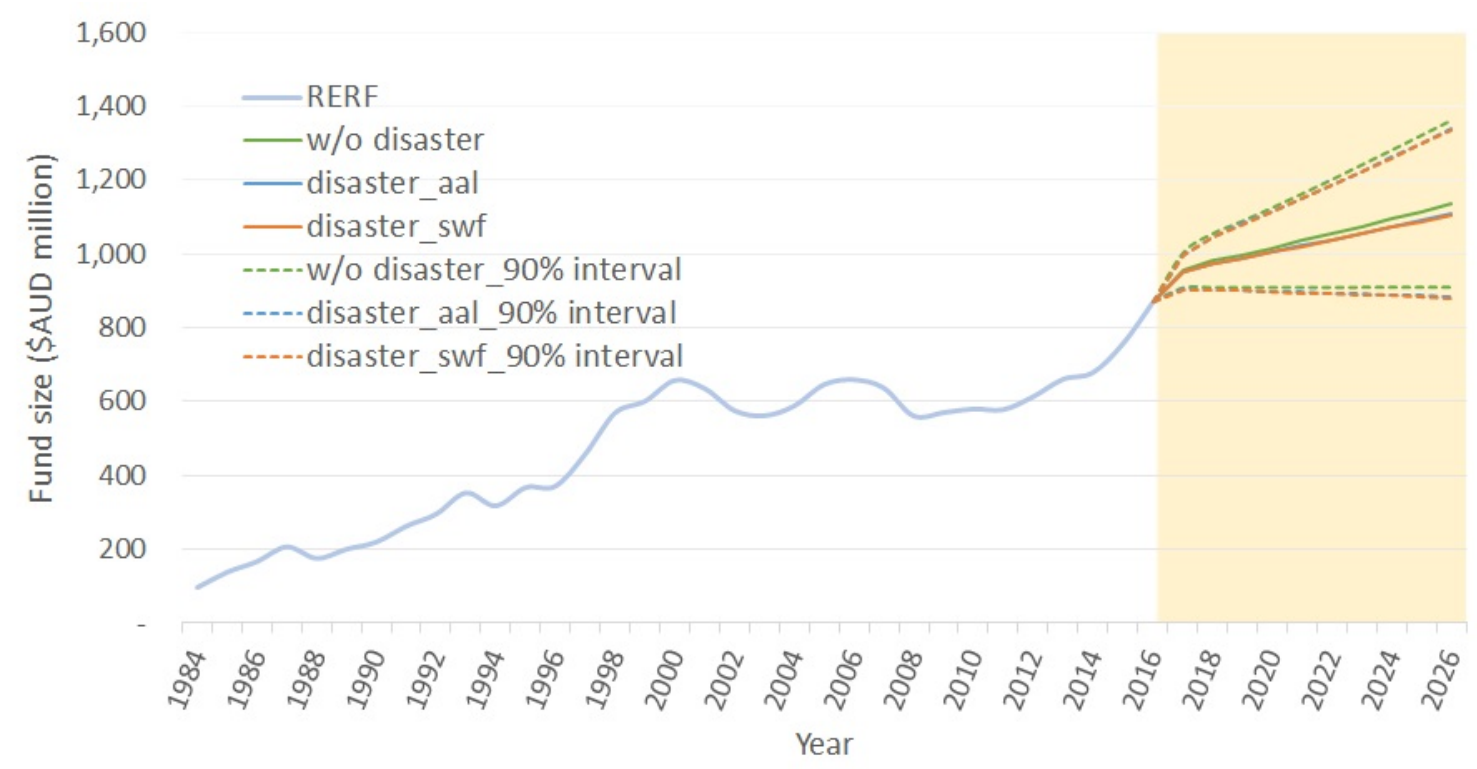

Source: Author's calculations and modelling. The disaster_aal is the RERF with incorporated contributions to the disaster fund using the adjusted AAL (fixed based on the calculated AAL in 2016 prices) as the annual contribution over time. The disaster_swf is the RERF with adjusted calculations to include the adjusted AAL as a percentage of the RERF, so that it changes overtime based on forecasted values of the RERF.

Figure 4.11: RERF forecast performance from 2017 to 2026 using an ARIMA model

2011 (AUD $\$ 4$ million), excluding the outlier in 1987 when TTF was established. ${ }^{61}$ There were no contributions from the government in those years, hence giving room for the government to divert or reallocate monies into accelerating other priorities and development projects.

Under the current structures, the TTF and RERF experienced average annual drawdowns of $7.395 \%$ of GDP (or $2.06 \%$ of TTF size) and $5.3 \%$ of GDP (or $1.44 \%$ of RERF size), respectively. However, the alternative structures that contribute into disaster funds would increase annual drawdowns of the current structure by 2.6 ( $0.68 \%$ of TTF size) and 1.1 (0.29\% of RERF size) percentage points for Tuvalu and Kiribati, respectively. On the other hand, the current average contributions into SWFs for the TTF is approximately $7.422 \%$ of GDP, which is only $\$ 0.011$ million above the average annual drawdowns. By contrast, the average annual contributions into the RERF for Kiribati are far lower than the average annual drawdowns, by

\footnotetext{
${ }^{61}$ Over time, the average annual donor contributions into TTF is AUD $\$ 1.04$ million.
} 
CHAPTER 4. FINANCING CLIMATE AND DISASTER RESILIENCE IN ATOLL ISLANDS: EVIDENCE FROM TUVALU AND KIRIBATI

approximately $\$ 8.2$ million. With the newly assumed responsibility of contributing into disaster funds, the alternative structures for drawdowns and contributions will change. The average annual drawdown as a percentage of the SWF would likely to increase by percentage points of 0.68 for the TTF and 0.29 for the RERF.

\subsection{Conclusion}

While much focus in the Pacific has been on improving economic sustainability, partly through strengthening the management of reserves in SWFs, the establishment of solid and sustainable disaster funds for preparedness and response is indispensable for SIDS like Tuvalu and Kiribati. To minimize the use of budget earmarked for development purposes to be utilised for immediate disaster response, Tuvalu and Kiribati can rely on disaster funds to provide an adequate financial buffer. Without contributions from SWFs to disaster funds, both the TTF and RERF are sustainable in the long run. Based on our forecasts on imposed scenarios, they are also likely to be feasible and sustainable even if they contribute to disaster funds.

One argument for not allocating money from the SWF for disasters is that it would decrease aid. Consequently, we ask who should fund the disaster fund? The international community could contribute to the disaster fund, but will that conflict with its willingness to pay for recovery after a disaster. Although the establishment of a disaster fund may alter the views of the international community in relation to disaster aid allocation for Tuvalu and Kiribati, the disaster fund will not deter foreign aid inflow from development partners in response for disasters since it is almost a tradition for allied nations, development partners, and international organisations to respond with disaster aid to affected allies, and vice versa. These aid for disasters are always viewed as supportive mechanisms that will also complement the disaster fund itself, thus easing the distress of responding and recovering from disasters.

Several other possible ways to fund the disaster fund might be possible. First, the government can have full ownership of its disaster fund, maybe through a loan from the Asian Development Bank (ADB) or World Bank (WB) to provide the start up

resources (e.g., \$5 million for the establishment of the Falekaupule Trust Fund) and 
invest the fund off-shore, leaving it to develop and build on its own interests without drawing out its gains. To boost the growth of the disaster fund, the government will need to invest money into it from its own revenues (including the TTF). If income from the TTF is used, it would probably be necessary to have the support of Australia and NZ, as board members of the TTF and continuing contributors.

In principle, the TTF responds well to external economic shocks, but it does not extend a consistent treatment for natural disasters. Natural disasters are often left to be dealt with by the government, people, and aid. In fact, economic shocks and natural disasters are both disruptions that affect the economy and the people, and so could be treated the same. It is clear that the TTF was established to broadly meet national budget deficits, support national economic development and achieve greater national financial autonomy, then why natural disasters as a great threat is excluded. However, it is not clearly stated in the TTF agreement that natural disasters are explicitly excluded. Given the recent threat from disasters (more than economic shocks), there should be a trigger clause in the TTF mandates to include disasters or they should revise and expand the TTF mandates to include some form of DRM function in it.

Second, the government can ask the international community to build and/or even contribute into the disaster fund. There are available and limited funds to tap into. However, the development should start from the national level with the government, i.e., through the Development Coordinating Committee (DCC) and the Cabinet levels. Then it could be raised and promoted in the donors round-table meeting (DRM) with trusted development and diplomatic partners. This can be raised by the Ministry of Finance in collaboration with the Climate Change \& Disaster Unit. At the international level, one way for example, is to be raised by the Prime Minister in his speech during the United Nations General Assembly (UNGA) in New York, then followed by advocating and promoting through side events with trusted representatives at the UN. This strategy can also be applied to other offices where Tuvalu is a member (World Bank and ADB) and represented (European Union (EU), NZ, Taiwan, and others) to advocate to the Diplomatic Corps especially their allies and those willing to help and contribute. We can also extend it to other international meetings focusing on climate change and disasters like the Convention of the Parties (COP) Meetings, UN World Conference on Disaster Risk Reduction, European Union 
CHAPTER 4. FINANCING CLIMATE AND DISASTER RESILIENCE IN ATOLL ISLANDS: EVIDENCE FROM TUVALU AND KIRIBATI

Meetings and others. An example of a nearby event is the $23^{r d}$ session of the COP (or COP 23) to the UN Convention on Climate Change (UNFCCC) that will be organised by Fiji and hosted by the UNFCC Headquarters in Germany. It has to be strategic in nature and with the awareness of the members of the AOSIS (Alliance of the Small Island States) who will all attend. If there is a need for technical support, then the government can always turn to the Pacific Islands Forum Secretariat (PIFS) and South Pacific Commission (SPC) as they both have Disaster Units too.

Last but not the least, the government can have a mixed strategy, where the government can start up the disaster fund by establishing it, and ask the international community who are willing to contribute into the fund. It can be seen as a responsibility to the main emission polluters (industrial nations) and a donation (for others). This disaster fund is part of building resilience to both climate change and disasters (since climate change induce disasters and their impact) which is an urgent need for small island countries in particular, and part of increasing adaptation and mitigation efforts. ${ }^{62}$ The Green Climate Fund and maybe a future Loss-and-Damage compensation mechanism are other potential sources of funding.

Nevertheless, these disaster funds could be converted into long-term investment funds comparable to the TTF and RERF when deemed viable and applicable. ${ }^{63}$ In this fashion, they could be operated separately in a sustainable manner that builds upon its capital with good governing rules to guide management and encourage prudent reinvestment and drawdown. It is also vital to allow space and time for the disaster funds to build-up in their initial phases as they transit to a sustainable stage with a sufficient principal value able to provide future sustainable revenue streams for supporting disaster risk reduction and management. ${ }^{64}$ With good governing rules,

\footnotetext{
${ }^{62}$ There are other options too such as establishing a climate and disaster insurance facility and the "crowd funding" that is defined by the World Bank (2013a, p.14) as an "internet-enabled way for businesses or other organizations to raise money - typically from about US $\$ 1,000$ to US $\$ 1$ million - in the form of either donations or investments from multiple individuals".

${ }^{63} \mathrm{~A}$ good example is the Falekaupule Trust Fund (FTF) which was purposely established for outer-island development. Its management and operation is very similar to the TTF. For the disaster fund, it could similarly be managed and operated in the same manner, but with the sole purpose of financing disaster preparedness, response, and recovery. Its governing rules should be set up in a way that manages the Fund in a prudent and sustainable way.

${ }^{64}$ Given prudent management and the fact that the Fund has reached a sustainable phase with the capacity to provide a sustainable flow of public revenues, we can permit drawing from the Fund in a manner that would not jeopardize their overall performance.
} 
proper management, and prudent and relatively conservative fiscal policies for both of these funds, they should successfully achieve set targets and be sustainable in the long run. There should also be a buffer account to meet immediate response to disasters. Thus, they could contribute to DRR through disaster preparation, response, and recovery. 


\section{Appendix}

\section{A Diagnostic Tests}

Table 4.A.1: Dickey-Fuller tests

\begin{tabular}{|c|c|c|c|c|}
\hline & $\begin{array}{l}\text { TTF } \\
D . y\end{array}$ & $\begin{array}{c}\text { TTF } \\
D 2 . y \text { or } \Delta \Delta y_{t}\end{array}$ & $\begin{array}{c}\text { RERF } \\
D . y\end{array}$ & $\begin{array}{c}\text { RERF } \\
D 2 . y \text { or } \Delta \Delta y_{t}\end{array}$ \\
\hline$L . y$ or $y_{t-1}$ & $\begin{array}{c}0.0401 \\
(0.0324)\end{array}$ & & $\begin{array}{l}-0.0414 \\
(0.0367)\end{array}$ & \\
\hline$L D . y$ or $\Delta y_{t-1}$ & & $\begin{array}{c}-0.970 * * * \\
(0.202)\end{array}$ & & $\begin{array}{c}-0.764^{* * *} \\
(0.180)\end{array}$ \\
\hline \multicolumn{5}{|l|}{ sigma } \\
\hline _cons & $\begin{array}{c}1562042.1 \\
(2739254.4)\end{array}$ & $\begin{array}{c}4595519.6^{* * *} \\
(1537342.6)\end{array}$ & $\begin{array}{c}40306992.2^{* *} \\
(18401249.2)\end{array}$ & $\begin{array}{l}15530515.0^{*} \\
(8212269.5)\end{array}$ \\
\hline$N$ & 29 & 28 & 32 & 31 \\
\hline
\end{tabular}

Source: Author's estimations from TTF and RERF data. 


\section{B ARIMA Models for SWF}

\begin{tabular}{lccc}
\multicolumn{4}{c}{ Table 4.B.1: Selected ARIMA models for TTF } \\
\hline \hline & $\begin{array}{c}\text { ARIMA } \\
(1,1,0)\end{array}$ & $\begin{array}{c}\text { ARIMA } \\
(1,1,1)\end{array}$ & $\begin{array}{c}\text { ARIMA } \\
(0,1,1)\end{array}$ \\
\hline TTF & & & \\
_cons & $\begin{array}{c}4605834.9^{* * *} \\
(1508774.7)\end{array}$ & $\begin{array}{c}4558357.1^{* * *} \\
(1546884.8)\end{array}$ & $\begin{array}{c}4618443.1^{* * *} \\
(1505470.3)\end{array}$ \\
\hline ARMA & & & \\
L.ar & 0.0281 & $0.890^{* *}$ & \\
& $(0.327)$ & $(0.394)$ & \\
& & -1.000 & 0.0255 \\
L.ma & & $(112.9)$ & $(0.331)$ \\
& & & \\
\hline sigma & & 6201262.6 & $6378794.1^{* * *}$ \\
-cons & $6382380.5^{* * *}$ & $(849014100.7)$ & $(827276.1)$ \\
\hline$N$ & $(83111.7)$ & 29 & 29 \\
\hline$A I C$ & 997.07 & 996.40 & 997.07 \\
$B I C$ & 1001.17 & 1000.87 & 1001.17 \\
\hline \hline Stan & 29 & & \\
\hline
\end{tabular}

Standard errors in parentheses

${ }^{*} p<0.10,{ }^{* *} p<0.05,{ }^{* * *} p<0.01$

Source: Author's estimations from TTF data.

Note: L1.ar is the first lag of the autoregressive part and L1.ma is the first lag of the moving average component. 
Table 4.B.2: Selected ARIMA models for RERF

\begin{tabular}{|c|c|c|c|}
\hline & $\begin{array}{c}\text { ARIMA } \\
(1,1,3)\end{array}$ & $\begin{array}{c}\text { ARIMA } \\
(2,1,1)\end{array}$ & $\begin{array}{c}\text { ARIMA } \\
(2,1,2)\end{array}$ \\
\hline $\begin{array}{l}\text { RERF } \\
\text { _cons }\end{array}$ & $\begin{array}{c}20553135.9 * * * \\
(3413232.1)\end{array}$ & $\begin{array}{c}20304646.1^{* * *} \\
(3578388.4)\end{array}$ & $\begin{array}{c}21073122.4^{* *} \\
(8967142.3)\end{array}$ \\
\hline $\begin{array}{l}\text { ARMA } \\
\text { L.ar }\end{array}$ & $\begin{array}{c}0.677^{* * *} \\
(0.231)\end{array}$ & $\begin{array}{c}1.142^{* * *} \\
(0.200)\end{array}$ & $\begin{array}{c}0.970 * * * \\
(0.289)\end{array}$ \\
\hline L2.ar & & $\begin{array}{l}-0.292 \\
(0.198)\end{array}$ & $\begin{array}{c}-0.862^{* * *} \\
(0.258)\end{array}$ \\
\hline L.ma & $\begin{array}{l}-0.632^{*} \\
(0.367)\end{array}$ & $\begin{array}{c}-1.000 * * * \\
(0.310)\end{array}$ & $\begin{array}{c}-0.743^{* *} \\
(0.377)\end{array}$ \\
\hline L2.ma & $\begin{array}{c}0.328 \\
(0.232)\end{array}$ & & $\begin{array}{c}0.803 \\
(0.514)\end{array}$ \\
\hline L3.ma & $\begin{array}{c}-0.696^{* * *} \\
(0.246)\end{array}$ & & \\
\hline $\begin{array}{l}\text { sigma } \\
\text { _cons }\end{array}$ & $\begin{array}{c}33671439.8 \\
-\end{array}$ & $\begin{array}{c}36538536.3 \\
-\end{array}$ & $\begin{array}{c}35404298.1^{* * *} \\
(7327269.8)\end{array}$ \\
\hline$N$ & 32 & 32 & 32 \\
\hline $\begin{array}{l}A I C \\
B I C\end{array}$ & $\begin{array}{l}1212.91 \\
1220.24\end{array}$ & $\begin{array}{l}1214.91 \\
1220.77\end{array}$ & $\begin{array}{l}1216.06 \\
1224.86\end{array}$ \\
\hline
\end{tabular}

Standard errors in parentheses

${ }^{*} p<0.10,{ }^{* *} p<0.05,{ }^{* * *} p<0.01$

Source: Author's estimations from RERF data.

Note: L1.ar is the first lag of the autoregressive (AR) part, L2.ar is the second lag of the AR part, L1.ma is the first lag of the moving average (MA) component while L2.ma refers to the second lag of the MA part, and L3.ma is the third lag of the MA component. 


\section{C Scenarios of Inundation by Sea Level Rise}

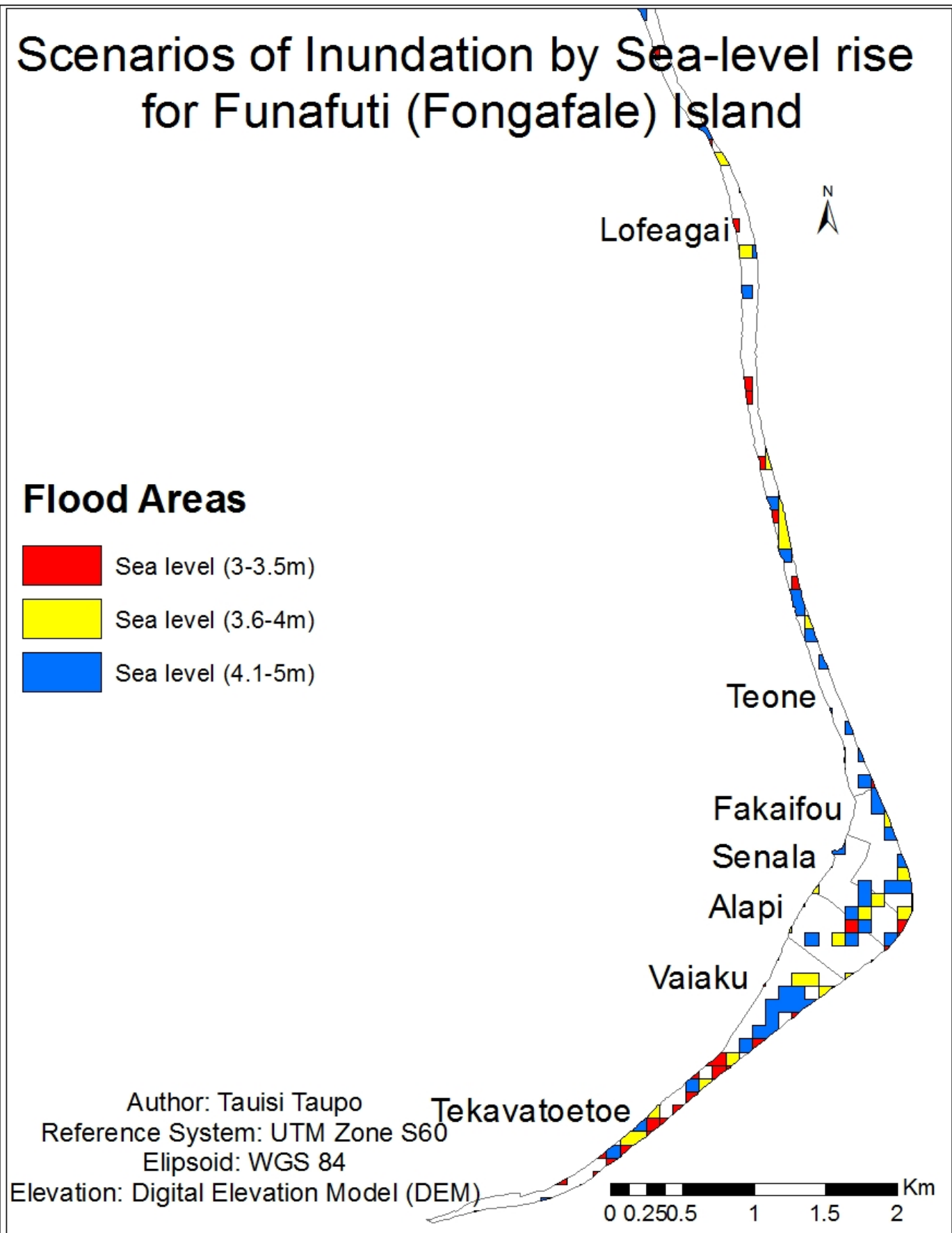

Source: Author's digitized maps.

Figure 4.C.1: Flood areas by sea-level on Funafuti Island 
CHAPTER 4. FINANCING CLIMATE AND DISASTER RESILIENCE IN ATOLL ISLANDS: EVIDENCE FROM TUVALU AND KIRIBATI

\section{D Contributions to the TTF}

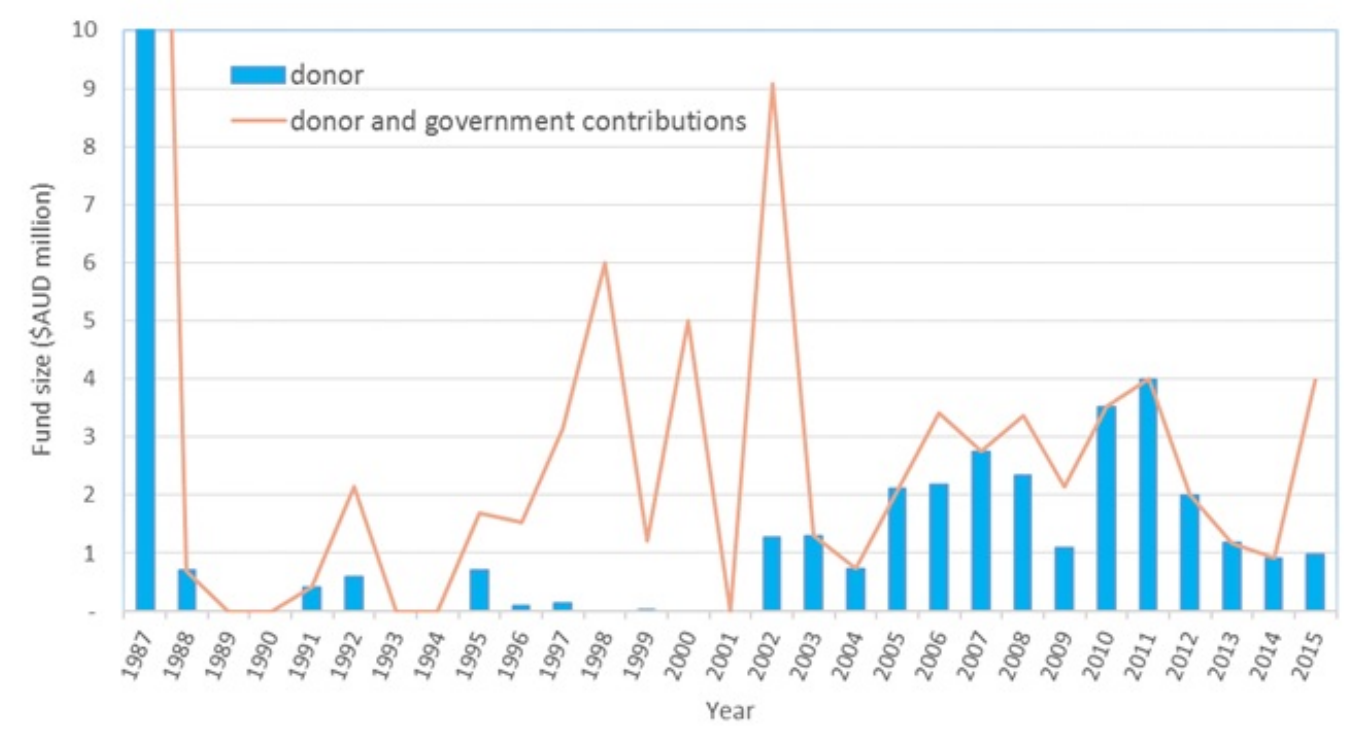

Source: TTF Advisory Committee Reports and National Budgets. Note that the outlier (1987) goes up to about AUD $\$ 24$ million, which was when the TTF was established.

Figure 4.D.1: Contributions to the TTF 


\section{E SWF vs GDP under MC Simulation}

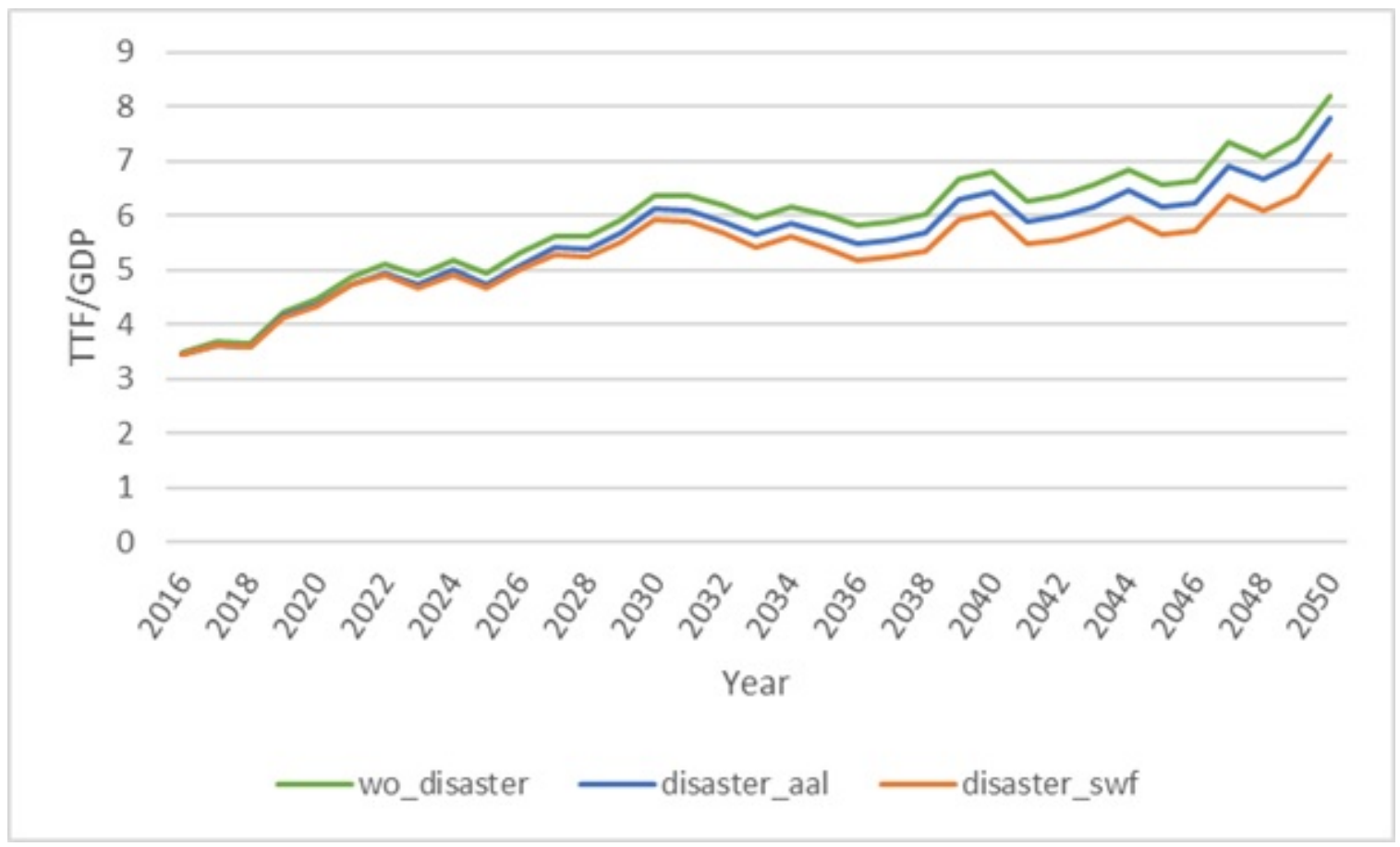

Source: Author's calculations.

Figure 4.E.1: TTF vs GDP under MC simulation 
CHAPTER 4. FINANCING CLIMATE AND DISASTER RESILIENCE IN ATOLL ISLANDS: EVIDENCE FROM TUVALU AND KIRIBATI

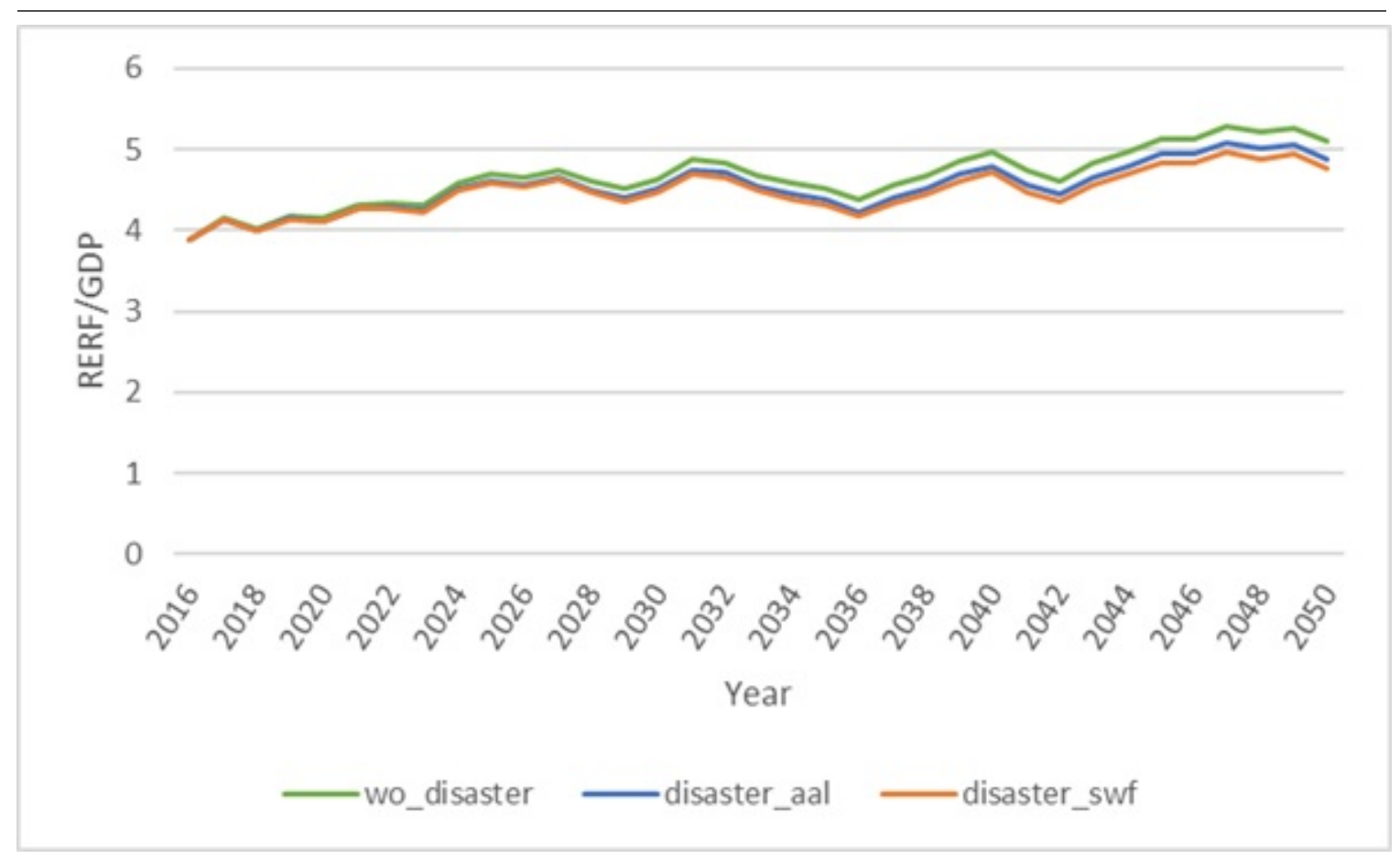

Source: Author's calculations.

Figure 4.E.2: RERF vs GDP under MC simulation 


\section{F SWF vs GDP under ARIMA}

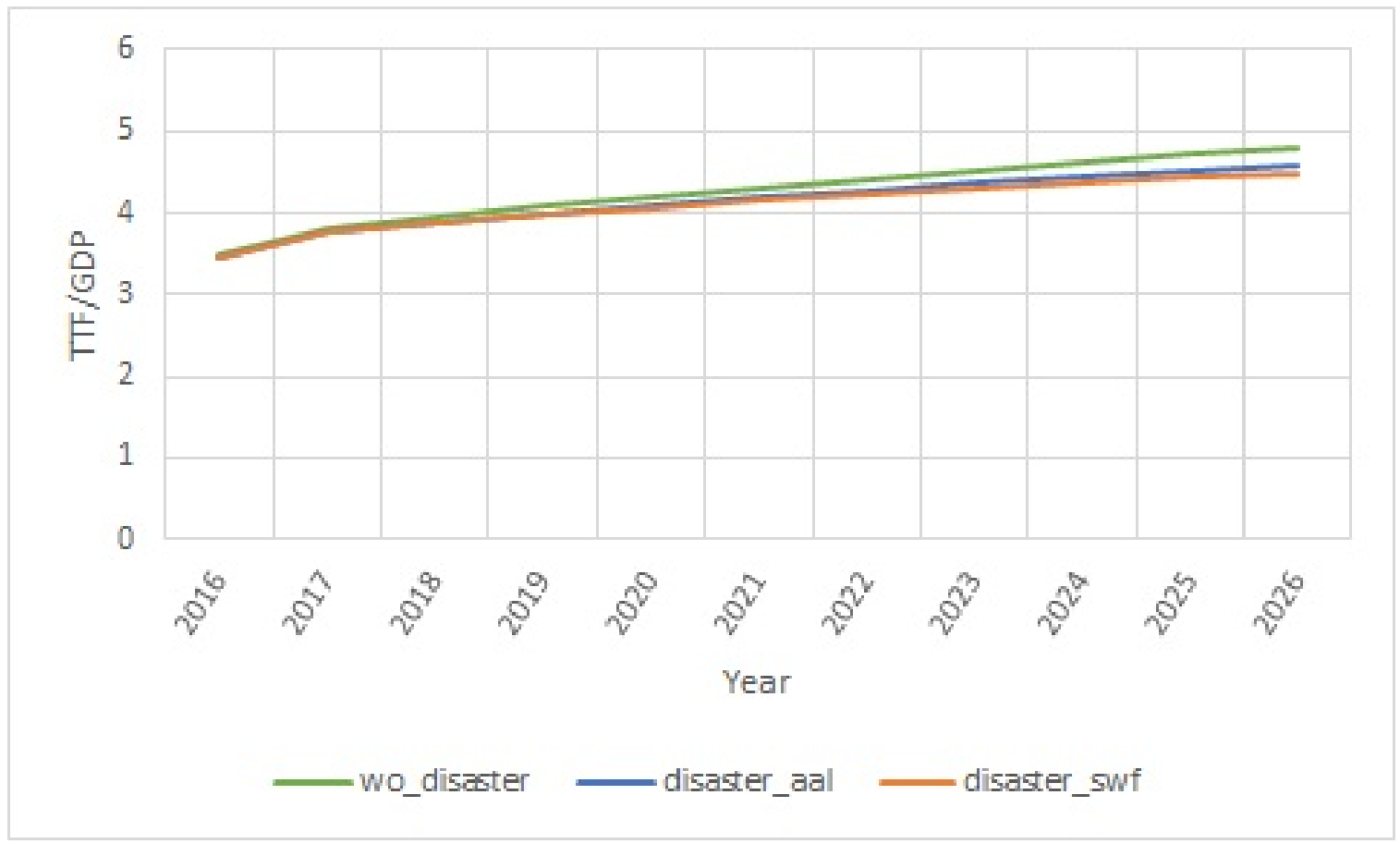

Source: Author's calculations.

Figure 4.F.1: TTF vs GDP under ARIMA 
CHAPTER 4. FINANCING CLIMATE AND DISASTER RESILIENCE IN ATOLL ISLANDS: EVIDENCE FROM TUVALU AND KIRIBATI

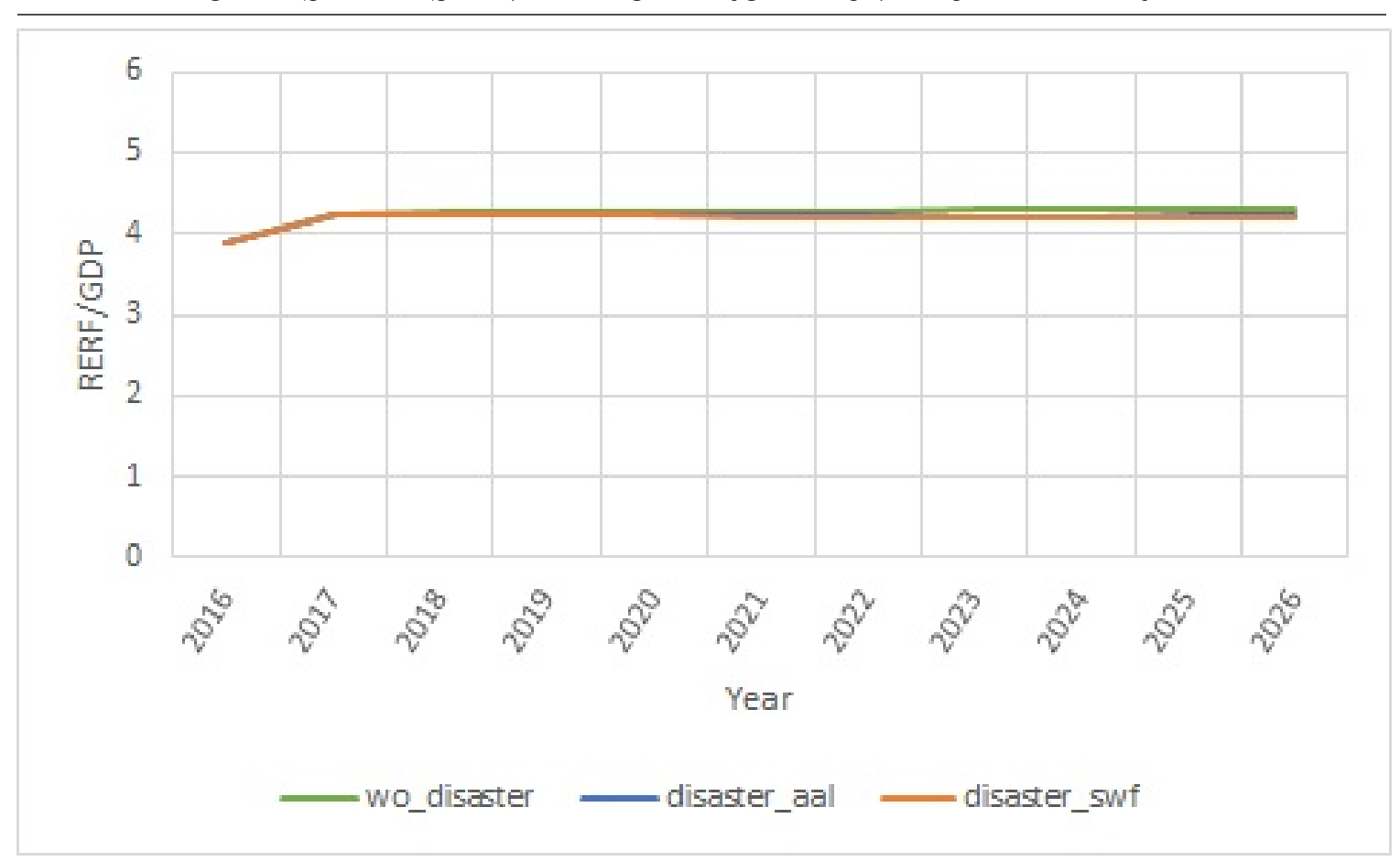

Source: Author's calculations.

Figure 4.F.2: RERF vs GDP under ARIMA 


\section{G Stylized Illustrations}

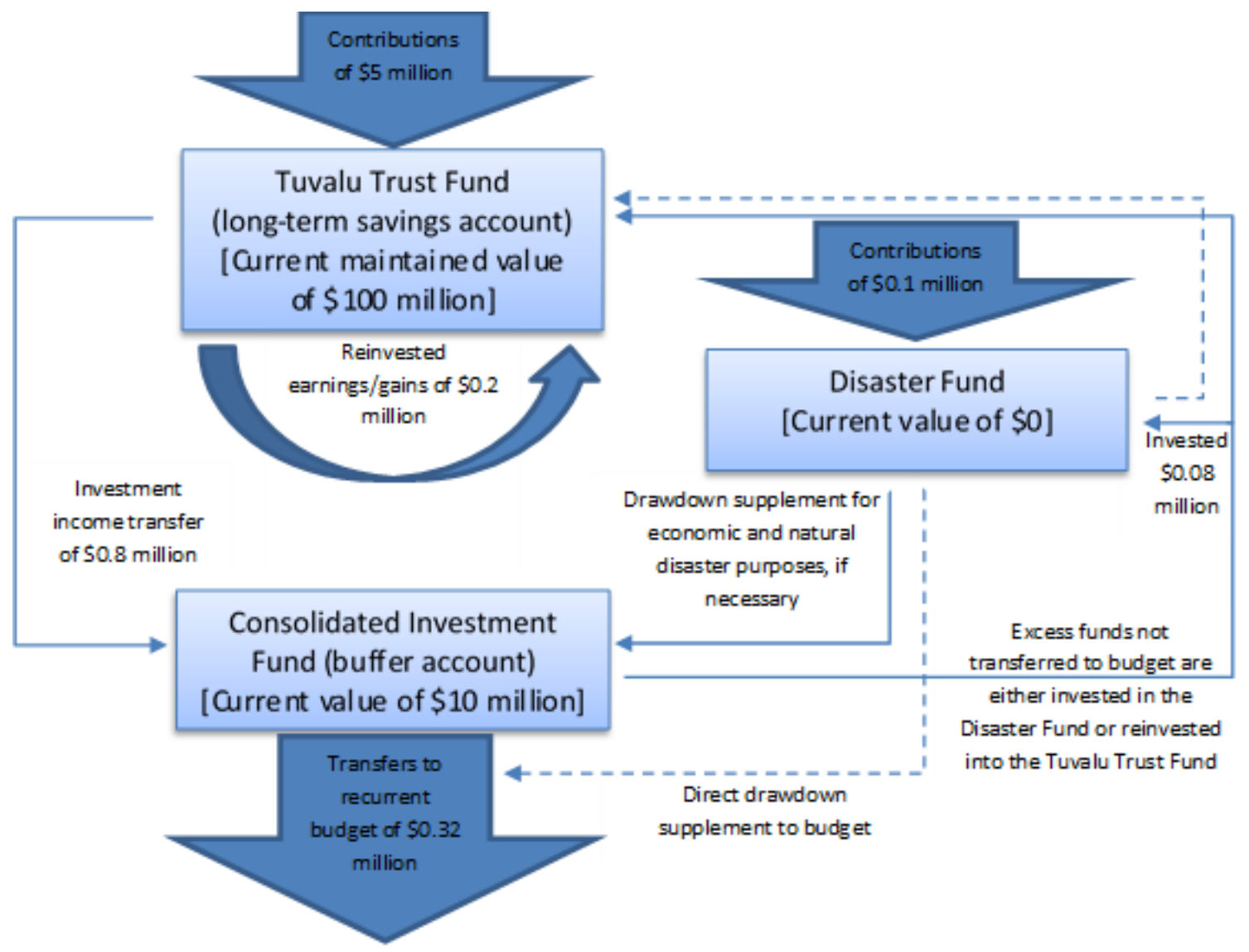

Source: Author's calculations. Suppose that at the beginning the year 2010, the Tuvalu Trust Fund (TTF) has a maintained value of $\$ 100$ million, the CIF has $\$ 10$ million, and contributions from development partners of $\$ 100,000$ into the Disaster Fund. During that financial year there were contributions of $\$ 5$ million into the TTF (i.e. $\$ 2$ million from the Tuvalu Government and $\$ 3$ million from development partners). So, if the current maintained value is $\$ 100$ million, then the new maintained value is $\$ 105$ million. Earnings/gains are calculated from the estimated difference between market and maintained values). This amount is regarded as investment income that can be either transferred into CIF or reinvested back into the TTF. So, since the new maintained value is $\$ 105$ million. At the end of the year, if the calculated market value is $\$ 106$ million, then the distribution is $\$ 1$ million. Note that if the market value is lower than its maintained value, then there is no distribution that year. Suppose that $20 \%$ of the distribution will be reinvested (i.e. $\$ 200,000)$, $80 \%$ will go into the CIF (i.e. $\$ 800,000$ ) that will be either kept in the CIF, invested in the Disaster Fund or later reinvested into the TTF. Suppose that 10\% (i.e. \$80,000) of the CIF will be invested into the Disaster Fund, $40 \%$ (i.e. \$320,000) was transferred to the government budget to meet the budget deficits, and $50 \%$ (i.e. $\$ 400,000$ ) were kept in the CIF.

Figure 4.G.1: Alternative Tuvalu Trust Fund Resource Flow Illustration for Year 1 
CHAPTER 4. FINANCING CLIMATE AND DISASTER RESILIENCE IN ATOLL ISLANDS: EVIDENCE FROM TUVALU AND KIRIBATI

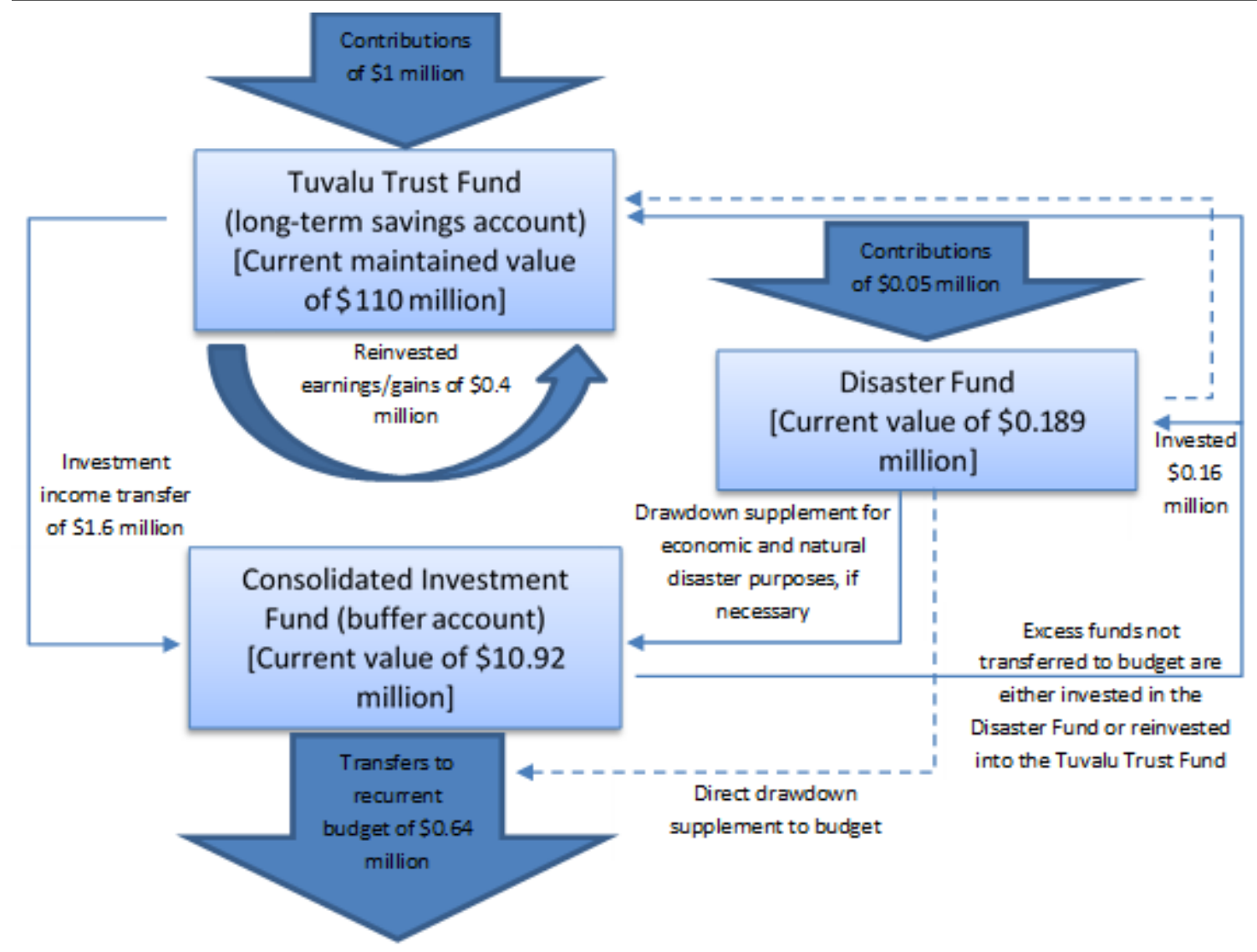

Source: Author's calculations. For simplicity, we assume that the annual interest rates is $5 \%$ for the CIF and the Disaster Fund. The TTF maintained and market values are calculated by the Fund Monitors. Therefore, at the beginning of the year 2011, the CIF would be $\$ 10,920,000$ (i.e. $[(\$ 10,000,000+\$ 400,000) \times 1.05])$; and the Disaster Fund would be $\$ 189,000$ (i.e. $[(\$ 100,000+$ $\$ 80,000) \times 1.05]$ ). In 2011 , the TTF maintained value was $\$ 110$ million and its market value was $\$ 108$, so the amount of distributions transferred to the CIF that year is $\$ 2$ million. So, if we follow the previous year 2010 distributions i.e. $10 \%$ (i.e. $\$ 160,000$ ) of the CIF will be invested into the Disaster Fund, $40 \%$ (i.e. $\$ 640,000$ ) was transferred to the government budget to meet the budget deficits, and $50 \%$ (i.e. $\$ 800,000$ ) were kept in the CIF. Therefore, at the beginning of 2012, the Disaster Fund is $\$ 418,950$ (i.e. $([\$ 50,000+\$ 160,000+\$ 189,000)$ x 1.05$]$ ).

Figure 4.G.2: Alternative Tuvalu Trust Fund Resource Flow Illustration for Year 2 


\section{H Summary}

Table 4.H.1: Summary of adjusted Annual Average Loss

\begin{tabular}{|c|c|c|c|}
\hline & & Tuvalu & Kiribati \\
\hline 1 & $\begin{array}{c}\text { PCRAFI } \\
\text { PCRAFI AAL (A) }\end{array}$ & 319,738 & 379,403 \\
\hline 2 & $\begin{array}{c}\text { Distant Cyclones } \\
\text { Estimated loss (10\% of GDP base on TC Pam) } \\
\text { Return Period } \\
\text { Distant Cyclone AAL }(B) \\
\text { Sub Total AAL }(A+B)\end{array}$ & $\begin{array}{c}4,120,000 \\
10 \\
412,000 \\
731,738\end{array}$ & $\begin{array}{c}8,403,006 \\
10 \\
840,301 \\
1,219,704\end{array}$ \\
\hline 3 & $\begin{array}{c}\text { Climate Change } \\
\text { Earthquake AAL } \\
\text { Cyclone AAL } \\
\text { Cyclone AAL + Distant Cyclone AAL } \\
\text { Cyclone intensity } \\
\text { Cyclone frequency } \\
\text { Climate Change AAL }(\mathrm{C}) \\
\text { Sub Total } A A L(A+B+C)\end{array}$ & $\begin{array}{c}213,159 \\
106,579 \\
518,579 \\
1.39 \\
719,508 \\
0.98 \\
705,118 \\
186,539 \\
918,277\end{array}$ & $\begin{array}{c}252,935 \\
126,468 \\
966,768 \\
1.39 \\
1,341,353 \\
0.98 \\
1,314,526 \\
347,758 \\
1,567,462\end{array}$ \\
\hline 4 & $\begin{array}{c}\text { Droughts } \\
2011 \text { Drought estimated cost } \\
\text { Return Period } \\
\text { Drought AAL }(\mathrm{D}) \\
\text { Sub Total } A A L(A+B+C+D)\end{array}$ & $\begin{array}{c}2,072,045 \\
20 \\
103,602 \\
1,021,879\end{array}$ & $\begin{array}{l}10,153,021 \\
20 \\
507,651 \\
2,075,113\end{array}$ \\
\hline 5 & $\begin{array}{c}\text { Sea Level Rise } \\
\text { Sea level rise effect } \\
\text { Sea level rise AAL }(\mathrm{E}) \\
\text { Sub Total } A A L(A+B+C+D+E)\end{array}$ & $\begin{array}{c}1.08 \\
79,707 \\
1,101,586\end{array}$ & $\begin{array}{c}1.08 \\
161,859 \\
2,236,972\end{array}$ \\
\hline 6 & $\begin{array}{c}\text { Overall AALs (from 2017-2050) } \\
\text { Total } A A L\end{array}$ & $\$ 37,453,924$ & $\$ 76,057,048$ \\
\hline
\end{tabular}

Source: Author's calculations. 


\section{Conclusions}

Natural disasters have distressing impacts on economies, communities, households and the lives of the people. Understanding the vulnerability and exposure of households to climatic disasters is imperative in reducing disaster risks and enhancing disaster risk management. Chapter 1 surveyed the concept of disaster risk that has developed over time, with initial focus on hazards, then expanded to include the elements exposed to the hazard and vulnerable populations affected by disasters. Disaster risk now also incorporates how prepared the affected populations are and how they would bounce back through resilience, adaptability, response capacity, and recovery.

In Chapter 2, we examined the vulnerability and exposure of households to disasters in Tuvalu. We concluded that households on the capital Funafuti are extremely vulnerable to disasters based on their exposure to the coast and elevation. We found that poor households are more likely to reside in areas prone to disasters and that they migrate less both within and between islands. For a small low-lying island like Tuvalu, with 70 percent of households residing less than 200 meters from the shoreline and with an elevation of no more than 5 meters above sea-level, vulnerability to climatic disasters is very high.

Cyclone damages for low-lying islands in the Pacific are projected to increase as exposure increases and climate science is predicting an increase in the intensity of cyclones. In Chapter 3, we conducted a detailed household survey on the impact of disasters in Tuvalu covering the majority of households in the five islands that were affected by Tropical Cyclone Pam in 2015. We found that even a distant cyclone is a great threat to the low-lying islands of Tuvalu, and this is an additional risk 
factor for low-lying islands that is often under-appreciated and ignored in national and international disaster risk assessments. We also described the ways in which hazard, exposure, and vulnerability interact to increase the overall risk that leads to losses and damages while improved responsiveness reduced these negative effects.

Our hypothetical calculations, based on the quantified responses from the household survey, highlight the various scenarios of loss and damage associated with both exposure and vulnerability which are essential for consideration in disaster risk reduction (DRR) policies. Since households in Tuvalu have no available insurance products and few options for transferring risk, mitigating has become an important policy option. We examine various scenarios for reducing levels of exposure and vulnerability.

It is well understood that most Pacific SIDS rely heavily on foreign aid for development. In the past decade, Tuvalu, which has no financial risk transfer mechanism available, has received significant funding for disaster response (e.g., after the 2011 drought and 2015 TC Pam). In Chapter 4, we examined the potential of sovereign wealth funds (SWFs) to contribute to disaster recovery funding, by looking at case studies of Tuvalu and Kiribati. Appropriate levels of expected annual recovery needs were calculated, building on the Pacific Catastrophe Risk Assessment and Financing Initiative (PCRAFI) calculated average annual loss. We then generated forecasts for these SWFs performance using Monte Carlo and ARIMA methods. Our aim is to examine the feasibility of SWFs in contributing to disaster recovery funding. This new disaster funding mechanisms can decrease reliance and dependency on foreign aid for disaster response and recovery, a dependence that is unreliable. 


\section{References}

Abbott, D. and Pollard, S. (2004). Hardship and Poverty in the Pacific. Asian Development Bank, Philippines.

ADB (2007). 2006 Tuvalu Economic Report: From Plan to Action. Pacific Study Series. Asian Development Bank, Philippines.

ADB (2015). Pacific Economic Monitor Midyear Review July. Asian Development Bank.

Adger, W. N. (2006). Vulnerability. Global Environmental Change, 16(3):268-281.

Ahsan, D. A. (2014). Does natural disaster influence peoples risk preference and trust? An experiment from cyclone prone coast of Bangladesh. International Journal of Disaster Risk Reduction, 9:48-57.

Ainuddin, S. and Routray, J. K. (2012). Community resilience framework for an earthquake prone area in Baluchistan. International Journal of Disaster Risk Reduction, 2:25-36.

Airriess, C. A., Li, W., Leong, K. J., Chen, A. C.-C., and Keith, V. M. (2008). Church-based social capital, networks and geographical scale: Katrina evacuation, relocation, and recovery in a New Orleans Vietnamese American community. Geoforum, 39(3):1333-1346.

Akter, S. and Mallick, B. (2013). The poverty-vulnerability-resilience nexus: Evidence from Bangladesh. Ecological Economics, 96:114-124.

Aldrich, D. P. (2011). The power of people: social capitals role in recovery from the 1995 Kobe earthquake. Natural Hazards, 56(3):595-611. 
Alhashel, B. (2015). Sovereign Wealth Funds: A literature review. Journal of Economics and Business, 78:1-13.

Angelo, T., Bell, B., and Roylance, B. (2016). Intergenerational Trust Funds in the Pacific. The Journal of Pacific History, 51(2):186-204.

Anselin (1988). Spatial Econometrics: Methods and Models. Kluwer Academics, Dordrecht.

Anselin, L., Bera, A. K., Florax, R., and Yoon, M. J. (1996). Simple diagnostic tests for spatial dependence. Regional Science and Urban Economics, pages 77-104.

Asadzadeh, A., Ktter, T., and Zebardast, E. (2015). An augmented approach for measurement of disaster resilience using connective factor analysis and analytic network process (FANP) model. International Journal of Disaster Risk Reduction, 14, Part 4:504-518.

Asian Development Bank (2013). The economics of climate change in the Pacific. Asian Development Bank, Philippines.

Australian Bureau of Meteorology and CSIRO (2011). Climate Change in the Pacific: Scientific Assessment and New Research, volume 2. Pacific Climate Change Science Program.

Bagnall, A. E. and Truman, E. M. (2011). IFSWF report on compliance with the Santiago principles: Admirable but flawed transparency. Policy Brief, pages 11-14.

Bagnall, A. E. and Truman, E. M. (2013). Progress on Sovereign Wealth Fund Transparency and Accountability: An Updated SWF Scoreboard. Policy Brief, (13-19):1-29.

Balding, C. (2012). Sovereign Wealth Funds: The New Intersection of Money and Politics. Oxford University Press, New York.

Barnett, J. (2005). Titanic states? Impacts and responses to climate change in the Pacific Islands. Journal of International Affairs, 59:203-219.

Barnett, J., Lambert, S., and Fry, I. (2008). The Hazards of Indicators: Insights from the Environmental Vulnerability Index. Annals of the Association of American Geographers, 98(1):102-119. 
Barnett, J. and Waters, E. (2016). Rethinking the Vulnerability of Small Island States: Climate Change and Development in the Pacific Islands. In The Palgrave Handbook of International Development, pages 731-748. Palgrave Macmillan, London. DOI: 10.1057/978-1-137-42724-3_40.

Becker, M., Meyssignac, B., Letetrel, C., Llovel, W., Cazenave, A., and Delcroix, T. (2012). Sea level variations at tropical Pacific islands since 1950. Global and Planetary Change, 80-81:85-98.

Bene, C., Wood, R., Newsham, A., and Davies, M. (2012). Resilience: New Utopia or New Tyranny? Reflection about the Potentials and Limits of the Concept of Resilience in Relation to Vulnerability Reduction Programmes.

Black, R. and Collyer, M. (2014). Populations' trapped' at times of crisis. Forced Migration Review, (45):52.

Box, G. E. and Jenkins, G. M. (1970). Time Series Analysis: Forecasting and Control. Holden-Day, San Francisco.

Box, G. E. and Jenkins, G. M. (1976). Time Series Analysis: Forecasting and Control. San Francisco, 2nd edition.

Bratley, P., Fox, B. L., and Schrage, L. E. (1987). A Guide to Simulation. Springer-Verlag, New York, 2nd edition.

Briguglio, L. (1995). Small island developing states and their economic vulnerabilities. World Development, 23(9):1615-1632.

Briguglio, L. (1997). Small island developing states and their economic vulnerabilities. Scope-Scientific Committee on Problems of the Environment International Council of Scientific Unions, 58:210-215.

Briguglio, L. (2003). The Vulnerability Index and small island developing states: a review of conceptual and methodological issues. Cape Verde.

Briguglio, L. (2004). Economic vulnerability and resilience: concepts and measurements. In Economic Vulnerability and Resilience of Small States. Islands and Small States Institute of the University of Malta and Commonwealth Secretariat. 
Briguglio, L., Cordina, G., Farrugia, N., and Vella, S. (2009). Economic Vulnerability and Resilience: Concepts and Measurements. Oxford Development Studies, 37(3):229-247.

Cabezon, E., Hunter, L., Tmbarello, P., Washimi, K., and Wu, Y. (2015). Enhancing Macroeconomic Resilience to Natural Disasters and Climate Change in the Small States of the Pacific. IMF Working Paper, WP/15/125.

Cavallo, E. and Noy, I. (2011). Natural Disasters and the Economy - A Survey. International Review of Environmental and Resource Economics, 5(1):63-102.

Christenson, E., Elliott, M., Banerjee, O., Hamrick, L., and Bartram, J. (2014). Climate-Related Hazards: A Method for Global Assessment of Urban and Rural Population Exposure to Cyclones, Droughts, and Floods. International Journal of Environmental Research and Public Health, 11(2):2169-2192.

Clark, G. E., Moser, S. C., Ratick, S. J., Dow, K., Meyer, W. B., Emani, S., Jin, W., Kasperson, J. X., Kasperson, R. E., and Schwarz, H. E. (1998). Assessing the vulnerability of coastal communities to extreme storms: the case of Revere, MA., USA. Mitigation and adaptation strategies for global change, 3(1):59-82.

Clark, G. L., Dixon, A. D., and Monk, A. H. (2013). Sovereign Wealth Funds: Legitimacy, Governance, and Global Power. Princeton University Press, Princeton.

Connell, J. (2003). Losing ground? Tuvalu, the greenhouse effect and the garbage can. Asia Pacific Viewpoint, 44(2):89-107.

Cutter, S. L., Barnes, L., Berry, M., Burton, C., Evans, E., Tate, E., and Webb, J. (2008). A place-based model for understanding community resilience to natural disasters. Global Environmental Change, 18(4):598-606.

Dasgupta, A. and Baschieri, A. (2010). Vulnerability to climate change in rural Ghana: Mainstreaming climate change in poverty-reduction strategies. Journal of International Development, 22(6):803-820.

De Haen, H. and Hemrich, G. (2007). The economics of natural disasters: implications and challenges for food security. Agricultural economics, 37(s1):31-45. 
Dercon, S. (2005). Risk, Poverty and Vulnerability in Africa. Journal of African Economies, 14(4):483-488.

Devroye, L. (1986). Non-uniform random variate generation. Springer, New York. OCLC: 13269466.

Diebold, F. X. (2006). Elements of Forecasting. Thomson South-Western, Ohio, 4th edition.

Dutta, I., Foster, J., and Mishra, A. (2011). On measuring vulnerability to poverty. Social Choice and Welfare, 37(4):743-761.

Echevin, D. (2014). Characterising Vulnerability to Poverty in Rural Haiti: A Multilevel Decomposition Approach. Journal of Agricultural Economics, 65(1):131-150.

ECLAC (2003). Handbook for estimating the socio-economic and environmental effects of disasters. United Nations, ECLAC \& International Bank for Reconstruction \& Development (The World Bank).

ECLAC (2014). Handbook for Disaster Assessment. United Nations and Economic Commission for Latin America and the Caribbean (ECLAC), Santiago, Chile.

Edmonds, C. (2015). Trust Funds in the Pacific: Operation and Performance Update.

Elhorst, J. P. (2014). Spatial Econometrics. SpringerBriefs in Regional Science. Springer Berlin Heidelberg, Berlin, Heidelberg.

Farquhar, H. (2015). Migration with Dignity: Towards a New Zealand Response to Climate Change Displacement in the Pacific. Victoria University of Wellington Law Review, 46(1):29-55.

Field, C. B., Barros, V. R., and Intergovernmental Panel on Climate Change, editors (2014a). Climate change 2014: impacts, adaptation, and vulnerability: Working Group II contribution to the fifth assessment report of the Intergovernmental Panel on Climate Change. Cambridge University Press, New York, NY. OCLC: ocn900613741. 
Field, C. B., Barros, V. R., Mastrandrea, M. D., Mach, K. J., Abdrabo, M.-K., Adger, N., Anokhin, Y. A., Anisimov, O. A., Arent, D. J., Barnett, J., and others (2014b). Summary for policymakers. Climate change 2014: impacts, adaptation, and vulnerability. Part A: global and sectoral aspects. Contribution of Working Group II to the Fifth Assessment Report of the Intergovernmental Panel on Climate Change, pages 1-32.

Fishman, G. (1996). Monte Carlo: Concepts, Algorithms, and Applications. Springer-Verlag, New York.

Folke, C. (2006). Resilience: The emergence of a perspective for socialecological systems analyses. Global Environmental Change, 16(3):253-267.

Fussel, H.-M. (2007). Vulnerability: A generally applicable conceptual framework for climate change research. Global Environmental Change, 17(2):155-167.

Gallopin, G. C. (2006). Linkages between vulnerability, resilience, and adaptive capacity. Global Environmental Change, 16(3):293-303.

Gentle, J. E. (1998). Random Number Generation and Monte Carlo Methods. Springer-Verlag, New York.

GeoEconomica (2014). Santiago Compliance Index 2014. Technical report, GeoEconomica.

GFDRR (2016). The making of a riskier future: How our decisions are shaping future disaster risk. Technical report, Global Facility for Disaster Reduction and Recovery, Washington D.C.

Gibson, J. and McKenzie, D. (2007). Using the global positioning system in household surveys for better economics and better policy. World Bank Policy Research Working Paper, (4195).

Gibson, J. and Rozelle, S. (2003). Poverty and Access to Roads in Papua New Guinea. Economic Development \&3 Cultural Change, 52(1):159-185.

Glasserman, P. (2003). Monte Carlo Methods in Financial Engineering, volume 53. Springer Science \& Business Media. 
Global Environment Facility Secretariat (2011). Accessing Resources under the Least Developed Countries Fund. Technical report, Global Environment Facility.

Government of Vanuatu (2015). Vanuatu Post-Disaster Needs Assessment: Tropical Cylone Pam. Technical report, Government of Vanuatu, Port Vila.

Gunasekera, R., Ishizawa, O., Aubrecht, C., Blankespoor, B., Murray, S., Pomonis, A., and Daniell, J. (2015). Developing an adaptive global exposure model to support the generation of country disaster risk profiles. Earth-Science Reviews, 150:594-608.

Hallegatte, S. (2013). A cost effective solution to reduce disaster losses in developing countries: hydrometeorological services, early warning, and evacuation. In Lomborg, B., editor, Global Problems, Smart Solutions, pages 481-499. Cambridge University Press, Cambridge.

Hallegatte, S., Bangalore, M., Bonzanigo, L., Fay, M., Kane, T., Narloch, U., Rozenberg, J., Treguer, D., and Vogt-Schilb, A. (2015). Shock Waves: Managing the Impacts of Climate Change on Poverty. The World Bank.

Hallegatte, S., Bangalore, M., and Vogt-Schilb, A. (2016). Assessing socioeconomic resilience to floods in 90 countries. World Bank Policy Research Working Paper, (7663).

Hallegatte, S., Vogt-Schilb, A., Bangalore, M., and Rozenberg, J. (2017). Unbreakable: Building the Resilience of the Poor in the Face of Natural Disasters. Climate Change and Development Series. World Bank, Washington D.C.

Haughton, J. and Khandker, S. (2009). Handbook on Poverty and Inequality. The World Bank.

Hawkins, R. L. and Maurer, K. (2010). Bonding, Bridging and Linking: How Social Capital Operated in New Orleans following Hurricane Katrina. British Journal of Social Work, 40(6):1777-1793.

Heger, M., Julca, A., and Paddison, O. (2008). Analysing the impact of natural hazards in small economies: the Caribbean case. UNU-WIDER, Helsinki. OCLC: 837055947 . 
Holling, C. S. (1973). Resilience and stability of ecological systems. Annual review of ecology and systematics, 4(1):1-23.

Hosseini, S. and Barker, K. (2016). Modeling infrastructure resilience using Bayesian networks: A case study of inland waterway ports. Computers $\&$ Industrial Engineering, 93:252-266.

Hyndman, R. J. and Athanasopoulos, G. (2014). Forecasting: Principles and Practice. OTexts.

IFRC (2016). Tropical Cyclone Pam: One-year progress report. Technical report, International Federation of Red Cross and Red Crescent Societies, Geneva.

International Forum of Sovereign Wealth Funds (2014). Santiago Principles: 15 Case Studies. Technical report, International Forum of Sovereign Wealth Funds, Doha.

International Monetary Fund (2016). IMF Country Report: Kiribati. Technical Report 16/292, International Monetary Fund, Washington D.C.

International Working Group of Sovereign Wealth Funds (2008). Sovereign Wealth Funds: General Accepted Principles and Practices "Santiago Principles".

IPCC (2012). Managing the risks of extreme events and disasters to advance climate change adaption: special report of the Intergovernmental Panel on Climate Change. Cambridge University Press, New York, NY.

IPCC (2014). Summary for Policymakers. In Climate Change 2014: Mitigation of Climate Change. Cambridge University Press, Cambridge, United Kingdom and New York, USA.

Islam, R. and Walkerden, G. (2017). Social networks and challenges in government disaster policies: A case study from Bangladesh. International Journal of Disaster Risk Reduction, 22:325-334.

Jalan, J. and Ravallion, M. (1998). Are there dynamic gains from a poor-area development program? Journal of public economics, 67(1):65-85.

Jalan, J. and Ravallion, M. (2002). Geographic poverty traps? A micro model of consumption growth in rural China. Journal of Applied Econometrics, 17(4):329-346. 
Jha, R. and Dang, T. (2010). Vulnerability to Poverty in Papua New Guinea in 1996: Vulnerability to Poverty in Papua New Guinea. Asian Economic Journal, 24(3):235-251.

Jha, R., Dang, T., and Sharma, K. L. (2009). Vulnerability to Poverty in Fiji. International Journal of Applied Econometrics and Quantitative Studies, 6(1):43-60.

Johnson, C. A. and Krishnamurthy, K. (2010). Dealing with displacement: Can social protection facilitate long-term adaptation to climate change? Global Environmental Change, 20(4):648-655.

Johnston, B. R., Hiwasaki, L., Klaver, I. J., Ramos Castillo, A., and Strang, V., editors (2012). Water, Cultural Diversity, and Global Environmental Change. Springer Netherlands, Dordrecht. DOI: 10.1007/978-94-007-1774-9.

Kahn, M. E. (2005). The Death Toll from Natural Disasters: The Role of Income, Geography, and Institutions. The Review of Economics and Statistics, 87(2):271-284.

Kalos, M. H. and Whitlock, P. A. (2008). Monte Carlo Methods. Wiley-Blackwell, 2nd edition.

Kaly, U. L. and Pratt, C. (2000). Environmental vulnerability index: development and provisional indices and profiles for Fiji, Samoa, Tuvalu and Vanuatu : EVI Phase II Report. SOPAC, Fiji.

Klomp, J. and Valckx, K. (2014). Natural disasters and economic growth: A meta-analysis. Global Environmental Change, 26:183-195.

Koubi, V., Spilker, G., Schaffer, L., and Bernauer, T. (2016). Environmental Stressors and Migration: Evidence from Vietnam. World Development, 79:197-210.

Kusumastuti, R. D., Viverita, Husodo, Z. A., Suardi, L., and Danarsari, D. N. (2014). Developing a resilience index towards natural disasters in Indonesia. International Journal of Disaster Risk Reduction, 10, Part A:327-340.

Le Borgne, E. and Medas, P. A. (2007). Sovereign wealth funds in the Pacific Island countries: Macro-fiscal linkages. Number 7-297. International Monetary Fund. 
LeSage, J. and Pace, R. K. (2009). Introduction to Spatial Econometrics. Taylor \& Francis Group.

Linnerooth-Bayer, J. and Mechler, R. (2009). Insurance against Losses from Natural Disasters in De-veloping Countries. New York, NY.

Lopez-Marrero, T. and Wisner, B. (2012). Not in the same boat: Disasters and differential vulnerability in the insular Caribbean. Caribbean Studies, 40(2):129-168.

Makridakis, S., Wheelwright, S. C., and Hyndman, R. J. (1997). Forecasting: Methods and Applications. Wiley, New York, 3rd edition.

Marino, E. (2012). The long history of environmental migration: Assessing vulnerability construction and obstacles to successful relocation in Shishmaref, Alaska. Global Environmental Change, 22(2):374-381.

Mayunga, J. S. (2007). Understanding and applying the concept of community disaster resilience: a capital-based approach. Summer academy for social vulnerability and resilience building, 1:16.

McLeod, H. (1999). Tuvalu Environmental Vulnerability Index Data Gathering Report. Technical report, SOPAC.

Mechler, R. and Schinko, T. (2016). Identifying the policy space for climate loss and damage. Science, 354(6310):290-292.

Mei, W., Xie, S.-P., Primeau, F., McWilliams, J. C., and Pasquero, C. (2015). Northwestern Pacific typhoon intensity controlled by changes in ocean temperatures. Science Advances, 1(4):e1500014-e1500014.

Meldelsohn, R., Emanuel, K., Chonabayashi, S., and Bakkensen, L. (2012). The Impact of Climate Change on Global Tropical Cyclone Damage. Nature Climate Change, 2:205-209.

Ministry of Finance and Economic Development (2016). 2017 National Budget for Tuvalu. Technical report, Tuvalu Government, Tuvalu.

Mitchell, T., Jones, L., Lovell, E., and Comba, E. (2013). Disaster Risk Management in Post-2015 Development Goals. Overseas Development Institute, London. 
Mortreux, C. and Barnett, J. (2009). Climate change, migration and adaptation in Funafuti, Tuvalu. Global Environmental Change, 19(1):105-112.

Nadiruzzaman, M. and Wrathall, D. (2015). Participatory exclusion Cyclone Sidr and its aftermath. Geoforum, 64:196-204.

Nasiru, M. O. and Olanrewaju, S. O. (2015). Forecasting Airline Fatalities in the World Using a Univariate Time Series Model. International Journal of Statistics and Applications, 5(5):223-230.

Niederreiter, H. (1992). Random number generation and quasi-Monte Carlo methods. Number 63 in CBMS-NSF regional conference series in applied mathematics. Society for Industrial and Applied Mathematics, Philadelphia.

Noy, I. (2015). Disasters in the Pacific: An Overview of Eonomic and Fiscal Issues. Pacific Economic Monitor, Asian Development Bank.

Noy, I. (2016a). The Economics of Climate Change and Natural Disaster Risk in the Pacific Island Countries by 2040. Technical report, Technical Report for the World Bank.

Noy, I. (2016b). Natural disasters in the Pacific Island Countries: new measurements of impacts. Natural Hazards, 84(S1):7-18.

Noy, I. (2017). To Leave or Not to Leave? Climate Change, Exit, and Voice on a Pacific Island. CESifo Economic Studies, 63(4):403-420.

Noy, I. and Edmonds, C. (2016). The economic and fiscal burdens of disasters in the Pacific. SEF Working Papers 25/2016 - Victoria University of Wellington.

Noy, I. and Yonson, R. (2016). Economic Vulnerability and Resilience to Natural Hazards. Oxford Research Encylopedia of Natural Hazard Science.

OECD and World Bank (2016). Climate and Disaster Resilience Financing in Small Island Developing States. Technical report, Organisation for Economic Cooperation and Development.

Olivia, S., Gibson, J., Rozelle, S., Huang, J., and Deng, X. (2011). Mapping poverty in rural China: how much does the environment matter? Environment and Development Economics, 16(02):129-153. 
Olivia, S., Gibson, J., Smith, A., Rozelle, S., and Deng, X. (2009). An Empirical Evaluation of Poverty Mapping Methodology: Explicitly Spatial versus Implicitly Spatial Approach. In A Contributed Paper to the Australian Agricultural $\mathcal{E}$ Resource Economics Societys Annual Conference, Cairns.

Parsons, M., Glavac, S., Hastings, P., Marshall, G., McGregor, J., McNeill, J., Morley, P., Reeve, I., and Stayner, R. (2016). Top-down assessment of disaster resilience: A conceptual framework using coping and adaptive capacities. International Journal of Disaster Risk Reduction, 19:1-11.

Pradhan, M. and Ravallion, M. (2000). Measuring poverty using qualitative perceptions of consumption adequacy. Review of Economics and Statistics, 82(3):462-471.

Qu, X. and Lee, L.-f. (2012). LM tests for spatial correlation in spatial models with limited dependent variables. Regional Science and Urban Economics, 42(3):430-445.

Raddatz, C. (2009). The Wrath of God Macroeconomic Costs of Natural Disasters. World Bank Policy Research Working Paper, (5039).

Raschky, P. and Weckhannemann, H. (2007). Charity hazardA real hazard to natural disaster insurance? Environmental Hazards, 7(4):321-329.

Raschky, P. A. (2008). Institutions and the losses from natural disasters. Natural Hazards and Earth System Sciences, 8(4):627-634.

Ravallion, M. (1996a). How well can method substitute for data? Five experiments in poverty analysis. The World Bank Research Observer, 11(2):199-221.

Ravallion, M. (1996b). Issues in Measuring and Modelling Poverty. The Economic Journal, 106(438):1328.

Ravallion, M. (1998). Poverty Lines in Theory and Practice. LSMS Working Paper No.133. World Bank, Washington D.C.

Reuveny, R. (2007). Climate change-induced migration and violent conflict. Political Geography, 26(6):656-673. 
Sanyal, S. and Routray, J. K. (2016). Social capital for disaster risk reduction and management with empirical evidences from Sundarbans of India. International Journal of Disaster Risk Reduction, 19:101-111.

Schumacher, I. and Strobl, E. (2011). Economic development and losses due to natural disasters: The role of hazard exposure. Ecological Economics, 72:97-105.

Shaw, R., Mallick, F., and Islam, A., editors (2013). Disaster Risk Reduction Approaches in Bangladesh. Disaster Risk Reduction. Springer Japan, Tokyo. DOI: 10.1007/978-4-431-54252-0.

Sinclair, P., Atumurirava, F., and Samuela, J. (2012). Rapid Drought Assessment Tuvalu. Technical report, Secretariat of the Pacific Commission, Suva.

Siqueira, A., Arthur, C., and Woolf, M. (2014). Evaluation of severe wind hazard from tropical cyclones - current and future climate simulations. Technical report, Geoscience Australia. DOI: 10.11636/Record.2014.047.

Smit, B., Burton, I., Klein, R. J., and Street, R. (1999). The science of adaptation: a framework for assessment. Mitigation and adaptation strategies for global change, 4(3):199-213.

Smith, R. and McNamara, K. E. (2015). Future migrations from Tuvalu and Kiribati: exploring government, civil society and donor perceptions. Climate and Development, 7(1):47-59.

Smith, R.-A. J. and Rhiney, K. (2015). Climate (in)justice, vulnerability and livelihoods in the Caribbean: The case of the indigenous Caribs in northeastern St. Vincent. Geoforum.

SOPAC (2004). EVI Report: The Environmental Vulnerability Index (EVI) 2004. Technical report, South Pacific Applied Geoscience Commission.

Strobl, E. (2012). The economic growth impact of natural disasters in developing countries: Evidence from hurricane strikes in the Central American and Caribbean regions. Journal of Development Economics, 97(1):130-141. 
Surminski, S. and Oramas-Dorta, D. (2014). Flood insurance schemes and climate adaptation in developing countries. International Journal of Disaster Risk Reduction, 7:154-164.

Taupo, T., Cuffe, H., and Noy, I. (2016). Household vulnerability on the frontline of climate change: The Pacific atoll nation of Tuvalu. SEF Working Paper 20/2016 - Victoria University of Wellington.

Taupo, T. and Noy, I. (2016). At the very edge of a storm: The impact of a distant cyclone on Atoll Islands. SEF Working Papers 24/2016 - Victoria University of Wellington.

Toatu, T. (1993). The Revenue Equalisation Reserve Fund. In Atoll Politics: The Republic of Kiribati, pages 183-185. Macmillan Brown Center for Pacific Studies.

Trease, H. V. (1993). Atoll Politics: The Republic of Kiribati. Macmillan Brown Center for Pacific Studies, Christchurch.

TTFAC Secretariat (2003). TTFAC Annual Report for 2003. Technical report, Tuvalu.

TTFAC Secretariat (2006). TTFAC Annual Report for 2006. Technical report, Tuvalu.

TTFAC Secretariat (2015). TTFAC Annual Report for 2015. Technical report, Tuvalu.

Turner, B. L., Kasperson, R. E., Matson, P. A., McCarthy, J. J., Corell, R. W., Christensen, L., Eckley, N., Kasperson, J. X., Luers, A., Martello, M. L., Polsky, C., Pulsipher, A., and Schiller, A. (2003). A framework for vulnerability analysis in sustainability science. Proc Natl Acad Sci U S A, 100(14):8074-8079.

Tuvalu Government (2008). Tuvalu Trust Fund (Finance and Information) Act: Agreement concerning an International Trust Fund for Tuvalu.

Tuvalu Government (2012). 2012 Population \& Housing Census: Preliminary Analytical Report. Technical report, Tuvalu Government.

Tuvalu Government (2015). Rapid Assessment Report: Tropical Cyclone Pam. Technical report, Tuvalu Government, Tuvalu. 
Tuvalu Trust Fund Board (2007). Tuvalu Trust Fund 20th Anniversary Profile. Technical report, Tuvalu Government.

UNCTAD, editor (2016). The path to graduation and beyond: making the most of the process. Number 2016 in The Least Developed Countries Report. United Nations, New York and Geneva.

UNESCAP and UNISDR (2012). Reducing Vulnerability and Exposure to Disasters: The Asia Pacific Disaster Report 2012. United Nations, Thailand.

UNISDR (2009). UNISDR Terminology on Disaster Risk Reduction. United Nations International Strategy for Disaster Reduction, Geneva, Switzerland.

United Nations (2015a). 2015 Global Assessment Report on Disaster Risk Reduction. United Nations Office for Disaster Risk Reduction, New York.

United Nations (2015b). Making development sustainable: the future of disaster risk management. Number 4.2015 in Global assessment report on disaster risk reduction. United Nations, Geneva. OCLC: 954270274.

United Nations (2015c). Tuvalu: Tropical Cyclone Pam Situation Report No.1. Technical report, UN Office for the Coordination for the Humanitarian Affairs (OCHA).

Wisner, B., Blaikie, P., Cannon, T., and Davis, I. (2003). At Risk: natural hazards, peoples vulnerability and disasters. Routledge, New York, 2nd edition edition.

Wisner, B., Gaillard, J. C., and Kelman, I. (2012). Framing disaster: theories and stories seeking to understand hazards, vulnerability and risk. In Handbook of hazards and disaster risk reduction, pages 18-33. Routledge, London.

World Bank (2007). Poverty and the Environment: Understanding Linkages at the Household Level. The World Bank, Washington D.C.

World Bank (2013a). Crowdfunding's Potential for the Developing World. World Bank.

World Bank (2013b). Pacific Catastrophe Risk Assessment and Financing Initiative (PCRAFI): Better Risk Information for Smarter Investments. Technical report, World Bank, Washington D.C. 
World Bank (2013c). World Development Report 2014: Risk and Opportunity Managing Risk for Development. The World Bank, Washington D.C.

World Bank (2014). Hardship and Vulnerability in the Pacific Island Countries. The World Bank, Washington D.C.

World Bank (2015a). International Development Association Supplemental Financing Document for a Proposed Supplemental Financing in the Amount of SDR 2.2 million from the Crisis Response window of the International Development Association to Tuvalu for the second development operation. Technical report, World Bank.

World Bank (2015b). Pacific Catastrophe Risk Assessment and Financing Initiative (PCRAFI): Advancing Disaster Risk Financing \& Insurance in the Pacific. Technical report, World Bank, Washington D.C.

World Bank (2016). Climate and Disaster Resilience. Pacific Possible, Washington D.C.

World Bank and GFDRR (2013). Building Resilience. The World Bank.

World Bank and United Nations (2010). Natural Hazards, UnNatural Disasters: The Economics of Effective Prevention. The World Bank, Washington D.C.

Wulfsohn, M. (2015). Trust Funds and Fiscal Risks in the North Pacific. Technical report, Asian Development Bank, Philippines.

Yamamoto, L. and Esteban, M. (2014). Atoll Island States and International Law. Springer Berlin Heidelberg, Berlin, Heidelberg. DOI: 10.1007/978-3-642-38186-7.

Yamano, H., Kayanne, H., Yamaguchi, T., Kuwahara, Y., Yokoki, H., Shimazaki, H., and Chikamori, M. (2007). Atoll island vulnerability to flooding and inundation revealed by historical reconstruction: Fongafale Islet, Funafuti Atoll, Tuvalu. Global and Planetary Change, 57(3-4):407-416.

Yodmani, S. (2001). Disaster risk management and vulnerability reduction: protecting the poor. Asian Development Bank. 
Yonson, R., Gaillard, J. C., and Noy, I. (2016). The measurement of disaster risk: An example from tropical cyclones in the Philippines. SEF Working Paper 04/2016 Victoria University of Wellington. 